Axel Gerloff

\title{
Wechselkurspolitik in Mittel- und Osteuropa
}

Eine theoretische Analyse unter besonderer Berücksichtigung der Erfahrungen der zehn Kandidaten für eine EU-Osterweiterung 


\section{Axel Gerloff}

\section{Wechselkurspolitik in Mittel- und Osteuropa}

Aufbauend auf der Analyse des Reformbedarfs $\mathrm{zu}$ Beginn der Transformationsprozesse in Mittel- und Osteuropa untersucht die Arbeit anhand von zwei Modellrahmen die Rolle der Wechselkurspolitik beim Übergang zur Marktwirtschaft. Es wird gezeigt, daß die Wahl des optimalen Wechselkurssystems von der relativen Gewichtung der beiden Zielsetzungen „Aufrechterhaltung der internationalen Wettbewerbsfähigkeit" und "makroökonomische Stabilisierung" sowie dem Offenheitsgrad der Volkswirtschaft abhängt. Den Ergebnissen der theoretischen Analyse werden die Erfahrungen der zehn mittel- und osteuropäischen EU-Beitrittskandidaten gegenübergestellt. Ein Ausblick behandelt die wechselkurspolitischen Herausforderungen, die sich für diese Länder aus einer EU-Mitgliedschaft ergeben.

Kai Stukenbrock was born in Bremen in 1971. Starting in 1992, he studied economics at the University of Göttingen and the University of California, Los Angeles. In 1997 he became a research fellow at the University of Göttingen, where he earned his doctorate. Since 2002 the author has been working as a rating specialist in sovereign ratings for a financial service provider in London. 


\section{Wechselkurspolitik}

in Mittel- und Osteuropa 


\section{Cege-Schriften}

Center for Globalization and Europeanization of the Economy Zentrum für Globalisierung und Europöisierung der Wirtschaft Georg-August-Universitöt Göttingen

\section{Band 1}

Herousgegeben von Wolfgang Benner, Günter Gabisch, Jörg GüBefeldt, Andreas Haufler, Helmut Hesse, Hans-Joachim Jarchow, Renate Ohr, Helgo Pollak, Peter Rühmann, Hermann Sautter, Stefan Tangermann und Wilhelm H. Wocker

Verontwortlicher Herausgeber für diesen Band: Hans-Joachim Jarchow

\section{(2) \\ PETER LANG}

Frankfurt am Main - Berlin - Bern - Bruxelles - New York · Oxford - Wien 


\section{Axel Gerloff}

\section{Wechselkurspolitik in Mittel- und Osteuropa}

Eine theoretische Analyse unter besonderer Berücksichtigung

der Erfahrungen der zehn Kandidaten

für eine EU-Osterweiterung

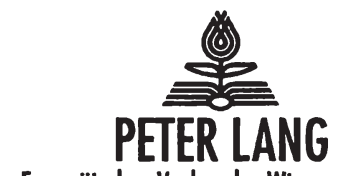

Europöischer Verlag der Wissenschaften 
Die Deutsche Bibliothek - CIP-Einheitsaufnahme

Gerloff, Axel:

Wechselkurspolitik in Mittel- und Osteuropa : eine theoretische Analyse unter besonderer Berücksichtigung der Erfahrungen der zehn Kandidaten für eine EU-Osterweiterung / Axel Gerloff. Frankfurt am Main ; Berlin ; Bern ; Bruxelles ; New York ;

Oxford; Wien : Lang, 2001

(CeGE-Schriften;Bd. 1)

Zugl.: Göttingen, Univ., Diss., 2001

ISBN3-631-38269-3

Open Access: The online version of this publication is published on www.peterlang.com and www.econstor.eu under the international Creative Commons License CC-BY 4.0. Learn more on how you can use and share this work: http://creativecommons. org/licenses/by/4.0.

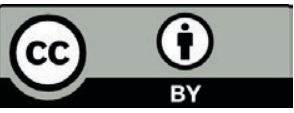

This book is available Open Access thanks to the kind support of ZBW - Leibniz-Informationszentrum Wirtschaft.

Gedruckt auf alterungsbeständigem, säurefreiem Papier.

D7

ISSN 1617-741X

ISBN3-631-38269-3

ISBN 978-3-631-75700-0 (eBook)

(C) Peter Lang $\mathrm{GmbH}$

Europäischer Verlag der Wissenschaften

Frankfurt am Main 2001

Alle Rechte vorbehalten.

Das Werk einschließlich aller seiner Teile ist urheberrechtlich geschützt. Jede Verwertung außerhalb der engen Grenzen des

Urheberrechtsgesetzes ist ohne Zustimmung des Verlages

unzulässig und strafbar. Das gilt insbesondere für

Vervielfältigungen, Übersetzungen, Mikroverfilmungen und die Einspeicherung und Verarbeitung in elektronischen Systemen.

Printed in Germany 124567

www.peterlang.de 


\section{Vorwort des verantwortlichen Herausgebers}

Nach dem Zusammenbruch der sozialistischen Systeme in Mittel- und Osteuropa Anfang der neunziger Jahre standen die betroffenen Länder vor einer doppelten Aufgabe: Zum einen hatten sie die für den Übergang von einem System der zentralen Verwaltungswirtschaft $\mathrm{zu}$ einer wettbewerbsorientierten Marktwirtschaft erforderlichen strukturellen Reformen durchzuführen, z.B. eine Liberalisierung des Preissystems, der Wechselkursbildung und des Außenhandels. Zum anderen mußten sie eine makroökonomische Stabilisierungspolitik betreiben, insbesondere mit dem Ziel, die als Folge des Geldüberhangs und der Preisliberalisierung stark erhöhten Inflationsraten zurückzuführen. Mit der ersten Aufgabe wurde u.a. eine Integration in den freien Welthandel und damit eine Einbindung in den internationalen Wettbewerb bezweckt. Sowohl für die außenwirtschaftliche Öffnung als auch in Hinblick auf das Ziel einer Preisniveaustabilisierung spielt die Wechselkurspolitik eine wesentliche Rolle. Die Frage ihrer angemessenen Ausgestaltung im Reformprozeß der ehemaligen sozialistischen Länder bildet die Thematik der vorliegenden Arbeit. Zentrale Aspekte der Betrachtung wechselkurspolitischer Regelungen sind dabei ihre Auswirkungen auf das Ziel der Preisniveaustabilisierung und der internationalen Wettbewerbsfähigkeit. Die Untersuchungen beschränken sich auf jene zehn Länder, die im Außenhandel eine ausgeprägte Westorientierung aufweisen und mit denen die EU Beitrittsverhandlungen führt.

Die behandelte Thematik ist nicht nur vor dem Hintergrund des noch nicht abgeschlossenen Transformationsprozesses in Mittel- und Osteuropa von großem Interesse und praktischer Bedeutung, sondern auch für die Frage einer zweckmäßigen Wechselkurspolitik als Schritt für den Beitritt zur EU, zum EWS II und zur EWWU. Letzteres rechtfertigt die Beschränkung auf eine bestimmte Länderauswahl.

Die inhaltliche Struktur der Arbeit wird durch drei Schwerpunkte bestimmt. Sie werden in den Kapiteln II, III und IV behandelt, die durch eine einleitende Beschreibung der Problemstellung und Vorgehensweise (I) und eine Schlußbetrachtung (V) eingerahmt werden:

- Kapitel II bietet dem Leser einen gründlichen, informativen und anschaulichen Einblick in die Ausgangslage und den Reformbedarf der ehemaligen sozialistischen Transformationsländer.

- Während Kapitel II mehr deskriptiv gehalten ist, bietet Kapitel III eine modelltheoretische Fundierung der Wahl des Wechselkursregimes. Dabei behandelt der Verfasser zunächst das mit den Namen von Swan und Salter verbundene, auf einem „tradable/nontradable“-Ansatz beruhende „Dependent-Economy- 
Modell“. Da ihm die Übertragung dieses bekannten Modells auf die Situation der Transformationsländer problematisch erscheint, präferiert er jedoch einen anderen Ansatz, wobei er die auf Agénor und Edwards zurückgehende Idee einer wirtschaftspolitischen Zielfunktion in Form einer zu minimierenden Verlustfunktion mit der Inflationsrate und dem realen Wechselkurs (als Indikator der internationalen Wettbewerbsfähigkeit) zu einem Partialmodell weiterentwickelt. Insbesondere berücksichtigt er bei der Preissetzung im Sektor der nicht-handelbaren Güter die Existenz administrierter Preise als spezifisches Kernelement der Transformationsländer. Wie der Verfasser anschaulich darstellt, hängen die Ergebnisse bezüglich des optimalen Wechselkursregimes von der relativen Gewichtung der Zielgrößen und dem Offenheitsgrad der Volkswirtschaft ab.

- Die Implikationen des Partialmodells bilden den modelltheoretischen Hintergrund für Kapitel IV. Dieses Kapitel befaßt sich zunächst mit einer Darstellung und Analyse der Wechselkurspolitik in den betrachteten zehn Transformationsländern, wobei die im Anhang dargestellten wechselkurspolitischen Chroniken dem interessierten Ökonomen eine ergiebige, aktuelle Informationsquelle bieten. Danach stellt der Verfasser anhand eigener empirischer Untersuchungen für eine erste Gruppe von acht Beitrittskandidaten im Ablauf von Inflation und Wachstum charakteristische Gemeinsamkeiten dar, die er dem Leser in stilisierter Form anschaulich vor Augen führt. Von dem dargestellten Ablaufmuster unterscheidet sich die Entwicklung in Bulgarien und Rumänien. Die Gründe für die Abweichungen werden in der Arbeit eingehend erörtert, wobei auch auf die Rolle der Ausgestaltung des Wechselkurssystems eingegangen wird. AbschlieBend diskutiert der Verfasser die wechselkurspolitischen Herausforderungen, die für die Beitrittsländer mit einer späteren Teilnahme am EWS II und der Zugehörigkeit zum Euro-System verbunden sind.

Mit der vorliegenden Publikation eröffnet das Centrum für Globalisierung und Europäisierung (CeGE) eine eigene Schriftenreihe. Der für diese Studie verantwortliche Herausgeber wünscht der Arbeit die - seiner Meinung nach verdiente Resonanz in der Fachwelt.

Hans-Joachim Jarchow 


\section{Inhaltsverzeichnis}

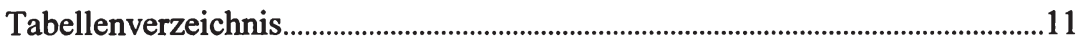

Verzeichnis der Abbildungen ...................................................................................12

Abkürzungsverzeichnis ..........................................................................................12

Währungsbezeichnungen ...........................................................................................13

I. Problemstellung und Vorgehensweise...................................................15

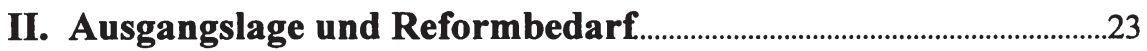

1. Real- und außenwirtschaftliche Ausgangsbedingungen.................24

1.1. Gemeinsame Charakteristika der Transformationsländer ........................24

1.2. Erklärungsansätze für die Transformationsrezession.................................25

1.3. Zusammenbruch des RGW und Neuausrichtung

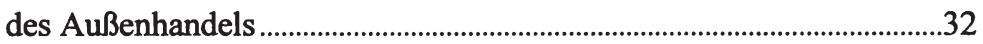

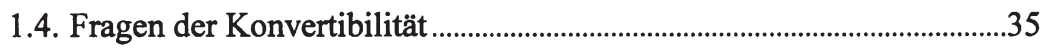

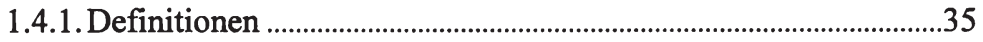

1.4.2. Zur Bedeutung der Konvertibilität im Transformationsproze $ß$....................................................................36

2. Ungleichgewichte im monetären Bereich.............................................41

2.1. Begründung der Priorität der Geldwertstabilität..........................................41

2.2. Das Problem des Geldüberhangs................................................................45

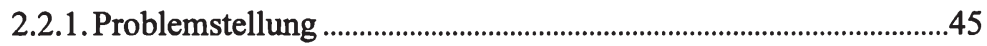

2.2.2. Möglichkeiten des Abbaus des Geldüberhangs ...............................46

2.3. Preisliberalisierung zu Beginn der Transformation ...................................49

3. Geld- und wechselkurspolitischer Entscheidungsbedarf................54

3.1. Schaffung der Voraussetzungen für eine marktgerechte und stabilitätsorientierte Geldpolitik ................................................................54

3.1.1. Institutionelle Reformen im Finanzsektor.......................................54

3.1.2. Wahl einer geldpolitischen (Zwischen-)Zielgröße ..........................56

3.2. Wahl des Wechselkursregimes ..............................................................65

3.2.1. Argumente für eine Wechselkursbindung ........................................65

3.2.2. Argumente für einen flexiblen Wechselkurs ....................................68

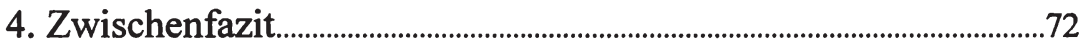




\section{III.Modelltheoretische Ansätze für die Wahl des}

Wechselkurssystems...........................................................................................75

1. Literaturüberblick .....................................................................................................

2. Das Dependent-Economy-Modell..............................................................78

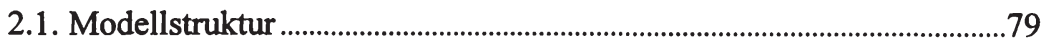

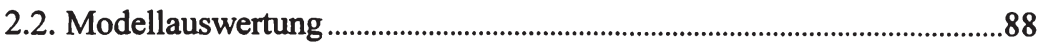

2.2.1. Stabilisierung bei festen Wechselkursen ..........................................89

2.2.2. Stabilisierung bei flexiblen Wechselkursen.....................................92

2.3. Zusammenfassung und Übertragbarkeit der Ergebnisse .........................94

3. Ein Partialmodell zur Wahl des Wechselkurssystems.....................97

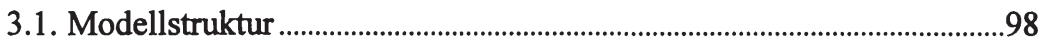

3.1.1. Die wirtschaftspolitische Zielfunktion .............................................98

3.1.2. Weitere Modellgleichungen ......................................................... 101

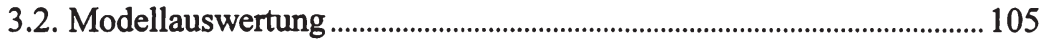

3.2.1. Stabilisierung bei festen Wechselkursen ..................................... 107

3.2.2. Stabilisierung bei flexiblen Wechselkursen.................................. 109

3.2.3. Vergleich der Ergebnisse beider Wechselkurssysteme ............. 112

3.3. Glaubwürdigkeitsprobleme einer Wechselkursfixierung...................... 119

3.4. Zusammenfassung und Übertragbarkeit der Ergebnisse ...................... 124

\section{Wechselkurs- und stabilitätspolitische Erfahrungen der} zehn mittel- und osteuropäischen EU-Beitrittskandidaten... 131

1. Wechselkurspolitische Maßnahmen ........................................................132

2. Auswertung der empirischen Literatur zur Rolle der Wechselkurspolitik im Transformationsprozeß................................140

2.1. Entwicklung des realen Wechselkurses .................................................. 140

2.2. Ergebnisse empirischer Studien zur Auswirkung des Wechselkursregimes auf Wachstum und Inflation................................... 145

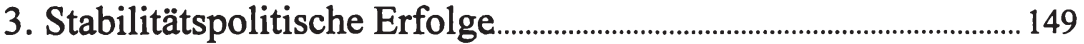

3.1. Verlauf von Wirtschaftswachstum und Inflation....................................150

3.1.1. Vorbemerkungen .......................................................................... 150

3.1.2. Entwicklungen in den zehn Transformationsländern.................. 153

3.1.3. Stilisierte Darstellung der Gemeinsamkeiten ................................ 162 
3.2. Mögliche Einflußfaktoren ........................................................................ 165

3.2.1. Unterschiedliche Ausgangsbedingungen..................................... 166

3.2.2. Bedeutung der Liberalisierungspolitik .......................................... 169

3.2.3.Zentralbankgesetzgebung............................................................ 172

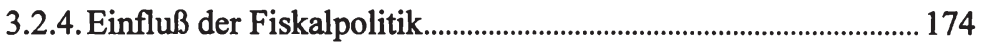

3.2.5. Geldpolitische Einflüsse................................................................. 179

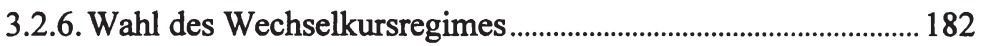

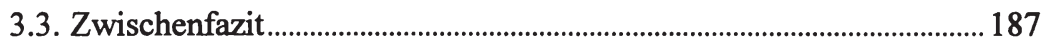

4. Mittelfristige wechselkurspolitische Perspektiven.......................... 190

4.1. Schritte auf dem Weg zu einer EU-Osterweiterung

- eine Bestandsaufnahme

4.2. Neue Rahmenbedingungen durch die Schaffung der

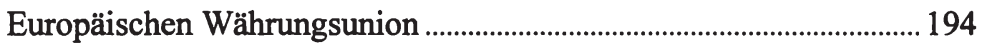

4.2.1. Vom EU-Beitritt über das EWS II zur Währungsunion............. 194

4.2.2. Ausgestaltung des Europäischen Wechselkursmechanismus EWS II

4.2.3. Auswirkungen der Währungsunion auf die Wechselkurspolitik der Beitrittskandidaten

4.3. Wechselkurspolitik nach dem EU-Beitritt.

\section{Schlußbetrachtung} 209

VI. Anhang 217

1. Mathematischer Anhang...............................................................................217

1.1. Berechnungen für ein System mit Wechselkursfixierung.....................217

1.2. Berechnungen für ein System flexibler Wechselkurse ........................... 218

1.3. Vergleich des Festkurssystems mit dem System

flexibler Wechselkurse.

1.3.1. Vergleich der Inflationsraten im Sektor der

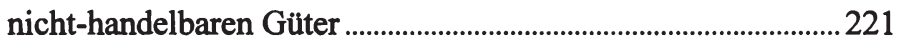

1.3.2. Vergleich der realen Wechselkursänderungsraten ........................ 222

1.3.3. Vergleich der gesamtwirtschaftlichen Inflationsraten ................ 222

1.3.4. Vergleich der wirtschaftspolitischen Kosten .................................223

1.4. Berechnungen für die Täuschungslösung ................................................226

1.5. Kostenvergleich zwischen der Wechselkursbindung und der

Täuschungslösung . 
2. Wechselkurspolitische Chroniken............................................................229

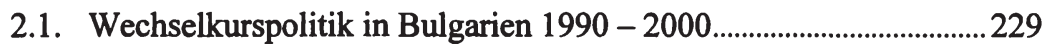

2.2. Wechselkurspolitik in Estland $1992-2000$.......................................230

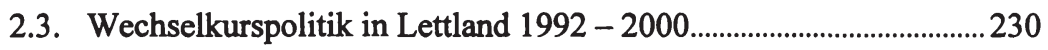

2.4. Wechselkurspolitik in Litauen $1992-2000$....................................... 231

2.5. Wechselkurspolitik in Polen 1990 - 2000............................................. 232

2.6. Wechselkurspolitik in Rumänien $1990-2000$..................................... 233

2.7. Wechselkurspolitik in der Slowakei $1993-2000$................................235

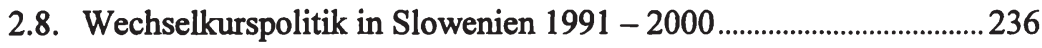

2.9. Wechselkurspolitik in Tschechien $1990-2000$...................................236

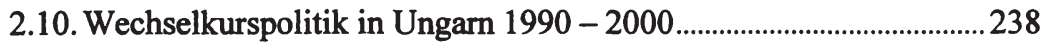

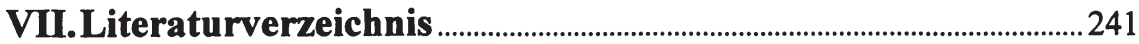




\section{Tabellenverzeichnis}

Tab. 1: Preisregulierung in Mittel- und Osteuropa

Tab. 2: Vergleich der Ergebnisse bei alternativen Wechselkurssystemen 114

Tab. 3: Ist ein Festkurssystem vorteilhafter als ein System flexibler Wechselkurse?

Tab. 4: Wechselkurssysteme in Mittel- und Osteuropa 138

Tab. 5: Entwicklung des realen Wechselkurses in der zweiten Hälfte der 1990er Jahre.

Tab. 6: Unterschiedliche Ausgangsbedingungen in Mittel- und Osteuropa ...... 166

Tab. 7: Indikatoren für Strukturreformen und die Liberalisierung der Wirtschaft

Tab. 8: Budgetsalden in den 1990er Jahren 175

Tab. 9: Komponenten der Staatsausgaben 1996 178

Tab. 10: Geldmengen- und Kreditwachstum 180

Tab. 11: Festkursperioden in Mittel- und Osteuropa 1990-1999. 183

Tab. 12: Formale Beziehungen der mittel- und osteuropäischen Staaten mit der EU

Tab. 13: Wertetabelle zum Kostenvergleich bei festen und flexiblen

Wechselkursen 226 


\section{Verzeichnis derAbbildungen}

Abb. 1: Internes und externes Gleichgewicht im Dependent-Economy-Modell

Abb. 2: Stabilisierung bei festem Wechselkurs

im Dependent-Economy-Modell

Abb. 3: Stabilisierung bei flexiblen Wechselkursen

im Dependent-Economy-Modell

Abb. 4: Brunos Darstellung von Krise, Anpassung und Reform

Abb. 5: Verlauf von Wirtschaftswachstum und Inflation in den zehn mittel- und osteuropäischen EU-Beitrittskandidaten

Abb. 6: Stilisierte Darstellung von Wirtschaftswachstum und Inflation im Transformationsprozeß.

\section{Abkürzungsverzeichnis}

BIP Bruttoinlandsprodukt

EBRD European Bank for Reconstruction and Development

EU Europäische Union

EWS Europäisches Währungssystem

EWU Europäische Währungsunion

EZB Europäische Zentralbank

IMF International Monetary Fund

IWF Internationaler Währungsfonds

OECD Organisation for Economic Cooperation and Development

RGW Rat für gegenseitige Wirtschaftshilfe

UdSSR Union der Sozialistischen Sowjetrepubliken 


\section{Währungsbezeichnungen}

$\begin{array}{ll}\text { ATS } & \text { Österreichischer Schilling } \\ \text { BGL } & \text { Bulgarischer Lew } \\ \text { CHF } & \text { Schweizer Franken } \\ \text { CZK } & \text { Tschechische Krone } \\ \text { DEM } & \text { Deutsche Mark } \\ \text { ECU } & \text { Europäische Währungseinheit (European Currency Unit) } \\ \text { EEK } & \text { Estnische Krone } \\ \text { EUR } & \text { Euro } \\ \text { FRF } & \text { Französischer Franc } \\ \text { GBP } & \text { Britisches Pfund } \\ \text { HUF } & \text { Ungarischer Forint } \\ \text { LTL } & \text { Litauischer Litas } \\ \text { LVL } & \text { Lettischer Lats } \\ \text { PLN } & \text { Polnischer Zloty } \\ \text { ROL } & \text { Rumänischer Leu } \\ \text { SDR } & \text { Sonderziehungsrecht (Special Drawing Right) } \\ \text { SIT } & \text { Slowenischer Tolar } \\ \text { SKK } & \text { Slowakische Krone } \\ \text { USD } & \text { US-amerikanischer Dollar }\end{array}$


Axel Gerloff - 978-3-631-75700-0

Downloaded from PubFactory at 01/11/2019 02:46:37AM

via free access 


\section{Problemstellung und Vorgehensweise}

Der Zusammenbruch der sozialistischen Systeme in Mittel- und Osteuropa Anfang der 1990er Jahre markierte für die Region den Beginn einer neuen postkommunistischen Ära. Mit dem Übergang von der Zentralverwaltungswirtschaft zu einem marktwirtschaftlich orientierten Wirtschaftssystem standen die betroffenen Länder zu Beginn der Transformation vor einer Fülle von Aufgaben und einem hohen Reformbedarf. Die Notwendigkeit weitreichender Reformen bestand dabei nicht nur in wirtschaftlicher Hinsicht, sondern umfaßte das gesamte Gesellschaftssystem. Die politischen und rechtlichen Verhältnisse mußten umfassend reformiert werden, ${ }^{1}$ wobei die herausragende ordnungspolitische Aufgabe darin bestand, die Trennung von Staat und Wirtschaft zu vollziehen. Im wirtschaftspolitischen Bereich lassen sich folgende wichtige Reformfelder identifizieren:2

- makroökonomische Stabilisierung, Liberalisierung von Preisen und Märkten,

- Liberalisierung des Wechselkurs- und Außenhandelssystems,

- Privatisierung von Staatsbetrieben,

- Etablierung einer Wettbewerbsordnung mit leichten Marktzutritts- und -austrittsmöglichkeiten,

- Neudefinition der Rolle des Staates als Garant für makroökonomische Stabilität und durchsetzbare Eigentumsrechte sowie als Korrektor von Marktunvollkommenheiten.

Während viele Länder inzwischen große Fortschritte auf den genannten Gebieten erreicht haben, hinken einige Länder auf dem Weg zu einer funktionierenden Marktwirtschaft noch hinterher. Im zurückliegenden Zehnjahreszeitraum seit dem Beginn tiefgreifender Reformen Anfang des Jahres 1990 in Polen hat sich gezeigt, daß die Länder zwar sehr unterschiedliche Reformansätze wählten, aber in allen Fällen sehr umfassende Reformbemühungen erforderlich waren, um den Übergang von der Plan- zur Marktwirtschaft zu bewältigen. Zwischen den einzelnen Politikbereichen bestehen starke Interdependenzen, so daß eine erfolgreiche Transformation die zügige Implementierung vielfältiger ordnungs- und prozeßpolitischer Maßnahmen erforderte. Sowohl die außenwirtschaftliche Öffnung als auch die makroökonomische Stabilisierung waren zentrale Politikfelder der frühen Transformationspolitik und stehen im Mittelpunkt der vorliegenden Arbeit. Einerseits erforderte die Integration in den Welthandel und der Wandel von relativ geschlossenen zu offenen Volkswirtschaften die Abschaffung der staatlichen Außenhandelsmonopole und den Übergang zu konvertiblen Währungen. Andererseits mußten alle Länder zu Beginn ihrer Transformation hohe Inflationsraten bekämpfen,

1 Für einen Überblick uber die verschiedenen Reformfelder siehe Stippler (1998), S. 19 ff.

2 Vgl. Havrylyshyn et al. (1998), S. 10. 
um eine Stabilisierung des Preisniveaus zu erreichen. Die Wechselkurspolitik spielte für beide Bereiche eine wichtige Rolle, insbesondere weil sich eine Vielzahl der mittel- und osteuropäischen Länder für einen festen Wechselkurs als Bestandteil ihrer Stabilisierungsprogramme entschied. Die Analyse der Wechselkurspolitik in der ersten Dekade der Transformation ermöglicht dabei nicht nur eine rückblickende Bewertung der gewählten Strategien. Aus ihr lassen sich auch Lehren für diejenigen Länder ableiten, die im Transformationsprozeß noch nicht so weit fortgeschritten sind wie die erfolgreichsten mittel- und osteuropäischen Staaten. Des weiteren bleibt die Wechselkurspolitik insbesondere für die Beitrittskandidaten zur Europäischen Union (EU) ein zentrales Politikfeld, weil sich mit der angestrebten EU-Mitgliedschaft die Perspektive einer Teilnahme am Europäischen Währungssystem EWS II und längerfristig auch an der Europäischen Währungsunion eröffnet. Dabei handelt es sich um neue Herausforderungen, für deren Bewältigung die Auswertung der bisherigen wechselkurspolitischen Erfahrungen wichtige Anhaltspunkte bietet.

Weltweit befinden sich fast dreißig Länder im Übergang von einer sozialistischen Planwirtschaft zu einer Marktwirtschaft. Der Transformationsprozeß startete von sehr unterschiedlichen Ausgangsbedingungen und war von einer Vielzahl differierender Zielsetzungen geprägt. Des weiteren wiesen die Länder erhebliche Unterschiede unter anderem in kultureller, institutioneller und politischer Hinsicht auf. Viele vergleichende empirische Studien beziehen nahezu alle Transformationsländer in die Untersuchung ein, um zu allgemeinen Aussagen über den Transformationsverlauf und die ihn prägenden Politikbereiche zu kommen. ${ }^{3}$ Demgegenüber beschränkt sich die vorliegende Arbeit auf die Betrachtung der Entwicklungen in den zehn mittel- und osteuropäischen Staaten, die einen Antrag auf EUMitgliedschaft gestellt haben. Die regionale Abgrenzung wurde gewählt, weil diese Transformationsländer gemeinsame Charakteristika aufweisen, die sie - mit Blick auf den Gang der Untersuchung - mit gewissen Einschränkungen zu einer relativ homogenen Gruppe machen. Neben der gemeinsamen geographischen Nähe zu Westeuropa gehört dazu ein ähnlicher kultureller Hintergrund, der sie zum Beispiel deutlich von den asiatischen Nachfolgestaaten der ehemaligen Sowjetunion unterscheidet. ${ }^{4}$ Ein gemeinsames Kennzeichen aller Transformationsökonomien ist der Wandel von relativ geschlossenen Volkswirtschaften und einer Handelsstruktur, die durch den Rat für gegenseitige Wirtschaftshilfe (RGW) geprägt war, zu offenen Wirtschaftssystemen und einer Integration in den Welthandel. Für die EUBeitrittskandidaten ist dies jedoch aufgrund derselben längerfristigen (wirtschafts-) politischen Zielsetzung, Mitgliedstaaten der EU zu werden, gleichbedeutend mit einer Westausrichtung der Handelsströme. Die Betonung der Priorität dieses Ziels

3 Siehe zum Beispiel de Melo et al. (1997b) und Sachs (1996b).

4 Außerdem verfolgen die kaukasischen Nachfolgestaaten der Sowjetunion auch aufgrund ihrer geopolitischen Lage andere Ziele als die mittel- und osteuropäischen Transformationslănder. 
nach Regierungsübernahmen durch Oppositionsparteien in Mittel- und Osteuropa zeigt, daß hierüber offensichtlich ein parteiübergreifender gesellschaftlicher Konsens besteht. Diese identische Zielvorstellung ist das entscheidende Kriterium für die gemeinsame Betrachtung dieser Länder im Rahmen der vorliegenden Arbeit, in deren theoretischem Teil unter anderem eine wirtschaftspolitische Zielfunktion modelliert wird. Da das Anliegen besteht, unterschiedliche wechselkurspolitische Strategien zu vergleichen, enthält die Arbeit - neben einem mathematischen Anhang - auch einen Anhang mit wechselkurspolitischen Chroniken für alle zehn betrachteten Länder. Dieser stellt ausführlich die wechselkurspolitischen Maßnahmen der mittel- und osteuropäischen EU-Beitrittskandidaten vom Transformationsbeginn bis zum Ende des Jahres 2000 dar, so daß der am Detail interessierte Leser umfassende Informationen über die Wechselkurspolitiken dieser Länder erhält. Da das Ländersample zehn Staaten umfaßt, kann die Darstellung der Erfahrungen in den einzelnen Ländern im Textteil jedoch nicht so ausführlich sein wie in einer Länderstudie, die nur ein Land betrachtet, oder wie in einer Arbeit, die sich nur auf einige wenige Länder konzentriert.

Die Debatte um die Wahl des Wechselkursregimes ist eine klassische Diskussion der wirtschaftswissenschaftlichen Literatur. ${ }^{5}$ Sie ist mit der Frage des angemessenen Wechselkurssystems im Zuge der Transformation der ehemaligen Staatshandelsländer um einen neuen Aspekt erweitert worden. Auch im Hinblick auf das angemessene Wechselkursregime im Übergang von der Plan- zur Marktwirtschaft gibt es unterschiedliche Auffassungen, wobei insbesondere ein Dissens darüber besteht, ob im Rahmen der Stabilisierungspolitik der Einsatz des Wechselkurses als nominaler Anker gewählt werden sollte oder ein flexibles Wechselkurssystem vorteilhafter ist. Die Beobachtung des Transformationsprozesses der neunziger Jahre in Mittel- und Osteuropa zeigt, daß die Mehrzahl der Länder anfangs den nominalen Wechselkurs als monetären Anker im Rahmen ihrer Stabilisierungsprogramme verwendet hat. Polen fixierte seine Währung von 1990 bis 1991 gegenüber dem US-Dollar, während die Tschechoslowakei und später die Tschechische Republik und die Slowakei ihre Währungen an einen Währungskorb banden. Einige Länder gingen noch weiter und fixierten ihre Währungen in Form eines Currency Boards gegenüber der Deutschen Mark oder dem US-Dollar, so z.B. Estland 1992, Litauen 1994 und Bulgarien 1997. Dabei ist zu berücksichtigen, daß ein paar Länder erst nach einer Phase flexibler Wechselkurse den Übergang zu einem Festkurssystem vollzogen haben, z.B. Bulgarien, Lettland und Litauen. Andere Länder, die zunächst eine Bindung ihrer Währung an einen Währungskorb oder eine kaufkraftstabile Währung vorgenommen hatten, sind inzwischen zu flexibleren Wechselkursregelungen übergegangen, wobei auch dabei in einigen Fällen durch die Wahl eines aktiven Crawling Pegs zunächst nicht auf den nominalen Wechselkurs

5 Für „klassische“ Beitrăge von Vertretern flexibler Wechselkurse siehe zum Beispiel Friedman (1953) und Johnson (1969). 
als geldpolitischen Anker verzichtet wurde. Diese Beobachtungen führen zu der Frage, ob unter Umständen die besonderen Probleme des Transformationsprozesses dazu führen, daß die Wahl eines festen nominalen Wechselkurses bei der Stabilisierung einer Strategie mit flexiblem Wechselkurs überlegen ist. Obwohl in der Literatur diese Frage nicht eindeutig beantwortet wird, scheint sich in den letzten Jahren eine Meinung herauszukristallisieren, daß kurzfristig ein fester Wechselkurs vorteilhafter sein kann, mittelfristig aber die Vorteile flexiblerer Wechselkursregelungen überwiegen. ${ }^{6}$ Zum Themenkomplex der Wahl des Wechselkurssystems in der Transformation existiert zwar eine umfangreiche Literatur, die sich insbesondere mit den bisherigen Erfahrungen in den Ländern beschäftigt. Es gibt aber nur wenige Arbeiten, die versuchen, die Entscheidung für die Wahl eines bestimmten Wechselkursregimes als Ergebnis einer formalanalytischen Modellierung des Transformationsprozesses zu entwickeln. Hier setzt die vorliegende Arbeit an, indem sie anhand zweier Modelle untersucht, ob sich aus diesen theoretischen Ansätzen konkrete Empfehlungen zur Wahl des Wechselkurssystems ableiten lassen. Das zuerst betrachtete Dependent-Economy-Modell wird sowohl in der entwicklungstheoretischen Literatur bei der Diskussion der Vor- und Nachteile von Wechselkurssystemen verwendet als auch zur Beantwortung der währungspolitischen Fragestellungen des Transformationsprozesses häufig herangezogen. Das zweite Modell ist ein neuer theoretischer Ansatz, der durch spezielle Modellformulierungen des monetären Sektors versucht, einige Charakteristika der mittel- und osteuropäischen Länder abzubilden. Unter Verwendung einer wirtschaftspolitischen Zielfunktion wird geprüft, ob sich die Vorteilhaftigkeit eines bestimmten Wechselkurssystems aus diesem formalanalytischen Ansatz ableiten läßt. Die Ergebnisse beider Modelle werden unter Berücksichtigung der Erfahrungen der zehn Beitrittskandidaten für die EU-Osterweiterung bewertet.

Die vorliegende Arbeit gliedert sich grob in zwei Teile und ist wie folgt aufgebaut: Der erste Teil wird von den Kapiteln II und III gebildet und behandelt die theoretischen Grundlagen der Wechselkurspolitik im Transformationsprozeß. Das Kapitel IV bildet den zweiten Teil, in dem vergleichende empirische Studien zum Themengebiet ausgewertet und die Erfahrungen in den zehn potentiellen EUBeitrittsländern Mittel- und Osteuropas betrachtet werden.

Im Kapitel II wird zunächst die Ausgangslage zu Beginn der Transformation dargestellt und diskutiert, vor welchen Schwierigkeiten die wirtschaftspolitischen Instanzen der Transformationsländer standen. Wie bereits erwähnt, bestehen zwischen den verschiedenen Politikfeldern große Interdependenzen. Um einerseits den Umfang der vorliegenden Arbeit zu begrenzen und andererseits eine Fokussierung auf die wechselkurspolitischen Implikationen zu gewährleisten, konzentrieren sich

6 Vgl. zu dieser Position z.B. Drabek/Brada (1998), S. 664, Rosati (1997), S. 486, und Sachs (1996a), S. 150. 
die Ausfuihrungen auf die wichtigsten Aspekte, die sich aus der spezifischen Ausgangslage der Transformationsländer ergeben. Nach einer kurzen Darstellung der Gemeinsamkeiten werden im ersten Abschnitt zunächst die möglichen Ursachen des Produktionseinbruchs diskutiert, der zu Transformationsbeginn in allen Reformländern zu beobachten war, weil dies für das Verständnis des gesamten Transformationsprozesses von großer Bedeutung ist. Die beiden zentralen Aspekte bei der Betrachtung der Wechselkurspolitik sind die internationale Wettbewerbsfähigkeit eines Landes und der geldpolitische Handlungsspielraum, den ein Wechselkurssystem der Zentralbank zur Verfolgung ihres Preisstabilitätsziels gewährt. Deshalb wird im ersten Abschnitt außerdem ausführlich die Bedeutung der außenwirtschaftlichen Öffnung und der Einführung der Konvertibilität diskutiert. Die monetären Ungleichgewichte zu Transformationsbeginn werden im zweiten Abschnitt des Kapitels II dargestellt. Es wird begründet, warum der Preisstabilität insbesondere auch im Transformationsprozeß eine herausragende Rolle beigemessen werden muß. Mit dem Übergang von der Plan- zur Marktwirtschaft wandelt sich die Funktion des Geldes. Die marktwirtschaftliche Signal- und Lenkungsfunktion kann der Preismechanismus nur übernehmen, wenn ein gewisses $\mathrm{Ma}$ an Geldwertstabilität erreicht ist. Es mußte jedoch zunächst der Geldüberhang aus der Zeit der Planwirtschaft abgebaut und eine Preisliberalisierung durchgeführt werden, wobei die Umsetzung dieser Maßnahmen mit dem Ziel der Preisstabilität in Konflikt geriet, weil sie zu einem deutlichen Anstieg des Preisniveaus führten. Ausgehend von den beschriebenen Problemen wird im dritten Abschnitt des zweiten Kapitels der geld- und wechselkurspolitische Entscheidungsbedarf analysiert. Um die Voraussetzungen für eine marktgerechte und stabilitätsorientierte Geldpolitik zu schaffen, mußte der Finanzsektor grundlegend reformiert werden. Die wichtigste Maßnahme war dabei die Einführung eines zweistufigen Bankensystems. Außerdem wird diskutiert, vor welchen Problemen die währungspolitisch Verantwortlichen bei der Entscheidung für eine geldpolitische Strategie standen, bevor die Argumente für die Wahl eines festen oder flexiblen Wechselkurssystems dargestellt werden. Die Ausgangslage und der sich daraus ergebende währungspolitische Reformbedarf werden in einem Zwischenfazit zusammengefaßt, das deutlich macht, daß für eine erfolgreiche Transformation der Stabilisierung des gesamtwirtschaftlichen Preisniveaus höchste Priorität eingeräumt werden mußte. Dieses Ergebnis bildet den Ausgangspunkt für die nachfolgende modelltheoretische Analyse.

Nach einem Überblick über die in der Literatur verwendeten theoretischen Ansätze zur Wahl des Wechselkursregimes im Transformationsprozeß untersucht das Kapitel III (wie erwähnt) anhand zweier unterschiedlicher Modellrahmen, ob sich aus der theoretischen Analyse konkrete wechselkurspolitische Handlungsanweisungen ableiten lassen. Dabei wird im zweiten Abschnitt zunächst das sogenannte Dependent-Economy-Modell als Erklärungsansatz herangezogen, weil es in der 
Literatur eine weite Verbreitung in der Diskussion um die Wahl des Wechselkursregimes im allgemeinen und speziell in der Literatur zur Wechselkurspolitik in den Transformationsländern gefunden hat. Basierend auf der im zweiten Kapitel abgeleiteten Notwendigkeit zur Stabilisierung wird untersucht, welche Anpassungsprozesse sich im Modell alternativ bei festen und flexiblen Wechselkursen einstellen. Im Anschluß an die Diskussion, ob sich das Modell dazu eignet, die Probleme der Transformation zu erfassen und daraus Lösungsvorschläge für die Wechselkurspolitik abzuleiten, wird im dritten Abschnitt dieses Kapitels ein einfaches Partialmodell entwickelt, das sich unter anderem auf Beiträge von Agénor (1994) und Edwards (1998) stützt und so konstruiert ist, daß es einige Merkmale der Transformationsländer abbildet, wie sie im zweiten Kapitel dargestellt werden. Es steht wiederum die Stabilisierung sowohl im Rahmen eines festen als auch eines flexiblen Wechselkurssystems im Mittelpunkt der Betrachtung, bevor die Eignung zur Lösung des wechselkurspolitischen Entscheidungsbedarfs und die Übertragbarkeit der Ergebnisse kritisch hinterfragt werden.

Die theoretischen Überlegungen und Modellergebnisse werden im Kapitel IV mit den Ergebnissen empirischer Arbeiten und den wechselkurspolitischen Erfahrungen in den zehn ausgewählten Transformationsländern konfrontiert. Der Abschnitt IV.1. gibt zunächst einen Überblick über die in den betrachteten Ländern betriebenen Wechselkurspolitiken. Im Anschluß daran erfolgt eine Literaturauswertung, die die Ergebnisse vergleichender empirischer Studien zur Entwicklung des realen Wechselkurses und zur Bedeutung des Wechselkurssystems für eine erfolgreiche Stabilisierung von Wachstum und Inflation im Transformationsprozeß darstellt. Es zeigt sich, daß die Frage nach dem Einfluß der Wechselkurspolitik in den empirischen Studien nicht einheitlich beurteilt wird. Im Abschnitt IV.3. wird deshalb anhand graphischer Darstellungen, die die Entwicklungen von Inflation und realem Wirtschaftswachstum einander gegenüberstellen, für die zehn mittel- und osteuropäischen EU-Beitrittskandidaten geprüft, ob durch diese Vorgehensweise weitergehende Schlüsse für diese Ländergruppe möglich sind. Bei der Auswertung wird neben der Wahl des Wechselkurssystems eine Reihe anderer Faktoren betrachtet, für die empirische Studien mit größerem Ländersample einen Einfluß auf die Stabilisierungserfahrungen von Transformationsländern vermuten lassen. In einem Zwischenfazit wird die Bedeutung des Wechselkursregimes im Vergleich zu den anderen Einflußgrößen bewertet. Dabei geht es insbesondere um das Verhältnis zwischen den aus der modelltheoretischen Analyse des dritten Kapitels abgeleiteten Ergebnissen und den Erfahrungen in den betrachteten Transformationsländern. Zum Abschluß des vierten Kapitels behandelt der Abschnitt IV.4 die mittelfristigen wechselkurspolitischen Perspektiven der zehn Länder vor dem Hintergrund des angestrebten EU-Beitritts, indem er aufzeigt, wie sich der Beitrittsprozeß vollzieht und wie die betrachteten Länder auf die neuen Rahmenbedingungen reagieren, die sich durch die Schaffung der Europäischen Währungsunion ergeben. Unter 
Berücksichtigung der Ergebnisse der theoretischen Analyse und den bisherigen wechselkurspolitischen Erfahrungen wird die Möglichkeit einer frühen Teilnahme am EWS II kritisch beleuchtet, weil die Beitrittskandidaten vor dieser Entscheidung stehen, wenn sie EU-Mitgliedstaaten geworden sind.

Eine Schlußbetrachtung faßt die wesentlichen Ergebnisse zusammen und unterstreicht die Besonderheiten, die sich aus dem in dieser Arbeit entwickelten theoretischen Ansatz und aus der sich von den meisten anderen Studien unterscheidenden Abgrenzung der betrachteten Länder ergeben. Die Arbeit endet mit einigen Folgerungen, die aus den Erfahrungen der EU-Beitrittskandidaten für weniger weit fortgeschrittene Transformationsländer resultieren, und einem Ausblick auf den wechselkurspolitischen Handlungsbedarf dieser Ländergruppe im Anschluß an die angestrebte EU-Mitgliedschaft. 
Axel Gerloff - 978-3-631-75700-0

Downloaded from PubFactory at 01/11/2019 02:46:37AM

via free access 


\section{Ausgangslage und Reformbedarf}

In diesem Kapitel wird dargelegt, vor welchen Problemen die Transformationsländer zu Beginn des Reformprozesses standen und welche Reformaufgaben daraus erwuchsen. Wie in der Einleitung verdeutlicht, zeichnete sich der Transformationsprozeß dadurch aus, daß auf einer Vielzahl von Gebieten - und zwar nicht nur auf ökonomischer, sondern auch auf politischer und gesellschaftlicher Ebene große Reformaufgaben zu bewältigen waren. Eine Analyse aller Reformfelder würde den Rahmen dieser Arbeit sprengen. Die Betrachtung der Wechselkurspolitik erfordert aber, daß zumindest zwei Politikfelder genauer betrachtet werden, ohne die eine Analyse der Wechselkurspolitik unmöglich ist. Dies sind zum einen außenwirtschaftliche Fragen und zum anderen die Geldpolitik. Um die Interdependenz zwischen diesen Politikbereichen und der Wechselkurspolitik zu verdeutlichen, zeigt dieses Kapitel im ersten Abschnitt zunächst auf, durch welche real- und außenwirtschaftlichen Bedingungen die Ausgangssituation der Transformationsländer gekennzeichnet war, wobei neben Fragen der Handelspolitik und der Konvertibilität auch der wirtschaftliche Einbruch in den Reformländern ausführlich betrachtet wird. Da die im Rahmen der vorliegenden Arbeit betrachteten Länder von unterschiedlichen Ausgangsbedingungen starteten und auch verschiedene Reformansätze wählten, konzentriert sich die Darstellung auf die grundlegenden Aspekte und weist auf einige gemeinsame Politikreaktionen hin. Es ist nicht das Ziel dieses Kapitels, die Ausgangslage in allen zehn mittel- und osteuropäischen EUBeitrittskandidaten im Detail zu beschreiben. Auf spezielle Ländererfahrungen wird nur vereinzelt zurückgegriffen, um bestimmte Aspekte zu veranschaulichen oder Reformansätze exemplarisch darzustellen. Im zweiten Abschnitt werden bei gleicher Vorgehensweise die Besonderheiten des monetären Sektors betrachtet, bevor der dritte Abschnitt auf die konkreten geld- und wechselkurspolitischen Fragestellungen eingeht, die den Ausgangspunkt bilden für die modelltheoretischen Betrachtungen im sich anschließenden dritten Kapitel. 


\section{Real- und außenwirtschaftliche Ausgangs- bedingungen}

\subsection{Gemeinsame Charakteristika der Transformations- länder}

Die Ausgangslage in den Transformationsökonomien war trotz gewaltiger Unterschiede zwischen den Ländern von einigen gemeinsamen Charakteristika geprägt. ${ }^{1}$ Konstitutives Merkmal aller Transformationsländer war der Übergang von einem weitgehend vom Staat dominierten Wirtschaftsleben zu einem auf marktwirtschaftlichen Kriterien basierenden Wirtschaftsablauf, der eine Fülle ordnungs- und prozeßpolitischer Veränderungen erforderte. Die staatlichen Regelungsmechanismen mußten durch neue Formen der Koordination ersetzt werden. Da früher die wirtschaftlichen Beziehungen zwischen den Unternehmen durch staatliche Vorgaben bestimmt wurden, mußten beim Übergang zum marktwirtschaftlichen System die Voraussetzungen für einen funktionierenden Wettbewerb geschaffen werden. Dies erforderte einerseits einen neuen institutionellen Rahmen in Form gesetzlicher Regelungen und andererseits eine Anpassung der Unternehmen an die veränderten Strukturen.

In der Zentralverwaltungswirtschaft folgte nicht nur der Einsatz der Produktionsfaktoren staatlichen Vorgaben, sondern der Staat besaß auch überwiegend das Eigentum an den Produktionsmitteln. Ein gemeinsames Kennzeichen der Reformländer war daher die Notwendigkeit, umfassende Privatisierungen durchzuführen. Diese wichtige ordnungspolitische Aufgabe wirkte sich unmittelbar auf die Fiskalpolitik aus, weil in Planwirtschaften die Staatseinnahmen zu einem großen Teil aus den Abführungen staatlicher Unternehmen bestanden. Die Überführung staatlichen Eigentums in private Hände erzwang daher eine Umstellung der Staatsfinanzierung, d.h. eine umfassende Reform des Steuersystems.

Außerdem ging der umfassende Strukturwandel mit großen Schwankungen der relativen Preise und der Produktivität einher. In den ehemaligen sozialistischen Ländern bestanden starke Preisverzerrungen, weil die Preise nicht durch Marktkräfte gebildet, sondern politischen Vorgaben folgend staatlich festgelegt wurden. Aufgrund der zurückgestauten Inflation, die sich durch Knappheiten auf den Konsumgüter- und Produzentenmärkten zeigte, führte die Preisfreigabe für viele Pro-

1 Vgl. zu der Charakterisierung der Ausgangslage Borensztein/Masson (1993), S. 37, Sachs (1996a), S. 147 ff., und Stippler (1998), S. 19 ff. Die Ausfuhrungen dieses Abschnitts beziehen sich insbesondere auf die zehn mittel- und osteuropäischen EU-Beitrittskandidaten. Die Beschreibung der Ausgangslage trifft jedoch im Hinblick auf die grundlegenden Probleme auch auf die meisten anderen Transformationsländer zu. 
dukte zu einem sprunghaften Anstieg der Preise und einer sich anschließenden Inflation. Die Länder waren also alle mit dem Erfordernis konfrontiert, möglichst schnell die hohen Inflationsraten zu reduzieren. Die Ungleichgewichte im monetären Bereich und die Möglichkeiten ihrer Beseitigung werden aufgrund ihrer wechselkurspolitischen Bedeutung in einem eigenen Abschnitt dieses Kapitels (Abschnitt II.2.) detailliert betrachtet.

Ein weiteres Kennzeichen aller Zentralverwaltungswirtschaften war, daß es sich um relativ geschlossene Volkswirtschaften handelte und nur wenige Handelsbeziehungen zu westlichen Marktwirtschaften bestanden. Die Länder handelten zwar untereinander im Rahmen des Rates für gegenseitige Wirtschaftshilfe (RGW), die Integration in den Welthandel war jedoch nur schwach ausgeprägt. Da das System des RGW auf Regierungsabsprachen und einem Zahlungssystem mit einer zentralen Verrechnungseinheit - dem sogenannten Transferrubel - basierte, standen die Länder am Transformationsbeginn vor der Aufgabe, sich dem Welthandel zu öffnen und zu einem auf marktwirtschaftlichen Kriterien basierenden Handel überzugehen. Des weiteren erforderte die außenwirtschaftliche Öffnung die Einführung einer konvertiblen Währung und eine Liberalisierung des Kapitalverkehrs, weil die Währungen in den Planwirtschaften generell nicht konvertibel waren. Es bestanden zumeist unterschiedliche Wechselkurse in Abhängigkeit von der Verwendung der Währung. ${ }^{2}$ Aspekte der Handelsliberalisierung und Fragen im Zusammenhang mit der Einführung der Konvertibilität werden in den Unterabschnitten 1.3. und 1.4. dieses Kapitels ausführlich diskutiert. Weil der gewaltige Umfang an Veränderungen und Reformen mit einem kräftigen Produktionseinbruch verbunden war, wird aber zunächst auf dessen Ursachen eingegangen. Denn ein Verständnis des Transformationsprozesses insgesamt setzt eine Ursachenanalyse der anfänglichen Wirtschaftskrise voraus.

\subsection{Erklärungsansätze für die Transformationsrezession}

Alle mittel- und osteuropäischen Transformationsländer sowie die Staaten der ehemaligen Sowjetunion haben einen drastischen Rückgang der Industrieproduktion zu Beginn der Transformation erfahren, der dazu führte, daß die Reformländer in der Regel über mehrere Jahre negative reale Wachstumsraten des Bruttoinlandsprodukts verzeichneten. ${ }^{3}$ Als generelles Phänomen dieser Transformationskrise ${ }^{4}$

2 Für eine Darstellung der Wechselkurssysteme in den Lăndern Mittel- und Osteuropas vor dem Zusammenbruch des Sozialismus siehe van Brabant (1985), S. 3 ff.

3 Siehe die Tabelle 1 in Berg et al. (1999), S. 6.

4 Schmieding (1992), S. 6, spricht von einer "transformation crisis“. Sie ist definiert als ein „decline in real gross domestic product (GDP) that is attributable to the systemic transformation from a Soviet-type economy to a market economy". In der Literatur wird in diesem Zusammenhang auch von der „Transformationsrezession“ gesprochen. Diese Bezeichnung geht zurück auf János Kornai, vgl. Kornai (1994), S. 1. 
ist zu beobachten, daß die ehemaligen Sowjetrepubliken (inklusive der baltischen Staaten) einen stärkeren Rückgang ihrer Wirtschaftsleistung erfahren haben als die Reformländer in Mittel- und Osteuropa. Im folgenden werden mögliche Ursachen dieses Wirtschaftseinbruchs genauer diskutiert, 5 wobei zunächst auf die Gefahr einer Fehlinterpretation hingewiesen werden soll. Die meisten mittel- und osteuropäischen Planwirtschaften hatten einen stark ausgebauten staatlichen Industriesektor, der durch eine schlechte Produktqualität und niedrige Produktivität gekennzeichnet war. Daraus wird als ein Standardargument zur Erklärung der Transformationskrise abgeleitet, daß die einzelnen sozialistischen Betriebe und die Kommandowirtschaft insgesamt höchst ineffizient waren. Diese Argumentation ist aber falsch, weil sie einen schlechten Zustand mit einem weiteren Verfall verwechselt, d.h. ein niedriges Niveau des Bruttoinlandsprodukts mit einem Rückgang der Wirtschaftsleistung. ${ }^{6}$ Wenn auch unstrittig ist, daß die zentralistische Organisation des Wirtschaftslebens zu großen Ineffizienzen führte, müssen die negativen Wachstumsraten andere Ursachen haben.

Einige Beobachter des Transformationsprozesses führen die Rezession unter anderem auf eine mangelnde Nachfrage zurück, die durch eine zu restriktiv wirkende Geld- und Fiskalpolitik (mit)verursacht wurde. ${ }^{7}$ Diese Sichtweise beruht auf dem Argument, daß einerseits der Staat als bisher dominierender Nachfrager in weiten Bereichen ausfällt und andererseits die durch die Liberalisierung bedingten höheren Preise zu sinkenden Reallöhnen und damit zu einer sinkenden privaten Konsumnachfrage führen. Weiter wird argumentiert, daß auch die Investitionsnachfrage zurückgeht, weil die Mehrzahl der Betriebe zunächst noch in Staatsbesitz ist. Der Staat als Eigentümer stellt jedoch keine Mittel für Investitionsvorhaben zur Verfügung, weil die Staatshaushalte aufgrund der makroökonomischen Stabilisierungsbemühungen nicht ausgeweitet werden sollen. Aber selbst eine zügige Privatisierung wirkt zunächst nicht zwangsläufig nachfragestimulierend. Mittel- bis langfristig bewirkt der steigende Anteil des privaten Sektors in der Volkswirtschaft eine Zunahme der Produktion in privatisierten Industriebereichen und insbesondere eine Ausweitung des Dienstleistungssektors. Auf kurze Sicht führt die Privatisierung allerdings zu höherer Arbeitslosigkeit, weil „überschüssiges“ Personal entlassen wird und nicht in Privatbesitz überführbare Unternehmen unter Umständen geschlossen werden. Durch diese Effekte kann eine forcierte Privatisierung die gesamtwirtschaftliche Nachfrage reduzieren und $\mathrm{zu}$ der Transformationsrezession beitragen, obwohl sie langfristig eine effizienzsteigernde Wirkung hat. Auch wenn

5 Vgl. zu mőglichen Erklärungsansătzen u.a. Kornai (1994), S. 39 ff., Sachs (1996b), S. 128 ff., Mundell (1997), S. 73 ff., und Pitlik (2000), S. $38 \mathrm{ff}$.

6 Siehe zu dieser Aussage Schmieding (1992), S. 8.

7 Vgl. z.B. Brada/King (1992), S. 51, und Berg/Blanchard (1994), S. 60. Dabei ist zu beachten, $\mathrm{da}$ eine Politikempfehlung, die sich aus dieser Ursachenanalyse ergibt, eine geldpolitische Expansion trotz hoher Inflationsraten zu Transformationsbeginn ist. 
einsichtig ist, daß die makroökonomischen Politikmaßnahmen zur Bekämpfung der Inflation und zur Verringerung von Budgetdefiziten möglicherweise zu einer Verschärfung der Kontraktion beitrugen, kann diese Argumentation nur einen Teil des Rückgangs erklären, denn alle Transformationsökonomien haben anfänglich, unabhängig davon, ob sie strukturelle Reformen und eine Stabilisierungspolitik betrieben oder nicht, einen Rückgang der Industrieproduktion erfahren. ${ }^{8}$ Aufgrund dieser Beobachtung werden angebotsseitige Effekte, wie zum Beispiel die Veränderung der inländischen Wirtschaftsstruktur und die Ressourcenreallokation, als wichtigste Ursachen des wirtschaftlichen Einbruchs angesehen. ${ }^{9}$

Ein konstitutives Merkmal der Systemtransformation ist der Zerfall alter Koordinationsmechanismen und eine daraus resultierende Unsicherheit im Reformprozeß. ${ }^{10}$ Der wirtschaftliche Umbruch erfordert eine völlig neue Verarbeitung und Bewertung von Informationen, wobei Unsicherheiten über die sich neubildenden Institutionen und die künftige Wirtschaftspolitik sowie ungeklärte Fragen im $\mathrm{Zu}-$ sammenhang mit der Privatisierung und Rückgabe staatlichen Eigentums die Neuorientierung erschwerten. Zur Verdeutlichung der verschiedenen Argumentationsmuster erfolgt eine getrennte Betrachtung der angebotsseitigen Auswirkungen des Transformationsprozesses auf die Volkswirtschaft insgesamt sowie speziell auf den (staatlichen) Unternehmenssektor und die privaten Wirtschaftssubjekte.

In der gesamten Wirtschaft kommt es aufgrund der Privatisierung von Staatsbetrieben und einer Änderung in den Größenklassen der Unternehmen zu unzähligen Änderungen. Während die Zahl der Großunternehmen sinkt, entstehen zunehmend kleinere und mittlere Betriebe. Dabei ist der Transformationsprozeß prinzipiell durch zwei gegenläufige Entwicklungen geprägt. Während es für einige Produkte keine hinreichende Nachfrage mehr gibt, steigen die Preise von anderen Gütern und Diensten, weil einerseits Preisregulierungen aufgehoben werden und andererseits bisher unbefriedigter Bedarf nachfragewirksam wird. Damit wird es profitabel, diese Güter und Dienste zu produzieren oder auch zu importieren. Es gibt expandierende und schrumpfende Sektoren in der Wirtschaft, ${ }^{11}$ wobei der beobachtete Rückgang der Wirtschaftsleistung in den Reformländern anzeigt, daß die Kontraktion schneller verlief als die Expansion. ${ }^{12}$ Dabei ist zu beachten, daß eine Faktor-Reallokation mit Kosten verbunden ist und die Wirtschaftssubjekte nicht

8 Eine Ausnahme in dieser Hinsicht bildet die Volksrepublik China, die nicht zu der in dieser Arbeit betrachteten Lăndergruppe gehört. Siehe hierzu aber die Fußnote 16 in diesem Kapitel.

9 Vgl. Sachs (1996b), S. 130.

10 Vgl. Blanchard/Kremer (1997), S. 1091 ff., und Roland/Verdier (1999), S. 2 ff.

11 Für ein Zwei-Sektoren-Modell, das diesen Sachverhalt formalisiert, siehe Hernández-Catá (1997), S. 411 ff. Pitlik (2000), S. 42, spricht in diesem Zusammenhang von „creation“ und „destruction effects“.

12 Kornai (1994), S. 45, weist darauf hin, daß die anfängliche Rezession durch die beschriebenen Abläufe eher einen schumpeterschen als einen keynesianischen Charakter hat. 
immer bereit waren, diese Kosten zu tragen, weil aufgrund der Unwägbarkeiten des Transformationsprozesses Planungssicherheit fehlte. Laut Pitlik kommt hinzu, daß die Faktorpreise nicht hinreichend flexibel waren. ${ }^{13}$ Preisrigiditäten führten zu Arbeitslosigkeit und zur Unterauslastung des Kapitalbestandes und haben so zum Produktionsrückgang beigetragen. Diese Position wird allerdings in der Literatur nicht durchgehend geteilt. Vielmehr bestand die Ansicht, daß die Faktorpreise in Mittel- und Osteuropa recht flexibel waren, und es wurde darauf hingewiesen, da $ß$ es teilweise zu substantiellen Rückgängen der Reallöhne kam, ohne daß diese zu Unruhen im großen Stil führten. ${ }^{14}$

Die Koordinierung der Beziehungen zwischen den Unternehmen oblag in den sozialistischen Staaten der zentralen Planungsbehörde. Mit dem Beginn der Systemtransformation ging nicht nur deren Aufsichtsfunktion verloren, sondern es setzte insgesamt ein Prozeß der „Desorganisation“ ein.15 Die Firmen mußten neue Formen der Zusammenarbeit entwickeln und zum Beispiel lernen, über Verhandlungen ihre alten Liefer- und Absatzbeziehungen zu erhalten und neue aufzubauen. Dies war mit erheblichen Problemen verbunden, weil unter zentraler Planung häufig nur ein Lieferant für einen bestimmten Einsatzfaktor existierte und auch auf der Abnehmerseite oft eine zentrale staatliche Handelsorganisation die Produkte aufkaufte. Während in einer Marktwirtschaft die Zusammenarbeit im Unternehmenssektor unter anderem durch langfristige Verträge und Kundenbeziehungen geprägt ist, waren diese Koordinationsmechanismen zu Beginn der Systemtransformation nicht sofort verfügbar. In der Transformation dominiert ein kurzfristiger Zeithorizont, weil der Prozeß von Firmenzusammenbrüchen und -neugründungen bestimmt ist. Dies erschwert zusätzlich die Entwicklung von dauerhaften Vertragsbeziehungen. Wenn die Kooperation zwischen mehreren spezialisierten Unternehmen, die aufeinander angewiesen sind, nicht funktioniert, brechen Produktionsketten zusammen und die Wirtschaftsleistung geht drastisch zurück. Die Untersuchung des Produktionsrückgangs verschiedener Gütergruppen stützt diese Argumentation, weil der Rückgang bei jenen Produkten am stärksten ausfiel, die in komplexen Produktionsprozessen hergestellt werden. ${ }^{16}$ Der Übergang von zentraler Planung zu dezentraler Koordinierung der wirtschaftlichen Aktivitäten mußte

13 Siehe zu diesem und dem folgenden Satz Pitlik (2000), S. 42.

14 Vgl. Schmieding (1992), S. 12 f.

15 Für eine einfache Modellierung des Prozesses der Desorganisation siehe Blanchard (1996), S. $118 \mathrm{f}$.

16 Siehe Blanchard/Kremer (1997), S. 1091 und 1122. Die Autoren weisen darauf hin, daß diese Argumentation auch zu erklären vermag, warum die Volksrepublik China in ihrem Transformationsprozeß keinen Produktionskollaps verzeichnete. Die Beibehaltung politischer Kontrolle und die fortgesetzte Bedeutung von Lieferquoten fur Staatsbetriebe signalisiert, daß die zentrale Allokation nicht vollstăndig durch dezentrale Verhandlungen ersetzt wurde (vgl. ebenda S. 1122). 
also aufgrund dieser Überlegungen zwangsläufig mit einem Produktionsrückgang verbunden sein.

Im Hinblick auf im Transformationsprozeß erforderliche Verhaltensänderungen wird argumentiert, daß die privaten Wirtschaftssubjekte nicht die Möglichkeiten ausschöpften, die sich ihnen boten, um unternehmerisch tätig zu werden und Güter und Dienstleistungen privat anzubieten. ${ }^{17}$ In diesem Zusammenhang sind ein soziologischer und ein ökonomischer Erklärungsansatz zu unterscheiden. Ersterer besagt, daß in vierzig Jahren Kommunismus der Unternehmergeist zerstört wurde und die Menschen deshalb nicht bereit waren, das Risiko eines privaten Engagements zu tragen. Dies könnte erklären, warum in den Nachfolgestaaten der Sowjetunion der Einbruch stärker ausfiel als in Mittel- und Osteuropa, denn diese Länder waren länger unter kommunistischer Herrschaft und die Menschen dadurch weniger mit der Funktionsweise privaten Unternehmertums vertraut. Der ökonomische Erklärungsansatz besagt, daß das Wachstum im privaten Sektor unter anderem durch übermäßige Reglementierung, zu hohe Steuersätze und inadäquate Kapitalmärkte gebremst wurde. Diejenigen Investoren, die bereit gewesen wären, sich privat zu engagieren, wurden durch unsichere Eigentumsverhältnisse und unzureichende Finanzierungsmöglichkeiten behindert. Sowohl der soziologische als auch der ökonomische Erklärungsansatz führen den Produktionseinbruch folglich darauf zurück, daß im Transformationsprozeß die Entfaltung privater Aktivitäten behindert wurde.

In engem Zusammenhang mit dem schwierigen Weg von einer Zentralplanung und bürokratischen Koordination des Wirtschaftslebens zu einem Marktmechanismus stehen Probleme der statistischen Erfassung. Einige Autoren unterstreichen, daß die unzureichende statistische Erfassung neuer Aktivitäten zu dem gemessenen Wirtschaftseinbruch beigetragen hat. ${ }^{18}$ Die statistischen Systeme in Planwirtschaften sind auf die Registrierung der Aktivitäten von Staatsbetrieben ausgelegt, die im Transformationsproze $ß$ einem Schrumpfungsproze $ß$ ausgesetzt sind. Dieser Prozeß wird von den Statistiken nicht nur annähernd korrekt erfaßt, sondern der Rückgang in diesen Sektoren wird von den offiziellen Statistiken vermutlich sogar überzeichnet. Dies liegt daran, daß unter dem sozialistischen Regime die Produktion eher zu hoch ausgewiesen wurde, weil die Erfassung sich stärker an Plangrößen als an tatsächlich erreichtem Output orientierte. Außerdem bestand zu planwirtschaftlichen Zeiten ein Anreiz zum erhöhten Ausweis der Produktionsergebnisse, um die Planvorgaben zu erfüllen oder sogar von einer Übererfüllung des Plansolls berichten zu können. Im Transformationsprozeß besteht hingegen ein Anreiz, das Ergebnis niedriger auszuweisen, um zum Beispiel die Steuerlast zu reduzieren. Des weiteren werden die neuen privatwirtschaftlichen Aktivitäten durch die noch

17 Siehe hierzu Mundell (1997), S. 79 f.

18 Vgl. exemplarisch Loungani/Sheets (1997), S. 395 f., und Christoffersen/Doyle (1998), S. 7. 
nicht hinreichend reformierten Statistiken nur ungenügend erfaßt, so daß der expandierende Zweig der Wirtschaft zu niedrig ausgewiesen wird. Ebenso wie für die Staatsbetriebe ist es für die Wirtschaftssubjekte im privaten Sektor von Vorteil, wenn sie ihre Einkünfte nicht in vollem Umfang angeben, um einer hohen Besteuerung zu entgehen. Zusammenfassend läßt sich sagen, daß die offiziellen Statistiken den Einbruch der Industrieproduktion während der Transformation zwar tendenziell zu hoch ausweisen, weil der Rückgang im Staatssektor eher überschätzt und die zunehmenden Aktivitäten des privaten Sektors eher unterschätzt werden. Allein eine statistische Überzeichnung des Ausmaßes vermag die wirtschaftliche Kontraktion jedoch nicht zu erklären. 19

Ein anderer Ansatz, der einige bereits erwähnte Argumente aufgreift, betont die Bedeutung von Kreditbeschränkungen und die Rückständigkeit des Finanzsektors für den wirtschaftlichen Rückgang in der Frühphase der Transformation. ${ }^{20}$ Der Kreditmarkt war einer der am stärksten unterentwickelten Märkte in den osteuropäischen Volkswirtschaften. Die Banken stellten den Betrieben zwar Mittel zur Verfügung, brauchten aber die Bonität der Unternehmen nicht zu prüfen, weil der Schuldendienst durch den Staat garantiert war. Sowohl Banken als auch Unternehmen waren zu Reformbeginn noch im Staatsbesitz, so daß aufgrund traditioneller Verbindungen und staatlicher Einflußnahme verlustreiche Unternehmen durch Bankkredite am Leben gehalten wurden, während insbesondere neugegründeten, privaten Betrieben der Zugang zu Krediten versperrt blieb. Der Abbau von Subventionen und Probleme bei der Aufnahme neuer Kredite brachten aber auch staatliche Unternehmen in Zahlungsschwierigkeiten. Diejenigen Unternehmen, die keine Kredite von Banken erhielten und auch nicht auf eine Kreditgewährung durch andere Unternehmen zurückgreifen konnten, mußten entweder ihre Produktion massiv einschränken oder gegebenenfalls ganz einstellen. ${ }^{21}$ Dies führt bei anderen Betrieben zu Forderungsausfällen und löst dadurch Folgeeffekte aus. Dabei ist allerdings zu berücksichtigen, daß diese Probleme nicht nur einen Produktionsrückgang bewirken, sondern daß es aus grundsätzlichen allokativen Überlegungen heraus vorteilhafter ist, wenn verlustbringende Unternehmen keine Kredite mehr erhalten und statt dessen neue Aktivitäten finanziert werden, wobei letzteres aus den genannten Gründen jedoch nicht in ausreichendem Maße geschah.

19 Als Alternative zur Verwendung des BIP schlagen Dobozi/Pohl (1995), S. 17 f., die Erfassung der Wirtschaftsleistung durch den Energieverbrauch vor. Wahrend ein Vergleich beider Meßgroßen fur die Nachfolgestaaten der Sowjetunion zu großen Diskrepanzen fuhrt und die durch den Energieverbrauch gemessene Wirtschaftstătigkeit wesentlich hoher ausfallt, sind die Unterschiede fur Mittel- und Osteuropa deutlich geringer.

20 Vgl. zum Beispiel Calvo/Coricelli (1993), S. $32 \mathrm{ff}$.

21 Die Verschuldung zwischen Unternehmen, auch ,interenterprise credit“" genannt, war insbesondere zu Reformbeginn ein weitverbreitetes Phănomen. Vgl. Pieper (1995), S. 58 ff. 
Im Zusammenhang mit Kreditbeschränkungen wird des weiteren häufig argumentiert, daß hohe Realzinsen Investitionen unrentabel machten und dies zum Rückgang der Produktion beigetragen habe. ${ }^{22}$ Eine empirische Überprüfung dieser These ist schwierig, weil man die für Investitionsentscheidungen relevante erwartete Inflationsrate nicht messen kann. Wenn man zur Deflationierung der nominalen Zinsen statt dessen die tatsächliche Inflationsrate verwendet, bestätigt sich die Aussage jedoch nicht. Die stärksten Einbrüche verzeichneten die Reformländer in den ersten Jahren ihrer Transformation. In dieser Zeit waren aber auch die Inflationsraten am höchsten, so daß trotz des relativ hohen Nominalzinsniveaus die Realzinsen verhältnismäßig niedrig waren. Zwar sind im Laufe des Transformationsprozesses die Nominalzinsen zum Teil nicht so schnell gefallen wie die Inflationsraten, so daß die Realzinsen anstiegen, aber zu diesem Zeitpunkt beobachtet man in Mittel- und Osteuropa keine rückläufige Entwicklung mehr, sondern bereits eine wirtschaftliche Erholung. ${ }^{23}$

Die relative Bedeutung der verschiedenen diskutierten Faktoren schwankt von Land zu Land. Auf eine Analyse der empirischen Relevanz für die einzelnen Länder wird hier - wie auch bei der weiteren Beschreibung der Ausgangslage im Rest des zweiten Kapitels - verzichtet. Das Fazit dieses Unterabschnitts lautet, daß die grundlegende Reformierung der Wirtschaftsstruktur mit ihren vielfältigen Änderungen der Produktions- und Anreizstrukturen, der Eigentumsverhältnisse und der Koordinationsmechanismen den wichtigsten Ansatzpunkt bildet, um zu erklären, warum alle Transformationsländer - wenn auch in unterschiedlichem Ausmaß eine Wirtschaftskontraktion erfuhren. Ohne Anspruch auf Vollständigkeit im Hinblick auf alle möglichen Erklärungsansätze zu erheben, ${ }^{24}$ wird deutlich, daß die Überwindung der unvermeidlichen und in ihrem Ausmaß nicht vorhersehbaren Produktionseinbußen am Anfang des Reformprozesses für die Länder eine außerordentlich große Herausforderung darstellte. Ein wichtiger Grund für die negativen Wachstumsraten, der bisher noch nicht berücksichtigt wurde, ist der Zusammenbruch der außenwirtschaftlichen Beziehungen zwischen den ehemaligen Staatshandelsländern. Dieser Aspekt wird im folgenden Unterabschnitt separat behandelt, weil er von besonderer Bedeutung für die Diskussion der Wechselkurspolitik ist.

22 Siehe zu den Ausfuhrungen in diesem Absatz Mundell (1997), S. 80 f.

23 Zur Entwicklung der Wachstums- und Inflationsraten im Reformprozeß siehe Unterabschnitt IV.3.1.

24 Macours/Swinnen (2000), S. 172 ff., analysieren zum Beispiel, welcher Anteil des Outputschocks auf Ursachen im landwirtschaftlichen Sektor zurluckgefuhrt werden kann. 


\subsection{Zusammenbruch des RGW und Neuausrichtung des Außenhandels}

Bis 1990 waren die Außenhandelsbeziehungen der mittel- und osteuropäischen Staaten durch den Rat für gegenseitige Wirtschaftshilfe (RGW) bestimmt. ${ }^{25}$ Allerdings zeigten sich nicht erst mit der Auflösung des RGW Anfang der neunziger Jahre Probleme. So waren zum Beispiel einige Länder Mittel- und Osteuropas Ende der 1980er Jahre gezwungen, die Exporte in die UdSSR einzuschränken, um Handelsüberschüsse gegenüber der Sowjetunion abzubauen. ${ }^{26}$ Der Außenhandel in den RGW-Staaten war gekennzeichnet durch ein staatliches Außenhandelsmonopol in den Mitgliedsländern und ein System von Lizenzen und quantitativen Beschränkungen. Die staatliche Planungsbehörde legte für die jeweilige Planperiode den Güteraustausch sowohl mengen- als auch wertmäßig fest. Die Export- und Importpreise richteten sich nicht nach Weltmarktpreisen, sondern nach Vorgaben der Regierung. ${ }^{27}$ Gemessen an der Importquote besaßen die Reformländer einen geringen Offenheitsgrad. Dieser zeigte sich auch darin, daß der Anteil der mittelund osteuropäischen Staaten und der Sowjetunion am Welthandel Ende der 1980er Jahre unter 8 v.H. lag. ${ }^{28}$ Der Güteraustausch der osteuropäischen Zentralverwaltungswirtschaften untereinander spielte eine deutlich größere Rolle als der Handel mit westlichen Industrieländern, wobei eine Konzentration auf den interindustriellen Handel erfolgte. Von besonderer Bedeutung waren für alle Staaten Mittel- und Osteuropas die Außenhandelsbeziehungen zur Sowjetunion, wobei die Bedeutung von Land zu Land variierte. Während zum Beispiel im Jahr 1989 über 57 v.H. der bulgarischen Exporte in den RGW gingen, und davon fast 85 v.H. in die UdSSR, lieferte Rumänien im gleichen Jahr nur zirka 20 v.H. seiner Ausfuhr in andere RGW-Staaten, wobei knapp 70 v.H. dieses Anteils in die Sowjetunion gingen. 29 Die Handelsbeziehungen innerhalb des RGW waren prinzipiell darauf ausgerichtet, daß Rohstoffe der UdSSR gegen Fertigerzeugnisse aus den anderen RGWLändern gehandelt wurden. Der intraindustrielle Handel hingegen machte nur einen sehr geringen Anteil am Gesamtvolumen aus. ${ }^{30}$ Für die Abwicklung des $\mathrm{Au}-$ Benhandels existierten verschiedene Wechselkurse, die zum Teil noch nach Wa-

25 Zur Funktionsweise des RGW sowie zu den sich bereits in der zweiten Hălfte der 1980er Jahre herauskristallisierenden Problemen innerhalb des RGW siehe Brada/King (1992), S. 41 ff., und Machowski (1989), S. 93 ff.

Dies geschah in Ungarn durch ein System von Exportlizenzen und in Polen durch eine Neubewertung des Austauschverhăltnisses gegenuber dem Transferrubel, so daß die Exporte in die Sowjetunion weniger profitabel wurden. Siehe Brada/King (1992), S. 42.

Vgl. Groner/Smeets (1991), S. 359.

28 Siehe Claassen (1991), S. 7.

29 Siehe zu diesen Zahlenangaben Kenen (1991), S. 240.

Vgl. Gröner/Smeets (1991), S. 382. 
rengruppen differenziert wurden. Diese Differenzierung entsprach einem System von Handelssubventionierung und -besteuerung. ${ }^{31}$

Auf der Tagung in Sofia 1990 beschlossen die Mitgliedsländer des RGW, den Handel untereinander ab Januar 1991 auf der Basis von Weltmarktpreisen abzuwickeln. Der bis Ende 1990 als Verrechnungseinheit dienende Transferrubel wurde abgeschafft. Die Berechnung der Ex- und Importwerte erfolgte ab diesem Zeitpunkt auf Dollarbasis. Die Auflösung des RGW erforderte eine grundlegende Reform der bestehenden Handelsstrukturen. Zum einen mußte ein neues System für die Zahlungsabwicklung geschaffen werden. Zum anderen wurde die außenwirtschaftliche Öffnung der Transformationsländer besonders durch die Konzentration des RGW-Handels auf staatliche Außenhandelsorganisationen erschwert, deren Existenz verhinderte, daß die Produzenten eine Vermarktungsinfrastruktur für den Export entwickelten, die sie für die Neuausrichtung des Handels benötigten. ${ }^{32}$ Diese Neuordnung der Außenwirtschaftsbeziehungen war dringend erforderlich, weil die enge Handelsverflechtung mit der Sowjetunion und den anderen RGWPartnern den Reformstaaten nicht nur die Möglichkeit versperrte, die durch den internen Strukturwandel ausgelösten Rezessionen durch stärkere Exporttätigkeit abzufedern. Vielmehr stellten sich mit Transformationsbeginn in den ehemaligen sozialistischen Ländern inklusive der Sowjetunion in der gesamten Region negative Wachstumsraten ein. Dadurch ging auch die Importnachfrage bei den bis dahin wichtigsten Handelspartnern drastisch zurück, und die Probleme verschärften sich außenhandelsbedingt. Als Ausgleich für den Verlust der östlichen Absatzmärkte strebten insbesondere die mittel- und osteuropäischen Transformationsländer eine Neuorientierung der Handelsströme auf die EU und andere westliche Länder an. Einige von ihnen konnten dabei zwar an traditionell gute Beziehungen aus vorsozialistischer Zeit anknüpfen, allerdings erforderte dieser Prozeß einige Zeit.

Bei den Auswirkungen des abnehmenden RGW-Handelsvolumens auf die Produktion ist zwischen der Export- und der Importseite zu differenzieren. Auf der Exportseite führte der Rückgang in vielen Fällen zu einer rückläufigen Produktion, weil zum Beispiel die für militärische Zwecke bestimmten Waren nicht auf dem Weltmarkt abgesetzt werden konnten und sich auch im Inland keine Verwendungsmöglichkeiten boten. Eine Konversion der Produktionsanlagen für eine zivile Nutzung war ebenfalls kurzfristig nicht möglich. ${ }^{33}$ Bei einigen Gütern bestand hingegen theoretisch die Möglichkeit, sie entweder im Inland abzusetzen oder ins westliche Ausland zu exportieren. Ersteres wurde dadurch erschwert, daß die Bevölkerung trotz massiver Abwertungen im Rahmen der Handelsliberalisierung, die die Importe verteuerten, häufig importierte Westprodukte vorzog. Eine erfolgrei-

31 Siehe Rodrik (1993), S. 65.

32 Vgl. Borensztein/Masson (1993), S. 53.

33 Siehe Brada/King (1992), S. 43. 
che Vermarktung auf dem Weltmarkt wurde durch die schlechte Produktqualität behindert. Auf der Importseite ist zu berücksichtigen, daß die Lieferschwierigkeiten bei Energieträgern und anderen verbilligten Rohstoffen, die die mittel- und osteuropäischen Länder überwiegend aus der Sowjetunion bezogen, einen Importrückgang bei importierten Vorprodukten hervorrief. Während ein Rückgang insbesondere konsumtiv verwendeter Importe bei konstantem Exportwert den Außenbeitrag und damit auch das Bruttoinlandsprodukt erhöht, führten diese Lieferengpässe zu importbedingten Produktionseinbußen in Mittel- und Osteuropa. ${ }^{34}$. Im Hinblick auf die Preiskomponente in diesem Argument ist allerdings zu beachten, daß zum Beispiel die Preise für Rohölimporte aus der UdSSR in der zweiten Hälfte der 1980er Jahre nicht deutlich unter den Weltmarktpreisen lagen. Die Rohölpreise wurden auf der Basis eines fünfjährigen gleitenden Durchschnitts festgelegt, so daß in der zweiten Hälfte der 1980er Jahre, in der auf dem Weltmarkt der Erdölpreis gesunken ist, der Preis für Importe aus der Sowjetunion über dem Weltmarktpreis lag. 35

Die Bedeutung der außenwirtschaftlichen Veränderungen kann anhand einiger Zahlen belegt werden, die zeigen, wie drastisch der Handel innerhalb des RGW nach 1990 abnahm. Das Volumen der Exporte der im Rahmen dieser Arbeit betrachteten Länder zu anderen ehemaligen Mitgliedern innerhalb des RGW ging 1991 um 60 v.H. bis 70 v.H. zurück. ${ }^{36}$ Ein derart drastischer Einbruch der Exporte $\mathrm{zu}$ den vormals wichtigsten Handelspartnern hat sich entsprechend deutlich auf das Wirtschaftswachstum in den Transformationsländern ausgewirkt. Rodrik macht den Handelsschock, der aus der Auflösung des RGW resultierte, für 60 v.H. des Rückgangs des Bruttoinlandsprodukts 1990/91 in der Tschechoslowakei verantwortlich. Für die größere und deshalb weniger offene Volkswirtschaft Polens ermittelt er ein Viertel bis ein Drittel, und in Ungarn ist nach seinen Berechnungen sogar der gesamte Rückgang der Wirtschaftsleistung 1990/91 auf den Handelsschock zurückzuführen. ${ }^{37}$ Unabhängig von der konkreten Höhe der Angaben, die aufgrund statistischer Erfassungsprobleme mit Vorsicht interpretiert werden müssen, verdeutlichen diese Zahlen, daß die Neuordnung der Handelsbeziehungen einen enormen „Schock“ darstellte, der einen sehr negativen Einfluß auf die wirtschaftliche Entwicklung in den betreffenden Ländern hatte und $\mathrm{zu}$ entsprechend großen Anstrengungen führte, die Handelsströme neu auszurichten.

34 Vgl. zu importbedingten Produktionsengpăssen Mundell (1997), S. 87 f.

35 Siehe Rodrik (1993), S. 65.

36 Vgl. Borensztein/Masson (1993), S. 54, Tabelle 3. Die Aussage bezieht sich nicht auf die baltischen Staaten und Slowenien, die erst zu einem spăteren Zeitpunkt ihre staatliche Unabhăngigkeit erlangten.

Siehe Rodrik (1993), S. 64. 


\subsection{Fragen der Konvertibilität}

Zentralverwaltungswirtschaften sind durch Währungsinkonvertibilität gekennzeichnet, denn eine Konvertierbarkeit würde das staatliche Außenhandelsmonopol untergraben, weil durch sie nicht geplante Im- und Exporte möglich wären. ${ }^{38}$ Ein zentraler Aspekt bei der außenwirtschaftlichen Öffnung ist deshalb die Einführung einer konvertiblen Währung. Während die Frage, ob schnell eine konvertible Währung gewünscht wird, aufgrund der angestrebten Integration in die Weltwirtschaft generell positiv beantwortet wurde, gab es erhebliche Diskussionen darüber, in welchem Umfang Konvertibilität hergestellt werden sollte. Der folgende Unterabschnitt definiert zunächst die wichtigsten Begriffe. Im Anschluß daran werden im Unterabschnitt 1.4.2. die Vor- und Nachteile der Einführung konvertibler Währungen diskutiert, und es wird dargestellt, welchen Weg die mittel- und osteuropäischen Länder gegangen sind.

\subsubsection{Definitionen}

Unter vollständiger Konvertibilität versteht man das uneingeschränkte Recht, die nationale Währung zum offiziellen Wechselkurs - sei er fest oder flexibel - in die wichtigsten internationalen Reservewährungen sowie diese in inländische Währung umzutauschen. ${ }^{39}$ Bei der Einführung der Konvertibilität gewährleisten viele Länder typischerweise nicht gleich die volle Konvertibilität ihrer Währungen, sondern erhalten zunächst gewisse Beschränkungen aufrecht. Man unterscheidet daher verschiedene Arten von Teilkonvertibilität, die in der Regel entweder nach Art der Transaktion oder nach der Personengruppe abgegrenzt werden..$^{40} \mathrm{Im}$ Hinblick auf den Verwendungszweck wird zwischen der Leistungsbilanzkonvertibilität und der Kapitalbilanzkonvertibilität unterschieden. Während erstere den Umtausch von Währungen für laufende realwirtschaftliche Transaktionen ermöglicht, die in der

38 Vgl. Hamacher (1992), S. 20. In diesem Unterabschnitt wird nicht zwischen der Konvertibilität des Warenverkehrs und den daraus resultierenden Zahlungsströmen differenziert. Freier Handel und Wăhrungskonvertibilität bedingen sich gegenseitig, denn letztere ist nur sinnvoll, wenn zumindest ein Teil der zugrundeliegenden Warenströme liberalisiert ist. Umgekehrt erfordert ein freier Austausch von Waren konvertible Wăhrungen. Siehe hierzu auch Backé (1996), S. 39.

39 In der Literatur wird hăufig bereits die Konvertierbarkeit von inlăndischer Wăhrung in Devisen als vollstăndige Konvertibilität bezeichnet. Siehe z.B. Greene/Isard (1991), S. 3, und Stippler (1998), S. 64. Dies durfte darauf zurluckzufuhren sein, daß fruher unter Konvertibilităt das Recht verstanden wurde, eine Wăhrung in Gold einzulösen. Vgl. Haberler (1954), S. $17 \mathrm{f}$. Hier soll mit vollstăndiger Konvertibilităt jedoch sowohl der freie Umtausch von inländischer in fremde Wăhrung als auch von Devisen in inländische Währung erfaßt werden. Vgl. dazu Lutz (1954), S. 297, und Gröner/Smeets (1994), S. 590.

40 Eine dritte mogliche Unterscheidung bezieht sich auf die Entstehung der Guthaben und differenziert zwischen Alt- und Neuguthaben. Siehe Haberler (1954), S. 19 f., und Greene/Isard (1991), S. 3. 
Leistungsbilanz gebucht werden, bezieht sich letztere auf Transaktionen, die in der Kapitalbilanz erfaßt werden. Im Hinblick auf die Besitzer von Devisen unterscheidet man zwischen Inländer- und Ausländerkonvertibilität oder synonym zwischen interner und externer Konvertibilität. Dabei versteht man unter Inländerkonvertibilität das Recht von Inländern, nationale Währung in Devisen umtauschen und Fremdwährungsbestände im Inland halten zu können sowie Devisen in Inlandswährung umtauschen zu dürfen; sei es in Form von Bargeld oder Guthaben auf inländischen Bankkonten. ${ }^{41}$ Bei interner Konvertibilität sind zwar der Erwerb sowie der Verkauf von Devisen im Inland gewährleistet, allerdings bedeutet dies nicht automatisch, daß die Devisenbestände uneingeschränkt für Auslandszahlungen verwendet werden können oder Devisen im Ausland gehalten werden dürfen. Des weiteren erstreckt sich das Recht im Prinzip nur auf Devisen, und nicht auf andere ausländische Finanzwerte, die Forderungen gegenüber Ausländern darstellen. In der Praxis wird es jedoch kaum möglich sein, den Inländern das uneingeschränkte Recht zum Erwerb und Besitz von Devisen zu gewähren, den Umtausch ausländischer Währung zur Abwicklung internationaler Geschäfte jedoch zu unterbinden. Ausländerkonvertibilität bedeutet analog, daß Personen, die nicht die inländische Staatsangehörigkeit besitzen, das Recht zum Umtausch der inländischen Währung in Devisen und von Devisen in inländische Währung haben.

\subsubsection{Zur Bedeutung der Konvertibilität im Transformations- prozeß}

Wie erwähnt, erforderte die Integration der Reformländer in die Weltwirtschaft den Übergang zu konvertiblen Währungen. Es bestanden jedoch unterschiedliche Auffassungen darüber, wie schnell die Länder die volle Konvertibilität oder eine der genannten Teilkonvertibilitäten anstreben sollten, denn sowohl die Einführung einer Leistungsbilanzkonvertibilität als auch einer Konvertibilität für Kapitalverkehrstransaktionen ist mit Vor- und Nachteilen verbunden, die im folgenden diskutiert werden.

Als direkte Vorteile einer Leistungsbilanzkonvertibilität werden unter anderem die größere Wahlfreiheit bei der Auswahl von Konsumgütern und die Förderung der heimischen Produktion genannt. 42 Während sich die Konsumenten nunmehr zwischen Produkten aus inländischer und ausländischer Herstellung entscheiden

41 Siehe zur Definition der Inländerkonvertibilităt Stippler (1998), S. 68 f. und Greene/Isard (1991), S. 4. Letztere weisen darauf hin, daß der Begriff im Zusammenhang mit sozialistischen Mangelwirtschaften auch dazu benutzt wird, das Recht zum Umtausch heimischer Wăhrung in Waren zu beschreiben.

42 Zu den Vor- und Nachteilen von Leistungsbilanzkonvertibilităt vgl. Bofinger (1991), S. 2 f., Borensztein /Masson (1993), S. 39 f., Greene/Isard (1991), S. 5 f., sowie Vaubel (1994), S. $561 \mathrm{ff}$. 
können, eröffnen sich den inländischen Unternehmen neue Bezugs- und Absatzmärkte im Ausland. Zusätzlich verringert die Konvertibilität die Möglichkeiten der politischen Einflußnahme auf die Unternehmen, weil diese nicht mehr von staatlicher Devisenzuteilung abhängig sind. Diese direkten Vorteile spielen im Reformprozeß aber im Vergleich zu den indirekten Vorteilen nur eine untergeordnete Rolle. Die Bedeutung der Leistungsbilanzkonvertibilität für die Transformation besteht insbesondere darin, daß - nachdem die größten Handelshemmnisse und Preisregulierungen beseitigt wurden - die inländischen Produzenten einem internationalen Wettbewerb ausgesetzt werden, so daß die inländischen Produktionsund Investitionsentscheidungen durch die Preisstruktur auf dem Weltmarkt geleitet werden. In der Zentralverwaltungswirtschaft weisen Preise keine Beziehung zu den Produktionskosten und den relativen Wertschätzungen der Konsumenten auf. Nach der Öffnung der Volkswirtschaften bieten die Weltmarktpreise eine wichtige Orientierungsgröße für relative Knappheitswerte von handelbaren Gütern, die auch die Preise für nicht-handelbare Güter beeinflussen. Da die ausländische Konkurrenz außerdem die Marktmacht der inländischen Unternehmen in den Branchen reduziert, die durch monopolistische und oligopolistische Strukturen geprägt sind, hat die Konvertibilität positive Rückwirkungen auf die Angebotsseite der Wirtschaft, deren Umstrukturierung eine zentrale Aufgabe im Rahmen der Transformation ist.

Damit die mit der Einführung von Leistungsbilanzkonvertibilität verbundenen Vorteile auch wirksam werden, müssen bestimmte Bedingungen erfüllt sein. ${ }^{43}$ So ist zum Beispiel ein Mindestmaß an internationaler Liquidität in Form von Währungsreserven oder einem Zugang zu ausländischer Finanzierung erforderlich, damit das Land zyklischen Schwankungen in der Handels- und Dienstleistungsbilanz widerstehen kann, ohne die Konvertibilität wieder aufheben oder Handelsbeschränkungen erlassen zu müssen. Allerdings argumentiert Vaubel (1994), daß dieses Argument bei flexiblen Wechselkursen unbedeutend ist und auch eine Wechselkursbindung keine umfangreichen Devisenreserven erfordert, solange die Geldpolitik strikt am Wechselkursziel ausgerichtet ist. ${ }^{44}$ Allgemein gilt, daß die außenwirtschaftliche Öffnung von fiskal- und geldpolitischen Maßnahmen begleitet sein muß, die ein gewisses $\mathrm{Ma} \beta$ an makroökonomischer Stabilität gewährleisten. Ist dies nicht der Fall, besteht die Gefahr, daß sich bei festen Wechselkursen ein außenwirtschaftliches Ungleichgewicht herausbildet oder daß es bei flexiblen Wechselkursen zu sehr starken nominalen Wechselkursänderungen kommt. Auch diese beiden Entwicklungen könnten dazu führen, daß die Leistungsbilanzkonvertibilität wieder eingeschränkt wird oder andere protektionistische Maßnahmen ergriffen werden. Um dies zu verhindern, ist eine stabilitätsorientierte Fiskalpolitik erforderlich; und auf Seiten der Geldpolitik muß die Zentralbank in der Lage sein, mit ihrem Instrumentarium den monetären Sektor zu stabilisieren. Schließlich

43 Siehe zum folgenden Greene/Isard (1991), S. 9 ff.

44

Vgl. Vaubel (1994), S. 563. 
müssen insbesondere die Voraussetzungen dafür geschaffen werden, daß die Weltmarktpreise als Knappheitsindikator wirksam werden können. Nur wenn Marktpreisänderungen bei den Wirtschaftssubjekten die richtigen Reaktionen hervorrufen, kann die Einführung der Konvertibilität ihre genannten positiven allokativen Wirkungen entfalten. Neben einer weitreichenden Preisliberalisierung, in deren Folge die Bestimmung der Preise überwiegend den Marktkräften überlassen wird, erfordert dies mikroökonomische Reformen. Vor allem darf der Staat nicht weiterhin unbegrenzt die Verluste der staatlichen Unternehmen übernehmen, sondern muß gegebenenfalls eine Schließung der Betriebe ins Auge fassen. Eine zügige Privatisierung bietet den besten Ansatzpunkt, um die richtigen Anreize für einen effizienten Ressourceneinsatz zu schaffen. Nur wenn dies gewährleistet ist, führt der Wettbewerb durch Importe langfristig zur Förderung von Innovationen und Qualitätsverbesserungen in der heimischen Wirtschaft und bewirkt eine Ressourcenreallokation, die die komparativen Vorteile des betreffenden Landes ausnutzt.

Neben den Vorteilen einer Leistungsbilanzkonvertibilität dürfen die Risiken nicht übersehen werden. Es besteht zum Beispiel die Gefahr, daß die Importe qualitativ minderwertige im Inland produzierte Güter verdrängen und deshalb die inländische Produktion eingeschränkt wird. Die inländische Beschäftigung geht zurück, und das Volkseinkommen sinkt. Über Multiplikatoreffekte kann sich dieser Prozeß verschärfen und gegebenenfalls dazu führen, daß die Regierung den politischen Rückhalt für das Reformprogramm verliert. Das Ausmaß der Auswirkungen hängt bei festen Wechselkursen entscheidend von der Wahl des Wechselkursniveaus ab. Wird die Einführung der Leistungsbilanzkonvertibilität von einer deutlichen Abwertung begleitet, verteuert dies die ausländischen Produkte und drosselt die Importnachfrage. Allerdings ist zu berücksichtigen, daß von einer Abwertung alle Importe betroffen sind, also auch jene, die wichtige Vorprodukte und Investitionsgüter darstellen. Bei flexiblen Wechselkursen hingegen führt ein wertmäßiger Importüberschuß zu einer Überschußnachfrage nach Devisen und zu einer Abwertung der heimischen Währung. Dadurch verbessert sich zwar die preisliche Konkurrenzfähigkeit der heimischen Industrie, allerdings steigt das inländische Preisniveau und es besteht die Gefahr von Abwertungs-Inflations-Spiralen. ${ }^{45}$

Die Entscheidung über die Einführung von Kapitalbilanzkonvertibilität hängt ebenfalls von einer Abwägung der Vor- und Nachteile ab. ${ }^{46}$ Ein Vorteil kann darin gesehen werden, daß die Integration in den internationalen Kapitalmarkt den Inländern eine Diversifikation ihrer Portefeuilles und damit höhere risikobereinigte

45 Siehe Ohr (1996), S. 219.

46 Die Ausfuhrungen zur Kapitalbilanzkonvertibilităt stutzen sich insbesondere auf Borensztein/Masson (1993), S. 40 f., Greene/Isard (1991), S. 6 f. und 16, sowie Vaubel (1994), S. 563 f. 
Kapitalerträge ermöglicht. Positiv zu bewerten ist ferner, daß die Kapitalbilanzkonvertibilität den Zugang zu modernen Technologien durch den Zufluß ausländischer Direktinvestitionen erweitert. Die Transformationsländer hatten einen hohen Bedarf an ausländischem Kapital zur Modernisierung ihrer Produktionsstrukturen, weil von vornherein feststand, daß sie auf absehbare Zeit nicht in der Lage sein würden, diesen Investitionsbedarf ausschließlich aus heimischem Kapitalangebot zu decken. Als Nachteile einer Kapitalbilanzkonvertibilität werden die Gefahren einer ausgeprägten Kapitalflucht und starke Schwankungen kurzfristiger Kapitalströme genannt, die zu einer höheren Volatilität bei Wechselkursen und Zinssätzen führen und damit die ohnehin bestehende große Unsicherheit im Transformationsprozeß verstärken. Allerdings ist zu berücksichtigen, daß die Gefahr von volatilen Kapitalbewegungen auch disziplinierend auf die Politik wirken kann. Um die Vorteile eines liberalisierten Kapitalverkehrs zu nutzen und einen Teil der negativen Effekte auszuschalten, ist verschiedentlich vorgeschlagen worden, daß die Reformländer für den Kapitalverkehr nur eine Ausländerkonvertibilität für langfristiges Kapital gewähren sollten, damit zumindest der Zustrom ausländischer Direktinvestitionen nicht behindert wird. ${ }^{47}$ Der Vorschlag zielt darauf ab, durch die Differenzierung nach der Fristigkeit der Kapitalströme die Länder vor kurzfristigen, spekulativen Kapitalbewegungen zu schützen.

Bisher ist bei der Betrachtung der Konvertibilität nach Art der Transaktion implizit unterstellt worden, daß die Entscheidungen über das Ausmaß der jeweiligen Liberalisierung separat getroffen werden können. Es ist jedoch unklar, inwieweit Kapitalverkehrsbeschränkungen effektiv sind, wenn Leistungsbilanztransaktionen keiner Regulierung mehr unterliegen. Die Durchsetzung von Kapitalverkehrskontrollen ist in neuerer Zeit sehr viel schwieriger geworden, weil die Fortschritte in den Bereichen der Informations- und Transaktionstechnologie zu einer starken Integration der internationalen Kapitalmärkte geführt haben. ${ }^{48}$ Sobald die Konvertibilität auf Kapitalbewegungen ausgedehnt wird, ist aus dem gleichen Grund mit einem starken Druck auf die Wechselkurse zu rechnen, wenn sich die wirtschaftlichen oder politischen Aussichten der Volkswirtschaft ändern. 49

Nach der Abwägung der Vor- und Nachteile einer Kapitalbilanz- und Leistungsbilanzkonvertibilität, die die besondere Bedeutung der außenwirtschaftlichen Liberalisierung für den Transformationsprozeß unterstreicht, soll noch kurz darauf eingegangen werden, wie die Konvertibilität in Mittel- und Osteuropa eingeführt wurde. In fast allen Ländern wurde zu Beginn des Transformationsprozesses eine Kombination aus interner Konvertibilität mit Konvertibilität für Leistungsbilanztransaktionen eingeführt, wobei teilweise besondere Regelungen für bestimmte

47 Vgl. zum Beispiel Ohr (1996), S. 219.

48 Vgl. Greene/Isard (1991), S. 7.

49 Siehe ebenda, S. 8. 
Personengruppen oder Verwendungszwecke fortbestanden. ${ }^{50}$ Die frühen Bestimmungen in der Tschechoslowakei zeigen exemplarisch, wie die wirtschaftspolitischen Entscheidungsträger zunächst nur eine eingeschränkte Inländerkonvertibilität mit Leistungsbilanzkonvertibilität kombinierten, um die Vorteile der Konvertibilität bei gleichzeitiger Minimierung der damit verbundenen Gefahren nutzen zu können. 51 Während für inländische Unternehmen die tschechoslowakische Krone ohne Beschränkungen zur Abwicklung von Leistungsbilanztransaktionen konvertibel war, galt dies zunächst noch nicht für inländische Haushalte und Ausländer. Die ausländischen Handelspartner konnten jedoch ihre Verbindlichkeiten mit ausländischer Währung begleichen und wurden auch in Devisen bezahlt. Bis März 1994 waren inländische Produzenten verpflichtet, die Exporterlöse in ausländischer Währung an autorisierte Banken abzuliefern. Im Gegenzug standen den tschechoslowakischen Firmen uneingeschränkt Devisen zur Bezahlung von Importen zur Verfügung. Die anfangs in vielen Reformländern noch bestehenden Einschränkungen der Leistungsbilanzkonvertibilität wurden sukzessive aufgehoben, und bis Ende des Jahres 1995 hatte die Mehrzahl der hier betrachteten Länder die Verpflichtungen aus Artikel VIII des Abkommens über den Internationalen Währungsfonds übernommen. 52

Die Kapitalverkehrsregelungen in den mittel- und osteuropäischen Reformländern lassen den Schluß zu, daß bei der Abwägung der Vor- und Nachteile einer Kapitalbilanzkonvertibilität die Gegenargumente überwogen, weil die Länder zunächst umfangreiche Beschränkungen aufrechterhielten. Im Laufe des Transformationsprozesses wurde dann auch der Kapitalverkehr sukzessive liberalisiert. Aufgrund der Gefahr stark schwankender Zu- und Abflüsse kurzfristigen Kapitals wurde dabei nach der Fristigkeit der Kapitalbewegungen differenziert. Insbesondere ausländische Direktinvestitionen wurden zugelassen, während die kurzfristigen Ströme oder bestimmte Arten von Transaktionen über längere Zeiträume hinweg einschränkenden Regelungen unterlagen und zum Teil auch heute noch unterliegen. 53

50 Vgl. Rosati (1997), S. 487, der darauf hinweist, daß die Beschrănkungen unter Berufung auf Artikel XIV des Abkommens uber den Internationalen Wahrungsfonds beibehalten wurden. $\mathrm{Zu}$ den Übergangsregelungen des Artikels XIV siehe Jarchow/Ruhmann (1997), S. $123 \mathrm{f}$.

Vgl. zu der folgenden Darstellung der tschechoslowakischen Regelungen Janácková (1995), S. 37.

52 Eine Ausnahme bilden Bulgarien und Rumănien, die erst 1998 zu „Artikel VIII-Lăndern“ wurden. Die konkreten Daten für die einzelnen Länder sind im Anhang VI.2. in den wechselkurspolitischen Chroniken angegeben. Zu den unter Artikel VIII erlaubten Devisenregelungen siehe Jarchow/Ruhmann (1997), S. $121 \mathrm{ff}$.

53 Dies trifft insbesondere fur Kontrollen im Zusammenhang mit grenzuberschreitenden Immobiliengeschăften zu. Siehe die Tabelle 6 bei Köhler/Wes (1999), S. 315, fur eine relativ aktuelle Übersicht uber die Kapitalverkehrsregelungen in den zehn mittel- und osteuropäischen EU-Beitrittskandidaten. 
Die Ausführungen des ersten Abschnitts zusammenfassend läßt sich sagen, daß der starke Rückgang der Industrieproduktion das herausragende Kennzeichen der Ausgangslage in den Reformländern war. Während der Zusammenbruch des RGW das Ausmaß der Transformationskrise noch verschlimmerte, hat sich die anschließende außenwirtschaftliche Öffnung verbunden mit relativ umfassender Konvertibilität positiv auf den Reformproze $ß$ ausgewirkt. Dabei ist insbesondere zu beachten, daß die Einführung der Leistungsbilanzkonvertibilität ein deutliches Signal für den Reformwillen darstellte, weil - wie erwähnt - Konvertibilität mit einem zentralverwaltungswirtschaftlichen System nicht vereinbar ist.

\section{Ungleichgewichte im monetären Bereich}

Nachdem im ersten Abschnitt des Kapitels die real- und außenwirtschaftlichen Umstände der Systemtransformation beschrieben wurden, werden in diesem Abschnitt die monetären Ungleichgewichte in der Ausgangslage betrachtet. Auf diesen beiden Abschnitten baut dann die Analyse des geld- und wechselkurspolitischen Handlungsspielraums im dritten Abschnitt auf.

\subsection{Begründung der Priorität der Geldwertstabilität}

Ein funktionierendes Geldwesen hat für die Transformation eine herausragende Bedeutung, weil der Übergang von einer sozialistischen Planwirtschaft zu einer marktwirtschaftlichen Organisation der Wirtschaftsabläufe mit einer grundlegenden Änderung der Funktion von Preisen und Geld verbunden ist. Prinzipiell erfüllt Geld sowohl in Plan- als auch in Marktwirtschaften die Funktionen eines Tauschmittels, einer Recheneinheit und eines Wertaufbewahrungsmittels. ${ }^{54}$ In einer marktwirtschaftlichen Wirtschaftsordnung werden Preise jedoch durch Angebot und Nachfrage bestimmt. Da der Preis den Knappheitsgrad eines Gutes widerspiegelt, erfüllt er eine wichtige Signal- und Steuerungsfunktion. Diese ermöglicht eine effiziente Allokation der Ressourcen sowie eine den Bedürfnissen der Wirtschaftssubjekte entsprechende Bereitstellung von Gütern. Ein solches Lenkungssystem der Preise existiert in Planwirtschaften nicht. ${ }^{55}$ Mengen und Preise werden von einer zentralen Instanz festgelegt, und die Allokation von Gütern erfolgt durch den Vollzug von Plänen. Dem Geld kommt in dieser Hinsicht nur eine passive Rolle zu. Es dient lediglich als Verrechnungseinheit. Beim Übergang von der Plan- zur Marktwirtschaft haben Preise aber die zentrale Aufgabe der Steuerung der Res-

54 Vgl. zu den Funktionen des Geldes ausfuhrlicher Jarchow (1998a), S. 1 ff.

55 Daß die Preise keine allokative Rolle spielten, gilt in stărkerem Maße für Bulgarien, Rumănien und die Tschechoslowakei als für Polen und Ungarn. In den beiden zuletzt genannten Lăndern war ein wesentlicher Teil der Preise bereits vor Transformationsbeginn nicht mehr staatlich festgelegt. Vgl. Calvo/Kumar (1993), S. 4. 
sourcenreallokation, wobei der Wettbewerb seine allokationsverbessernden Wirkungen nur entfalten kann, wenn die Preise längerfristig die tatsächlichen Knappheitsverhältnisse widerspiegeln.

Da Inflation mit volkswirtschaftlichen Kosten verbunden ist, wird Preisstabilität im allgemeinen als ein wichtiges wirtschaftspolitisches Ziel angesehen. ${ }^{56}$ Selbst wenn die Wirtschaftssubjekte die Inflation korrekt vorhersehen, müssen sie zusätzliche Transaktionskosten in Kauf nehmen, um sich gegen die negativen Folgen der Inflation zu schützen. Diese Kosten können in Form zusätzlichen Zeitaufwands oder durch den Einsatz realer Ressourcen zur Absicherung gegen die Inflation entstehen, die damit einer anderen volkswirtschaftlichen Verwendung nicht mehr zur Verfügung stehen. Inflation verändert die Zahlungsgewohnheiten und führt zu einer Ökonomisierung der Kassenhaltung, weil die Alternativkosten des Haltens von Geld ansteigen. Bei starker Inflation verliert das Geld seine effizienzfördernden Funktionen ganz. Ein oft beobachtetes Phänomen in Ländern mit hohen Inflationsraten ist, daß die Wirtschaftssubjekte statt der heimischen Währung Devisen als Tauschmittel nutzen oder im Extremfall sogar auf den Naturaltausch zurückgreifen. Des weiteren sind in einer stark inflationären Wirtschaft Redistributionseffekte $\mathrm{zu}$ erwarten, die sich insbesondere bei nicht antizipierter Inflation einstellen und unter sozialen Gesichtspunkten unerwünscht sind. Werden zum Beispiel die Einkommen von Rentnern und abhängig Beschäftigten nicht in sehr kurzen zeitlichen Abständen dem steigenden Preisniveau angepaßt, ergeben sich für diese Personen reale Einkommensverluste und eine Einkommensumverteilung zu Lasten dieser Bevölkerungsgruppe, weil sich andere gesellschaftliche Gruppen besser vor den Folgen der Inflation schützen können. Zwei weitere Probleme, die mit fehlender Geldwertstabilität verbunden sind, wirken sich zwar ebenfalls in allen Volkswirtschaften negativ aus, sind jedoch besonders nachteilig für die Reformländer, weil sie die Systemtransformation behindern. Dies sind einerseits die mit der Inflation einhergehenden Veränderungen der relativen Preise und andererseits die Tatsache, daß hohe Inflation zu einer höheren Variabilität der Inflationsraten und damit zu einer steigenden Unsicherheit führt. 57

Bei hohen Inflationsraten ändert sich ständig das System der relativen Preise und ist dadurch nicht transparent. Die Veränderungen der relativen Preise resultieren daraus, daß sich nicht alle Preise gleich entwickeln und deshalb nicht nur die Inflationsrate insgesamt stärker schwankt, sondern auch die Variabilität der relativen Preise ansteigt. Dies hängt insbesondere damit zusammen, daß aufgrund von Anpassungskosten (sog. menu costs) Preisänderungen nicht stetig, sondern in diskre-

$56 \mathrm{Zu}$ den Nachteilen von Inflation siehe u.a. Jarchow (1998a), S. 311 ff., Burdekin et al. (1995), S. 13 ff., und Europarische Zentralbank (1999), S. 44.

57 Zum Zusammenhang zwischen Hobe und Variabilităt von Inflationsraten siehe Issing (1989), S. 358. 
ten Zeitabständen erfolgen. Des weiteren wird es für die Wirtschaftssubjekte in einem inflationären Umfeld schwieriger, zwischen Änderungen der relativen Preise und des allgemeinen Preisniveaus zu unterscheiden. Die Signal- und Lenkungsfunktion des Preismechanismus wird beeinträchtigt. Dies führt zu Verzerrungen und behindert die optimale Allokation der Ressourcen. Da die Herausbildung eines neuen relativen Preissystems und die Ressourcenreallokation Bedingungen für einen erfolgreichen Transformationsproze $ß$ sind, wirken sich hohe Inflationsraten besonders nachteilig auf die Systemtransformation aus; gerade im Transformationsprozeß spielt die „Interdependenz von Wettbewerbsordnung und Währungspolitik"58 eine herausragende Rolle. Die systemtransformierenden Länder wollen ein marktwirtschaftliches System implementieren. Damit der Wettbewerb funktionieren kann, ist aber aufgrund der geschilderten Probleme ein Mindestma $ß$ an Preisstabilität erforderlich. Eucken formuliert dies wie folgt: „Alle Bemühungen, eine Wettbewerbsordnung zu verwirklichen, sind umsonst, solange eine gewisse Stabilität des Geldwertes nicht gesichert ist. Die Währungspolitik besitzt daher für die Wettbewerbsordnung ein Primat."59

Auch die aus hoher Inflation resultierende Unsicherheit stellt ein besonderes Problem im Rahmen der Transformation dar. Hohe, schwankende Inflationsraten führen zu höheren Risikoprämien auf die Zinssätze, denn bei gegebenem Nominalzinssatz steigt bei entsprechend stark schwankenden Inflationsraten ceteris paribus die Ungewißheit über den für die Investitionsentscheidung relevanten Realzins. Da sich dieses Problem mit zunehmenden Laufzeiten von Verträgen verschärft, ergibt sich eine Tendenz zu kurzfristigen Anlageperioden. Die Verkürzung des Planungshorizonts und höhere Zinssätze führen jedoch zur Einschränkung der Investitionstätigkeit. Obwohl dieses Argument in allen Wirtschaften Gültigkeit hat, stellt es wiederum für die Transformationsökonomien ein besonderes Problem dar, weil das Tempo und der Erfolg des Transformationsprozesses entscheidend davon abhängt, ob die wirtschaftliche Restrukturierung zügig vorangeht. Diese erfordert wie im Unterabschnitt 1.2. dieses Kapitels ausfuhrlich dargestellt - neben dem Schrumpfen bestimmter Wirtschaftszweige, zum Beispiel des sekundären Sektors wegen der Überindustrialisierung in vielen ehemaligen Zentralverwaltungswirtschaften, Investitionen in neue private Aktivitäten, zum Beispiel für den Aufbau eines in den Planwirtschaften völlig unterentwickelten Dienstleistungssektors. Neben den bereits dargestellten Problemen dieses Prozesses beeinträchtigt also eine hohe Inflation die wirtschaftliche Restrukturierung zusätzlich.

Ein Argument aus der Debatte um die angemessene Höhe der Inflationsrate lautet, daß die „optimale“ Inflationsrate - hier verstanden als Inflation, die sich nicht ne-

58 Issing (1989), S. 354. Zur Interdependenz von Wirtschaftsordnungen siehe Eucken (1952), S. $304 \mathrm{ff}$.

Eucken (1952), S. 256. 
gativ auf das Wirtschaftswachstum auswirkt - in sich entwickelnden Volkswirtschaften höher ist als in Industrieländern. ${ }^{60}$ Dies wird damit begründet, daß der Nutzungsgrad des Preissystems und der Finanzmärkte in der zuletzt genannten Ländergruppe höher ist und sich dadurch die Inflation dort schädlicher auswirkt als in Ländern, die durch relativ unterentwickelte Märkte gekennzeichnet sind. ${ }^{61}$ Daraus ergibt sich eine wichtige Implikation für die Transformationsländer. Da ein konstitutives Merkmal dieser Länder darin besteht, daß sie ihre Wirtschaftssysteme auf Marktmechanismen umstellen, steigen die Kosten hoher Inflationsraten im Zeitablauf und erschweren den Übergang zu effizienten Märkten. Auch aus dieser Überlegung folgt, daß der Preisstabilisierung im Reformprozeß von Beginn an eine große Aufmerksamkeit geschenkt werden muß.

Die mit hoher Inflation verbundenen Probleme erfordern grundsätzlich in allen Ländern, daß der Preisstabilität seitens der wirtschaftspolitischen Instanzen eine hohe Priorität beigemessen wird. Dies hat zum Beispiel seinen Niederschlag in Art. 3a (2) des EG-Vertrags gefunden, der festlegt, daß in den EU-Mitgliedstaaten sowohl die Geld- als auch die Wechselkurspolitik ,vorrangig das Ziel der Preisstabilität verfolgen“. Da fehlende Geldwertstabilität in den Reformländern elementare Anpassungsprozesse der Transformation behindert, muß Preisstabilität auch in der speziellen Situation des Übergangs von der Plan- zur Marktwirtschaft von Anfang an zentrale wirtschaftspolitische Zielsetzung sein. Es besteht daher in der Literatur weitgehend Konsens, daß eine zügige monetäre Stabilisierung ein zentraler Politikbestandteil im Frühstadium der Transformation sein muß und die Implementierung eines Antiinflationsprogramms vielen anderen Politikmaßnahmen vorausgehen sollte. ${ }^{62}$

Zwei Ausgangsprobleme der Transformationsländer standen im Konflikt mit dem Ziel der Preisstabilität, weil sie große Inflationspotentiale bargen. Zum einen waren alle Länder - wenn auch in unterschiedlichem Ausmaß - mit dem Problem des Geldüberhangs konfrontiert. Eine Definition des Begriffs und eine Erläuterung der grundsätzlichen Möglichkeiten des Abbaus erfolgt im nächsten Unterabschnitt. Zum anderen hatten die Länder ein völlig verzerrtes Preissystem aus der Zeit der Planwirtschaft geerbt. Dies steht in engem Zusammenhang mit dem Geldüberhang

60 Es ist in der Literatur umstritten, wie stark die Inflation zuruckgefuhrt werden muß, um unschådlich zu sein. Bruno/Easterly (1998), S. 5 f., ermitteln einen Schwellenwert von 40 v.H. p.a., wăhrend Burton/ Fischer (1998), S. 24, davon ausgehen, daß bereits niedrige zweistellige Inflationsraten die wirtschaftliche Entwicklung beeintrăchtigen.

61 Vgl. zu dieser Argumentation und den beiden folgenden Sătzen Burdekin et al. (1995), S. 29.

62 Siehe Edwards (1996a), S. 134, und Hartwig (1995), S. 11. Auf die Frage der optimalen Abfolge wirtschaftspolitischer Maßnahmen, dem sogenannten Sequencing, wird im folgenden nicht năher eingegangen. Im Rahmen dieser Arbeit wird die Position vertreten, daß eine fruhe umfassende Reformpolitik erforderlich ist. 
und ließ sich nur durch eine umfassende Liberalisierung korrigieren. Die damit verbundenen Probleme werden im Unterabschnitt 2.3. diskutiert.

\subsection{Das Problem des Geldüberhangs}

\subsubsection{Problemstellung}

Wie in anderen Bereichen des Sozialismus auch entsprach die Realität im monetären Sektor nicht den theoretischen Idealvorstellungen, so daß bereits vor Beginn der Transformation einige Indikatoren auf monetäre Ungleichgewichte hinwiesen. In einzelnen Ländern nahm die Überversorgung mit Zahlungsmitteln zu und dadurch die Akzeptanz der heimischen Währung bei der Bevölkerung ab. ${ }^{63}$ In Marktwirtschaften führt ein Anstieg der Geldmenge, der stärker ausfällt als die Zunahme des Realwertes der Gütertransaktionen, zu einem Anstieg des Preisniveaus. ${ }^{64}$ Hält dieser Zustand über einen längeren Zeitraum an, spricht man von offener Inflation. Im Gegensatz dazu war die Situation in den Transformationsländern durch eine „unterdrückte“ oder „zurückgestaute“ Inflation gekennzeichnet. Dieser Begriff bezeichnet eine Situation, in der das Preisniveau durch eine administrative Festlegung von Preisen fixiert wird und gleichzeitig ein Überschußangebot an Geld (der Geldüberhang) und eine korrespondierende Überschußnachfrage nach Gütern herrscht. ${ }^{65}$ Die Vermeidung eines Preisanstiegs durch die staatliche Kontrolle führt zu einem Mangel an Gütern zu offiziellen Preisen, was sich in Warteschlangen vor Geschäften und der Entwicklung von Schwarzmärkten niederschlägt.

Die Lohnsteigerungen, die kein Ergebnis von Verhandlungen zwischen Arbeitgebern und Arbeitnehmern - sondern ein Resultat staatlicher Planungen - sind, übersteigen die Fähigkeit der Wirtschaft, Konsumgüter bereitzustellen. Da die Planungsvorgaben monetär alimentiert werden, steigt die Geldmenge schneller als die Güterproduktion, und es kommt zu einer zunehmenden Bargeldhaltung und steigenden Guthaben auf Bankkonten, die Ausdruck unfreiwilliger Anhäufung von finanziellem Vermögen sind. ${ }^{66}$ Lipton/Sachs (1990) weisen darauf hin, daß eine wichtige Implikation der zurückgestauten Inflation ist, daß der gemessene Effekt der Reformen vom tatsächlichen Effekt abweicht. Zum Beispiel kann ein Rückgang der Reallöhne mit einem Anstieg des realen Lebensstandards verbunden sein, weil nach der Liberalisierung die Produkte tatsächlich verfügbar sind, während sie vorher zu den niedrigeren Preisen nicht erworben werden konnten. ${ }^{67}$

\footnotetext{
63 Vgl. Thieme (1995), S. 5.

64 Dieser Zusammenhang ergibt sich aus der Quantitătsgleichung, wenn eine konstante Umlaufgeschwindigkeit des Geldes unterstellt wird. Siehe hierzu genauer Jarchow (1998a), S. $168 \mathrm{f}$.

65 Vgl. Claassen (1991), S. 8 f.

66 Siehe de Melo et al. (1997a), S. 20.

67 Vgl. Lipton/Sachs (1990), S. 89.
} 
Zu Transformationsbeginn standen die Reformländer vor dem Problem, den Geldüberhang abbauen zu müssen, um ein Gleichgewicht auf dem Geldmarkt zu erreichen. $\mathrm{Ob}$ es dabei zu einem Preisschock kommt, hängt von der gewählten Vorgehensweise beim Abbau des Geldüberhangs ab.

\subsubsection{Möglichkeiten des Abbaus des Geldüberhangs}

Zur Beseitigung des Geldüberhangs sind grundsätzlich mehrere Wege denkbar.68 Eine einfache Methode zur Reduktion des Geldvermögens ist, einen Teil der Bankguthaben im Wege einer Währungsreform zu beschlagnahmen. ${ }^{69}$ Dabei ist unerheblich, ob im Rahmen der Reform eine neue Währung eingeführt wird. Das entscheidende Merkmal der Umstellung muß darin bestehen, daß die monetären Bestände stärker entwertet werden als laufende Zahlungen, wie zum Beispiel Löhne und Mieten. Eine Währungsreform hat den Vorteil, daß sie einen einmaligen administrativen Akt darstellt, der zwar gewisse logistische Vorbereitungen erfordert, ansonsten aber schnell umsetzbar ist. Mit einer Währungsreform sind aber auch einige Probleme verbunden. Weil die genaue Höhe des Geldüberhangs unbekannt ist, bestehen große Schwierigkeiten, ein angemessenes Umtauschverhältnis festzulegen. Wird ein Verhältnis gewählt, das zu günstig für die Besitzer von Geldvermögen ausfällt, werden die Finanzbestände nicht ausreichend reduziert, und es kommt zu Preissteigerungen, wenn diese nachfragewirksam werden. Einem ungünstigeren Umtauschverhältnis stehen häufig politische Überlegungen im Wege, weil mit der Währungsreform Umverteilungseffekte verbunden sind, die sich daraus ergeben, daß im Gegensatz zu Geldvermögensbeständen das Sachvermögen nicht entwertet wird. Unabhängig von der Frage, ob eine Währungsreform politisch überhaupt durchsetzbar ist, ist mit ihr die Gefahr verbunden, daß die Wirtschaftssubjekte der Regierung auch zukünftig die Durchführung ähnlicher Maßnahmen zutrauen. Die Glaubwürdigkeit einer Politik, die den Übergang zu marktwirtschaftlicher Koordination propagiert, leidet erheblich unter einer Währungsreform, die das genaue Gegenteil darstellt.

Während eine Währungsreform an den Nominalwerten des Finanzvermögens ansetzt, besteht alternativ die Möglichkeit, die realen Bestände über eine einmalige Anhebung des Preisniveaus zu reduzieren. Diese Vorgehensweise reduziert das reale Geldangebot bei konstanten nominalen Geldbeständen. ${ }^{70}$ Dies kann als eine

$68 \mathrm{Zu}$ den Moglichkeiten der Beseitigung des Gelduberhangs vgl. Bernholz (1994), S. 542 f., Fröhlich (1992), S. 28 ff., und Tober (1995), S. $48 \mathrm{ff}$.

69 Eine Variante, die der Wahrungsreform sehr nahe kommt oder auch Komponente einer Wăhrungsreform sein kann, ist die Einfrierung von Bankguthaben. Damit dies nicht nur zu einer zeitlichen Verschiebung des Problems fuhrt, muß geklärt werden, für welchen Zeitraum die $\mathrm{Maßnahme} \mathrm{gilt} \mathrm{und} \mathrm{fur} \mathrm{welche} \mathrm{zuklinftigen} \mathrm{Verwendungen} \mathrm{eine} \mathrm{Freigabe} \mathrm{erfolgt.}$

70 Anders argumentiert, bewirkt die Preisanhebung einen Anstieg der nominalen Geldnachfrage bei unverăndertem nominalen Geldangebot. Beide Aussagen sind inhaltlich identisch. 
indirekte Form der Konfiszierung des Geldüberhangs angesehen werden. Allerdings ruft diese Maßnahme in der Regel weniger gesellschaftliche Widerstände hervor als der direkte Weg einer Währungsreform. Obwohl theoretisch nur ein einmaliger Preissprung erforderlich ist, sind mit dieser Methode erhebliche Risiken verbunden, weil der Anstieg der Preise unter Umständen Inflationserwartungen hervorruft, so daß die Gefahr einer sich anschließenden Anpassungsinflation und Preis-Lohn-Spirale besteht.

Eine dritte Möglichkeit, den Geldüberhang abzubauen, besteht in der Umwandlung der monetären Bestände, die in der Regel aus Guthaben auf Spar- und Girokonten bestehen, in attraktive langfristige Finanzanlagen, zum Beispiel in Form von Staatsanleihen. Diese Umschichtung innerhalb des Finanzvermögens bindet zwar den Geldüberhang über einen längeren Zeitraum; je nach Tilgungsstruktur der Papiere wird er aber sukzessive wieder freigegeben. Ein grundlegendes Problem besteht darin, daß die notwendigen Finanzanlagen nicht vorhanden sind, sondern erst geschaffen werden müssen, wobei vermutlich nur der Staat als Emittent in Frage kommt. Der Staat muß in diesem Fall hohe Zinsverpflichtungen eingehen, weil die Papiere eine gute Verzinsung bieten müssen, um attraktiv zu sein. Es kommt zu einer Belastung des Staatshaushaltes mit Tilgungs- und Zinszahlungen, so daß der Abbau von Budgetdefiziten erschwert wird. Diese Lösungsmöglichkeit hat zwar den Vorteil, daß sie auf marktwirtschaftlichen Prinzipien beruht. Dies stellt aber zugleich ein großes Problem dar, weil nicht abgeschätzt werden kann, ob die privaten Wirtschaftssubjekte die langfristigen Finanzanlagen erwerben oder trotz gebotener attraktiver Verzinsung die Geldbestände lieber nachfragewirksam einsetzen. Genau wie bei einer Währungsreform stellt sich außerdem wieder die Frage, wie hoch der Geldüberhang tatsächlich ist, so daß die Regierung auch aus diesem Grund nicht wissen kann, in welchem Volumen langfristige Finanzanlagen emittiert werden müssen.

Schließlich wäre noch denkbar, die Abschöpfung des Geldüberhangs mit der Privatisierung zu verbinden und durch den Verkauf von Staatseigentum die monetären Bestände in Sachvermögen umzuwandeln. Wichtige Voraussetzung für die Wirksamkeit dieser Maßnahme ist, daß der Staat die Privatisierungserlöse stillegt. Das Verfahren ist jedoch mit mehreren Problemen verbunden. Die Bevölkerung kann nicht gezwungen werden, ihr Geld in die Privatisierung zu stecken, und es ist fraglich, ob die Haushalte an einem Kauf interessiert sind. Eine solche Entscheidung ist mit großen Unsicherheiten verbunden, insbesondere weil über die zukünftige Ertragslage der Unternehmen in einem völlig veränderten wirtschaftlichen Umfeld kaum Prognosen möglich sind. Am ehesten wäre dieses Verfahren wohl noch für Immobilien denkbar. Im Hinblick auf die Durchführung besteht das Problem, daß für eine erfolgreiche Privatisierung zeitaufwendige rechtliche und administrative Vorarbeiten notwendig sind. Die Beseitigung des Geldüberhangs ist 
aber eine Voraussetzung für den Reformprozeß und muß daher am Anfang stehen. Aufgrund des hohen Zeitbedarfs kommt dieses Instrument nicht in Frage, obwohl es einen gewissen theoretischen Charme entfaltet.

Die Betrachtung der einzelnen Möglichkeiten legt den Schluß nahe, daß insbesondere mit Blick auf die Priorität der Preisstabilität eine Währungsreform die optimale Lösung des Problems darstellt, weil sie einen Preisschock vermeidet. Auch Tober (1995) argumentiert, daß eine Anpassungsinflation die Glaubwürdigkeit der neuen Regierung schwächt, weil das Stabilisierungsprogramm zunächst destabilisierend wirkt. „Gerade in den Transformationsökonomien, in denen zu Beginn des Transformationsprozesses neue Verhaltensmuster und entsprechende Sanktionsund Anreizmechanismen etabliert werden müssen, erscheint dieser Weg verfehlt."71 Um so mehr überrascht es, daß alle betrachteten Länder die Anhebung des Preisniveaus zur Beseitigung des Geldüberhangs wählten, an die sich ein längerer Zeitraum mit hohen Inflationsraten anschloß. Selbst jene vier Länder, die drei baltischen Staaten und Slowenien, die ihre Transformation mit einer Währungsreform begannen, führten in deren Rahmen zwar neue nationale Währungen ein. Den Abbau des Geldüberhangs regulierten sie jedoch durch Preisanhebungen, und nicht in Form deutlich ungünstigerer Umtauschverhältnisse für Vermögensbestände im Gegensatz zu Stromgrößen. ${ }^{72}$ Wäre eine Währungsreform nicht der bessere, weil inflationsvermeidende Weg gewesen?

Wenn der Preisstabilität aus den diskutierten Gründen ein hohe Priorität eingeräumt werden muß, erscheint es in der Tat widersprüchlich, daß sich alle Länder für eine Preisanpassung entschieden. Zwei Nachteile einer Währungsreform wogen jedoch offensichtlich so schwer, daß sich die verantwortlichen wirtschaftspolitischen Instanzen gegen diese Vorgehensweise entschieden. Erstens handelt es sich - wie erwähnt - bei einer Währungsreform mit Enteignung von Geldvermögen in einer Marktwirtschaft um eine systemfeindliche Maßnahme. Es wäre entsprechend schwer gewesen, der Öffentlichkeit zu erklären, daß der Übergang zu einer marktwirtschaftlichen Organisation eines solchen systemfeindlichen Schrittes bedarf. Zweitens erfordert eine Währungsreform eine ungefähre Vorstellung über die Höhe des bestehenden Geldüberhangs, wobei die Schwierigkeiten bei der Schätzung des Ausmaßes in Osteuropa extrem groß gewesen sind. ${ }^{73} \mathrm{Da}$ keine zuverlässigen Angaben existierten, bestand die Gefahr, daß eine Währungsreform den Abbau

71 Tober (1995), S. $48 \mathrm{f}$.

72 Dabei ist zu berucksichtigen, daß sowohl im Baltikum als auch in Slowenien bereits vor der staatlichen Unabhängigkeit erste Preisanpassungen durchgefuhrt wurden.

73 Siehe hierzu Edwards (1996a), S. 137. Er illustriert die Problematik mit Zahlen furr die Sowjetunion. Danach beliefen sich die Schătzungen, um wieviel das Preisniveau fur einen Abbau des uberschussigen Geldangebots hătte steigen mussen, auf Werte zwischen 50 v.H. und dem Drei- oder gar Vierfachen des Preisniveaus. 
nicht erreicht, was ebenfalls zu einem schwerwiegenden Vertrauensverlust gegenüber der Regierung geführt hätte. Die Anpassung über das Preisniveau erfordert hingegen keine Abschätzung über die Höhe des Geldüberhangs, da sich nach Freigabe der Preise über den Ausgleich von Angebot und Nachfrage automatisch ein neues, angemessenes Preisniveau einstellt. Schließlich muß drittens noch berücksichtigt werden, daß die Länder eine Preisliberalisierung durchführen mußten, die einen Anstieg der Preise bewirkte. Dadurch bot sich die Gelegenheit, zwei Ziele mit einer Maßnahme zu erreichen. Auf die Preisliberalisierung wird im folgenden näher eingegangen.

\subsection{Preisliberalisierung zu Beginn der Transformation}

Es muß zunächst festgehalten werden, daß zwar ein enger Zusammenhang zwischen dem Abbau des Geldüberhangs und der Preisliberalisierung besteht, beide Phänomene aber analytisch getrennt zu sehen sind. Wie gerade gezeigt, gibt es prinzipiell mehrere Möglichkeiten, den Geldüberhang zu beseitigen, so daß diese Maßnahme nicht zwangsläufig mit einem Preisanstieg verbunden sein muß. Des weiteren ist eine Preisliberalisierung möglich, die den Geldüberhang nicht beseitigt. Dies ist dann der Fall, wenn die Preisanpassung von einer entsprechenden Anhebung der Löhne und Finanzvermögen begleitet ist. ${ }^{74}$ Allerdings führt die Preisliberalisierung immer zu einem Anstieg des Preisniveaus. Die ehemaligen Planwirtschaften kennzeichnete eine völlig verzerrte Preisstruktur, weil für viele Güter die Preise durch Subventionierung und staatliche Kontrollen auf niedrigem Niveau fixiert wurden. Der Abbau von Subventionen und Preiskontrollen bewirkte einen Anstieg der vorher niedrig gehaltenen Preise. Bei hinreichend flexiblen Preisen kann ein Teil der relativen Preisanpassung dadurch erreicht werden, daß neben der Erhöhung einiger Preise andere Preise des Warenkorbs sinken. Wenn aber diejenigen Preise, die eigentlich sinken müßten, nach unten nicht flexibel reagieren, dann muß die relative Preisanpassung durch einen stärkeren Anstieg derjenigen Preise erreicht werden, die anderenfalls nur schwach gestiegen oder sogar unverändert geblieben wären. ${ }^{75} \mathrm{Je}$ mehr Preise nach unten nicht flexibel sind, um so wahrscheinlicher ist, daß eine Preisliberalisierung zu einem kräftigen Anstieg des Preisniveaus führt. Außerdem ist neben der Anpassung der relativen Preise zu beachten, daß die überwiegende Zahl der inländischen Preise unter dem entsprechenden Weltmarktniveau lag. Um die internationalen Preisdifferenzen auszugleichen,

74 Havrylyshyn/Williamson (1991), S. 34, nennen als ein Beispiel hierfur die sowjetische Preisreform vom April 1991. Die deutliche Anhebung der staatlich festgelegten Preise um durchschnittlich ca. 50 v.H. hatte nur eine begrenzte Wirkung auf den Geldüberhang, weil sie von deutlichen Lohnerhöhungen und einer Anhebung der Werte von Sparguthaben in Höhe von 40 v.H. begleitet war.

75 Vgl. zu den Ergebnissen einer empirischen Studie zu diesem Thema Coorey et al. (1998), S. $240 \mathrm{ff}$. 
wurde einerseits der nominale Wechselkurs angehoben; andererseits wurden die Preise in inländischer Währung heraufgesetzt. Beides trug zur Erhöhung des gesamtwirtschaftlichen Preisniveaus bei. Für die Transformationsländer ist außerdem zu berücksichtigen, daß die in verschiedenen Bereichen der Volkswirtschaft fortbestehenden monopolistischen Marktstrukturen erheblich zur Inflexibilität des inländischen Preissystems beitrugen.

Die mittel- und osteuropäischen Transformationsökonomien haben im Zuge der Preisliberalisierung nicht nur einen einmaligen Preissprung erlebt, sondern wiesen über einen längeren Zeitraum zum Teil extrem hohe Inflationsraten auf. Da sowohl der Abbau des Geldüberhangs als auch die Preisliberalisierung theoretisch zunächst nur einen einmaligen Preissprung erklären, deutet dies auf eine zusätzliche Geldschöpfung im Transformationsproze $ß$ hin und zeigt, daß nicht nur Bestandssondern auch Stromprobleme gelöst werden mußten. Auf die vielfältigen Ursachen für eine anhaltende Inflation wird im folgenden näher eingegangen, weil sie einerseits das Bild abrunden, das die Ausgangslage und den Reformbedarf skizziert, und andererseits für die modelltheoretischen Überlegungen im Kapitel III wichtig sind.

Neben den aufgeführten Gründen ist als wichtigste Ursache anhaltender Preissteigerungen eine expansive Geldpolitik zu nennen, denn eine anhaltende Inflation erfordert eine monetäre Akkommodation. Auf diesen Aspekt wird an dieser Stelle nicht näher eingegangen, weil die Probleme, die mit der Steuerung der Geldmenge im Transformationsprozeß verbunden sind, erst im Unterabschnitt II.3.1.2. behandelt werden. Im fiskalpolitischen Bereich bergen zum einen Budgetdefizite ein erhebliches Inflationspotential, wenn sie teilweise über Notenbankkredite finanziert werden. Zum anderen ist auch der Umbau des Steuersystems mit inflationären Risiken verbunden. In Zentralverwaltungswirtschaften dominierten die direkten Steuern. Es existierte kein Mehrwertsteuersystem nach westlichen Maßstäben, so daß im Rahmen der Umgestaltung der Steuersysteme nach marktwirtschaftlichen Vorbildern insbesondere indirekte Steuern eingeführt wurden, die preissteigernd wirkten. ${ }^{76}$ Aus dieser einmaligen Maßnahme folgt ein Anstieg der Inflation, wenn die Wirtschaftssubjekte höhere Löhne fordern oder sich Inflationserwartungen bilden, weil es ein Jahr dauert, bevor der Basiseffekt dieses einmaligen, administrativ bedingten Preisanstiegs verschwindet.

Ein weiterer Faktor, der zu dem Preisauftrieb im Transformationsprozeß beitrug, ist die Tatsache, daß die wirtschaftspolitischen Entscheidungsträger, wenn sie sich

76 Aus diesem Grund nehmen zum Beispiel Horvath/Jonas (1998), S. 11, bei der Bewertung der Inflationsentwicklung in Tschechien explizit die Effekte aus der Einfuhrung der Umsatzsteuer aus. Janácková (1995), S. 37, fuhrt uber 40 v.H. des Preisanstiegs (8,5 Prozentpunkte von insgesamt 20 v.H.) im Jahr 1993 auf die Einfuhrung der Mehrwertsteuer zuruck. 
für ein festes Wechselkurssystem entschieden, durchgängig Ausgangsniveaus für den nominalen Wechselkurs wählten, die auf eine starke Unterbewertung der Währung hinausliefen. In einer Situation mit unterbewerteter Währung liegt der reale Wechselkurs über dem Gleichgewichtskurs. Die Bewegung des realen Wechselkurses hin zum Gleichgewichtswert muß in einem Festkurssystem über eine höhere inländische Inflationsrate erreicht werden, weil der nominale Wechselkurs nicht angepaßt wird.

Mit der schrittweisen Liberalisierung des Kapitalverkehrs kam es nach ersten Reformerfolgen zu erheblichen Kapitalzuflüssen in einige Transformationsländer. Ihre Auswirkungen auf das Preisniveau sind dabei sehr stark vom Wechselkursregime abhängig. Bei einer Wechselkursbindung ist die Zentralbank gezwungen, die zufließenden Devisen gegen Hergabe heimischer Währung anzukaufen. Auf die Dauer kann sie die daraus resultierende Geldmengenausweitung nicht neutralisieren, so daß die inländische Geldmenge und die Preise steigen. Bei flexiblen Wechselkursen stellen starke Kapitalzuflüsse unter dem Aspekt einer Inflationsvermeidung kein Problem dar. Die Zentralbank braucht in diesem Fall nicht am Devisenmarkt einzugreifen. Statt dessen kommt es bei freier Wechselkursbildung zu einer preissenkenden nominalen Aufwertung. Die sich verbilligenden Importe und die schlechtere preisliche Wettbewerbsfähigkeit der Exporte wirken sich allerdings über einen rückläufigen Außenbeitrag negativ auf das Bruttoinlandsprodukt des Landes aus, so daß auch bei flexiblen Wechselkursen die Zentralbank unter Umständen am Devisenmarkt eingreift, um die negativen Auswirkungen der nominalen Aufwertung auf Produktion und Beschäftigung zu begrenzen. ${ }^{77}$

Eine wesentliche Ursache anhaltender Inflation im Transformationsproze $\beta$ ist, daß nicht alle Preise sofort freigegeben wurden. Der größte Schritt erfolgte zwar in der Regel zu Beginn der Transformation, ein Teil der Preise unterlag jedoch weiterhin der staatlichen Regulierung. Aufgrund der herausragenden Bedeutung der sukzessiven Anpassung der administrativ festgelegten Preise für das Modell im dritten Abschnitt des Kapitels III wird im folgenden von dem Grundsatz abgewichen, daß in diesem Kapitel keine detaillierte Betrachtung der Entwicklung in den zehn EUBeitrittskandidaten erfolgt. Die Tabelle 1 gibt einen Überblick über die Zeitpunkte, zu denen die betrachteten Länder den überwiegenden Teil der Preise freigaben, und darüber, welche Anteile am Konsumgüterpreisindex in den nachfolgenden Jahren noch der staatlichen Regulierung unterlagen. ${ }^{78}$

77 Fur dieses Vorgehen finden sich zahlreiche Beispiele in Mittel- und Osteuropa. Zu Slowenien 1994/95 siehe Burton/Fischer (1998), S. 84. Zu entsprechenden Interventionen der tschechischen Nationalbank im Fruhjahr 2000 vgl. DB Research (2000c), S. 47.

$78 \mathrm{Zu}$ letzterem enthălt die der Tabelle zugrunde liegende Quelle keine Daten fur Litauen. Da entsprechende Angaben sehr stark zwischen verschiedenen Quellen schwanken und es keine bessere Zusammenstellung in der Literatur gibt, die alle zehn Lănder berucksichtigt, wird dieser Nachteil zugunsten einer einheitlichen Systematik für alle Lănder in Kauf genommen. 
Tabelle 1: Preisregulierung in Mittel- und Osteuropa

\begin{tabular}{|c|c|c|c|c|c|c|c|c|c|c|}
\hline & & 1990 & 1991 & 1992 & 1993 & 1994 & 1995 & 1996 & 1997 & 1998 \\
\hline \multirow[b]{2}{*}{ Bulgarien } & \multicolumn{10}{|c|}{ Monat mit stärkster Preisliberalisierunga: Februar 1991} \\
\hline & \begin{tabular}{|l|} 
Anteil administ- \\
rativ festgelegter \\
Preise am KPI \\
\end{tabular} & 70,0 & 24,0 & 16,0 & 26,0 & 43,0 & 46,0 & 52,0 & 14,4 & 15,8 \\
\hline \multirow[b]{2}{*}{ Estland } & \multicolumn{10}{|c|}{ Monat mit stärkster Preisliberalisierunga: Dezember 1992} \\
\hline & $\begin{array}{l}\text { Anteil administ- } \\
\text { rativ festgelegter } \\
\text { Preise am KPI }^{c}\end{array}$ & - & - & - & - & 21,1 & 18,0 & 24,0 & 24,0 & 24,0 \\
\hline \multirow[b]{2}{*}{ Lettland } & \multicolumn{10}{|c|}{ Monat mit stärkster Preisliberalisierunga: Januar 1992} \\
\hline & $\begin{array}{l}\text { Anteil administ- } \\
\text { rativ festgelegter } \\
\text { Preise am KPI } \\
\end{array}$ & - & - & 6,1 & 6,1 & 16,6 & 16,6 & 17,8 & 19,6 & 20,4 \\
\hline \multirow[b]{2}{*}{ Litauen } & \multicolumn{10}{|c|}{ Monat mit stärkster Preisliberalisierungb: Oktober 1992} \\
\hline & $\begin{array}{l}\text { Anteil administ- } \\
\text { rativ festgelegter } \\
\text { Preise am KPI }\end{array}$ & - & - & - & - & - & - & - & - & - \\
\hline \multirow[b]{2}{*}{ Polen } & \multicolumn{10}{|c|}{ Monat mit stärkster Preisliberalisierungb: Januar 1990} \\
\hline & $\begin{array}{l}\text { Anteil administ- } \\
\text { rativ festgelegter } \\
\text { Preise am KPI }\end{array}$ & 11,0 & 11,0 & 11,0 & 10,6 & 12,0 & 12,0 & 11,6 & 10,6 & 10,6 \\
\hline \multirow[b]{2}{*}{ Rumänien } & \multicolumn{10}{|c|}{ Monat mit stärkster Preisliberalisierungb: Juli 1995} \\
\hline & $\begin{array}{l}\text { Anteil administ- } \\
\text { rativ festgelegter } \\
\text { Preise am KPI }\end{array}$ & 85,0 & 47,0 & 29,0 & 20,0 & 18,0 & 18,0 & 18,0 & 7,0 & - \\
\hline \multirow[b]{2}{*}{ Slowakei } & \multicolumn{10}{|c|}{ Monat mit stärkster Preisliberalisierungb: Januar 1991} \\
\hline & \begin{tabular}{|l} 
Anteil administ- \\
rativ festgelegter \\
Preise am KPI \\
\end{tabular} & - & - & - & 21,8 & 21,8 & 21,8 & 21,8 & 14,9 & 14,9 \\
\hline \multirow[b]{2}{*}{ Slowenien } & \multicolumn{10}{|c|}{ Monat mit stärkster Preisliberalisierungb: Juni 1994} \\
\hline & \begin{tabular}{|l|} 
Anteil administ- \\
rativ festgelegter \\
Preise am KPI \\
\end{tabular} & - & - & 23,7 & 19,8 & 18,4 & 22,5 & 22,4 & 20,4 & 17,0 \\
\hline \multirow[b]{2}{*}{ Tschechien } & \multicolumn{10}{|c|}{ Monat mit stärkster Preisliberalisierungb: Januar 1991} \\
\hline & $\begin{array}{l}\text { Anteil administ- } \\
\text { rativ festgelegter } \\
\text { Preise am KPI }\end{array}$ & - & 27,9 & 18,3 & 17,9 & 18,1 & 17,4 & 17,4 & 13,3 & 13,3 \\
\hline \multirow[b]{2}{*}{ Ungarn } & \multicolumn{10}{|c|}{ Monat mit stärkster Preisliberalisierung $\mathrm{b}$ :Januar 1991} \\
\hline & $\begin{array}{l}\text { Anteil administ- } \\
\text { rativ festgelegter } \\
\text { Preise am KPI }\end{array}$ & 16,0 & 11,0 & 10,9 & 10,8 & 11,8 & 12,9 & 12,8 & 15,9 & - \\
\hline
\end{tabular}

2uelle: Zusammengestellt aus den Angaben auf den Lănderseiten von EBRD (1999). 
Die Tabelle zeigt einerseits, daß in den meisten Ländern der größte Teil der Preise Anfang der 1990er Jahre freigegeben wurde. Andererseits ist ersichtlich, daß während des gesamten Transformationsprozesses fast ausnahmslos mindestens 10 v.H. des Konsumgüterpreisindexes weiterhin der staatlichen Regulierung unterlagen, wobei die Anteile zum Teil im Zeitablauf sogar anstiegen. Letzteres Phänomen weist darauf hin, daß das Ausmaß der Preisliberalisierung in der Tabelle nur teilweise erfaßt wird. Wird der Preis für ein Gut, das einer staatlichen Preiskontrolle unterliegt, vollkommen freigegeben, verringert sich der Anteil der Güter am Warenkorb mit administrativer Preisfestlegung. Eine vollständige Preisfreigabe einiger Güter führt in der Tabelle daher zu sinkenden Anteilen regulierter Preise. Die schrittweise Anhebung der staatlich festgelegten Preise hingegen kann sich sogar in einer Erhöhung des Anteils niederschlagen, weil das Gewicht am Warenkorb des weiterhin regulierten Gutes durch die Heranführung an das Marktniveau steigt. Insofern ist bei der Interpretation der Daten Vorsicht geboten. Festzuhalten bleibt die Erkenntnis, daß die Preisliberalisierung der mittel- und osteuropäischen Länder auch Ende der 1990er Jahre noch nicht abgeschlossen war. Die sukzessiven Anhebungen der staatlich regulierten Preise führten im gesamten Verlauf der Transformation immer wieder zu Preisschüben und trugen entscheidend zu längeren Phasen mit höheren Inflationsraten bei. ${ }^{79}$ Die Bedeutung und die fortbestehende Relevanz dieses Einflusses soll jeweils an einem Länderbeispiel illustriert werden. Nach Aussagen des nationalen Amtes für Statistik in Ungarn war die Hälfte des Anstiegs der Konsumgüterpreise im Juli 1999 (im Vormonatsvergleich) auf administrative Preisänderungen zurückzuführen, wobei sich insbesondere eine Reduzierung der Subventionierung von Medikamenten auswirkte, die zu einem Anstieg der Arzneimittelpreise um 17 v.H. (im Vormonatsvergleich) führte. ${ }^{80}$ Auch zehn Jahre nach dem Reformbeginn ist die Preisliberalisierung in Mittel- und Osteuropa noch nicht abgeschlossen, wie das Beispiel Tschechien zeigt. Die Regierung hat im Jahr 1999 eine Erhöhung der Strom- und Gaspreise für Januar 2000 um jeweils 15 v.H. angekündigt und dabei bereits weitere Anhebungen der Erdgaspreise in 2001 und 2002 um 10,7 v.H. bzw. 7,5 v.H. in Aussicht gestellt. ${ }^{81}$

Die Entscheidung für die Anhebung der Preise zur Beseitigung des Geldüberhangs und die.Preisliberalisierung zu Beginn der Transformation führte in allen Ländern zu einer offenen Inflation mit zum Teil vierstelligen Inflationsraten. ${ }^{82}$ Zusätzlich haben die anderen diskutierten Einflüsse während des Reformprozesses die zügige Disinflation erschwert. Unter Berücksichtigung der Probleme, die sich aus hoher

79 Vgl. zum Beispiel Wozniak (1998), S. 34 ff., fur den Einfluß der administrativen Preisanpassungen auf die Inflation in Polen.

80 Vgl. DB Global Markets Research (1999), S. 22.

81 Siehe DB Research (1999b), S. 8.

82 Zur Entwicklung der Inflationsraten in Mittel- und Osteuropa siehe Unterabschnitt IV.3.1. 
Inflation im allgemeinen und in den Reformländern im speziellen ergeben, stellte sich die Stabilisierungsaufgabe um so dringlicher.

\section{Geld- und wechselkurspolitischer Entscheidungsbedarf}

Nach der Darstellung der real- und außenwirtschaftlichen Bedingungen und der Ungleichgewichte im monetären Sektor widmet sich dieser Abschnitt den Fragen, welche Handlungsspielräume für die Implementierung einer stabilitätsorientierten Geldpolitik bestanden und welche Argumente für alternative wechselkurspolitische Optionen sprachen.

\subsection{Schaffung der Voraussetzungen für eine markt- gerechte und stabilitätsorientierte Geldpolitik}

\subsubsection{Institutionelle Reformen im Finanzsektor}

Die Reformen im Finanzsektor sind in zweierlei Hinsicht von herausragendem Interesse. Zum einen ist die funktionierende Finanzintermediation eine wichtige Voraussetzung für den Übergang von der Planwirtschaft zu marktwirtschaftlichen Koordinationsmechanismen. Zum anderen ist die Wirkungsweise der Geldpolitik von der Organisation des Finanzsektors abhängig und unterliegt gravierenden Änderungen, solange die Reformen im Bankwesen noch nicht abgeschlossen sind. ${ }^{83}$

In einer Zentralverwaltungswirtschaft ist das Finanzsystem kaum mehr als ein Buchhaltungsmechanismus, der dazu dient, die Entscheidungen der Planungsinstanzen über die Ressourcenallokation zwischen den verschiedenen Unternehmen und Sektoren aufzuzeichnen. ${ }^{84}$ Es existierten daher in Mittel- und Osteuropa auch keine zweistufigen Bankensysteme, sondern sogenannte Monobanksysteme, in denen die Zentralbank dominierte. Neben der Zentralbank gab es nur wenige (meist weniger als fünf) Spezialbanken, die in speziellen Sektoren der Wirtschaft operierten. ${ }^{85}$ Des weiteren fehlten Finanzmärkte, weil es in den Planwirtschaften keine Finanzinstrumente gab, die auf solchen Märkten üblicherweise gehandelt werden. Beim Übergang zur Marktwirtschaft mußte der Finanzsektor also grundlegend umstrukturiert werden, indem Geld- und Kapitalmärkte aufgebaut und ein auf zwei Säulen ruhendes Bankensystem mit einer Zentralbank und mit Geschäfts-

83 Siehe zur Reform des Bankensektors in Mittel- und Osteuropa u.a. Buch (1995a), S. 3 ff., Buch (1995b), S. 2 ff., EBRD (1998), S. 92 ff., und Schmieding/Buch (1992), S. 3 ff. Vgl. EBRD (1998), S. 92.

85 Vgl. Calvo/Kumar (1993), S. 7. Fur die sich in der Namensgebung der Geschaftsbanken niederschlagende sektorale Gliederung am Beispiel Bulgariens siehe Hamacher (1992), S. 63. 
banken nach westlichem Vorbild eingeführt wurde. Letzteres geschah in Ungarn bereits 1987, in Polen 1989 und in Bulgarien, der Tschechoslowakei und Rumänien 1990.86 Zum einen wurde durch die Trennung der Geschäftsbankaktivitäten von der Zentralbank die direkte Steuerung der Geldversorgung im alten System von einem mehrstufigen Geldschöpfungsprozeß abgelöst. Zum anderen ersetzten die Notenbanken in den Transformationsländern zunehmend direkte Instrumente wie Zins- oder Kreditobergrenzen - durch indirekte geldpolitische Instrumente, wie Offenmarktgeschäfte und Veränderungen von Refinanzierungssätzen.

Mit der Trennung der Geschäftsbankaktivitäten von der Zentralbank war allerdings zunächst noch keine Privatisierung der Banken verbunden. Da die überwiegende Zahl der Banken in Staatsbesitz blieb, bestand für die Führungskräfte weder ein Anreiz noch die Notwendigkeit, im Interesse privater Anteilseigner oder der Einleger zu handeln. Vielen Managern fehlte außerdem das Wissen, wie ein Kreditinstitut im marktwirtschaftlichen Umfeld geführt werden muß. Des weiteren bestand die Gefahr, daß die aus sozialistischen Zeiten bestehenden engen Verbindungen zwischen staatlichen Banken und noch nicht privatisierten Unternehmen dazu führten, daß die Kreditvergabe nicht nach Wirtschaftlichkeitskriterien erfolgte. Aber selbst in den Fällen, in denen strenge Kreditprüfungen vollzogen wurden, standen die Verantwortlichen vor extrem schwierigen Entscheidungen, denn die zukünftige Ertragssituation der Unternehmen war in der Zeit des wirtschaftlichen Umbruchs kaum zu prognostizieren. Es zeigte sich dann auch, daß ein großer Teil der Kredite notleidend wurde, weil die Unternehmen nicht in der Lage waren, den Schuldendienst zu leisten. Außerdem war es eine Folge des alten Systems, daß die Kredite eines Unternehmens bei wenigen Banken konzentriert waren. Eine Einstellung der Kreditvergabe hätte unter Umständen zur Zahlungsunfähigkeit des Kunden und aufgrund des hohen Ausleihevolumens an einen Kreditnehmer zur Gefährdung der Bank selbst geführt. Dies ist ein wichtiger Faktor, warum die Banken verlustbringende Unternehmen zum Teil weiterhin mit Krediten versorgten und der Anteil der notleidenden Kredite in den mittel- und osteuropäischen Bankensystemen sehr hoch blieb, so daß die Finanzsysteme für längere Zeiträume durch große Instabilität gekennzeichnet waren.

Ein instabiles Finanzsystem gefährdet jedoch die zentrale Intermediationsfunktion von Banken, die ein wichtiges Bindeglied zwischen Sparern und Investoren darstellen, weil sie die Mittel von Kapitalanlegern bündeln, eine Fristentransformation durchführen, die Investitionsentscheidungen der Kreditnehmer prüfen und damit zur effizienten Verwendung finanzieller Ressourcen beitragen. Weil entwickelte Finanzmärkte fehlten, bestand auch nicht die Alternative, Nachfrage und Angebot von Finanzmitteln ohne die Vermittlerfunktion von Kreditinstituten direkt über

86 Vgl. Calvo/Kumar (1993), S. 10. 
entsprechende Märkte auszugleichen. Sowohl die Märkte für den Handel von Eigentums- als auch von Schuldtiteln mußten erst aufgebaut werden, weil in den Zentralverwaltungswirtschaften weder Aktien- noch Rentenmärkte existierten.

Um die Überwachung der aus dem Monobankensystem ausgegliederten Geschäftsbanken zu gewährleisten und die Zulassung neuer Kreditinstitute zu regeln, mußten neue gesetzliche Grundlagen geschaffen und eine Bankenaufsicht eingerichtet werden. Die Schaffung von Anreizen für eine dem westlichen Standard entsprechende Kreditvergabe wurde allerdings durch die anfänglich noch unzureichenden Rechnungslegungsvorschriften erheblich erschwert. Trotz der Tatsache, daß einige Länder eine zügige Bankenprivatisierung betrieben und zum Teil über eine Beteiligung ausländischer Kreditinstitute Know-how importierten, kam es in fast allen betrachteten Ländern im Laufe der 1990er Jahre zu Bankenkrisen, die durch den Zusammenbruch einer großen Zahl kleinerer Kreditinstitute oder einiger großer Banken gekennzeichnet waren. 87

Die großen Probleme bei der Etablierung eines stabilen und marktwirtschaftlich organisierten Bankensystems haben Rückwirkungen auf die Stabilisierungsanstrengungen, weil zwischen der Reform des Finanzsektors und der Umsetzung einer stabilitätsorientierten Geldpolitik eine enge Interdependenz besteht. Einerseits hängt die Durchführung einer erfolgreichen Geldpolitik von der Stabilität struktureller Parameter ab, die durch die Entwicklungen im Finanzsektor gefährdet ist, weil letztere entscheidende Auswirkungen auf die Geldnachfrage und den Transmissionsmechanismus monetärer Impulse haben. ${ }^{88}$ Andererseits verbessern sich die Chancen auf eine erfolgreiche Umgestaltung des Finanzsystems und eine Verbesserung der Verteilung finanzieller Ressourcen, wenn es den geldpolitischen Instanzen gelingt, die Inflation schnell zu senken.

\subsubsection{Wahl einer geldpolitischen (Zwischen-)Zielgröße}

Nachdem im Abschnitt 2 ausführlich begründet wurde, warum im Transformationsprozeß der Preisstabilisierung höchste Priorität eingeräumt werden muß, wird im folgenden unterstellt, daß die Zentralbank dies erkennt und als vorrangiges Ziel Preisstabilität anstrebt. ${ }^{89} \mathrm{Da}$ die Notenbank dieses Ziel nicht direkt steuern kann, bedient sie sich in der Regel eines Zwischenziels. Darunter versteht man eine Größe, die der Zentralbank eine Orientierungshilfe für den geldpolitischen Instrumen-

87 Vgl. EBRD (1998), S. 99 f. Für eine Datierung der Bankenkrisen siehe Gerloff/Speidel-Walz (2000), S. 12.

88 Siehe Buch (1995a), S. 3.

89 Die meisten mittel- und osteuropäischen Staaten waren diesem Ziel bereits in der Fruhphase der Transformation verpflichtet. Vgl. zu einigen Zielformulierungen in den Notenbankgesetzen Radzyner/Riesinger (1997), S. 64. Siehe zur Zentralbankgesetzgebung ausfuhrlicher den Unterabschnitt 3.2.3. im Kapitel IV. 
teneinsatz bietet. ${ }^{90}$ Damit eine Zwischenzielvariable diese Aufgabe erfüllen kann, muß sie bestimmten Anforderungen genügen. Geldpolitische Aktionen müssen sich relativ schnell in Änderungen des Zwischenziels niederschlagen, wobei letztere ohne großen Aufwand und zeitliche Verzögerungen meßbar sein müssen. Des weiteren ist ein enger Zusammenhang zwischen der Zwischenzielvariablen und der wirtschaftspolitischen Endzielgröße (hier also der Preisstabilität) erforderlich.

Für die geldpolitische Strategie stehen grundsätzlich fünf (Zwischen-)Zielgrößen zur Auswahl: ein Zinsziel, ein nominales Einkommensziel, ein direktes Inflationsziel, ein Geldmengenziel und ein Wechselkursziel. ${ }^{91}$ Es soll im folgenden nicht im Detail auf alle Ziele eingegangen werden. Ziel dieses Unterabschnitts ist es zu beleuchten, welche der genannten geldpolitischen Strategien für die Transformationsländer generell in Betracht kommen und welche Probleme mit ihnen unter den speziellen Bedingungen des Reformprozesses verbunden sind. Über den Transmissionsmechanismus der monetären Impulse besteht auch in entwickelten Volkswirtschaften Unsicherheit. Aufgrund der geschilderten Umstände in den ersten beiden Abschnitten dieses Kapitels ergibt sich, daß die Unsicherheiten über die ökonomischen Zusammenhänge in den Transformationsländern noch größer sind. Es wird deshalb zunächst begründet, warum die beiden zuerst genannten Zwischenzielkandidaten ausscheiden, bevor auf die drei anderen Konzeptionen - direktes Inflationsziel, Geldmengensteuerung und Wechselkursziel - ausführlicher eingegangen wird, weil sie im Laufe des Reformprozesses von einigen betrachteten Ländern angewendet wurden.

In der Literatur herrscht die Auffassung vor, daß ein Zinsziel als geldpolitische Zwischenzielvariable nicht geeignet ist. ${ }^{92}$ Begründet wird dies damit, daß einerseits die Höhe der Zinssätze nicht unwesentlich von Entwicklungen im güterwirtschaftlichen Bereich beeinflußt wird und andererseits geldpolitische Maßnahmen Änderungen des Zinsniveaus hervorrufen, die kurzfristig in eine andere Richtung zielen als langfristig. Diese entgegengerichteten Einflüsse erhöhen die Gefahr geldpolitischer Fehleinschätzungen. ${ }^{93}$ Die speziellen Gegebenheiten des Reformprozesses verstärken die Bedenken gegenüber der Verwendung eines Zinsziels für Transformationsländer. Zu Beginn der Transformation dominierten direkte geldpolitische Instrumente, wie Zinsobergrenzen und mengenmäßige Kreditbeschrän-

90 Vgl. zur Funktion und den Anforderungen an ein geldpolitisches Zwischenziel Bofinger et al. (1996), S. 246 ff., und Jarchow (1995), S. 202 ff., insbesondere S. 206.

91 Es handelt es sich um die funf Strategien, deren Eignung das Europăische Währungsinstitut auch fur die 3. Stufe der Europäischen Wirtschafts- und Wahrungsunion gepruft hat. Siehe Europäisches Währungsinstitut (1997), S. 8.

92 Vgl. Bofinger et al. (1996), S. 327.

93 Vgl. Issing (1996), S. 200 f. Zu den verschiedenen Effekten, die durch Zinsănderungen hervorgerufen werden, siehe Jarchow (1995), S. $208 \mathrm{ff}$. 
kungen. Die Einlagen- und Kreditzinssätze waren keine Funktionen von Angebot und Nachfrage finanzieller Mittel oder der Kreditwürdigkeit von Kreditnehmern. ${ }^{94}$ Der Bankensektor und die Finanzmärkte befanden sich noch im Aufbau, so daß es weder einen Wettbewerb zwischen den Finanzinstitutionen noch einen funktionierenden Geldmarkt gab. Im Hinblick auf die obengenannten Anforderungen an ein Zwischenziel läßt sich daraus schließen, daß die Notenbank in diesem Umfeld zwar eine gute Kontrolle über die Zinssätze besaß, diese aber eher Instrument als Zwischenzielgröße darstellten. Schwerer wiegt noch, daß im Umfeld tiefgreifender Umstrukturierungen im Finanzsektor der Zusammenhang zwischen dem Zinssatz und dem Endziel Preisstabilität unsicher ist, so daß die Zinsen als Zwischenzielvariable ausscheiden.

Eine weitere theoretisch denkbare Zielgröße ist ein nominales Einkommensziel. Vertreter dieser Strategie, bei der die Zentralbank entweder eine bestimmte Wachstumsrate oder ein festgelegtes Niveau des nominalen Bruttoinlands- bzw. Bruttosozialprodukts als Orientierungswert anstrebt, betonen insbesondere, daß sie die beiden Endziele Beschäftigung und Preisniveau gleichermaßen berücksichtigt. ${ }^{95}$ Neben vielen grundsätzlichen Problemen eines nominalen Einkommensziels als geldpolitische Zwischenzielgröße, wie zum Beispiel der späten Verfügbarkeit der entsprechenden Daten, ${ }^{96}$ sprechen wiederum die besonderen Umstände des Transformationsprozesses gegen diese Zielgröße. Der Reformprozeß ist von extremer Unsicherheit über die reale wirtschaftliche Entwicklung und die Preise gekennzeichnet, also genau den beiden Komponenten, aus denen sich das Zwischenziel zusammensetzt. Trotz der starken Rezessionen ist in den Reformländern zu Beginn der Transformation das nominale Bruttoinlandsprodukt gestiegen, weil der durch die Preisliberalisierung ausgelöste Preisschub den realen Rückgang überkompensiert hat. Es ist zum einen vollkommen unklar, aufgrund welcher theoretischer Zusammenhänge und in welcher Höhe die Zentralbank in dieser Situation einen Zielwert für die Wachstumsrate des nominalen Bruttoinlandsprodukts hätte formulieren sollen. Zum anderen ist zu Transformationsbeginn die Bedingung nicht erfüllt, daß ein enger Zusammenhang zwischen dem nominalen Einkommensziel als Zwischenzielvariable und der Endzielgröße Preisstabilität besteht.

Bei der Verwendung eines direkten Inflationsziels handelt es sich um eine neuere geldpolitische Strategie, die trotz zahlreicher Publikationen zu diesem Thema noch einer theoretischen Fundierung in der Literatur bedarf. ${ }^{97}$ In den 1990er Jahren hat das Konzept in unterschiedlichen Ausprägungen zunehmende Verbreitung gefunden, nachdem Neuseeland 1990 als erstes Land ein direktes Inflationsziel einge-

94

95

Vgl. Calvo/Kumar (1993), S. 21.

Vgl. Mishkin (1999), S. 597, der diese Strategie nicht befurwortet.

Siehe Bofinger et al. (1996), S. 349 ff., und Issing (1996), S. 190 f.

Vgl. zu dieser Aussage Bofinger et al. (1996), S. 365. 
führt hat. In den Folgejahren sind weitere Länder wie zum Beispiel Kanada und Großbritannien zu einer direkten Inflationssteuerung übergegangen. 98 Neben den grundsätzlichen Voraussetzungen, daß die Zentralbank im Einsatz ihrer Instrumente unabhängig von anderen wirtschaftspolitischen Entscheidungsträgern ist und sie keine Zielvorstellungen im Hinblick auf weitere nominale Variablen (wie zum Beispiel dem Wechselkurs) verfolgt, muß das Konzept eines direkten Inflationsziels folgende vier Elemente enthalten:99

- ein klares Signal, daß die Erreichung des Inflationsziels höchste Priorität besitzt,

- ein explizit quantifiziertes Inflationsziel für eine oder mehrere Perioden im voraus,

- ein Modell zur Vorhersage der Inflation und

- eine vorausschauende Handlungsweise, bei der Inflationsprognosen als geldpolitische Zwischenzielgröße verwendet werden.

Während die erste Bedingung in den Transformationsländern von Anfang an erfüllt gewesen sein dürfte, stellt die Festlegung auf einen konkreten Zielwert zu Beginn der Transformation in zweierlei Hinsicht ein Problem dar. Zum einen müßte die Zentralbank eine relativ hohe Inflationsrate festlegen, weil sich aufgrund der unvermeidbaren Preissteigerungen im Zuge der Preisliberalisierung keine niedrigen Zielwerte realisieren lassen. Dies könnte jedoch den Stabilisierungswillen der monetären Instanzen in Frage stellen. Weil höhere Inflationsraten mit einer höheren Variabilität einhergehen, ist zum anderen unabhängig vom festgelegten Zielwert mit häufigen und relativ deutlichen Zielverfehlungen zu rechnen, die die Glaubwürdigkeit der Zentralbank ebenfalls beeinträchtigen. Dies wird dadurch unterstrichen, daß eine direkte Inflationssteuerung bisher noch nicht zur Reduzierung mittlerer bis hoher Inflationsraten eingesetzt wurde. Die Industrieländer, die zu einem direkten Inflationsziel übergegangen sind, wiesen vor der Einführung dieser Strategie bereits Inflationsraten von unter 10 v.H. auf. 100

Im Hinblick auf die dritte und vierte Bedingung für ein Inflation Targeting ist $\mathrm{zu}$ berücksichtigen, daß die Änderungen der administrativ festgelegten Preise ein wichtiger Faktor sind, der die Inflation in den Transformationsländern mitbestimmt, von der Zentralbank aber nicht beeinflußt werden kann. Es ist zwar möglich, daß die Zentralbank eine Kerninflationsrate als Zielgröße verwendet, die die Preisänderungen staatlich regulierter Güter und Dienstleistungen nicht berücksich-

98 Siehe Mishkin (1999), S. 591. In der Literatur sind für diese Konzeption auch die Begriffe „Inflation Targeting“ oder „Direct Inflation Targeting“ gebräuchlich. Vgl. Wagner (1998a), S. $295 \mathrm{ff}$., und Krzak/Ettl (1999), S. $28 \mathrm{ff}$. Zu den theoretischen und konzeptionellen Problemen eines direkten Inflationsziels vgl. Bofinger et al. (1996), S. $365 \mathrm{ff.}$

99 Vgl. Masson et al. (1997), S. 9.

100 Siehe ebenda, S. 20. 
tigt. 101 Während dies für spätere Jahre eine Option darstellt, um ein direktes Inflationsziel trotz noch nicht abgeschlossener Preisanpassungen einführen zu können, ist jedoch davon auszugehen, daß das Ausmaß aller Preisänderungen zu Transformationsbeginn so gewaltig war, daß es. von der Zentralbank nicht einmal annähernd prognostiziert werden konnte.

Während das direkte Inflationsziel eine Endzielgröße ist, deren Höhe von vielen Faktoren bestimmt wird, die die Zentralbank nicht beeinflussen kann, hat die Notenbank eine bessere Kontrolle über ein Geldmengenziel. ${ }^{102}$ In Abhängigkeit vom gewählten Geldmengenaggregat ist die Zielgröße zwar unter Umständen von Umschichtungen zwischen verschiedenen Einlageformen seitens der Wirtschaftssubjekte abhängig. Insgesamt gesehen handelt es sich jedoch um eine Größe, die einer besseren Kontrolle der Zentralbank unterliegt als ein direktes Inflationsziel, selbst wenn letzteres in Form einer Kerninflationsrate formuliert wird. Ein weiterer Vorteil einer Geldmengensteuerung besteht darin, daß bald nach der Durchführung einer geldpolitischen Maßnahme Informationen über die Geldmengenentwicklung verfügbar sind, weil sich der Instrumenteneinsatz relativ schnell in Änderungen der Geldmenge niederschlägt und es keine großen zeitlichen Verzögerungen bei der Beobachtung monetärer Aggregate gibt. Allerdings wird die Beurteilung der Geldpolitik, d.h. ob eine Maßnahme expansiv oder kontraktiv wirkt, dadurch erschwert, daß Unsicherheit über die Zeiträume herrscht, die zwischen dem Instrumenteneinsatz und der Wirkung auf die Geldmenge einerseits und zwischen der Geldmengenentwicklung und der gesamtwirtschaftlichen Endzielgröße andererseits liegen. ${ }^{103}$ Die Vorteile der Geldmengenstrategie hängen davon ab, ob ein enger $\mathrm{Zu}$ sammenhang zwischen der Geldmenge und dem gesamtwirtschaftlichen Endziel also insbesondere der Preisstabilität - besteht und ob dieser Zusammenhang im Zeitablauf stabil ist.

Es liegt die Vermutung nahe, daß diese Voraussetzung im Transformationsproze $\beta$ nicht erfüllt ist. Den Ausgangspunkt der Überlegungen bildet die Fishersche Quantitätsgleichung

101 Zum Beispiel verwendet die tschechische Nationalbank seit dem Übergang zu einem direkten Inflationsziel im Dezember 1997 ein sogenanntes ,net inflation target“. Diese Zielgroßße ist definiert als der Anstieg eines um die Effekte von Veränderungen staatlich regulierter Preise und indirekter Steuern bereinigten Preisindizes. Vgl. Cihák/Holub (1998), S. 49.

$102 \mathrm{Vgl}$. zum Geldmengenziel allgemein Bofinger et al. (1996), S. 248 ff., Issing (1996), S. 183 ff., und Mishkin (1999), S. 586 ff. Fur die Probleme einer Geldmengensteuerung im Transformationsprozeß siehe Wagner (1998b), S. 22 ff., sowie Petersen/Sowada (1995), S. 387 ff.

$103 \mathrm{Vgl}$. zur Unsicherheit uber die Lănge der verschiedenen time lags und deren Schwankungen im Zeitablauf Jarchow (1995), S. 200 ff. Die Unsicherheit Uber die zeitliche Verzögerung zwischen Durchfuhrung der geldpolitischen Maßnahme und der Wirkung auf das Endziel Preisstabilităt besteht im ubrigen in gleicher Weise bei der direkten Inflationssteuerung. 


$$
M \cdot V=P_{T} \cdot T^{r} \cdot 104
$$

Dabei bezeichnet $M$ die nominale Geldmenge, $V$ die Umlaufgeschwindigkeit des Geldes und $T^{r}$ den Realwert aller während des Betrachtungszeitraums gehandelten Güter und Dienstleistungen. Der Durchschnittspreis dieses Transaktionsvolumens wird mit $P_{T}$ angegeben. Die Konzeption einer Geldmengensteuerung basiert auf der aus der Gleichung ablesbaren Erkenntnis, daß sich das Preisniveau erhöht, wenn die Geldmenge bei konstanter Umlaufgeschwindigkeit stärker als das Volumen der Transaktionen ansteigt. Eine erfolgreiche Geldmengenstrategie setzt nun dreierlei voraus: Erstens muß die Zentralbank in der Lage sein zu beurteilen, wie sich der Einsatz der geldpolitischen Instrumente auf die Geldmenge auswirkt. Zweitens muß sie das Transaktionsvolumen prognostizieren können. Und schließlich muß sie drittens einschätzen können, ob und wie sich die Umlaufgeschwindigkeit des Geldes verändert.

Die zuletzt genannte Bedingung erfordert eine hinreichend stabile Nachfrage nach heimischer Währung, wie sie jedoch in Transformationsländern in der Anfangszeit nicht anzutreffen ist. ${ }^{105}$ Insbesondere der hohe Dollarisierungsgrad in den Reformländern und die damit verbundene Währungssubstitution verursacht hohe Schwankungen der Geldnachfrage. In Polen wurde zum Beispiel der US-Dollar neben dem Zloty als Zahlungsmittel verwendet und diente insbesondere als Anlagemedium. ${ }^{106}$ Mit zunehmenden Stabilisierungserfolgen gewinnen die privaten Wirtschaftssubjekte Vertrauen in die heimische Währung zurück und setzen sie wieder verstärkt für Transaktionszwecke ein. Auch die Wertaufbewahrungsfunktion gewinnt bei stark rückläufiger Inflation an Bedeutung. Dies gilt um so mehr, wenn die Nominalzinsen nicht in gleichem Umfang wie die Inflationsraten zurückgehen, so daß eine Anlage in Inlandswährung eine entsprechend hohe Realverzinsung erbringt. Die Remonetisierung der Wirtschaft bewirkt eine Senkung der Umlaufgeschwindigkeit des Geldes, und die Zentralbank muß ceteris paribus - wie sich aus der Quantitätsgleichung ablesen läßt - die Geldmenge stärker ausweiten. $\mathrm{Da}$ die beschriebenen Effekte nur schwierig oder gar nicht zu quantifizieren sind, besteht die Gefahr, daß die Zentralbank das Ausmaß überschätzt, das Geldangebot zu stark ausweitet und damit zur Inflation beiträgt. Im umgekehrten Fall, in dem sie die Effekte unterschätzt, würde sie ein zu niedriges Geldmengenwachstum anstreben und eine kontraktive Geldpolitik betreiben.

Die Prognose des Transaktionsvolumens wird in erster Linie durch die Transformationsrezession erschwert, weil die Vorhersagen über die wirtschaftliche Entwicklung zu Reformbeginn mit größerer Unsicherheit behaftet sind als unter nor-

104 Siehe zur Fisherschen Quantitătsgleichung Jarchow (1998a), S. 169.

105 Vgl. Calvo/Kumar (1993), S. 21 ff., und Szapáry/Jakab (1998), S. 708.

106 Siehe Petersen/Sowada (1995), S. 387 f. 
malen Bedingungen. Darüber hinaus ist zu berücksichtigen, daß das Volumen der Geldtransaktionen zwischen Unternehmen in sozialistischen Planwirtschaften aufgrund der Existenz großer Kombinate relativ gering ist. Einerseits wird ein großer Teil des Handels durch Lieferungen zu internen Verrechnungspreisen abgewickelt, andererseits erfordert eine starke vertikale Integration von Produktionsstufen einen geringeren Geldumlauf. Die Auflösung der Kombinate und die zunehmende Zahl kleinerer privater Betriebe führt zu einem starken Anstieg von Zahlungsvorgängen zwischen Unternehmen, der den Geldbedarf für Transaktionszwecke unabhängig von der Entwicklung des Sozialprodukts erhöht. 107 Die Zentralbank wird aber nicht in der Lage sein vorherzusagen, in welchem Ausmaß sie die Geldmenge erhöhen muß, um den zusätzlichen Transaktionsbedarf angemessen zu monetisieren.

Schließlich dürfte auch die zuerst genannte Voraussetzung für eine Geldmengensteuerung - eine relativ gute Kenntnis des geldpolitischen Transmissionsmechanismus innerhalb des monetären Bereichs - zu Reformbeginn nicht erfüllt sein. Solange noch kein Wettbewerb zwischen den Banken besteht und die institutionellen Reformen im Finanzsektor noch nicht abgeschlossen sind, werden die Auswirkungen bestimmter geldpolitischer Maßnahmen auf das Geldangebot schwer abzuschätzen sein, zumal die Zentralbank selbst ihr Instrumentarium erst nach und nach entwickelt und von direkten zu indirekten Instrumenten übergeht. Aus diesen Gründen erscheint die Festlegung eines Geldmengenziels als geldpolitische Strategie in der Anfangsphase der Transformation problematisch. Nach einer Übergangszeit stellt die Geldmenge hingegen eine mögliche (Zwischen-)Zielgröße dar, wenn sich zum einen das wirtschaftliche Umfeld stabilisiert hat und zum anderen die Zentralbank erste Erfahrungen mit dem Einsatz indirekter geldpolitischer Instrumente sammeln konnte, so daß die Prognoseschwierigkeiten abnehmen.

Bei der Betrachtung des Geldmengenziels wurde impliziert unterstellt, daß die Geldpolitik bei flexiblen Wechselkursen betrieben wird, denn eine Geldmengensteuerung und ein Wechselkursziel schließen sich gegenseitig aus. Wenn ein fester Wechselkurs als geldpolitische (Zwischen-)Zielgröße gewählt wird, ist zwangsläufig die Geldmenge endogen und kann nicht von der Zentralbank gesteuert werden. Unter besonderer Berücksichtigung der Gegebenheiten in den Transformationsländern wird eine solche Strategie im folgenden betrachtet, wobei sich die Diskussion zunächst auf die Eignung des fixierten nominalen Wechselkurses als Zwischenzielvariable beschränkt. Eine allgemeinere Abwägung der Vor- und Nachteile einer Wechselkursbindung erfolgt erst im nächsten Unterabschnitt.

Als Anforderung an ein geldpolitisches Zwischenziel wurde formuliert, daß es relativ einfach und zeitnah meßbar sein und ohne größere Verzögerungen auf eine

107 Siehe zu diesem Zusammenhang Petersen/Sowada (1995), S. 395. 
geldpolitische Maßnahme reagieren sollte. Insbesondere die Transparenz und klare Signalfunktion eines festen Wechselkurses sind in der Literatur betont worden. 108 Ein fester Wechselkurs ist leicht zu verstehen und sowohl von der Zentralbank als auch von der Öffentlichkeit jederzeit beobachtbar, wobei die „Einfachheit" noch erhöht wird, wenn der Wechselkurs gegenüber einer einzelnen Währung und nicht gegenüber einem Währungskorb gebunden wird. ${ }^{109}$ Mishkin (1999) weist allerdings darauf hin, daß ein fester nominaler Wechselkurs auch die Signalkraft des Wechselkurses für die Einschätzung der Geldpolitik außer Kraft setzen kann. ${ }^{110}$ Während sich in einem System flexibler Wechselkurse eine Geldpolitik, die expansiver oder kontraktiver als im Ausland ausfällt, in Veränderungen des nominalen Wechselkurses niederschlägt, geschieht dies bei festen Wechselkursen nicht. Mishkin sieht das Problem besonders ausgeprägt in Schwellenländern, in denen die Tätigkeiten und Bilanzen der Zentralbanken nicht so transparent sind wie in den Industrieländern. Diesem Nachteil kann man allerdings begegnen, indem die Zentralbank dazu verpflichtet wird, in sehr kurzen Abständen Daten über die Entwicklung der Währungsreserven zu veröffentlichen. ${ }^{111}$ Die Reaktion auf geldpolitische Maßnahmen zeigt sich nämlich bei einem festen nominalen Wechselkurs als Zwischenziel per Definition nicht in einer Änderung des Wechselkurses. Eine Geldpolitik, die nicht mit der Geldpolitik des entsprechenden Ankerwährungslandes übereinstimmt, schlägt sich vielmehr in einer Änderung der Währungsreserven nieder, weil in diesem Fall die Zentralbank am Devisenmarkt intervenieren muß, um den festen Wechselkurs aufrecht zu erhalten. Anhand dieser Notwendigkeit können die Öffentlichkeit und die Zentralbank überprüfen, ob der tatsächliche geldpolitische Kurs mit der verkündeten Zielsetzung übereinstimmt, die in diesem Fall beinhaltet, daß die monetären Instanzen ihre Geldpolitik an der Politik der Zentralbank des Ankerwährungslandes ausrichten.

Für die Frage, ob ein enger Zusammenhang zwischen dem nominalen Wechselkurs als Zwischenzielgröße und dem wirtschaftspolitischen Endziel der Preisstabilität besteht, sind zwei Transmissionsprozesse zu beachten: einerseits Übertragungseffekte im güterwirtschaftlichen Bereich und andererseits die Inflationserwartungen der privaten Wirtschaftssubjekte. ${ }^{112}$ Der zuerst genannte güterwirtschaftliche Einflußkanal resultiert aus dem internationalen Preiszusammenhang. Ein fester Wechselkurs fixiert die Inflationsrate für handelbare Güter auf das niedrige aus-

108 Vgl. Aghevli et al. (1991), S. 17, Corden (1993), S. 206, und Sachs (1996a), S. 149.

109 Siehe Corden (1991), S. 233.

110 Siehe Mishkin (1999), S. 582.

111 Beispielsweise wurde das Issue Department der bulgarischen Nationalbank im Rahmen der Einfuhrung des Currency Boards dazu verpflichtet, seine Konten wöchentlich zu publizieren, um die offentliche Überprufung der Einhaltung der Regeln zu gewăhrleisten. Vgl. Gulde (1999), S. 10.

112 Siehe Bofinger et al. (1996), S. 306. 
ländische Niveau und trägt durch den Anteil der handelbaren Güter am Warenkorb direkt dazu bei, die Inflation unter Kontrolle zu halten. Streben die Arbeitnehmer eine Reallohnsicherung an, werden sie aufgrund einer niedrigeren Preissteigerung ihre Lohnforderungen nach unten anpassen, so daß sich die Wechselkursfixierung auch indirekt stabilisierend auf die Inflation nicht-handelbarer Güter auswirkt. Den zweiten Übertragungskanal bilden die Inflationserwartungen. Wenn die Wechselkursbindung glaubwürdig ist, trägt sie dazu bei, die Inflationserwartungen zu reduzieren, und zwar im Extremfall bis auf das Niveau im Ankerland. Weil der Wechselkurs ein sehr sichtbarer, leicht definierbarer und kontrollierbarer nominaler Anker ist, stellt er eine gute Orientierungsgröße dar, und die Wahrscheinlichkeit steigt, daß die privaten Wirtschaftssubjekte ihre Erwartungen anpassen. Diese Funktion wird noch verstärkt, wenn die ausländische Währung im Inland als Zahlungsmittel verwendet wird. ${ }^{113} \mathrm{Da}$ nicht nur die Inflations- sondern auch die Wechselkurserwartungen stabilisiert werden, bietet eine glaubwürdige Wechselkursfixierung eine gute Möglichkeit, um die bestehende Dollarisierung in Osteuropa abzubauen. Vertrauen die Wirtschaftssubjekte den Stabilisierungsbemühungen der Notenbank und werden deshalb Teile des in Devisen gehaltenen Finanzvermögens in Inlandswährung umgetauscht, erfolgt eine automatische Remonetisierung der Wirtschaft. Die Zentralbank kauft die Devisen gegen Inlandswährung zum festgelegten Wechselkurs an, und die offiziellen Devisenreserven sowie die Geldmenge erhöhen sich entsprechend. ${ }^{114}$

Die Abwägung der verschiedenen theoretisch denkbaren Zielgrößen läßt folgende Schlußfolgerung zu: Ein Zinsziel scheidet für die Transformationsländer ebenso aus wie ein nominales Einkommensziel. Auch die Bedingungen, die ein direktes Inflationsziel an die Prognosefähigkeit der wirtschaftspolitischen Entscheidungsträger stellt, werden zu Beginn der Transformation nicht erfüllt sein. Im Hinblick auf die Entscheidung zwischen einer Geldmengenorientierung und einem Wechselkursziel liegt die Vermutung nahe, daß in der Frühphase der Transformation aufgrund der bestehenden Unsicherheiten über die wirtschaftlichen Zusammenhänge ein fester Wechselkurs einer Geldmengenstrategie wegen seiner „Einfachheit" überlegen ist, während nach einiger Zeit erfolgreicher Reformen die Voraussetzungen für eine Geldmengensteuerung erfüllt sein und die damit verbundenen Vorteile für einen Übergang zu dieser Strategie sprechen könnten. Gegebenenfalls ist dann auch bereits eine direkte Inflationssteuerung möglich. Allerdings sind mit einer Wechselkursfixierung auch Probleme verbunden, die bisher nicht analysiert wurden. Bevor die Wahl des Wechselkursregimes einer formaltheoretischen Analyse unterzogen wird, werden daher zunächst weitere Argumente betrachtet, die entweder für eine Wechselkursfixierung oder für ein flexibles Wechselkurssystem sprechen.

113 Vgl. Wagner (1998b), S. 19.

114 Siehe Sachs (1996a), S. 149. 


\subsection{Wahl des Wechselkursregimes}

Die Diskussion um feste versus flexible Wechselkurse ist eine der „klassischen Debatten" in der wirtschaftswissenschaftlichen Literatur. Diese Diskussion soll hier nicht aufgegriffen werden, weil dies über den Rahmen der Arbeit hinausgehen würde. ${ }^{115}$ Die nachfolgenden Ausführungen konzentrieren sich auf die Vor- und Nachteile eines Wechselkursregimes beim Übergang von der sozialistischen Planwirtschaft zur marktwirtschaftlichen Organisation des Wirtschaftslebens. Die Länder mußten sich zu Beginn ihrer Transformation für ein bestimmtes Wechselkurssystem entscheiden. Sofern die währungspolitisch Verantwortlichen eine Wechselkursbindung wählten, war zusätzlich festzulegen, gegenüber welcher Währung oder welchem Währungskorb und in welcher Höhe die Währung fixiert werden sollte. Um in der Diskussion die verschiedenen Argumente einander klar gegenüberstellen zu können, beschränkt sich die Analyse auf die Vor- und Nachteile von festen bzw. flexiblen Wechselkursen. Mischsysteme, die in Abhängigkeit von ihrer Ausgestaltung bestimmte Vorteile beider Wechselkurssysteme miteinander verknüpfen, werden nicht betrachtet. ${ }^{116}$ Für ein Festkurssystem wird keine unwiderrufliche Fixierung gefordert, sondern der allgemeinere Fall betrachtet, in dem das Land einseitig die heimische Währung gegenüber einer anderen Währung oder einem Währungskorb bindet, also einen festen, aber anpassungsfähigen Wechselkurs wählt. Dabei wird die Frage, ob eine solche Wechselkursbindung glaubwürdig ist, hier nur ansatzweise diskutiert. Eine ausführliche Behandlung des Problems erfolgt erst im Kapitel III bei der modelltheoretischen Analyse. ${ }^{117}$ Für ein System flexibler Wechselkurse wird nicht gefordert, daß es sich um eine vollkommen unbeeinflußte Kursbildung handelt. Die Aussagen werden nicht dadurch beeinträchtigt, daß die Zentralbank gelegentlich am Devisenmarkt eingreift, um erratische Ausschläge des nominalen Wechselkurses zu glätten. Es wird jedoch unterstellt, daß sich die Notenbank nicht mit massiven Interventionen gegen einen Trend stemmt.

\subsubsection{Argumente für eine Wechselkursbindung}

Die Ausführungen im Unterabschnitt 3.1.2. haben gezeigt, daß ein großer Vorteil eines festen Wechselkurses darin liegt, daß er ein Zwischenziel der Geldpolitik ist, das von der Öffentlichkeit leicht zu verstehen und zeitnah zu beobachten ist. Weil

115 Vgl. zu dieser Diskussion z.B. Jarchow/Ruhmann (1997), S. 201 ff., und Södersten/Reed (1994), S. 643 ff. Die Tabelle 17 in IMF (1997a), S. 83, gibt einen zusammenfassenden Überblick uber den theoretisch wünschenswerten Grad an Wechselkursflexibilităt in Abhängigkeit von den Eigenschaften einer Volkswirtschaft wie Größe, Offenheitsgrad usw.

116 Für eine Übersicht über die wechselkurspolitischen Optionen im Transformationsprozeß, die auch Mischstrategien wie ein Crawling Peg System und die Extremlosung eines Currency Boards enthalt, siehe Jarchow/Ruhmann (1997), S. $350 \mathrm{ff}$.

117 Siehe Unterabschnitt III.3.3. 
die Zielerreichung leicht kontrolliert werden kann, ist die Wahrscheinlichkeit höher als bei einer anderen Zielgröße, daß sich die privaten Wirtschaftssubjekte auf die Geldpolitik der Zentralbank einstellen und ihre Inflationserwartungen anpassen.

Ebenfalls im geldpolitischen Bereich liegt der Vorzug einer Wechselkursbindung, daß unter diesem System - wenn man realistischerweise von der Existenz einer Bandbreite ausgeht - ein gewisser Automatismus die Durchführung der Geldpolitik bestimmt. ${ }^{118}$ Ist der Preisanstieg im Inland stärker als im Ausland, entstehen Abwertungserwartungen. Normalerweise kann die Zentralbank über eine Anhebung von Refinanzierungssätzen oder andere kontraktive geldpolitische Maßnahmen, die die Ausweitung der Geldmenge begrenzen und dämpfend auf die zinsabhängigen Investitionen einwirken, die Wirtschaftsentwicklung drosseln und den Anstieg des Preisniveaus begrenzen. ${ }^{119}$ Führt der Instrumenteneinsatz im Inland nicht $\mathrm{zu}$ der notwendigen Anpassung von Zinsniveau und Geldmenge, weil zum Beispiel die Transmission der monetären Impulse nicht korrekt eingeschätzt wird, bleibt die Tendenz zur nominalen Abwertung bestehen, und die Zentralbank muß am Devisenmarkt intervenieren. Der Ankauf heimischer Währung gegen Hergabe von Währungsreserven verringert bei einem Verzicht auf eine Neutralisierungspolitik die monetäre Basis, so daß die inländische Geldmenge sinkt und das inländische Zinsniveau ansteigt. Das inländische Preisniveau wird stabilisiert, und die Abwertungserwartungen verschwinden. Umgekehrt bewirken die erforderlichen Maßnahmen bei einer Aufwertungstendenz der Währung automatisch eine expansivere Geldpolitik.

Als wichtigster Vorteil eines festen Wechselkurses im Rahmen der Transformation wird jedoch die Übertragung von Weltmarktpreisen auf die inländische Volkswirtschaft genannt. ${ }^{120}$ Durch die anfängliche Preisliberalisierung und den Übergang zu konvertiblen Währungen kommt es zum starken Anstieg des Preisniveaus und zu gravierenden Veränderungen der Preisstruktur. In diesem Zusammenhang stellt der feste Wechselkurs eine wichtige Anhaltsgröße dar, weil mit ihm die ausländische Preisstruktur der handelbaren Güter importiert wird, die eine wichtige Leitlinie für die Anpassung der relativen Preise bildet. Im Gegensatz zum Preisindex, dessen Veränderung in der Regel nur einmal monatlich mit erheblicher zeitlicher Verzögerung publiziert wird, ist der Wechselkurs ein Schlüsselpreis, der täglich beobachtbar ist. Zwar hat die Wechselkursbindung keinen direkten Einfluß auf die nicht-handelbaren Güter. In einer offenen Volkswirtschaft machen die handelbaren

118 Vgl. Mishkin (1999), S. 581. Existiert keine Bandbreite, dann wird die Geldpolitik ausschließlich durch die Aufrechterhaltung der Parität bestimmt.

119 Gleichzeitig dürften die kontraktiven geldpolitischen Maßnahmen auch die Abwertungserwartungen dămpfen.

120 Vgl. Bruno (1991), S. 23, Fröhlich (1992), S. 34, und Williamson (1991), S. 43. 
Güter jedoch einen nicht unerheblichen Anteil am Warenkorb des gesamtwirtschaftlichen Preisniveaus aus. Die Stabilisierung eines Teils der Preise stellt auch für die Preisbildung im Sektor der nicht-handelbaren Güter eine wichtige Orientierungshilfe dar und trägt zur Herausbildung einer neuen, knappheitsgerechten Preisstruktur bei.

Darüber hinaus wird argumentiert, daß durch die Wechselkursbindung nicht nur ein Import ausländischer Preisstabilität möglich ist, sondern daß die Zentralbank ausländische Reputation von der Notenbank des Ankerlandes importieren kann, die sie selbst noch nicht besitzt. Durch die Einschränkung des eigenen Entscheidungsspielraums in Form der Wechselkursfixierung - dem sogenannten „Binden der eigenen Hände“ - signalisiert die Zentralbank der Öffentlichkeit, daß sie die inländische Geldpolitik an der stabilitätsorientierten Geldpolitik der ausländischen Währungsbehörde ausrichtet. ${ }^{121}$ Allerdings erfordert ein Erfolg dieser Strategie, daß es sich um eine glaubwürdige Wechselkursgarantie handelt. Ist dies der Fall, dann können durch den Wechselkurs als nominalem Anker sehr hohe Inflationsraten schnell und radikal gesenkt werden, weil sich die Inflationserwartungen entsprechend stark reduzieren. Eine glaubwürdige Festkurspolitik erfordert insbesondere eine mit ihr im Einklang stehende Geld- und Fiskalpolitik. ${ }^{122}$ Ohne Unterstützung durch entsprechende geld- und fiskalpolitische Maßnahmen ist die Politik einer Wechselkursbindung im Rahmen der Stabilisierungspolitik nicht durchhaltbar und damit nicht glaubwürdig. Die Befürworter einer Wechselkursbindung unterstellen, daß der feste Wechselkurs disziplinierend auf die Wirtschaftspolitiker wirkt und somit eher die erforderlichen geld- und fiskalpolitischen Maßnahmen ergriffen werden. ${ }^{123}$ Wie bereits erwähnt, erfolgt eine detaillierte Diskussion, welche Bedingungen erforderlich sind, damit die Glaubwürdigkeit eines Festkurssystems gewährleistet ist, erst im Rahmen der modelltheoretischen Analyse im nächsten Kapitel.

Als ein weiterer Vorteil fester Wechselkurse wird genannt, daß flexible Wechselkurse nur effizient funktionieren, wenn gut entwickelte Kapitalmärkte bestehen, die in den Transformationsländern jedoch anfangs nicht vorhanden sind. ${ }^{124}$ Während in den Industrieländern die mit flexiblen Wechselkursen verbundene Wechselkursvolatilität keine negativen Auswirkungen auf die Handelsbeziehungen hat,

121 Siehe Sachs (1996a), S. 149, und Funke (1993), S. 78. Rodrik (1989), S. 13 f., illustriert das Binden der Hănde sehr anschaulich: Ebenso wie Odysseus sich an den Mast seines Schiffes binden ließ, um den Lockrufen der Sirenen nicht zu erliegen, muß die Făhigkeit der wirtschaftspolitischen Instanzen eingeschrănkt werden, den Stabilităts- bzw. Reformkurs zu verlassen.

122 Siehe u.a. Corden (1993), S. 204, und Rosati (1997), S. 485.

$123 \mathrm{Vgl}$. Aghevli/Montiel (1991), S. 228.

124 Siehe zu diesem Argument Williamson (1991), S. 41, Bofinger (1991), S. 8, und Hrncir (1994), S. 232. 
wird unterstellt, daß sich in Mittel- und Osteuropa schwankende Wechselkurse schädlich auf den Außenhandel auswirken, weil Absicherungsmöglichkeiten fehlen, und daher ein fester Wechselkurs vorteilhafter ist. Es gab zu Transformationsbeginn vor allem keine Devisenterminmärkte, auf denen Arbitrage und spekulative Bewegungen zu einer Stabilisierung des Wechselkurses hätten beitragen können. Allerdings weisen Gröner/Smeets (1991) darauf hin, daß eine Kurssicherung von Außenhandelsgeschäften nicht unbedingt Terminmärkte in den Reformländern selbst erfordert, sondern es ausreicht, wenn die gewünschten Verträge im Ausland ohne Schwierigkeiten abgeschlossen werden können. ${ }^{125}$

Es wird außerdem argumentiert, daß das geringere Wechselkursänderungsrisiko bei festem Wechselkurs nicht nur auf die Handelsströme, sondern auch auf den Kapitalverkehr einen positiven Einfluß ausübt. 126 Weil die Kalkulationsgrundlage sicherer wird, steigt die Attraktivität von Investitionen im Inland, und es fließt Auslandskapital ins Land, das die Transformationsländer dringend benötigen. Wenn die ausländischen Investoren allerdings nicht mit einer dauerhaften Wechselkursfixierung rechnen, werden sie keine langfristigen Engagements eingehen, sondern nur in kurzfristige, schnell liquidierbare Anlageformen investieren, die keine Grundlage für einen langfristigen Wachstumsprozeß in den Reformländern bieten.

\subsubsection{Argumente für einen flexiblen Wechselkurs}

Der zentrale Nachteil eines Wechselkurses als nominaler Anker ist, daß das Wechselkursziel mit höherer Wahrscheinlichkeit zu Zahlungsbilanzproblemen führt als flexible Wechselkurse. Die Festkursstrategie erfordert eine schnelle und dauerhafte Reduzierung der Inflationsrate auf das Niveau im Ankerland. Wenn dies nicht geschieht, stellt sich eine reale Aufwertung ein, die die internationale Wettbewerbsfähigkeit beeinträchtigt und mit Beschäftigungsverlusten verbunden ist. Insbesondere in den Transformationsländern ist damit zu rechnen, daß es aus den erwähnten Gründen 127 über längere Zeiträume zu Preisschüben kommt, die zu höheren Inflationsraten als im Ankerwährungsland führen. Die damit einhergehende reale Aufwertung ist nicht unbegrenzt durchhaltbar, so daß die Gefahr von Währungs- und Finanzkrisen besteht. Muß in einer krisenhaften Zuspitzung der feste Wechselkurs freigegeben werden, beeinträchtigt dies nachhaltig die Glaubwürdigkeit der wirtschaftspolitischen Instanzen. Die massive Abwertung im Zuge der Währungskrise kann darüber hinaus zu einer Finanzkrise führen, wenn sich die inländischen Unternehmen und Banken in ausländischer Währung verschuldet haben, weil sie auf die feste Wechselkursrelation vertrauten und das niedrigere ausländische Zinsni-

$125 \mathrm{Vgl}$. Gröner/Smeets (1991), S. 380.

126 Vgl. Diehl/Schweickert (1997), S. 12, und Fröhlich (1992), S. 34.

127 Siehe Unterabschnitt 2.3. in diesem Kapitel. 
veau ausnutzten. ${ }^{128}$ Aufgrund der Abwertung steigt einerseits der Schuldendienst und sinkt andererseits die Eigenkapitalquote der Banken, weil die Verbindlichkeiten - ausgedrückt in inländischer Währung - zunehmen, ohne daß dem eine bewertungsbedingte Zunahme des Vermögens gegenübersteht. Die Zahlungsunfähigkeit einiger Kreditinstitute kann sich über die Interbanken-Beziehungen auf den gesamten Bankensektor negativ auswirken und unter Umständen eine schwere Finanzkrise hervorrufen.

Bei der Wahl eines festen Wechselkurses müssen außerdem zwei grundsätzliche Fragen beantwortet werden, die sich bei einem flexiblen Wechselkurs nicht stellen und deshalb auch keine Probleme verursachen: Gegenüber welcher Währung bzw. welchem Währungskorb und auf welchem Niveau wird der Wechselkurs fixiert? Die Frage, gegenüber welcher Währung die Wechselkursbindung erfolgen soll, ist noch vergleichsweise einfach zu beantworten. Einerseits muß es sich um die Währung eines Landes handeln, das eine hohe stabilitätspolitische Reputation besitzt. Andererseits sollte die Ankerwährung ein relativ hohes Gewicht im Außenhandel aufweisen, d.h. es sollten enge Handelsbeziehungen zum Ankerwährungsland und zu Ländern bestehen, die ebenfalls stabile Wechselkursrelationen gegenüber der entsprechenden Währung aufweisen. ${ }^{129}$ Große Schwierigkeiten bereitet hingegen die Festlegung eines angemessenen Wechselkursniveaus, weil die Regierung nicht das notwendige Wissen besitzt, um den „richtigen“ Wechselkurs festzulegen. Theoretisch gibt es mehrere Konzepte, mit deren Hilfe sich gleichgewichtige Wechselkurse bestimmen lassen. ${ }^{130}$ Wegen der grundlegenden Veränderungen in Mittel- und Osteuropa können die dafür erforderlichen Vergangenheitswerte aber kein Maßstab für die Ermittlung von Gleichgewichtszuständen sein.

Das Problem ist deshalb so gravierend, weil sowohl mit einer Unter- als auch mit einer Überbewertung erhebliche Risiken verbunden sind. ${ }^{131}$ Eine Unterbewertung verbessert - wenn man zunächst den Blick auf die Leistungsbilanz richtet - die internationale Wettbewerbsfähigkeit des Exportsektors. Negativ wirkt sich hingegen aus, daß eine starke Abwertung des nominalen Wechselkurses den Preisauftrieb verstärkt, der sich aus der Preisliberalisierung ergibt, und damit zu sinkenden Realeinkommen beiträgt. Auch im Hinblick auf die Kapitalbilanz ist eine Unter-

128 Zum gemeinsamen Auftreten von Wăhrungs- und Finanzkrisen siehe Kaminsky/Reinhart (1999), S. 473 ff., und Joebges (2000), S. 38 ff.

$129 \mathrm{Zu}$ den Kriterien fur die Wahl einer Reservewăhrung siehe Freytag (1998), S. 10, und Smeets (1995), S. 93. Fur die These, daß die ECU die Kriterien in Mittel- und Osteuropa am besten erfullt hatte, vgl. Bofinger (1991), S. 18, und Williamson (1991), S. 45.

130 Vgl. z.B. Fröhlich (1992), S. 37, der erläutert, warum die Konzepte der Kaufkraftparităt und des fundamentalen Gleichgewichtskurses in den mittel- und osteuropäischen Staaten nicht anwendbar waren.

131 Siehe zu den Problemen eines zu hohen oder zu niedrigen Kurses Ohr (1996), S. 220 f., und die Übersicht 1 bei Fröhlich (1992), S. 38. 
bewertung kritisch zu sehen. Einerseits begünstigt sie Kapitalzuflüsse, wenn die Wirtschaftssubjekte in der Zukunft mit einer nominalen Aufwertung rechnen. Andererseits kann sie auch zu einer Kapitalflucht führen, wenn eine InflationsAbwertungs-Spirale befürchtet wird. Demgegenüber ermöglicht eine Überbewertung einen günstigeren Zugang zu modernen westlichen Produktionsmitteln, während sie mit einer Dämpfung der Exportnachfrage und dadurch einer Belastung der inländischen Konjunktur verbunden ist. Auf der Seite des Kapitalverkehrs hat eine Überbewertung den positiven Aspekt, daß Investitionsgüter billiger importiert werden können, so daß sich die Angebotsbedingungen verbessern und die im Inland erzielbaren Renditen steigen. Allerdings besteht die latente Gefahr einer nominalen Abwertung, die die erwartete Rendite auf das eingesetzte Kapital entsprechend verringert. Ein flexibler Wechselkurs bietet den entscheidenden Vorteil, diese Probleme bei der Bestimmung des angemessenen Wechselkursniveaus zu Beginn der Transformation zu vermeiden, weil der freigegebene Wechselkurs sich automatisch auf dem angemessenen Marktniveau einpendelt.

Ein flexibler Wechselkurs ermöglicht außerdem eine flexiblere Reaktion auf realwirtschaftliche Schocks, die ihren Ursprung im Inland haben. Die tiefgreifenden Veränderungen im Verlauf des Transformationsprozesses erfordern reale Wechselkursanpassungen, die sich leichter über eine Änderung des nominalen Wechselkurses erreichen lassen. ${ }^{132}$ Bei fixiertem Wechselkurs muß die Anpassung über Preisreaktionen erfolgen, die unter Umständen mit höheren volkswirtschaftlichen Anpassungskosten verbunden sind als eine externe Anpassung über eine Korrektur des nominalen Wechselkurses. Setzt sich eine reale Wechselkursänderung nicht durch, weil die Preis- und Lohnbildungsmechanismen nicht flexibel genug sind, kann dies negative Folgen für die Produktion und die Beschäftigung haben und dauerhafte Fehlallokationen bewirken. Es handelt sich im Grunde genommen um die Umkehrung der Argumentation, bei der der geldpolitische Automatismus fester Wechselkurse positiv bewertet wurde. In einer Welt mit internationalem Kapitalverkehr - auch wenn in den Reformländern noch nicht die volle Kapitalverkehrsfreiheit gewährleistet ist - läßt ein Festkurssystem keinen Spielraum, um auf besondere heimische Umstände $\mathrm{zu}$ reagieren, sondern erzwingt eine vollständige Ausrichtung der Geldpolitik am Wechselkursziel.

Darüber hinaus reduzieren feste Wechselkurse die Flexibilität der Politiker, auf externe Schocks reagieren zu können. Da Schocks aus dem Ausland nicht über Wechselkursanpassungen abgefedert werden können, ist die inländische Volkswirtschaft ähnlichen Einkommensschwankungen ausgesetzt wie das Ankerwährungsland. ${ }^{133}$ Allerdings kann in diesem Zusammenhang die Vermutung geäußert werden, daß dieser Nachteil einer Wechselkursbindung für die Transformations-

132 Siehe hierzu Ohr (1996), S. 224, und Williamson (1991), S. 44.

133

Vgl. Diehl/Schweickert (1997), S. 12. 
länder zu Reformbeginn keine große Bedeutung hatte. Solange noch nicht die Voraussetzungen geschaffen sind, um erfolgreich eine diskretionäre Geldpolitik zu betreiben, "they may have little to gain from an independent monetary policy, but a lot to lose."134

Eine weiterer Vorteil flexibler Wechselkurse besteht darin, daß viele Probleme vermieden werden, die sich in einem Festkurssystem bei zunehmenden Kapitalimporten ergeben. Es handelt sich um ein Argument, das während des Reformprozesses an Bedeutung gewinnt, wenn die noch bestehenden Kapitalverkehrsbeschränkungen schrittweise aufgehoben werden. Durch die feste Wechselkursrelation kann das wahrgenommene Risiko für ausländische Investoren sinken, so daß es verstärkt zu Kapitalzuflüssen kommt. Bei der Bewertung dieser Entwicklung kommt es in erster Linie darauf an, wie das zuströmende Kapital verwendet wird. Handelt es sich um langfristiges Kapital, das in produktive Investitionen fließt und damit das Wachstum in den Transformationsländern stimuliert, ist der Zustrom wünschenswert. Handelt es sich hingegen um kurzfristiges Kapital, dessen primäres Ziel darin besteht, internationale Zinsdifferenzen auszunutzen, besteht die Gefahr, daß es aufgrund veränderter Risikoeinschätzungen internationaler Investoren zu plötzlichen Kapitalabflüssen kommt, die das Festkurssystem gefährden und in eine Währungskrise münden. ${ }^{135}$

Unabhängig von ihrer Fristigkeit und Verwendung gefährden steigende Kapitalimporte bei festen Wechselkursen das Ziel der Preisstabilität. Um die Wechselkursbindung aufrecht zu erhalten, muß die Zentralbank die angebotenen Devisen ankaufen. Betreibt sie keine Neutralisierungspolitik, erhöhen sich die monetäre Basis und die Geldmenge und mittel- bis langfristig auch das Preisniveau. Selbst der Versuch, die Interventionen zu neutralisieren, bietet keine Lösung des Problems, weil das Zinsniveau auf hohem Niveau verharrt oder sogar steigt, so daß weitere Kapitalströme angezogen werden. Zwar bereiten auch in einem flexiblen Wechselkurssystem steigende Kapitalimporte Probleme, sie gefährden jedoch nicht das Preisstabilitätsziel. Ganz im Gegenteil führen Kapitalzuflüsse bei flexiblen Wechselkursen zu einer nominalen Aufwertung, die tendenziell das inländische Preisniveau senkt. Bei anhaltend starkem Kapitalzufluß verschlechtert diese Aufwertung allerdings die internationale Wettbewerbsfähigkeit, so daß sich negative Rückwirkungen auf die wirtschaftliche Entwicklung ergeben.

Schließlich wird als ein wichtiger Vorteil eines flexiblen Wechselkurssystems noch genannt, daß es per Definition das Zahlungsbilanzgleichgewicht erhält und deshalb auch bei knappen Devisenreserven funktioniert. Williamson (1991) vertritt

134 Mishkin (1999), S. 584.

135 Zur Entstehung von Währungskrisen aufgrund eines Herdenverhaltens internationaler Investoren siehe Angermuller (2000), S. 25, der einen Überblick uber verschiedene Wăhrungskrisenmodelle gibt. 
die Auffassung, daß ein Festkurssystem nicht praktikabel ist, wenn keine ausreichend hohen Währungsreserven zur Verfügung stehen. ${ }^{136}$ Auch France Arhar, der Gouverneur der slowenischen Nationalbank, hat unter anderem fehlende Währungsreserven als einen Grund für die Entscheidung Sloweniens zugunsten eines flexiblen Wechselkurssystems genannt. ${ }^{137}$ Allerdings ist $\mathrm{zu}$ berücksichtigen, daß ein großer Bestand an Währungsreserven zwar eine Wechselkursbindung unterstützen kann, daß er aber keine notwendige Bedingung für einen festen Wechselkurs darstellt. Solange die Geldpolitik strikt am Wechselkursziel ausgerichtet wird, sind umfangreiche Devisenmarktinterventionen für die Aufrechterhaltung eines Wechselkurses nicht erforderlich. ${ }^{138}$ Dies wird durch das Beispiel Polens unterstrichen. Zur Unterstützung der Wechselkursbindung am Beginn des Reformprozesses wurde ein Stabilisierungsfonds eingerichtet, der mit einer Milliarde USDollar dotiert war, auf den Polen jedoch nicht zurückgegriffen hat. 139

\section{Zwischenfazit}

Die Ausführungen in diesem Kapitel haben die Probleme aufgezeigt, mit denen die Reformländer zu Beginn ihrer Transformation konfrontiert waren. Alle Länder waren - zwar in unterschiedlichem Ausmaß, aber unabhängig vom gewählten Politikansatz - von der Auflösung des RGW betroffen und erlebten einen drastischen Einbruch der Industrieproduktion. Auch das Problem des Geldüberhangs und die Notwendigkeit zur Preisliberalisierung bestand in allen Ländern. Die Diskussion der Möglichkeiten zur Beseitigung des Geldüberhangs hat gezeigt, daß im Hinblick auf das Preisstabilitätsziel eine Währungsreform die „First-B st"-Lösung gewesen wäre, weil sie einen Preisanstieg hätte vermeiden können. ssus anderen Gründen, die gegen eine Währungsreform sprachen, und aufgrund der Tatsache, daß für die erforderliche Preisliberalisierung ein solches „First-Best“-Instrument nicht zur Verfügung stand, haben sich die Länder für eine Anpassungsinflation als „Second-Best“-Lösung entschieden, so daß die herausragende Reformaufgabe der frühen Transformation die Stabilisierung des Preisniveaus war. Die Besonderheiten der Transformationsrezession und die Bedeutung der Preisstabilität für einen funktionierenden Wettbewerb legen zudem die Vermutung nahe, daß die Reduzierung der hohen Inflationsraten sich gleichzeitig positiv auf das Wirtschaftswachstum auswirkt.

Die Analyse des geld- und wechselkurspolitischen Handlungsspielraums hat gezeigt, daß die Unsicherheiten des Transformationsprozesses für einen festen Wech-

136 Siehe Williamson (1991), S. 42.

137 Vgl. IMF (1995), S. 363.

138 Vgl. Vaubel (1994), S. 566.

139 Siehe Borensztein/Masson (1993), S. 47. 
selkurs als geldpolitisches Zwischenziel sprechen, weil er eine sehr leicht zu beobachtende Zwischenzielgröße ist und Devisenmarktinterventionen der Zentralbank eine automatische Anpassung der Geldpolitik bewirken, wenn der inländische Instrumenteneinsatz nicht richtig dimensioniert ist. Die anderen geldpolitischen Zwischenzielgrößen haben den entscheidenden Nachteil, daß sie zu hohe Anforderungen an die Prognosefähigkeit der Zentralbank stellen, so daß die richtige Einschätzung der geldpolitischen Notwendigkeiten - insbesondere zu Reformbeginn nicht gewährleistet sein dürfte. Allerdings hat die Abwägung der Vor- und Nachteile einer Wechselkursbindung auch gezeigt, daß mit einem festen Wechselkurs erhebliche Risiken verbunden sind und einige der genannten Vorteile einer genaueren Überprüfung bedürfen.

Da die theoretische Analyse der Wechselkurspolitik ein wesentliches Anliegen der vorliegenden Arbeit darstellt, wird im folgenden dritten Kapitel - wieder länderunabhängig, allein ausgehend von den dargestellten Ausgangsbedingungen $\mathrm{zu}$ Transformationsbeginn und dem sich daraus ergebenden Reformbedarf - anhand modelltheoretischer Überlegungen untersucht, welche Politikempfehlungen für die Wahl des Wechselkurssystems abgeleitet werden können, wenn die zentrale wirtschaftspolitische Aufgabe die Stabilisierung des gesamtwirtschaftlichen Preisniveaus ist. Im vierten Kapitel wird dann ausführlich dargestellt, für welche Wechselkurspolitiken sich die zehn betrachteten Kandidaten für eine EU-Osterweiterung entschieden haben und welche stabilisierungspolitischen Erfolge diese Länder verzeichneten. 
Axel Gerloff - 978-3-631-75700-0

Downloaded from PubFactory at 01/11/2019 02:46:37AM

via free access 


\section{Modelltheoretische Ansätze für die Wahl des Wechselkurssystems}

In diesem Kapitel wird zunächst ein Überblick über die in der Literatur verwendeten theoretischen Ansätze zur Wahl des Wechselkursregimes im Transformationsprozeß gegeben, bevor anhand zweier unterschiedlicher Modellrahmen untersucht wird, ob sich aus der theoretischen Analyse konkrete wechselkurspolitische Handlungsanweisungen ableiten lassen. Dabei wird im zweiten Abschnitt das sogenannte Dependent-Economy-Modell als Erklärungsansatz herangezogen, weil es in der Literatur eine weite Verbreitung in der Diskussion um die Wahl des Wechselkursregimes im allgemeinen und speziell in der Literatur zur Wechselkurspolitik in den Transformationsländern gefunden hat. Im dritten Abschnitt wird ein einfaches Partialmodell entwickelt, das sich unter anderem auf Beiträge von Agénor (1994) und Edwards (1998) stützt und so konstruiert ist, daß es einige Merkmale der Transformationsländer abbildet, wie sie im zweiten Kapitel dargestellt wurden. In beiden Modellanalysen steht die Stabilisierung sowohl im Rahmen eines festen als auch eines flexiblen Wechselkurssystems im Mittelpunkt der Betrachtung. Danach werden sie im Hinblick auf ihre Eignung zur Lösung des wechselkurspolitischen Entscheidungsbedarfs und die Übertragbarkeit der Ergebnisse kritisch ausgewertet.

\section{Literaturüberblick}

Der Umfang der theoretischen Literatur zur Wahl des Wechselkursregimes ist sehr groß. Das Problem wird unter verschiedenen Aspekten diskutiert, und mit der Fragestellung, welches Wechselkursregime für die Länder im Transformationsprozeß gewählt werden sollte, ist diese Literatur um eine weitere Facette bereichert worden. Allerdings ist festzustellen, daß relativ wenige Autoren mit konkreten formalanalytischen Modellansätzen arbeiten. Die Frage der Wahl des Wechselkurssystems im Transformationsprozeß wird zwar kontrovers diskutiert, und die Vor- und Nachteile werden abgewogen. Eine Argumentation innerhalb eines bestimmten Modells erfolgt jedoch nur selten. Die Literaturauswertung dieses Abschnitts konzentriert sich auf Modellformulierungen, die sich explizit mit der Wahl des Wechselkurssystems im Transformationsprozeß auseinandersetzen. Da in der Literatur jedoch nur wenige Modelle verwendet wurden, werden auch einige neuere Arbeiten in die Auswertung einbezogen, die sich generell mit der relativen Vorteilhaftigkeit eines festen oder flexiblen Wechselkurssystems befassen, sofern von den Autoren eine Übertragbarkeit ihrer Modellüberlegungen auf die Transformationsländer für möglich gehalten wird. 
Ein Beispiel hierfür sind die Aufsätze von Tornell und Velasco (1998, 2000). Sie entwickeln allgemeine dynamische Gleichgewichtsmodelle, anhand derer untersucht wird, ob ein fester oder flexibler Wechselkurs einen stärkeren Anreiz bietet, im Rahmen der Stabilisierung fiskalpolitische Disziplin zu üben. Es handelt sich um dynamische Gleichgewichtsmodelle mit nutzenoptimierenden Wirtschaftssubjekten, vollkommener Kapitalmobilität und Preisflexibilität, in denen die Fiskalpolitik endogenisiert wird. ${ }^{1}$ Beide Arbeiten kommen zu dem Ergebnis, daß die Ausgaben und damit das staatliche Budgetdefizit bei geldmengenorientierter Stabilisierungspolitik und Wechselkursflexibilität niedriger ausfallen als bei einer Wechselkursstabilisierung, wenn die Regierung die Zukunft stärker diskontiert als die Allgemeinheit, z.B. aufgrund der Unsicherheit über die Chancen einer Wiederwahl. Dies ergibt sich daraus, daß das fiskalische Fehlverhalten bei festen Wechselkursen erst später zu einer „Bestrafung“ führt, wenn es über die Abnahme der Währungsreserven schließlich zum Zusammenbruch der Wechselkursfixierung kommt. Bei flexiblen Wechselkursen erfolgt die Bestrafung unverzüglich durch sofortige Wechselkursbewegungen. Während sich die Ausführungen nicht auf eine bestimmte Ländergruppe beziehen, werden in den empirischen Teilen der beiden Arbeiten von Tornell und Velasco Stabilisierungsprogramme in Südamerika untersucht bzw. die Erfahrungen der Länder südlich der Sahara in den frühen 1980er Jahren betrachtet. Neben Lateinamerika und Afrika nennen die Autoren aber auch Osteuropa als eine Region, für die ihre Argumente relevant sein könnten. ${ }^{2}$

Grafe und Wyplosz (1998) gehören zu den wenigen Autoren, die explizit eine systemtransformierende Wirtschaft modellieren, um wechselkurspolitische Fragestellungen zu untersuchen. ${ }^{3}$ Die Autoren entwickeln ein Drei-Sektoren-Modell, das den Zusammenhang zwischen Produktivität, Kapitalakkumulation, Reallöhnen und relativen Preisen unterstreicht, wenn der Staatssektor sukzessive durch expandierende private Sektoren verdrängt wird. Zielsetzung dieses Beitrags ist jedoch, ein Modell zu formulieren, das die reale Wechselkursentwicklung in der Transformation abbildet. Es eignet sich daher nicht zur Betrachtung des Einflusses des Wechselkurssystems auf den Erfolg einer Stabilisierungspolitik. ${ }^{4}$

Insbesondere in der frühen Literatur zur Wechselkurspolitik im Transformationsprozeß ist auf Modelle zurückgegriffen worden, die in anderen Zusammenhängen von Fischer (1986) und Cukierman (1988) entwickelt worden sind. ${ }^{5}$ Fischer

1 Tornell/Velasco (1998), S. 1 ff., betrachten ein diskretes Modell, wăhrend die Analyse in Tornell/Velasco (2000), S. 406 ff., stetig ist.

2 Vgl. Tornell/Velasco (2000), S. 405.

3 Siehe Grafe/Wyplosz (1998), S. 4 ff.

4 Auf das Phănomen der realen Aufwertung im Transformationsprozeß wird im Unterabschnitt IV.2.1. genauer eingegangen.

5 Vgl. Schmieding (1992), S. 70 ff. Siehe aber auch Pieper (1995), S. 101 ff., und Toren (1999), S. $109 \mathrm{f}$. 
untersucht die Kosten einer Inflationsbekämpfung anhand eines Modells, in dem Lohnverträge für zwei Perioden im voraus festgelegt werden. ${ }^{6}$ Dabei steht im Mittelpunkt der Betrachtung, ob die Kosten der Stabilisierung bei einem Geldmengen- oder einem Wechselkursziel geringer ausfallen. Auch in Cukiermans Modell - zur Erklärung der Stabilisierungserfolge 1985 in Israel - bestehen Lohnstarrheiten aufgrund länger laufender Lohnkontrakte. Er untersucht eine Geldmengenregel und eine direkte Preiskontrolle als Politikalternativen. ${ }^{7}$ Anhand dieser Modelle sind zwar die Vor- und Nachteile einer Wechselkursfixierung zur Stabilisierung des Preisniveaus analysiert worden, und die Modelle wurden dahingehend überprüft, inwieweit sie die Situation in den Transformationsländern angemessen abbilden. ${ }^{8}$ Allerdings erfolgte keine Modifikation, um sie gegebenenfalls den Umständen des Reformprozesses anzupassen.

Eine weitere wichtige Gruppe von theoretischen Aufsätzen, die die Rolle der Wechselkurspolitik im Stabilisierungsprozeß untersucht, greift auf den von Barro und Gordon für geldpolitische Problemstellungen entwickelten spieltheoretischen Ansatz zurück. ${ }^{9}$ Dabei wird eine wirtschaftspolitische Zielfunktion modelliert, die die beiden Zielgrößen Preisstabilität und Beschäftigung bzw. Sozialprodukt beinhaltet. Anhand unterschiedlicher konkreter Modellausprägungen, deren zentraler Bestandteil jeweils eine solche Zielformulierung ist, wird untersucht, unter welchem Wechselkurssystem die Kosten der Stabilisierung geringer ausfallen. ${ }^{10} \mathrm{Al}-$ lerdings gibt es kaum Arbeiten, die versuchen, diesen Ansatz auf die Entscheidung für ein Wechselkurssystem im Transformationsprozeß zu übertragen. ${ }^{11}$ Rodrik (1995) untersucht im Rahmen eines solchen Modells handelspolitische Fragestellungen und analysiert insbesondere den Konflikt zwischen einem flexiblen Wechselkurs als Garanten für internationale Wettbewerbsfähigkeit und einem festen Wechselkurs als nominalen Anker für das Preisniveau. Die Untersuchung bezieht sich auf lateinamerikanische Länder, allerdings erwähnt Rodrik auch Polen als ein Beispiel, für das die Analyse zutreffend sein könnte. ${ }^{12}$ Agénor (1994) und Ed-

6 Vgl. Fischer (1986), S. 247 ff.

7 Siehe Cukierman (1988), S. 65 ff. Da in der Modellanalyse nur ein handelbares Gut unterstellt wird, ist die direkte Preiskontrolle mit einer Wechselkursfixierung identisch.

8 Siehe Pieper (1995), S. 102 und 104.

9 Vgl. Barro/Gordon (1983a), S. 589 ff., und Barro/Gordon (1983b), S. $101 \mathrm{ff}$.

10 Siehe z.B. Andersen/Risagen (1991), S. 85 ff., Edwards (1996b), S. 2 ff., und Horn/Perrson (1988), S. 1621 ff. Der Ansatz wird von Canzoneri et al. (1997), S. 46 ff., und Giavazzi/Pagano (1998), S. 1055 ff., zur Analyse der Glaubwurdigkeit einer Wechselkursbindung im Rahmen des Europåischen Wăhrungssystems verwendet. Devarajan/Rodrik (1992), S. 70 ff., und Rodrik (1995), S. 302 ff., sind Arbeiten, die die Wechselkurspolitik in Entwicklungsländern analysieren.

11 Eine Ausnahme bildet Edwards (1993), S. 1 ff., der diesen Modellrahmen nicht nur fur Lateinamerika verwendet, sondern auch auf Mittel- und Osteuropa luberträgt und eine Schätzung für Jugoslawien durchfuhrt. Siehe ebenda S. 2 und $16 \mathrm{f}$.

12

Siehe Rodrik (1995), S. 291. 
wards (1998) gehen noch einen Schritt weiter und formulieren Zielfunktionen, in denen explizit ein Preisstabilitätsziel und ein reales Wechselkursziel berücksichtigt werden. ${ }^{13}$ Die Autoren unterstellen eine Übertragbarkeit der Ergebnisse auf Entwicklungsländer. Auf diesen beiden Ansätzen baut das Modell auf, das im Abschnitt 3 vorgestellt wird und einigen Merkmalen der Transformationsländer Rechnung trägt.

Wie bereits erwähnt, ist das sogenannte Dependent-Economy-Modell ein Analyserahmen, der in der Literatur häufig für die Untersuchung der Wechselkurspolitik in den Transformationsländern herangezogen wird. Ursprünglich wurde dieses Modell von Swan $(1960,1963)$ und Salter (1959) für die australische Wirtschaft entwickelt, ${ }^{14}$ diente dann aber zur Beantwortung verschiedener Fragestellungen. Das Modell wurde zum Beispiel verwendet für die Analyse der Wechselkurspolitik in Entwicklungsländern ${ }^{15}$ und fand insbesondere im deutschsprachigen Raum bei der Analyse der Wechselkurspolitik im Rahmen der Stabilisierungsbemühungen der Transformationsländer eine weite Verbreitung. ${ }^{16}$ Die Mehrheit der Autoren kommt im Rahmen dieses Modells zu dem Ergebnis, daß feste und flexible Wechselkurse die gleichen Anstrengungen erfordern und ein Stabilisierungsprogramm durch eine einseitige Wechselkursfixierung nicht glaubwürdiger wird. ${ }^{17}$ Aufgrund der großen Bedeutung dieses Modells in der theoretischen Literatur zur Wechselkurspolitik im Transformationsprozeß wird es auch in dieser Arbeit zunächst dargestellt, wobei sich die Ausführungen - basierend auf den Ergebnissen aus dem zweiten Kapitel auf die Bedeutung des Wechselkursregimes im Stabilisierungsprozeß konzentrieren.

\section{Das Dependent-Economy-Modell}

Trotz der Tatsache, daß das Modell von sehr vielen Autoren für die Analyse der Wechselkurspolitik herangezogen wird, ist die Darstellung in der Literatur nicht einheitlich. Es bestehen insbesondere unterschiedliche Auffassungen darüber, auf welchen Annahmen das Modell beruht, so daß die Aussagen erheblich voneinander abweichen. Dies ist zum Teil darauf zurückzuführen, daß sich die Behandlung in einer Vielzahl der Arbeiten auf die graphische Darstellung des Modells beschränkt,

13 Vgl. Agénor (1994), S. 3 ff., und Edwards (1998), S. 684 ff.

14 Aus diesem Grund wird es in der Literatur auch ,australisches Modell“ genannt. Als weitere Bezeichnung findet man ,macroeconomic balance approach“. Siehe Clark et al. (1994), S. 11, und Williamson (1994), S. 187.

15 Vgl. u.a. Corden (1991), S. $226 \mathrm{ff}$., und Wohlmann (1998), S. $41 \mathrm{ff}$.

16 Siehe Buch et al. (1995), S. 21 ff., Diehl/Schweickert (1997), S. 142 ff., Pieper (1995), S. 107 ff., Schäfer (1994), S. 198 ff., Schăfer (1998), S. 131 ff., Schweickert et al. (1992), S. 5 ff., Schweickert (1993), S. 208 ff., Stippler (1998), S. 83 ff., und Toren (1999), S. 102 ff.

Vgl. exemplarisch Schäfer (1994), S. 202 und 204. 
ohne daß die zugrundeliegenden Modellannahmen genau formuliert werden. Während einige Autoren im Rahmen der Analyse verzögerte Preisreaktionen zulassen, 18 argumentieren andere, daß es sich um ein Vollbeschäftigungsmodell mit flexiblen Löhnen und Preisen handelt. ${ }^{19} \mathrm{Um}$ Mißverständnisse zu vermeiden, werden im folgenden Unterabschnitt zunächst detailliert die Modellstruktur und die Annahmen des Modells vorgestellt, wie sie in der vorliegenden Arbeit verwendet werden. In den darauf folgenden Unterabschnitten erfolgt eine Auswertung des Modells jeweils für eine Stabilisierung bei festen und flexiblen Wechselkursen, wobei diese Auswertung anhand der in der Literatur üblichen graphischen Darstellung vorgenommen wird.

\subsection{Modellstruktur}

Die Wirtschaft besteht aus zwei Sektoren: In einem Sektor werden international handelbare Güter hergestellt, während der zweite Sektor nicht-handelbare Güter produziert. ${ }^{20}$ Eine zentrale Annahme des Modells ist der Fall des „kleinen Landes“, aus der sich auch die Bezeichnung „Dependent-Economy-Modell“ ableitet. Die Preise für handelbare Güter sind exogen vorgegeben und nicht vom Inland zu beeinflussen. Es ist daher nicht erforderlich, zwischen exportierten und importierten Gütern zu unterscheiden. Diese werden zusammen mit den Importsubstituten zu einem Güterbündel, den sogenannten handelbaren bzw. internationalen Gütern, zusammengefaßt. ${ }^{21}$ Dabei ist zu berücksichtigen, daß ein Teil der für den Export vorgesehenen Produkte auch im Inland abgesetzt wird. Preisänderungen bei den internationalen Gütern können sich nur durch Veränderungen der Weltmarktpreise oder durch Wechselkursschwankungen ergeben. Demgegenüber werden die Preise nicht-handelbarer Güter durch Angebot und Nachfrage im Inland bestimmt. Zwischen den handelbaren und nicht-handelbaren Gütern bestehen sowohl in der Produktion als auch im Konsum Substitutionsbeziehungen.

Bevor auf die Angebots- und Nachfrageseite des Modells eingegangen wird, soll zunächst der reale Wechselkurs erläutert werden, der in diesem Modell ein zentrale Rolle spielt. Der reale Wechselkurs $W^{r}$ ist definiert als das Verhältnis des Preises handelbarer Güter $P_{T}$ - durch Multiplikation mit dem nominalen Wechselkurs $W$ umgerechnet in inländische Währung - zum Preis der nicht-handelbaren Güter $P_{N}$, d.h.

18 Vgl. zum Beispiel Schweickert (1993), S. 208 und 210, sowie Stippler (1998), S. 85.

19 Siehe zu dieser Position exemplarisch Dornbusch (1980), S. 97, und Visser (1995), S. 68.

20 Die Ausfuhrungen in diesem Unterabschnitt stutzen sich insbesondere auf Dornbusch (1980), S. 97 ff., Swan (1963), S. 386 ff., und Wohlmann (1998), S. 43 ff.

21 Die Begriffe internationale und handelbare Güter einerseits sowie nationale und nichthandelbare Guter andererseits werden synonym verwendet. Vgl. zu der Unterscheidung zwischen den beiden Kategorien Jarchow/Ruhmann (2000), S. 65. 
(1) $\quad W^{r}=\frac{W \cdot P_{T}}{P_{N}}$.

Der nominale Wechselkurs ist in Preisnotierung angegeben, d.h. er mißt den Wert einer ausländischen Währungseinheit in Einheiten der inländischen Währung, so daß ein Anstieg (Rückgang) von $W$ eine nominale Abwertung (Aufwertung) beschreibt. Einerseits beschreibt diese Definition des realen Wechselkurses die Anreize zur Ressourcenreallokation zwischen den Sektoren. Steigt der reale Wechselkurs, wird die Produktion internationaler Güter profitabler, und es besteht ein Anreiz, Ressourcen aus dem Sektor der nicht-handelbaren Güter in den internationalen Sektor umzulenken. Andererseits stellt diese Definition einen Index für die internationale Wettbewerbsfähigkeit dar. ${ }^{22}$ Eine reale Aufwertung bedeutet, daß die Kosten für die Produktion handelbarer Güter gestiegen sind, weil zum Beispiel der sinkende reale Wechselkurs auf einen Anstieg von $P_{N}$ zurückzuführen ist. Auch wenn die Preise der internationalen Güter in ausländischer Währung sinken, weil die ausländischen Anbieter aufgrund verbesserter Angebotsbedingungen das gleiche Produkt zu einem niedrigeren Preis anbieten, verschlechtert sich die Wettbewerbsfähigkeit gegenüber dem Ausland bei unveränderten inländischen Bedingungen.

Als nächstes wird die Angebotsseite der Volkswirtschaft näher betrachtet. Auf kurze Sicht sind ein konstanter Kapitalbestand und ein konstantes Arbeitskräfteangebot gegeben. Die Güter werden unter Einsatz dieser beiden Produktionsfaktoren hergestellt. Während jedoch die Aufteilung des Faktors Kapital auf die Produktionsprozesse internationaler bzw. nationaler Güter nur langfristig geändert werden kann, sind die Arbeitskräfte auch kurzfristig zwischen den Sektoren mobil. ${ }^{23}$ Die Unternehmen stehen in vollkommenem Wettbewerb miteinander, und vollständige Lohn- und Preisflexibilität garantieren Vollbeschäftigung.

Aufgrund dieser Angebotsbedingungen ist das Angebot an internationalen und nationalen Gütern nur abhängig vom Relativpreis der beiden Güter. Steigt der Preis der handelbaren Güter - in Inlandswährung ausgedrückt - im Verhältnis zum Preis der nicht-handelbaren Güter, dann wird es attraktiver, handelbare Güter herzustellen. Die Ertragslage in diesem Sektor verbessert sich, und die Produktion wird ausgeweitet. Analog dazu muß die Produktion im Sektor der nichthandelbaren Güter eingeschränkt werden. Sinkt hingegen der reale Wechselkurs, d.h. die Preise nationaler Güter steigen im Verhältnis zu den Preisen internationa-

22 Vgl. zu dieser Definition des realen Wechselkurses ausfuhrlicher Edwards (1989), S. 5 f., der auch auf den Unterschied zu der ebenfalls gebrăuchlichen Definition des realen Wechselkurses eingeht, die auf der Kaufkraftparitătentheorie beruht.

23 Für eine detailliertere Darstellung des Arbeitsmarktes im Dependent-Economy-Modell siehe Dornbusch (1980), S. 98. 
ler Güter an, dann gilt der umgekehrte Zusammenhang. Die Angebotsseite der Volkswirtschaft wird durch die Gleichungen (2) und (3) beschrieben:

$$
\begin{aligned}
& \text { (2) } Y_{T}=Y_{T}\left(\stackrel{+}{W^{r}}\right), \\
& \text { (3) } Y_{N}=Y_{N}\left(\stackrel{-}{W}^{r}\right) .24
\end{aligned}
$$

Dabei bezeichnet $Y_{T}$ das Angebot an handelbaren Gütern und $Y_{N}$ das Angebot an nicht-handelbaren Gütern. Das gesamte Güterangebot wird mit $Y$ bezeichnet, wobei eine Addition der Mengen eine Vereinheitlichung der Dimensionen erfordert. Im folgenden werden alle Gütermengen in Einheiten handelbarer Güter gemessen, so daß die Produktion nationaler Güter mit Hilfe des realen Wechselkurses in internationale Güter umgerechnet werden muß. Es gilt

$$
Y=Y_{T}+\frac{1}{W^{r}} Y_{N}
$$

$\mathrm{Da}$ in diesem Modell von Abschreibungen, indirekten Steuern und Transferzahlungen des Staates abgesehen wird, entspricht $Y$ nicht nur der Produktion, sondern zugleich dem realen Vollbeschäftigungseinkommen, und zwar ebenfalls in handelbaren Gütern ausgedrückt.

Die Nachfrage nach internationalen Gütern $N_{T}$ hängt von dem Preisverhältnis $W^{r}$ sowie von der realen Absorption $A^{r}$ ab. ${ }^{25}$ Die reale Absorption ist die Summe aus privatem und staatlichem realen Konsum sowie privater und staatlicher realer Investitionen. Sie wird - ebenso wie die Produktion - in handelbaren Gütern gemessen.

$$
N_{T}=N_{T}\left(\overrightarrow{W^{r}}, \stackrel{+}{A^{r}}\right)
$$

Der negative Zusammenhang zwischen einer Änderung des realen Wechselkurses und der Nachfrage nach handelbaren Gütern resultiert aus zwei Effekten. Einerseits fragen die Wirtschaftssubjekte verstärkt heimische Produkte nach, wenn die internationalen Güter im Vergleich zu den nationalen Gütern relativ teurer werden (Substitutionseffekt). Andererseits bewirkt ein Anstieg des realen Wechselkurses

24 Ein Plus- bzw. Minuszeichen uber einer Variablen gibt das Vorzeichen der ersten Ableitung an. In Gleichung (2) gilt also zum Beispiel $\partial Y_{T} / \partial W^{r}>0$.

25 Die Gutternachfrage hăngt im Dependent-Economy-Modell nicht vom Realeinkommen sondern von der realen Absorption ab, weil die Wirtschaftssubjekte entweder sparen oder sich verschulden können. 
einen Rückgang des Realeinkommens (Einkommenseffekt). ${ }^{26}$ Da beide Effekte in die gleiche Richtung gehen, ist die Wirkung auf die Nachfrage - wie in Gleichung (5) angegeben - eindeutig negativ. Ein Anstieg der realen Absorption hingegen bewirkt eine steigende Nachfrage nach handelbaren Gütern, weil der zusätzliche Konsum bzw. die höhere Investition zu größerer Nachfrage nach beiden Güterkategorien führt.

Folglich ist auch die Nachfrage nach nationalen Gütern $N_{N}$ vom Relativpreis der beiden Gütergruppen und der realen Absorption abhängig:

$$
N_{N}=N_{N}\left(\stackrel{?}{W^{r}}, \stackrel{+}{A^{r}}\right) \text {. }
$$

Während für die reale Absorption analog zur Nachfrage nach handelbaren Gütern ein positiver Einfluß gilt, ist das Vorzeichen einer Änderung des realen Wechselkurses theoretisch unbestimmt. Dies ergibt sich daraus, daß im Sektor der nichthandelbaren Güter der Substitutions- und der Einkommenseffekt gegenläufig auf die Nachfrage einwirken. Während ein Anstieg des realen Wechselkurses eine höhere Nachfrage nach nicht-handelbaren Gütern hervorruft (Substitutionseffekt), senkt der Einkommenseffekt die Nachfrage nach nationalen Gütern. Es wird im folgenden jedoch unterstellt, daß der Substitutionseffekt den Einkommenseffekt dominiert, die Wirkung einer realen Abwertung auf die Nachfrage nichthandelbarer Güter also positiv ist.

Die Gleichungen (2) und (5) lassen sich zusammenfassen zur Gleichgewichtsbedingung für den Markt handelbarer Güter. Sie lautet

$$
Y_{T}\left(\stackrel{+}{W^{r}}\right)=N_{T}\left(\stackrel{-}{W^{r}}, \stackrel{+}{A^{r}}\right) .
$$

Gleichung (7) wird in Abbildung 1 durch die TT-Kurve mit positiver Steigung in einem $A^{r}-W^{r}$-Diagramm dargestellt und beschreibt Kombinationen von $W^{r}$ und $A^{r}$, bei denen außenwirtschaftliches Gleichgewicht herrscht. Dieses wird auch als externes Gleichgewicht bezeichnet und beschreibt Situationen, in denen die Handels- und Dienstleistungsbilanz ausgeglichen ist. ${ }^{27}$ Der Verlauf der TT-Kurve erklärt sich wie folgt: Steigt in einer Situation mit außenwirtschaftlichem Gleichgewicht die reale Absorption und mit ihr die Nachfrage nach handelbaren Gütern,

26 Ein sinkendes Realeinkommen ergibt sich nach Gleichung (4) unabhängig davon, ob die reale Abwertung durch einen Anstieg der Preise handelbarer Guter oder eine Senkung der Preise nicht-handelbarer Guter hervorgerufen wird.

27 Mit dem Begriff „Guter" sollen sowohl Waren als auch Dienstleistungen erfaßt werden, so daß vom Handels- und Dienstleistungsbilanzsaldo bzw. vom Außenbeitrag gesprochen werden kann. 
dann muß, damit das Gleichgewicht auf dem Markt für internationale Güter erhalten bleibt, eine Änderung des realen Wechselkurses entweder einen Anstieg des Angebots bewirken (über die linke Seite der Gleichung (7)) und/oder die Nachfrage abschwächen (über die rechte Seite der Gleichung (7)). Beides wird durch eine reale Abwertung erreicht, die zum einen eine Nachfragesubstitution zugunsten der relativ billiger werdenden nicht-handelbaren Güter auslöst und zum anderen das Angebot an handelbaren Gütern erhöht. Der ausgeglichene Handels- und Dienstleistungsbilanzsaldo kann so aufrechterhalten werden.

\section{Abbildung 1: Internes und externes Gleichgewicht im Dependent-Economy-Modell}

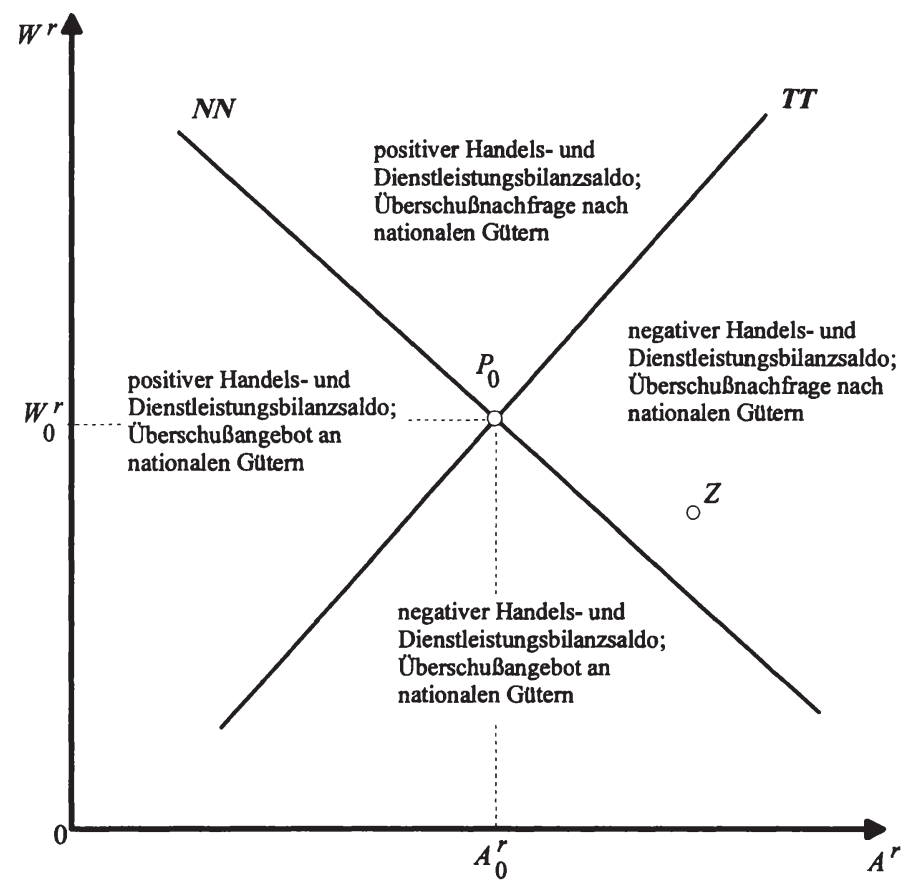

Quelle: Swan (1963), S. 387.

Stimmen Angebot und Nachfrage auf dem Markt für nicht-handelbare Güter überein, herrscht internes Gleichgewicht. Es ergibt sich aus Gleichung (3) mit (6) unter 
Berücksichtigung der Annahme, daß der Substitutionseffekt einer realen Wechselkursänderung stärker ist als der Einkommenseffekt:

$$
Y_{N}\left(\stackrel{-}{W^{r}}\right)=N_{N}\left(\stackrel{+}{W^{r}}, \stackrel{+}{A^{r}}\right)
$$

bzw. in Einheiten internationaler Güter ausgedrückt

$$
\frac{1}{W^{r}} Y_{N}\left(\stackrel{-}{W^{r}}\right)=\frac{1}{W^{r}} N_{N}\left(\stackrel{+}{W^{r}}, \stackrel{+}{A^{r}}\right)
$$

Die Gleichgewichtssituation auf dem Markt für nicht-handelbare Güter wird durch die $N N$-Kurve beschrieben, die im $A^{r}-W^{r}$-Diagramm der Abbildung 1 eine negative Steigung hat, denn ausgehend von einem internen Gleichgewicht führt ein Anstieg der realen Absorption zu einer Überschußnachfrage im Sektor der nationalen Güter. Zum Abbau dieser Überschußnachfrage ist eine Senkung des realen Wechselkurses erforderlich, die - wie aus Gleichung (8) ersichtlich - einerseits die Nachfrage dämpft und andererseits zu einer Ausweitung des Angebots beiträgt, so daß das Gleichgewicht auf dem Markt für nicht-handelbare Güter wieder hergestellt wird. ${ }^{28}$

$\mathrm{Zu}$ berücksichtigen ist, daß sich der Markt für nicht-handelbare Güter immer im Gleichgewicht befindet. Wie bereits erwähnt, wird der Preis der nationalen Güter durch Angebot und Nachfrage im Inland bestimmt. Neben den Mengeneffekten, die anhand der Gleichungen (3) und (6) beschrieben wurden, kommt es auch zu Preisreaktionen, weil flexible Preise unterstellt werden. So sinkt der Preis nichthandelbarer Güter, wenn ein Überschußangebot vorliegt. Umgekehrt steigt er bei einer Überschußnachfrage. Die Änderung des Preises nationaler Güter bewirkt eine entsprechende Änderung des realen Wechselkurses, so daß Gleichung (8) immer erfüllt ist.

$\mathrm{Da}$ der Markt für nicht-handelbare Güter immer im Gleichgewicht sein muß, läßt sich auch aus saldenmechanischen Zusammenhängen ableiten. Dabei ist zu beachten, daß die reale Absorption, also die Summe aller Ausgaben im Inland für Konsum- und Investitionszwecke, gleich der Nachfrage nach handelbaren und nicht-handelbaren Gütern ist, d.h.

28 Die Argumentation hebt allein auf die durch die reale Wechselkursănderung hervorgerufenen Mengenreaktionen ab. Die aus der realen Aufwertung gleichzeitig resultierende Verănderung der Bewertung in internationalen Gutern durch die Multiplikation der Mengen mit dem Kehrwert des realen Wechselkurses bleibt auf den Anpassungsprozeß ohne Auswirkung, weil sie im Gleichgewicht die Angebots- und Nachfrageseite gleichermaßen betrifft. 


$$
A^{r}=\frac{1}{W^{r}} N_{N}+N_{T}
$$

wobei die Nachfrage nach nationalen Gütern wieder in internationale Güter umgerechnet werden muß, damit die Gleichung dimensionsmäßig homogen ist und die reale Absorption, wie oben erwähnt, ebenso wie die gesamtwirtschaftliche Produktion in handelbaren Gütern ausgedrückt wird. Löst man Gleichung (9) nach $N_{T}$ und Gleichung (4) nach $Y_{T}$ auf und subtrahiert sie voneinander, dann erhält man

$$
\begin{aligned}
& N_{T}-Y_{T}=\left(A^{r}-\frac{1}{W^{r}} N_{N}\right)-\left(Y-\frac{1}{W^{r}} Y_{N}\right) \text { bzw. } \\
& Y_{T}-N_{T}=\left(Y-A^{r}\right)+\frac{1}{W^{r}}\left(N_{N}-Y_{N}\right) .
\end{aligned}
$$

Die linke Seite der Gleichung (10) gibt den Außenbeitrag an, während der erste Klammerausdruck auf der rechten Seite von Gleichung (10) die Differenz zwischen Einkommen und Absorption angibt und der zweite Klammerausdruck für $N_{N} \neq Y_{N}$ ein Ungleichgewicht auf dem Markt nicht-handelbarer Güter beschreibt. Aus der volkswirtschaftlichen Gesamtrechnung ergibt sich jedoch aus der Verwendungsgleichung des Sozialprodukts, das in diesem Modell mit dem Volkseinkommen übereinstimmt, daß der Außenbeitrag immer gleich der Differenz aus Sozialprodukt bzw. Volkseinkommen und Absorption (Summe aus Konsum und Investition) ist. ${ }^{29}$ Dabei ist zu beachten, daß es sich bei dieser Beziehung nicht um eine Gleichgewichtsbedingung handelt, sondern um eine Identität, die zu jeder Zeit erfüllt ist. Das heißt mit anderen Worten, daß der erste Klammerausdruck auf der rechten Seite von Gleichung (10) immer gleich der linken Seite von Gleichung (10) ist. Und dies wiederum impliziert, daß immer $N_{N}=Y_{N}$ gelten muß, sich der Markt für nicht-handelbare Güter also stets im Gleichgewicht befindet. 30

Für den außenwirtschaftlichen Bereich wird hingegen unterstellt, daß im Rahmen der hier erfolgenden relativ kurzfristigen Betrachtung positive oder negative Salden der Handels- und Dienstleistungsbilanz möglich sind, d.h. Defizite bzw. Über-

Siehe Rose/Sauernheimer (1999), S. 23 ff., und Jarchow/Ruhmann (2000), S. 23 f.

Über diesen Zusammenhang besteht in der Literatur offensichtlich einige Unklarheit. So schreibt Dornbusch (1980), S. 102, im Zusammenhang mit Gleichung (10): „A trade surplus either reflects an excess of income over spending or an excess demand for nontraded goods." Auch Wohlmann (1998), S. 46, argumentiert mit Ungleichgewichten auf dem Markt fur nichthandelbare Guter, wăhrend Visser (1995), S. 69, unterstreicht, daß ,the distinguishing characteristic of the model is that the nontradeables sector is in continuous equilibrium." 
schüsse durch entsprechende Veränderungen in der Kapital- und/oder Devisenbilanz ausgeglichen werden. ${ }^{31}$ In dieser Hinsicht wird Kapitalverkehr im Modell berücksichtigt, während die Modellanalyse ansonsten von internationalen Kapitalströmen absieht. Auf den Einfluß von Nettokapitalbewegungen wird erst in der abschließenden Bewertung des Modells eingegangen.

Die $T T$ - und die $N N$-Kurve teilen das Diagramm in vier Bereiche, die - wie in Abbildung 1 eingetragen - jeweils durch eine bestimmte Konstellation aus internem und externem Ungleichgewicht gekennzeichnet sind. ${ }^{32}$ Exemplarisch sei dies anhand des Punktes $Z$ verdeutlicht. Im Punkt $Z$ übersteigt die Nachfrage nach nichthandelbaren Gütern das Angebot. Das Ungleichgewicht im nationalen Sektor kann zum Beispiel beseitigt werden, indem bei unverändertem Preisverhältnis die reale Absorption eingeschränkt wird. Alternativ wird bei gleichem Ausgabenniveau wie in $Z$ das interne Gleichgewicht wiederhergestellt, wenn die Preise im nationalen Sektor so lange steigen, bis die erforderliche Senkung des realen Wechselkurses erreicht ist. Auch Kombinationen aus beiden Entwicklungen führen zum Ausgleich von Angebot und Nachfrage im nationalen Sektor, ohne jedoch den negativen Wert des Außenbeitrags zu beseitigen. Wie aus Abbildung 1 ersichtlich, beschreiben Punkte links von der TT-Kurve einen Überschuß in der Handels- und Dienstleistungsbilanz, während rechts von der TT-Kurve ein negativer Außenbeitrag herrscht. Damit gleichzeitig ein ausgeglichener Saldo der Handels- und Dienstleistungsbilanz und ein Gleichgewicht im nationalen Sektor realisiert werden, ist eine reale Abwertung - d.h. ein Anstieg von $W^{r}$ - und eine Einschränkung der realen Absorption erforderlich. Nur im Punkt $P_{0}$ herrscht simultan internes und externes Gleichgewicht. Eine solche Situation wird deshalb als gesamtwirtschaftliches Gleichgewicht bezeichnet.

Damit die Wirkung einer Wechselkurspolitik auf die Stabilisierung des Preisniveaus untersucht werden kann, muß das Modell noch um zwei Gleichungen ergänzt werden. Die Gleichung (11) stellt einen Zusammenhang zwischen den Preisen in den beiden Sektoren der Wirtschaft und dem gesamtwirtschaftlichen Preisniveau her. Die Veränderung des gesamtwirtschaftlichen Preisniveaus $P$ hängt von der Preisentwicklung in beiden Sektoren der Volkswirtschaft ab. Es gilt in allgemeiner Formulierung

31 Würde kein Ausgleich des Außenbeitrags uber andere Teilbilanzen der Zahlungsbilanz zugelassen, mußten entsprechende Wechselkursänderungen kontinuierlich einen Ausgleich der Handels- und Dienstleistungsbilanz herbeifuhren. Die Volkswirtschaft befände sich dann immer im gesamtwirtschaftlichen Gleichgewicht.

32 Es werden vereinfachend lineare Kurvenverläufe unterstellt. Tatsächlich müßte die TT-Kurve einen immer steiler werdenden Verlauf aufweisen, weil bei ansteigender Absorption irgendwann auch ein noch so starker Anstieg des realen Wechselkurses ein Handelsbilanzdefizit nicht wird verhindern kőnnen. Siehe Swan (1963), S. 386. Die Ergebnisse der Untersuchung bleiben von dieser Vereinfachung unberuhrt. 


$$
P=P\left(\stackrel{+}{W}, \stackrel{+}{P_{T}}, \stackrel{+}{P_{N}}\right)
$$

denn Erhöhungen des nominalen Wechselkurses, des Preises internationaler Güter (in ausländischer Währung) und des Preises nationaler Güter führen zu einem Anstieg des gesamtwirtschaftlichen Preisniveaus.

Schließlich muß noch der monetäre Sektor abgebildet werden, um den Einfluß der Geldpolitik auf das gesamtwirtschaftliche Preisniveau und die reale Absorption beschreiben zu können. Diejenigen Autoren, die das Dependent-Economy-Modell für eine Analyse der Wechselkurspolitik verwenden, argumentieren in der Regel damit, daß eine Geldmengenkontraktion zu einer Absorptionseinschränkung führt, ohne jedoch diesen Zusammenhang zu modellieren. ${ }^{33}$ Eine Formalisierung erfolgt im folgenden unter Verwendung einer leicht modifizierten Form der bereits im Unterabschnitt II.3.1.2. vorgestellten Quantitätsgleichung

$$
M \cdot V=P \cdot T^{r},
$$

in der $M$ die nominale Geldmenge, $V$ die Umlaufgeschwindigkeit des Geldes, $P$ das durchschnittliche Preisniveau des Transaktionsvolumens und $T^{r}$ den Realwert aller gehandelten Güter und Dienstleistungen bezeichnet. Um einen Zusammenhang zwischen dem monetären Sektor und dem realwirtschaftlichen Bereich herzustellen, wird der Realwert des Transaktionsvolumens durch die reale Absorption angenähert und $P$ mit dem in Gleichung (11) definierten gesamtwirtschaftlichen Preisniveau gleichgesetzt:

$$
M \cdot V=P \cdot A^{r} \cdot 34
$$

Bei der Modellauswertung wird außerdem eine konstante Umlaufgeschwindigkeit des Geldes unterstellt, so daß eine Erhöhung der nominalen Geldmenge eine $\mathrm{Zu}$ nahme der realen Absorption bewirkt. ${ }^{35}$ Bei einer Geldmengenkontraktion gilt entsprechend der umgekehrte Zusammenhang.

33 Siehe z.B. Schweickert (1993), S. 210, Schafer (1998), S. 133, und Wohlmann (1998), S. 56. Der Realkasseneffekt - der sogenannte Pigou-Effekt - als ein möglicher Einflußkanal wird dabei von einigen Autoren sogar bewußt vernachlässigt. Vgl. Schweickert (1993), S. 210, und Stippler (1998), S. 87.

Im Dependent-Economy-Modell stimmen reale Absorption und reales Volkseinkommen nur bei ausgeglichener Handels- und Dienstleistungsbilanz uberein. Diese Ungenauigkeit der Gleichung (12) gegenüber der üblichen Formulierung der Quantitătsgleichung wird zugunsten einer Formalisierung der Verbindung zwischen monetärem Sektor und realwirtschaftlichem Bereich in Kauf genommen. Siehe auch die Fußnote 41 in diesem Kapitel.

35 Im Unterabschnitt II.3.1.2. wurde erlăutert, daß sich die Umlaufgeschwindigkeit des Geldes im Laufe des Stabilisierungsprozesses verăndern kann. Dieser Aspekt wird hier vernachläs- 
Die Analyse der Wechselkurspolitik im Rahmen von Stabilisierungsprogrammen wird in den beiden folgenden Unterabschnitten anhand der zusammenfassenden Modelldarstellung im $A^{r}-W^{r}$-Diagramm vorgenommen. Weil die Verwendung der graphischen Darstellung jedoch nur Aussagen über die Veränderung realer Größen und (anhand des realen Wechselkurses) über die Preise in den jeweiligen Sektoren ermöglicht, wird bei den Erläuterungen der Auswirkungen einer Politikmaßnahme - die graphische Analyse ergänzend - auch auf die Gleichungen (11) und (12) Bezug genommen.

Das Ziel der wirtschaftspolitischen Entscheidungsträger ist die Erreichung eines gesamtwirtschaftlichen Gleichgewichts, wie es in Abbildung 1 durch den Punkt $P_{0}$ beschrieben wird. Die Wirtschaftspolitiker streben also einen realen Wechselkurs in Höhe von $W_{0}^{r}$ und eine reale Absorption in Höhe von $A_{0}^{r}$ an. Neben der Wechselkurspolitik steht ihnen dafür insbesondere die Geldpolitik zur Verfügung. Allerdings wird bei der Analyse zum Teil auch auf die unterstützende Wirkung entsprechender fiskalpolitischer Maßnahmen eingegangen. Bei der Modellauswertung steht im Vordergrund, welche Auswirkungen unterschiedliche Politikstrategien auf die gesamtwirtschaftliche Preisentwicklung haben, d.h. ob eine Stabilisierung des Preisniveaus gelingt.

\subsection{Modellauswertung}

Bei der Auswertung des Modells wird vereinfachend angenommen, daß die Preise der handelbaren Güter in ausländischer Währung konstant sind. Diese Annahme bleibt ohne inhaltliche Auswirkungen auf die Ergebnisse, erleichtert jedoch das Verständnis der verbalen Ausführungen. Des weiteren erfolgt eine Analyse der Auswirkungen stabilitätspolitischer Maßnahmen auf das Preisniveau. Dies stellt eine konsistente Vorgehensweise dar, weil bei der Modellformulierung ebenfalls mit Niveaugrößen und nicht mit Inflationsraten gearbeitet wurde.

Alternativ wäre aber auch eine Betrachtung von Änderungsraten möglich. Bei der Auswertung des Modells müßte für die Entwicklung der Preise internationaler Güter in Auslandswährung lediglich eine Inflationsrate von Null unterstellt werden. Anstatt ein bestimmtes Preisniveau anzustreben, würde die stabilitätspolitische Zielsetzung der Zentralbank dann darin bestehen, einen Anstieg des Preisniveaus zu verhindern. Das Preisstabilitätsziel der wirtschaftspolitischen Entscheidungsträger wäre in diesem Fall erreicht, wenn die inländische Preissteigerungsrate Null betrüge, wobei sich die gesamtwirtschaftliche Inflationsrate aus zwei

sigt, um auf eine relativ einfache und anschauliche Weise eine Verbindung zwischen dem monetăren Sektor und der realen Absorption herstellen zu können. Der Leser beachte, daß das Preisniveau bereits durch die Gleichung (11) bestimmt ist. 
Komponenten zusammensetzt: dem Preisanstieg nationaler und internationaler Güter. 36

\subsubsection{Stabilisierung bei festen Wechselkursen}

Bei einer Wechselkursfixierung sind die Preise der internationalen Güter auch in inländischer Währung konstant. Es folgt aus Gleichung (11), daß sich ein inländischer Preisanstieg nur durch höhere Preise der nationalen Güter ergeben kann. Wie im Kapitel II geschildert, ergab sich in den Transformationsländern durch die Preisliberalisierung und den Abbau des Geldüberhangs ein deutlicher Anstieg der Preise. Im folgenden wird davon ausgegangen, daß der nominale Wechselkurs bei der Einführung der Konvertibilität so stark abgewertet wird, daß die heimischen Produzenten zu den dann geltenden Preisen internationaler Güter in Inlandswährung wettbewerbsfähig sind und ihre Produkte auch im Ausland absetzen können. Allerdings ist die anfängliche Abwertung nicht so stark, daß sie den aus der Preisliberalisierung resultierenden Preisanstieg im Sektor der nationalen Güter dergestalt ausgleicht, daß sich bereits ein Relativpreis einstellt, der zu einem gesamtwirtschaftlichen Gleichgewicht führt. Die Preise nicht-handelbarer Güter verharren nach der Preisliberalisierung zunächst auf dem neuen hohen Niveau. Zwar ist der Markt für nationale Güter immer geräumt, aber die Preise sind in Relation zu den Preisen handelbarer Güter zu hoch, so daß die Allokation der Ressourcen verzerrt ist. Es werden zu viele Produktionsfaktoren im nationalen Sektor eingesetzt, weil der reale Wechselkurs zu niedrig ist. In Abbildung 2 bildet $P_{1}$ einen möglichen Ausgangspunkt, der eine Situation mit negativem Handels- und Dienstleistungsbilanzsaldo beschreibt. Eine solche Situation ist aufgrund der Beobachtung, daß die Bevölkerung in den Transformationsländern zu Reformbeginn westliche Waren vorgezogen hat, eine realistische Konstellation. ${ }^{37}$

Ist der nominale Wechselkurs fixiert, dann kann die erforderliche Anpassung des realen Wechselkurses nur durch eine Senkung der Preise nationaler Güter erfolgen. Dies geschieht über den folgenden Anpassungsprozeß. Das Defizit der Handelsund Dienstleistungsbilanz würde normalerweise eine Abwertung der Währung

36 Es wird hăufig implizit unterstellt, daß das Preisstabilitătsziel erreicht ist, wenn der Preisanstieg nationaler Güter dem Preisanstieg der handelbaren Güter in ausländischer Wăhrung entspricht. Siehe hierzu zum Beispiel die Fußnote 2 bei Schweickert et al. (1992), S. 6. In diesem Fall wird bereits eine positive Inflationsrate als Preisstabilität interpretiert. Es ist zusätzlich zu beachten, daß innerhalb des Modells nicht mit dem Erreichen der ausländischen Inflationsrate argumentiert werden kann, weil die Preisentwicklung der nicht-handelbaren Güter im Ausland unbekannt ist.

37 Siehe auch Schăfer (1994), S. 199, der den Ausgangspunkt für die Transformationsländer allerdings links von der $N N$-Kurve (aber auch rechts von $P_{0}$ ) markiert, weil er Unterbeschäftigung im nationalen Sektor unterstellt. 


\section{Abbildung 2: Stabilisierung bei festem Wechselkurs im Dependent-Economy-Modell}

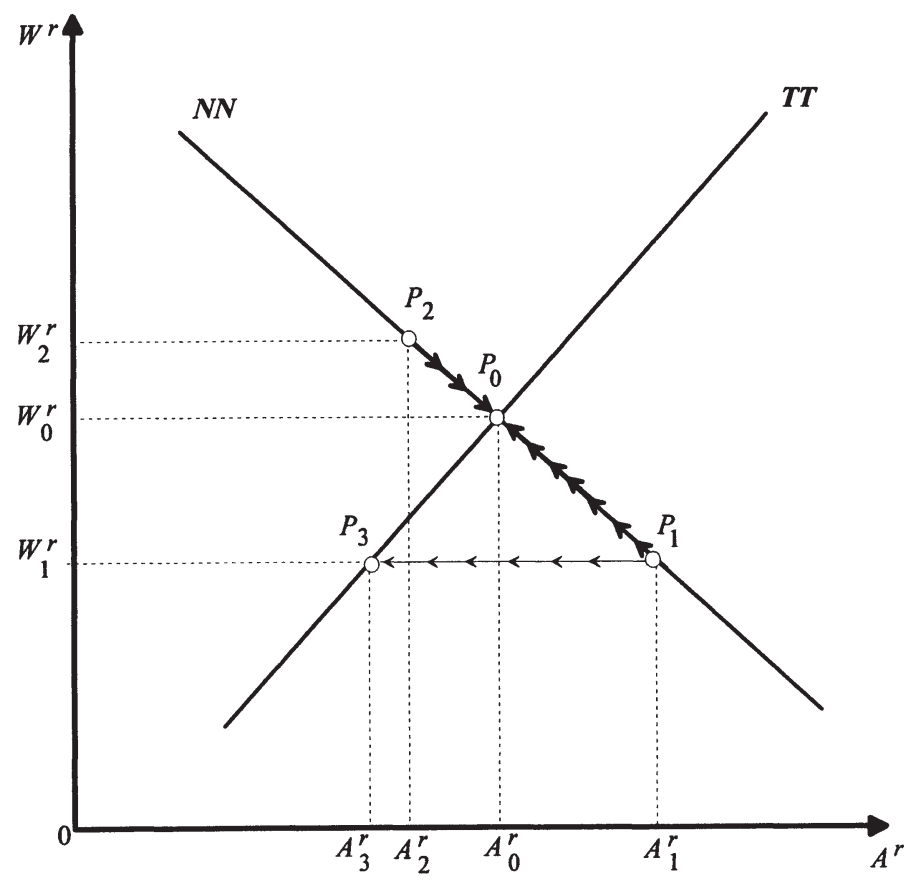

Quelle: Eigene Darstellung in Anlehnung an Schweickert (1993), S. 209.

bewirken, weil die Nachfrage nach Devisen das Angebot übersteigt. Da die Notenbank jedoch eine Festkurspolitik betreibt, interveniert sie am Devisenmarkt und verkauft Währungsreserven, um den Kurs zu stützen. Dies ist gleichbedeutend mit einer kontraktiven Geldpolitik, weil ohne Neutralisierungspolitik die monetäre Basis sinkt und somit auch die nominale Geldmenge zurückgeht. Wie aus Gleichung (12) hervorgeht, wird bei sinkender Geldmenge die reale Absorption eingeschränkt. Gleichzeitig muß der reale Wechselkurs ansteigen, um das Gleichgewicht auf dem Markt nicht-handelbarer Güter zu erhalten. Diese reale Abwertung kann nur durch einen Rückgang der Preise nationaler Güter erreicht werden, weil eine Anpassung der Preise internationaler Güter aufgrund der Wechselkursbindung ausgeschlossen ist. Wie aus Abbildung 2 ersichtlich, führt die Kombination aus einer Preissenkung nationaler Güter (die den realen Wechselkurs von $W_{1}^{r}$ auf $W_{0}^{r}$ erhöht) und einem Rückgang der realen Absorption von $A_{1}^{r}$ auf $A_{0}^{r}$ zum gesamt- 
wirtschaftlichen Gleichgewicht in $P_{0}$. Bei diesem Prozeß kann die Fiskalpolitik flankierend eingesetzt werden, indem die geldpolitisch induzierte Absorptionseinschränkung durch eine Verringerung der Staatsausgaben verstärkt wird. ${ }^{38}$ Im Festkurssystem findet aufgrund der interventionsbedingten Einschränkung der Geldmenge - unter Umständen ergänzt durch eine kontraktive Fiskalpolitik - bei sinkenden Preisen nicht-handelbarer Güter eine Bewegung entlang der $N N$-Kurve hin zum Gleichgewichtspunkt $P_{0}$ statt. Bei konstanten Preisen handelbarer Güter in inländischer Währung bewirken sinkende Preise nationaler Güter bei festem Wechselkurs eine Stabilisierung des gesamtwirtschaftlichen Preisniveaus. ${ }^{39}$

Wie bei der Diskussion der Vor- und Nachteile der Wechselkursregime im vorangegangenen Kapitel dargestellt, ist die Festlegung des angemessenen Wechselkursniveaus bei der Wechselkursbindung ein besonders schwer zu lösendes Problem. Entscheiden sich die Wirtschaftspolitiker dafür, den nominalen Wechselkurs stärker abzuwerten, um die Gefahr einer realen Überbewertung zu vermeiden, dann kann sich zum Beispiel eine Situation wie im Punkt $P_{2}$ der Abbildung 2 als möglicher Ausgangspunkt einstellen. Bei zunächst noch unveränderten Preisen im nationalen Sektor ergibt sich durch die starke nominale Abwertung ein relatives Preisverhältnis in Höhe von $W_{2}^{r}$. Die Produktion handelbarer Güter ist aufgrund des hohen Preises in inländischer Währung sehr rentabel, und es werden Überschüsse in der Handels- und Dienstleistungsbilanz erwirtschaftet. Bei fixiertem nominalem Wechselkurs muß die Zentralbank das Devisenüberschußangebot ankaufen, um eine Senkung des nominalen Wechselkurses zu verhindern. Die Währungsreserven steigen an, und die monetäre Basis sowie die Geldmenge werden ausgeweitet. Es kommt im Sektor der nicht-handelbaren Güter zu Preissteigerungen, die eine Verschiebung der Ressourcen in die Produktion dieser Güter anregt. Die Preissteigerung hält so lange an, bis der reale Wechselkurs auf das Niveau $W_{0}^{r}$ gefallen ist und sich wieder gesamtwirtschaftliches Gleichgewicht einstellt. In diesem Fall trägt der feste Wechselkurs nicht zu einer Stabilisierung des gesamtwirtschaftlichen Preisniveaus bei, sondern wirkt aufgrund von zwei Effekten destabilisierend. Erstens führt die starke nominale Abwertung in der Ausgangslage zu einem Anstieg der Preise handelbarer Güter in Inlandswährung. Zweitens zieht sie aufgrund einer entstehenden Überschußnachfrage einen Anstieg der Preise nicht-handelbarer Güter nach sich, der zwar den realen Wechselkurs auf das gleichgewichtige Niveau senkt, aber das gesamtwirtschaftliche Preisniveau weiter erhöht.

38 Sowohl der staatliche Konsum als auch die staatlichen Investitionen sind Bestandteile der realen Absorption. Eine Senkung der Staatsausgaben ist also gleichbedeutend mit einer Absorptionseinschränkung.

$39 \mathrm{Da}$ in den Ausfuhrungen Niveaugrößen verwendet werden, fuhrt der feste Wechselkurs zu einer Senkung des inländischen Preisniveaus. Erfolgt die Betrachtung in Änderungsraten, bewirkt die Wechselkursbindung eine Reduzierung der inlandischen Inflation auf die Inflationsrate der handelbaren Guter in Auslandswährung, die hier Null beträgt. 
$\mathrm{Da}$ es in der Literatur weit verbreitet ist, im Rahmen des Anpassungsprozesses Preisstarrheiten zu unterstellen, ${ }^{40}$ soll auch hier kurz darauf eingegangen werden, welche Probleme sich einstellen, wenn die Preisflexibilität nicht gewährleistet ist, und es dadurch zu Unterbeschäftigung kommt. ${ }^{41}$ Wenn die Preise nicht flexibel sind und zunächst auf ihrem alten Niveau verharren, kann die Bewegung zum Abbau des negativen Außenbeitrags - ausgehend von $P_{1}$ - nur durch eine Einschränkung der Absorption geschehen, d.h. bildlich ausgedrückt in horizontaler Richtung. Bei zunächst noch unverändertem inländischem Preisniveau führt die interventionsbedingte Geldmengenkontraktion zu einer entsprechend stärkeren Einschränkung der realen Absorption, und zwar von $A_{1}^{r}$ über $A_{0}^{r}$ bis hin zu $A_{3}^{r}$. Die Verringerung der Konsum- und Investitionsausgaben bewirkt einen Rückgang der inländischen Nachfrage nach handelbaren Gütern, und das Handels- und Dienstleistungsbilanzdefizit verringert sich, bis im Punkt $P_{3}$ externes Gleichgewicht erreicht wird. Diese Situation ist jedoch mit einem starken Überschußangebot an nationalen Produkten verbunden, führt also zu einer Unterauslastung der Kapazitäten und Arbeitslosigkeit in diesem Sektor. ${ }^{42}$ Um das Ungleichgewicht zu beseitigen, müssen die Preise nicht-handelbarer Güter letztlich sinken. Die Anpassung erfolgt bei ausgeglichener Handels- und Dienstleistungsbilanz entlang der TTKurve zum Punkt $P_{0}$, in dem bei gesunkenem Preisniveau internes Gleichgewicht erreicht wird. Es wird deutlich, daß bei einem festen Wechselkurs - ausgehend von einer Situation wie $P_{1}$ - auf jeden Fall eine Korrektur der Preise nationaler Güter nach unten erfolgen muß, sonst kann der reale Wechselkurs $W_{0}^{r}$ und damit ein gesamtwirtschaftliches Gleichgewicht nicht erreicht werden.

\subsubsection{Stabilisierung bei flexiblen Wechselkursen}

Ausgangspunkt der Betrachtung einer Stabilisierungspolitik bei flexiblen Wechselkursen ist ebenfalls eine Situation, wie sie durch den Punkt $P_{1}$ in Abbildung 3 beschrieben wird. Es wird weiterhin unterstellt, daß die Preise der internationalen Güter in ausländischer Währung konstant sind. Das Defizit der Handels- und

40 Siehe zum Beispiel Pieper (1995), S. 109, Schafer (1994), S. 199, und Schweickert (1993), S. 210.

41 Dies erfordert eigentlich eine Neuformulierung der Angebotsseite. Wie bereits erwăhnt, geschieht dies in der Literatur nicht. Auch an dieser Stelle wird darauf verzichtet, weil es nicht das Anliegen der vorliegenden Arbeit ist, das Dependent-Economy-Modell auszubauen. In diesem Abschnitt soll lediglich das Modell dargestellt werden, das sehr hăufig zur Diskussion der Wechselkurspolitik im Transformationsprozeß herangezogen wurde, bevor im Abschnitt III.3. ein neuer Modellansatz vorgestellt wird.

42 Wie anhand der Gleichung (10) gezeigt, ist eine solche Kombination bei der hier vorgestellten Modellformulierung nicht möglich. Wenn in der Literatur im Rahmen des Anpassungsprozesses Preisrigidităten unterstellt werden, bedarf es also furr eine konsistente Argumentation einer entsprechenden modifizierten Modelldarstellung. Siehe hierzu auch die vorhergehende Fußnote. 


\section{lung 3: Stabilisierung bei flexiblen Wechselkursen im Dependent-Economy-Modell}

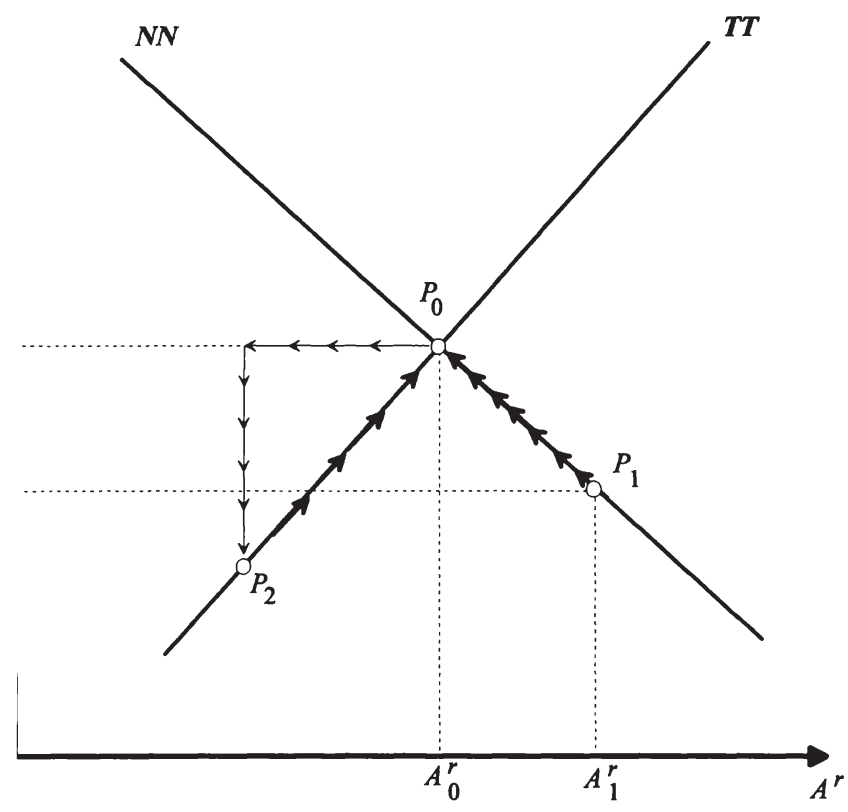

Eigene Darstellung in Anlehnung an Schăfer (1998), S. 135.

tleistungsbilanz führt zu einer Überschußnachfrage nach Devisen, die den ıalen Wechselkurs ansteigen läßt. Solange keine Aussagen über die Reaktischwindigkeiten der Variablen getroffen werden, kann die Entwicklung des I Wechselkurses vom Punkt $P_{1}$ zum Gleichgewicht in $P_{0}$ prinzipiell auf zwei $\mathrm{n}$ erfolgen: entweder allein aufgrund der nominalen Abwertung bei konstan'eisen nationaler Güter oder aufgrund einer Kombination aus einer nominalen rtung und einer Preissenkung. Letzteres setzt jedoch voraus, daß die Preise tionalen Sektor extrem schnell reagieren. Unterstellt man realistischerweise, ie Preise nicht-handelbarer Güter - anders als der Wechselkurs als Finanzvariable - nicht sofort reagieren, fällt der Anstieg des nominalen Wechsels genau so stark aus, daß der reale Gleichgewichtskurs $W_{0}^{r}$ ohne eine Ändeder Preise nicht-handelbarer Güter erreicht wird. Obwohl im nationalen Seke Preise konstant bleiben, erhöht sich das gesamtwirtschaftliche Preisniveau, 
weil durch die nominale Abwertung die Preise internationaler Güter in heimischer Währung ansteigen.

Das Modell veranschaulicht einerseits den Vorteil eines flexiblen Wechselkurssystems, automatisch den neuen Gleichgewichtswechselkurs zu erreichen. Andererseits ist aber zu beachten, daß bei verzögerter Preisreaktion im nationalen Sektor der Anstieg des nominalen Wechselkurses einen Preisanstieg internationaler Güter auslöst. Als wichtiges Ergebnis im Hinblick auf die Stabilisierungsbemühungen ist deshalb festzuhalten, daß das flexible Wechselkurssystem zunächst zu einer Erhöhung des inländischen Preisniveaus führt.

Eine Senkung des inländischen Preisniveaus erfordert bei flexiblen Wechselkursen - genauso wie im Festkurssystem - eine kontraktive Geld- oder Fiskalpolitik. Werden zum Beispiel im Punkt $P_{0}$ die Geldmenge und/oder die Staatsausgaben gesenkt, und die Preise nationaler Güter bleiben zunächst unverändert, dann geht die reale Absorption zurück. ${ }^{43}$ Es stellt sich ein positiver Außenbeitrag ein, der ein Devisenüberschußangebot hervorruft und zu einer nominalen Aufwertung führt. Es wird zum Beispiel der Punkt $P_{2}$ in Abbildung 3 realisiert. Bei wieder ausgeglichener Handels- und Dienstleistungsbilanz und simultanem Überschußangebot im nationalen Sektor wird der gleichgewichtige reale Wechselkurs $W_{0}^{r}$ dadurch erreicht, daß die Preise im nationalen Sektor sinken. Die Senkung des gesamtwirtschaftlichen Preisniveaus wird also über zwei Kanäle erreicht: zum einen durch den Rückgang der Preise internationaler Güter aufgrund der nominalen Aufwertung, zum anderen durch die Senkung der Preise nationaler Güter. Auch bei flexiblen Wechselkursen ist eine Stabilisierung des inländischen Preisniveaus möglich, wobei eine stärkere Variabilität des Preisniveaus zu beobachten ist, wenn man unterstellt, daß der Wechselkurs schneller als die anderen Variablen des Modells reagiert. Es kommt zuerst zu einem abwertungsbedingten Anstieg, bevor das Preisniveau durch die nominale Aufwertung und die Senkung der Preise nationaler Güter wieder fällt. Dabei ist zu berücksichtigen, daß die Senkung über das ursprüngliche $\mathrm{Ma} ß$ hinaus erfolgen muß, wenn das Ausgangsniveau als zu hoch angesehen und deshalb ein Stabilisierungsprogramm eingeleitet wurde.

\subsection{Zusammenfassung und Übertragbarkeit der Ergebnisse}

Der Vergleich der Stabilisierungsbemühungen bei festen und flexiblen Wechselkursen im Rahmen des Dependent-Economy-Modells läßt einige Schlußfolgerun-

43 Die Absorptionseinschrankung ergibt sich im Fall einer kontraktiven Fiskalpolitik unmittelbar, weil die Staatsausgaben Bestandteil der Absorption sind. Im Fall einer restriktiven Geldpolitik ergibt sich der Ruckgang der realen Absorption bei zunăchst noch unverănderten Preisen aus Gleichung (12). 
gen zu, die im Hinblick auf die Wahl des Wechselkursregimes von Bedeutung sind. Ein wichtiges Ergebnis der Analyse ist, daß es nicht in erster Linie auf ein bestimmtes Wechselkursregime ankommt, sondern darauf, daß tatsächlich eine Anpassung der Preise im nationalen Sektor erfolgt. Allerdings verhindert die Modellannahme vollständiger Preisflexibilität eine weitergehende Analyse. Wird ergänzend unterstellt, daß die Preise im Sektor der nicht-handelbaren Güter nicht sofort reagieren, während sich der Wechselkurs unverzüglich anpaßt, dürfte es sich hierbei zwar um eine realistische Annahme handeln, allerdings geht sie über das Modell hinaus, das von Lohn- und Preisflexibilität ausgeht.

Des weiteren wird deutlich, daß nicht ein fester oder flexibler Wechselkurs die Anpassung möglich macht, sondern daß unter beiden Systemen eine restriktive Stabilisierungspolitik erforderlich ist. Unter welchem Regime die Stabilisierung eher gelingt, muß im Rahmen des Modells offenbleiben. Da die Preisreaktionen sofort erfolgen, müssen beide Strategien gleich bewertet werden. Wenn einige Autoren argumentieren, daß ein flexibler Wechselkurs im Rahmen des Stabilisierungsprogramms die glaubwürdigere Alternative ist, dann basiert dies wiederum auf der Annahme, daß die Preise der nicht-handelbaren Güter nur verzögert reagieren, was jedoch nicht der Modellformulierung entspricht. Außerdem hat die Auswertung für ein flexibles Wechselkurssystem gezeigt, daß mit diesem Regime die Gefahr stärkerer Schwankungen des Preisniveaus verbunden ist.

Schließlich hebt die Auswertung des Modells noch einen wichtigen Aspekt hervor, der bereits bei der Diskussion der Vor- und Nachteile der Wechselkurssysteme angesprochen wurde. Mit einem festen Wechselkurs ist die Gefahr verbunden, daß sich außenwirtschaftliche Ungleichgewichte ergeben. Neben der graphischen Darstellung zeigt sich dies vor allem sehr anschaulich an Gleichung (10). Wenn die Absorption über dem Volkseinkommen liegt, stellt sich ein negativer Saldo der Handels- und Dienstleistungsbilanz ein. Dieses Ergebnis ist nicht abhängig von der Annahme verzögerter Preisreaktionen, sondern ergibt sich aus der volkswirtschaftlichen Gesamtrechnung einer offenen Volkswirtschaft. Bei flexiblen Wechselkursen hingegen führt die Wechselkursreaktion automatisch zu einem außenwirtschaftlichen Gleichgewicht.

Allerdings sind mit der Anwendung des Dependent-Economy-Modells für die Betrachtung der Wechselkurspolitik im Transformationsprozeß auch einige Probleme verbunden. Problematisch ist die Tatsache, daß strukturelle Veränderungen zu Verschiebungen der $T T$ - und der $N N$-Kurven führen. Gerade der Transformationsprozeß ist von diesen strukturellen Veränderungen geprägt. Ändern die beiden Gleichgewichtskurven ihre Lage, ist es schwierig, innerhalb des $A^{r}-W^{r}$ Diagramms zu argumentieren. Solange sich nur eine Kurve verschiebt, bleiben qualitative Aussagen möglich, weil die Richtung der Änderung eindeutig ist. Als 
Beispiel seien hier Kapitalströme genannt. Ein Zufluß an ausländischem Kapital verschiebt zum Beispiel die TT-Kurve nach rechts, so daß sich ein neues Gleichgewicht bei niedrigerem realen Wechselkurs und höherer realer Absorption einstellt. ${ }^{4}$ Eine Bewertung dieser Entwicklung ist aber bereits davon abhängig, ob die Kapitalzuströme kurzfristiger Natur sind, also nach einer gewissen Zeit zum Beispiel aufgrund veränderter Ertragseinschätzungen der Investoren das Land wieder verlassen, oder ob es sich um dauerhafte ausländische Direktinvestitionen handelt. Wohlmann (1998) zeigt außerdem, daß die Art der Verwendung des zuflieBenden Kapitals entscheidende Auswirkungen auf die Bewertung der Verschiebung hat. So ist der Anpassungsbedarf bei sich umkehrenden Kapitalströmen insbesondere davon abhängig, ob die Mittel im Sektor der handelbaren oder nichthandelbaren Güter investiert wurden. 45

Verschieben sich bei bestimmten Änderungen beide Kurven, sind qualitative Aussagen nicht mehr möglich. Auch dies soll an einem Beispiel illustriert werden. Eine Verbesserung der Produktivität verschiebt sowohl die TT-Kurve als auch die $N N$-Kurve nach rechts. ${ }^{46}$ Während mit dem neuen Gleichgewicht eindeutig eine höhere reale Absorption vereinbar ist, läßt sich keine Aussage darüber machen, ob der reale Wechselkurs steigt oder fällt. Gerade Produktivitätszuwächse sind aber ein typisches Kennzeichen der Transformationsländer; und der reale Wechselkurs ist die entscheidende Variable, die Auskunft über den Preisanpassungsbedarf gibt. Es dürfte zwar kaum möglich sein, den Transformationsprozeß in jeder Hinsicht angemessen zu modellieren. ${ }^{47}$ Problematisch erscheint es jedoch, ein Modell für die Analyse zu verwenden, das auf den Annahmen vollkommen flexibler Löhne und Preise basiert und Vollbeschäftigung unterstellt. Unter Berücksichtigung der Ausführungen im Kapitel II ist nicht damit zu rechnen, daß diese Voraussetzungen in den Transformationsökonomien erfüllt sind.

Schließlich wirkt sich noch besonders nachteilig aus, daß das Modell ursprünglich dazu diente, realwirtschaftliche Probleme zu analysieren. Das Anliegen der australischen Wissenschaftler, von denen das Modell entwickelt wurde, bestand vor allem darin, die Voraussetzungen für Vollbeschäftigung und außenwirtschaftliches Gleichgewicht zu untersuchen und den Zusammenhang zwischen einem zu hohen inländischen Ausgabenniveau und Zahlungsbilanzproblemen aufzuzeigen. ${ }^{48}$ Durch diese Konzentration auf real- und außenwirtschaftliche Fragestellungen fehlen in dem Modell Formulierungen von Preiszusammenhängen, die für die Analyse einer Stabilisierungspolitik besonders wichtig sind. Auch die zusätzlich eingeführten

Vgl. Swan (1963), S. 388.

Siehe Wohlmann (1998), S. $57 \mathrm{ff}$.

Vgl. Swan (1963), S. 388 f.

Vgl. Kloten (1989), S. 100.

Vgl. Salter (1959), S. 226, und Swan (1963), S. 385. 
Gleichungen (11) und (12), die überhaupt erst eine explizite Berücksichtigung von gesamtwirtschaftlichen Preisänderungen und von geldpolitischen Einflüssen auf die reale Absorption erlauben, können diesen Mangel nur bedingt beheben.

Zusammenfassend läßt sich sagen, daß das Dependent-Economy-Modell zwar in der Lage ist, auf Probleme bei der Wahl des Wechselkurssystems im Transformationsprozeß hinzuweisen und einige Anforderungen an die Stabilisierungspolitik $\mathrm{zu}$ formulieren, allerdings stellt es auf eine Volkswirtschaft ab, die sehr viele Merkmale aufweist, die auf Reformländer nicht zutreffen. Im folgenden Abschnitt wird deshalb ein einfaches Partialmodell entwickelt, das darauf verzichtet, die Angebotsseite der Volkswirtschaft abzubilden, weil eben dies für Transformationsländer kaum gelingen wird. Statt dessen werden die Preisentwicklungen ausführlich modelliert, die eine besondere Rolle bei der Betrachtung der Stabilisierungspolitik spielen.

\section{Ein Partialmodell zur Wahl des Wechselkurs- systems}

Das besondere Problem einer Preisstabilisierung mit Hilfe des Wechselkurses als nominalem Anker, das sich auch bei der Analyse im vorangegangenen Abschnitt zeigte, ist ein möglicher Konflikt mit der Aufrechterhaltung der internationalen Wettbewerbsfähigkeit. Während das außenwirtschaftliche Gleichgewicht im Dependent-Economy-Modell durch die TT-Kurve sehr anschaulich modelliert ist, wird das Ziel der Preisstabilität nur durch eine sehr allgemeine Formulierung des Preisniveaus in Form der Gleichung (11) einbezogen. Im Modell dieses Abschnitts werden hingegen beide Ziele explizit in einer wirtschaftspolitischen Zielfunktion berücksichtigt. Eine Parallele zum Dependent-Economy-Modell besteht darin, daß ebenfalls eine Zwei-Sektoren-Wirtschaft mit nationalen und internationalen Gütern betrachtet und der Fall eines kleinen Landes unterstellt wird. Allerdings wird die Annahme der vollkommenen Preis- und Lohnflexibilität aufgegeben. Es bestehen Preisstarrheiten aufgrund von Lohnkontrakten und Preissetzungen im privaten Sektor, die für bestimmte Zeiträume erfolgen, und zwar bevor die Änderung des nominalen Wechselkurses beobachtet werden kann. Im Unterabschnitt 3.1. wird zunächst ausführlich die Modellstruktur erläutert, bevor in den Unterabschnitten 3.2. und 3.3. die Auswertung des Modells erfolgt. Dabei steht - wie im vorangegangenen Abschnitt - der Vergleich zwischen einer Stabilisierungspolitik mit festen bzw. flexiblen Wechselkursen im Mittelpunkt der Betrachtung. Die Ergebnisse werden im Unterabschnitt 3.4. zusammengefaßt, wobei zum Teil auch schon analysiert wird, inwiefern die Modellergebnisse auf die mittel- und osteuropäischen Transformationsländer übertragbar sind. Dieser Frage wird dann umfassender im Kapitel IV nachgegangen. 


\subsection{Modellstruktur}

\subsubsection{Die wirtschaftspolitische Zielfunktion}

Zentraler Bestandteil des Modells, das in diesem Abschnitt ausgewertet wird, ist eine wirtschaftspolitische Zielfunktion. Sie soll deshalb zunächst ausführlich vorgestellt werden, wobei auch auf die Unterschiede zu zwei ähnlichen Zielfunktionen eingegangen wird, die in der Literatur verwendet werden. Die wirtschaftspolitischen Entscheidungsträger verfolgen zwei Ziele. Einerseits streben die Verantwortlichen Preisstabilität an. Andererseits soll eine reale Über- oder Unterbewertung des Wechselkurses vermieden werden. Dabei wird im folgenden nicht zwischen den verschiedenen wirtschaftspolitischen Entscheidungsträgern differenziert. Es wird vereinfachend unterstellt, daß es sich bei der wirtschaftspolitischen Instanz um die Zentralbank handelt. ${ }^{49}$ Die zu minimierende Verlustfunktion lautet

$$
K=\frac{1}{2}(\pi-\hat{\pi})^{2}+\frac{1}{2} \alpha\left(w^{r}-\hat{w}^{r}\right)^{2}, \quad \alpha>0 .
$$

Der erste Summand auf der rechten Seite von Gleichung (1) verdeutlicht, daß die wirtschaftspolitischen Entscheidungsträger bestimmte Zielvorstellungen über die Preisentwicklung haben. Mit $\pi$ wird die (realisierte) inländische Inflationsrate bezeichnet, während $\hat{\pi}$ den Inflationszielwert der Zentralbank angibt. Da auch in den mittel- und osteuropäischen Transformationsländern die Zentralbanken in der Regel dem Ziel der Preisstabilität verpflichtet sind, kann realistischerweise unterstellt werden, daß eine Inflation in Höhe von Null angestrebt wird. Allerdings ließen sich auch positive Werte für $\hat{\pi}$ begründen. Zum einen kann argumentiert werden, daß für Transformationsländer eine Inflationsrate in Höhe von Null übermäBig ehrgeizig ist, weil wichtige Handelspartner dieser Länder - z.B. die Mitgliedsländer der EU - ebenfalls positive Inflationsraten aufweisen. Es wäre deshalb denkbar, daß die Zielinflationsrate dem (relativ geringen) Preisanstieg in den wichtigsten westlichen Partnerländern im Außenhandel entspricht. Zum anderen könnte ein Zielwert oberhalb von $\hat{\pi}=0$ auch damit begründet werden, daß positive Inflationsraten Geldschöpfungsgewinne ermöglichen. 50

Der zweite Summand auf der rechten Seite von Gleichung (1) beschreibt den Wunsch der Wirtschaftspolitiker, die tatsächliche reale Wechselkursänderung $w^{r}$ möglichst nah an einem Zielwert für die reale Wechselkursentwicklung - hier mit $\hat{w}^{r}$ bezeichnet - zu halten. Entscheidend ist, daß die Formulierung in Änderungsraten erfolgt. Die Wirtschaftspolitiker streben nur dann ein bestimmtes reales

49 Fur die im Laufe der Untersuchung analysierte Entscheidung uber das Wechselkurssystem ist in der Regel eine Abstimmung zwischen der Zentralbank und der Regierung erforderlich. In dieser Hinsicht kann die Verlustfunktion als zusammengefaßte Zielsetzung der Wirtschaftspolitiker aufgefaßt werden, die sich uber die Wechselkurspolitik abstimmen.

Vgl. Jarchow (1998a), S. 279. 
Wechselkursniveau an, wenn $\hat{w}^{r}=0$ gilt, d.h. ein konstanter realer Wechselkurs gewünscht wird. Auch für den Zielwert $\hat{w}^{r}$ ist wieder vorstellbar, daß Zielgrößen als optimal angesehen werden, die von Null abweichen. Wenn sich zum Beispiel das Niveau des realen Gleichgewichtskurses im Zeitablauf ändert, ist anzunehmen, daß die Zentralbank eine entsprechende reale Wechselkursänderung anstrebt. 51

Während das Preisstabilitätsziel in der wirtschaftspolitischen Verlustfunktion eine übliche Formulierung darstellt, gibt es bisher kaum Arbeiten, die als zweite Komponente ein reales Wechselkursziel berücksichtigen. ${ }^{52}$ Diese Zielsetzung wird deshalb nachfolgend detailliert erläutert, wobei gezeigt wird, daß mit ihr indirekt auch Vorstellungen über das Sozialprodukt und das Beschäftigungsniveau berücksichtigt werden. Der zweite Term der Gleichung (1) spiegelt wider, daß sowohl mit einer realen Über- als auch mit einer realen Unterbewertung der heimischen Währung Probleme verbunden sind, wobei jeweils export- und importseitige Effekte beachtet werden müssen. Eine überbewertete Währung bewirkt eine Veränderung des relativen Preisverhältnisses zugunsten ausländischer Konkurrenten. Deren Produkte werden in Relation zu den heimischen Gütern billiger, so daß die inländischen Wirtschaftssubjekte die Importe steigern. Isoliert betrachtet, stellt die Verbilligung von Importgütern einen Vorteil für die Inländer dar. Allerdings beeinträchtigt die reale Überbewertung die internationale Wettbewerbsfähigkeit der inländischen Volkswirtschaft. Aufgrund der billigeren Auslandsprodukte sinken die Exporte und das Angebot inländischer Güter, die mit Importen konkurrieren. Sowohl die steigenden Importe als auch die zurückgehenden Exporte bewirken somit neben einer Abnahme des Handelsbilanzsaldos einen Rückgang des Sozialprodukts mit negativen Auswirkungen auf die Beschäftigungssituation im Inland. Analog sind auch bei einer realen Unterbewertung die Veränderungen auf der Import- und der Exportseite zu beachten. Zwar regt sie die Exporttätigkeit an, was zu mehr Beschäftigung in diesem Sektor führt und das Sozialprodukt erhöht. Die hiermit verbundene Konjunkturbelebung führt aber tendenziell zu einem Preisauftrieb. Insbesondere ist mit Preissteigerungen auch deshalb zu rechnen, weil auf der Importseite nicht nur die Güter der gesamtwirtschaftlichen Endnachfrage relativ teurer werden, sondern auch die importierten Vorprodukte. Außerdem erweist sich der Rückgang der mengenmäßigen Importe für die Transformationsländer insofern als nachteilig, weil diese mit Güterimporten ausländisches Know-how importieren können. Dieses Know-how trägt zu einer Produktivitätssteigerung bei und verbes-

51 In welchem Ausmaß sich der reale Gleichgewichtskurs andert, ist abhăngig vom zugrundegelegten Wechselkursmodell. Zu den Problemen bei der Bestimmung eines Gleichgewichtswechselkurses siehe auch die Ausführungen im Unterabschnitt II.3.2.1. Einen Überblick über verschiedene Wechselkursmodelle in Abhängigkeit vom Zeithorizont der Betrachtung gibt Visser (1995), S. 1 ff.

52 Zwei Ausnahmen sind Agénor (1994), S. 3 ff., und Edwards (1998), S. 684 ff. Auf die Unterschiede zu diesen Arbeiten wird im folgenden năher eingegangen. 
sert die Aussichten auf ein höheres Wirtschaftswachstum sowie ein zunehmendes Beschäftigungsniveau. Sowohl eine reale Über- als auch eine reale Unterbewertung haben also einen negativen Einfluß auf die wirtschaftliche Entwicklung, wobei nicht entschieden werden kann, ob die jeweiligen positiven Effekte ausreichen, um die negativen Auswirkungen zu kompensieren. Aus diesem Grund wird der zweite Term in der Verlustfunktion quadriert, was eine symmetrische Bewertung einer zu starken oder zu schwachen Änderung des realen Wechselkurses im Vergleich zum Zielwert impliziert. ${ }^{53}$ In diesem Punkt unterscheidet sich die Zielfunktion vom Modell von Agénor (1994). Agénor unterstellt einen linearen Zusammenhang und vernachlässigt damit die Probleme, die mit einer starken realen $\mathrm{Ab}$ wertung verbunden sind. ${ }^{54}$ In seinem Modell führt eine reale Abwertung über den Zielwert hinaus zu negativen Werten für denjenigen Teil der wirtschaftspolitischen Zielfunktion, der das reale Wechselkursziel beschreibt. Dieser negative Wert ermöglicht es, Zielverfehlungen beim Preisstabilitätsziel zu kompensieren und damit insgesamt niedrigere Verluste zu erreichen. Diese Möglichkeit wird durch die hier gewählte Form vermieden.

Edwards (1998) verwendet eine wirtschaftspolitische Zielfunktion, die der hier gewählten Formulierung sehr ähnlich ist und in der die Abweichung vom realen Wechselkursziel ebenfalls quadriert wird. Allerdings geht bei ihm die Preisentwicklung in Form der Inflationsrate in die Zielfunktion ein, während bei der Abweichung des realen Wechselkurses vom Zielwert die Wechselkursniveaus miteinander verglichen werden. Eine solche Formulierung ist zwar ökonomisch plausibel, erschwert jedoch erheblich die mathematische Handhabung. ${ }^{55}$ Aus diesem Grund werden in der Gleichung (1) das Preisstabilitätsziel und das Wechselkursziel in Änderungsraten erfaßt. 56

Das von der Zentralbank zur Erreichung ihrer Ziele benutzte wirtschaftspolitische Instrument ist der nominale Wechselkurs. Bei einer Wechselkursfixierung muß die Zentralbank, um den Wechselkurs konstant zu halten, entweder zugunsten der heimischen Währung oder zugunsten der ausländischen Währung intervenieren,

53 Die quadratische Formulierung des realen Wechselkursziels kann auch mit politðkonomischen Überlegungen begrundet werden. Unterstellt man, daß die wirtschaftspolitischen Entscheidungsträger von export- und importabhängigen Lobbygruppen beeinflußt werden, die ihre Aktivităten entsprechend erhð̌hen, wenn deutliche Unter- oder Überbewertungen der Wăhrung eintreten, dann ist ebenfalls anzunehmen, daß beide Entwicklungen vermieden werden sollen.

54 Siehe Agénor (1994), S. 3.

55 So erfolgt bei Edwards (1998), S. 686 ff., auch keine allgemeine Modellauswertung, sondern nur eine Betrachtung von zwei Spezialfallen.

56 Der Vollstăndigkeit halber sei darauf hingewiesen, daß Frankel (1995), S. 63 ff., ein Modell verwendet, in dem - neben dem Preisniveau und dem Sozialprodukt - der nominale Wechselkurs in der wirtschaftspolitischen Zielfunktion berucksichtigt wird. 
wenn sich Angebot und Nachfrage auf dem Devisenmarkt nicht ausgleichen. Auch in einem System flexibler Wechselkurse kann die Zentralbank ein bestimmtes nominales Wechselkursniveau über Interventionen am Devisenmarkt erreichen, wenn als Wechselkursregime ein Managed Floating unterstellt wird. Strebt sie eine nominale Abwertung an, kauft die Zentralbank Devisen gegen Hergabe heimischer Währung. Die erhöhte Devisennachfrage läßt den nominalen Wechselkurs so lange ansteigen, bis die Zentralbank ihr Wechselkursziel erreicht. Im Hinblick auf die Geldmengenentwicklung wird unterstellt, daß die Notenbank die Interventionen nicht neutralisiert, so daß sich die inländische Geldmenge ausweitet und das Preisniveau im Inland steigt. ${ }^{57}$ Möchte die Zentralbank hingegen eine nominale Aufwertung erreichen, gelten die entsprechend umgekehrten Zusammenhänge. Dabei ist allerdings zu berücksichtigen, daß der Mechanismus in diesem Fall ausreichende Währungsreserven erfordert, weil die Zentralbank am Devisenmarkt ausländische Währung anbieten muß. Einer solchen Beschränkung unterliegt sie bei einer angestrebten Erhöhung des nominalen Wechselkursniveaus nicht, weil sie die für die Interventionen erforderliche heimische Währung selbst schaffen kann.

Nachdem die beiden Zielgrößen und das Instrumentarium der Zentralbank ausführlich erläutert wurden, sei noch darauf hingewiesen, daß der Parameter $\alpha$ in Gleichung (1) die Gewichtung des realen Wechselkursziels in der wirtschaftspolitischen Zielsetzung reflektiert. Je größer $\alpha$ ist, um so stärker gewichtet die Zentralbank das reale Wechselkursziel in der Zielfunktion. Umgekehrt gilt für kleinere Werte von $\alpha$, daß die Zentralbank das Ziel der Preisstabilität stärker beachtet. Im Extremfall, in dem $\alpha$ den Wert Null annimmt, wird ausschließlich das Ziel der Preisstabilität verfolgt. Dieser Fall ist hier ausgeschlossen, kann aber als Sonderfall für Vergleichszwecke herangezogen werden. ${ }^{58}$ Das Gleiche gilt für den Fall, in dem die Wirtschaftspolitiker ausschließlich das Ziel verfolgen, eine reale Überoder Unterbewertung der heimischen Währung zu verhindern. In diesem zweiten Extremfall entfiele der erste Summand auf der rechten Seite von Gleichung (1).

\subsubsection{Weitere Modellgleichungen}

Nachdem die wirtschaftspolitische Zielfunktion dargestellt und die Formulierung ökonomisch begründet wurde, werden in diesem Unterabschnitt die weiteren Bestandteile des Modells erläutert. Dabei wird zunächst eine Definition für die gesamtwirtschaftliche Inflationsrate gegeben. Die inländische Preissteigerung $\pi$ ist definiert als

57 Im Modell wird der preissteigernde Effekt einer nominalen Wechselkurserhöhung in der Definition fur die gesamtwirtschaftliche Preisniveauanderung berücksichtigt, die jedoch erst in Form der Gleichung (2) im Unterabschnitt 3.1.2. eingefuhrt wird.

58 Auf die Bedeutung und die Ergebnisse dieses Spezialfalls wird im Unterabschnitt III.3.4. eingegangen. 


$$
\pi=\mu \pi_{N}+(1-\mu) \pi_{T}, \quad 0<\mu<1
$$

Die gesamtwirtschaftliche Inflationsrate ist also ein gewichteter Durchschnitt aus den Preissteigerungen handelbarer und nicht-handelbarer Güter. Die Preissteigerung der handelbaren Güter wird mit $\pi_{T}$, die der nicht-handelbaren Güter mit $\pi_{N}$ bezeichnet. Der Parameter $\mu$ gibt den Anteil nicht-handelbarer Güter am Warenkorb des gesamtwirtschaftlichen Preisniveaus wieder, während $1-\mu$ den Anteil der internationalen Güter widerspiegelt. Insofern stellt $1-\mu$ ein Maß für die Offenheit der betrachteten Volkswirtschaft dar.

Für die Preissetzung im Sektor der handelbaren Güter wird unterstellt, daß sich die Inflation der internationalen Güter aus dem Preisanstieg in Auslandswährung zuzüglich der Änderungsrate des nominalen Wechselkurses ergibt. Es gilt

$$
\pi_{T}=w+\pi_{T}^{a} .
$$

Dabei bezeichnet $\pi_{T}^{a}$ die Preissteigerung der handelbaren Güter in ausländischer Währung und $w$ die Änderungsrate des nominalen Wechselkurses. Der Wechselkurs wird wieder in der Preisnotierung verwendet, d.h. eine nominale Abwertung wird durch einen Anstieg des Wechselkurses $(w>0)$ beschrieben. Die durch Gleichung (3) beschriebene Beziehung zwischen der in- und ausländischen Inflationsrate der handelbaren Güter impliziert, daß für diese Waren die Kaufkraftparitätentheorie in ihrer relativen Form erfüllt ist. Um dies zu zeigen, wird auf die folgende Gleichung zurückgegriffen, die in Niveauschreibweise formuliert ist: $P_{i}=\phi W P_{a}$. Die relative Form der Kaufkraftparitätentheorie besagt, daß der Ausdruck $\phi$ in dieser Gleichung, der die Abweichung zwischen dem inländischen Preisniveau $P_{i}$ und dem mit dem Wechselkurs $W$ in Inlandswährung umgerechneten ausländischen Preisniveau $P_{a}$ angibt, im Zeitablauf konstant ist. 59 Überträgt man diesen Zusammenhang, der normalerweise auf die gesamtwirtschaftlichen Preisniveaus bezogen ist, auf die Preisindizes für die internationalen Güter, ergibt sich Gleichung (3), weil die Änderungsrate von $\phi$ gleich Null ist. Diese Überlegung schließt die auf restriktiveren Annahmen basierende absolute Form der Kaufkraftparitätentheorie ein, für die $\phi=1$ gilt.

Die Preissetzung im Sektor der nicht-handelbaren Güter wird durch zwei Einflüsse beschrieben und in Form der folgenden Gleichung wiedergegeben:

$$
\pi_{N}=\delta \pi^{e r w}+\lambda \pi_{a d m}, \quad 0<\delta, \lambda<1
$$

59 Siehe hierzu Rose/Sauernheimer (1999), S. 179, und Jarchow/Ruhmann (2000), S. 267. 
Der erste Summand in Gleichung (4) bringt zum Ausdruck, daß die Preise im nationalen Sektor steigen, wenn ein gesamtwirtschaftlicher Preisanstieg erwartet wird. Dieser Zusammenhang kann entweder durch erwartete Kostensteigerungen oder durch eine antizipierte Zunahme der Nachfrage erklärt werden. ${ }^{60}$ Die Kosten im Sektor nicht-handelbarer Güter werden steigen, wenn die Arbeitnehmer in diesem Sektor höhere Lebenshaltungskosten erwarten. Streben sie nach Reallohnsicherung, werden die Arbeitnehmer höhere Löhne fordern. Dies schlägt sich in einem Preisanstieg der nationalen Güter nieder, weil die Unternehmer mit Preiserhöhungen auf die gestiegenen Lohnkosten reagieren. Mit einem nachfrageinduzierten Preisanstieg im Sektor der nicht-handelbaren Güter ist insbesondere dann zu rechnen, wenn die Inflation auf Preissteigerungen bei den internationalen Gütern zurückzuführen ist. Solange gewisse Substitutionsbeziehungen zwischen den Güterkategorien bestehen, werden die Inländer verstärkt die relativ günstiger gewordenen nationalen Güter wählen. Dies wird von den Produzenten dieser Güter antizipiert, so daß sie wegen der erwarteten steigenden Nachfrage die Preise heraufsetzen. 61

Der zweite Summand in Gleichung (4) erfaßt Faktoren, die ihren Ursprung im Sektor der nicht-handelbaren Güter haben. Dies kann eine steigende Nachfrage aufgrund exogen bestimmter Veränderungen der Präferenzen sein. Eine andere für Reformländer typische Konstellation ist ein Preisanstieg, der aus der Verbesserung der Produktqualität resultiert. Insbesondere im nationalen Sektor waren die Produkte aufgrund des fehlenden Wettbewerbs in der Zentralverwaltungswirtschaft durch eine schlechte Qualität gekennzeichnet. Es ist daher damit zu rechnen, daß der Transformationsprozeß eine Qualitätssteigerung bewirkt. Diese Qualitätsverbesserung wirkt sich preiserhöhend aus, weil ihr bei der Messung der Inflation nicht durch kontinuierliche Veränderungen des Warenkorbs Rechnung getragen werden kann. Wie im Unterabschnitt II.2.3. ausführlich erläutert, ist die Anpassung administrativ festgelegter Preise ein weiterer - für Transformationsländer spezifischer - Faktor. Trotz weitreichender Preisliberalisierungen zu Beginn der Transformation unterliegt in allen Ländern bis zum heutigen Tage ein Teil der Güterpreise im Warenkorb der staatlichen Regulierung, so daß die Preisanpassung von staatlichen Entscheidungen abhängt. ${ }^{62}$ Hierunter fallen zum Beispiel Preise für öffentliche Verkehrsmittel, Mieten sowie andere Güter und Dienstleistungen, die

60 Siehe zur Unterscheidung zwischen einem kosten- und einem nachfrageinduzierten Preisauftrieb sowie zu den im folgenden beschriebenen Zusammenhängen Jarchow/Rühmann (2000), S. 66.

61 Wird in Gleichung (2) das gesamtwirtschaftliche Preisniveau in Form eines Preisindexes definiert, der nicht nur Endprodukte umfaßt, sondern auch Vorprodukte enthält, dann ergibt sich noch ein weiterer Einflußkanal. Der Einsatz importierter Vorprodukte im Sektor der nichthandelbaren Guter bewirkt, daß die Unternehmen in diesem Sektor höhere Produktionskosten einplanen, die sie in Form höherer Preise an die Verbraucher weitergeben.

Siehe hierzu insbesondere die Tabelle $1 \mathrm{im}$ Unterabschnitt II.2.3. 
typischerweise dem nationalen Sektor zugerechnet werden und aus sozialpolitischen Gründen nicht sofort freigegeben wurden. Die sukzessive Anhebung dieser staatlich regulierten Preise bis hin zur vollständigen Freigabe ist für die Reformländer eine unabdingbare Voraussetzung, um die aus der sozialistischen Zeit geerbten allokativen Verzerrungen abbauen und zu einem marktwirtschaftlich orientierten System übergehen zu können. ${ }^{63}$ Zur Veranschaulichung dieser Zusammenhänge wird der zweite Einflußkanal in Gleichung (4) mit der Variablen $\pi_{\text {adm }}$ bezeichnet, wobei zu berücksichtigen ist, daß gegebenenfalls auch andere Faktoren, die die Preisentwicklung im Sektor der nicht-handelbaren Güter beeinflussen, durch diese Größe erfaßt werden können.

Nachdem die beiden Einflußfaktoren der Preissetzung im nationalen Sektor erläutert wurden, soll noch auf die Parameterrestriktionen eingegangen werden. Damit die Zentralbank mit ihrer Wechselkurspolitik den realen Wechselkurs beeinflussen kann, muß $\delta<1$ gelten. Würde $\delta=1$ zugelassen, ergäbe sich unabhängig vom nominalen Wechselkurs immer der gleiche reale Wechselkurs. ${ }^{64}$ In dieser Situation wäre es für die Zentralbank nicht mehr sinnvoll, sowohl das Preisstabilitätsziel als auch das reale Wechselkursziel zu verfolgen. Sie könnte sich ganz dem Ziel der Preisstabilität zuwenden, weil die reale Wechselkursposition von ihrer Wechselkurspolitik unabhängig wäre. Dieser Fall soll hier ausgeschlossen sein. Der Parameter $\lambda$ ist kleiner als Eins, weil nur ein gewisser Teil der nicht-handelbaren Güter einer staatlichen Regulierung unterliegt. In der Frühphase der Transformation, in der ein großer Teil der Preise liberalisiert wurde, wird $\lambda$ einen Wert in der Nähe von Eins angenommen haben, während der Wert dann im Laufe des Reformprozesses mit zunehmender Deregulierung gesunken ist.

Im Hinblick auf die Änderungen der administrativ festgelegten Preise wird unterstellt, daß die Regierung zu Beginn der Beobachtungsperiode ankündigt, in welchem Ausmaß die Preise angepaßt werden sollen, und die Änderungen im angekündigten Maße durchführt. Die Wirtschaftssubjekte können daher diese Entwicklung beobachten und bei der eigenen Preissetzung berücksichtigen. Im Hinblick auf die Erwartungen über die gesamtwirtschaftliche Preisentwicklung wird unterstellt, daß die Wirtschaftssubjekte rationale Erwartungen haben. Es gilt:

63 Üblicherweise werden in den Transformationsländern auch die Preise einiger handelbarer Guter, wie zum Beispiel Gas und Benzin, staatlich festgesetzt. Die betreffenden Waren mussen im Rahmen des Modells dem nationalen Sektor zugerechnet werden, weil die Preisentwicklung in diesem Fall nicht von Wechselkursänderungen oder Änderungen des Preises in auslăndischer Wăhrung abhängt, wie von Gleichung (3) für internationale Guter gefordert. Die entsprechenden Preisentwicklungen, die sich durch die Entscheidungen inlăndischer Behörden ergeben, werden deshalb ebenfalls uber den zweiten Summand in Gleichung (4) erfaßt.

64 Um dies zu sehen, ist die Kenntnis der gesamten Modellstruktur erforderlich. Der Beweis erfolgt deshalb erst in der Fußnote 69 zur Gleichung (7') im Unterabschnitt 3.2. 


$$
\pi^{e r w}=\pi
$$

Rationale Erwartungen implizieren, daß die Wirtschaftssubjekte alle in einer bestimmten Periode verfügbaren Informationen für die Vorhersage der zu prognostizierenden Größe verwenden. ${ }^{65}$ In dem hier vorliegenden Fall bedeutet die Annahme rationaler Erwartungen in Gleichung (5) im Zusammenhang mit den Gleichungen (2) und (3), daß die Wirtschaftssubjekte sowohl über die Wechselkursentwicklung als auch die Entwicklung der Preise in den beiden Sektoren der Volkswirtschaft rationale Erwartungen haben, sie die Änderungen dieser drei Größen also korrekt vorhersehen. Das Modell wird vervollständigt durch die Definitionsgleichung für die Änderung des realen Wechselkurses. Sie ist gegeben durch

$$
w^{r}=\pi_{T}-\pi_{N}
$$

und beinhaltet, daß der reale Wechselkurs - wie auch im Dependent-EconomyModell - als das Verhältnis zwischen den Preisen handelbarer Güter und nichthandelbarer Güter definiert ist. 66

Für die Auswertung des Modells ist entscheidend, in welcher Reihenfolge die Akteure handeln. Die Abfolge der Schritte im Modell ist folgendermaßen. Wie bereits erwähnt, wird die Anhebung der staatlich regulierten Preise zu Beginn der Periode angekündigt, in der sie im angekündigten Ausmaß durchgeführt wird. Die Wirtschaftssubjekte im Sektor der nicht-handelbaren Güter berücksichtigen diese Preisderegulierung in ihrem Preissetzungskalkül und legen ihre Preise fest, bevor schließlich die Zentralbank ihre Entscheidung über die Änderung des nominalen Wechselkurses trifft.

\subsection{Modellauswertung}

Im folgenden wird das Modell - ebenso wie das Dependent-Economy-Modell im vorangegangenen Abschnitt - für die beiden Wechselkurssysteme „feste Wechselkurse" und "flexible Wechselkurse" ausgewertet. Dabei werden einige vereinfachende Annahmen getroffen, die einerseits für Transformationsländer plausible

65 Das Konzept der rationalen Erwartungen geht zuruck auf Muth (1961), S. 315 ff., der den Begriff im Zusammenhang mit Inflationserwartungen eingefuhrt hat. Dogmengeschichtlich interessant ist, daß Keuzenkamp (1991), S. 1245 ff., argumentiert, Tinbergen habe bereits 1932 eine Erwartungsbildung formuliert, die dem Konzept der rationalen Erwartungen entspricht. Bei Tinbergen (1932), S. 172, heißt es: „Wir werden sogar noch einen Schritt weiter gehen und auch annehmen, daß die Erwartungen, vernunftig' sind, d.h. mit den wirtschaftlichen Zusammenhängen ubereinstimmen." Siehe zur rationalen Erwartungshypothese auch Illing (1997), S. 93 ff., und Jarchow (1998a), S. 255 f.

Gleichung (6) entspricht der Definition des realen Wechselkurses $W^{r}=P_{T} / P_{N}$ bei Schreibweise in Änderungsraten. Im Unterschied zum Abschnitt III.2. bezeichnet $P_{T}$ in dieser Gleichung das Preisniveau der handelbaren Güter in inländischer Wăhrung, d.h. $P_{T}=W \cdot P_{T}^{a}$. 
Konstellationen darstellen und andererseits das Verständnis der Modellimplikationen vereinfachen. Für die Preise der handelbaren Güter in ausländischer Währung wird ohne qualitative Auswirkungen auf die Ergebnisse unterstellt, daß Preisstabilität herrscht. Es gilt also $\pi_{T}^{a}=0 .{ }^{67} \mathrm{Im}$ Hinblick auf die beiden Zielgrößen in der wirtschaftspolitischen Zielfunktion wird angenommen, daß die Zentralbank eine Inflationsrate in Höhe von Null und einen konstanten realen Wechselkurs anstrebt, d.h. $\hat{\pi}=0$ und $\hat{w}^{r}=0.68$ Wie bei der Vorstellung der Zielfunktion bereits ausführlich erläutert, bringen diese Annahmen zum Ausdruck, daß die Wirtschaftspolitiker einerseits eine Reduzierung der hohen Inflationsraten zu Transformationsbeginn anstrebten und andererseits aufgrund der Bedeutung der außenwirtschaftlichen Öffnung für den Transformationsprozeß und der zunehmenden Integration der Reformländer in den Welthandel auf die internationale Wettbewerbsfähigkeit der Volkswirtschaft achteten.

Vor der Analyse der beiden Wechselkurssysteme sollen jedoch die Veränderungen, die sich durch die getroffenen Annahmen in den Gleichungen ergeben, explizit dargestellt werden. Es ist zunächst zu berücksichtigen, daß die Entwicklung der Preise internationaler Güter aufgrund der Annahme von Preisstabilität in Auslandswährung ausschließlich durch die Veränderung des nominalen Wechselkurses bestimmt wird, denn mit $\pi_{T}^{a}=0$ folgt aus Gleichung (3) $\pi_{T}=w$. Die Definitionsgleichung (6) für den realen Wechselkurs vereinfacht sich damit zu

$$
w^{r}=w-\pi_{N}
$$

und für die gesamtwirtschaftliche Inflationsrate ergibt sich

$$
\pi=\mu \pi_{N}+(1-\mu) w .
$$

Die Preisbildung im Sektor der nicht-handelbaren Güter kann folgendermaßen in einer Gleichung zusammengefaßt werden. Berücksichtigt man die durch Gleichung (5) beschriebene Erwartungsbildung und die Definitionsgleichung (2') der gesamtwirtschaftlichen Preisentwicklung in der Gleichung (4), die die Inflationsrate $\pi_{N}$ angibt, erhält man

$$
\pi_{N}=\delta \mu \pi_{N}+\delta(1-\mu) w+\lambda \pi_{a d m} \quad \text { bzw. }
$$

67 Der Leser beachte, daß diese Annahme nicht Preisstabilităt im Ausland voraussetzt. Solange im Ausland die Preise der dortigen nationalen Guter ansteigen, ergibt sich eine positive ausländische Inflationsrate.

68 Im Anhang VI.1. wird das Modell fur den allgemeinen Fall mit $\hat{\pi}, \hat{w}^{r} \neq 0$ ausgewertet. Die Ergebnisse dieses Abschnittes lassen sich durch Einsetzen von $\hat{\pi}=0$ und $\hat{w}^{r}=0$ aus den im Anhang ermittelten Gleichungen ablesen. 


$$
\pi_{N}=\frac{1-\mu}{1-\delta \mu} \delta w+\frac{\lambda}{1-\delta \mu} \pi_{a d m} \quad \text { bzw. }
$$

$$
\pi_{N}=\beta w+\gamma \pi_{a d m}
$$

mit $\quad 0<\beta=\frac{1-\mu}{1-\delta \mu} \delta<1$ und $0<\gamma=\frac{\lambda}{1-\delta \mu} \stackrel{\gtrless}{\gtrless} 1.69$

Schließlich vereinfacht sich noch die wirtschaftspolitische Zielfunktion durch die Festlegung der beiden Zielwerte auf $\hat{\pi}=0$ und $\hat{w}^{r}=0 \mathrm{zu}$

$$
K=\frac{1}{2} \pi^{2}+\frac{1}{2} \alpha \hat{w}^{r 2} .
$$

Diese Gleichung (1') bildet zusammen mit der Gleichung (7') für die Preisentwicklung im Sektor der nicht-handelbaren Güter und den Gleichungen (2') und (6'), die die Änderungsraten des gesamtwirtschaftlichen Preisniveaus und des realen Wechselkurses beschreiben, die Grundlage für die nachfolgende Modellauswertung.

\subsubsection{Stabilisierung bei festen Wechselkursen}

Im folgenden wird zunächst ein Wechselkursregime mit festem Wechselkurs betrachtet. Die Zentralbank kündigt an, den nominalen Wechselkurs auf einem bestimmten Niveau zu fixieren und hält ihn auch tatsächlich konstant. Normalerweise kann sie nach erfolgter Preisderegulierung und Festlegung der Preise nationaler Güter die für sie optimale Wechselkursänderung bestimmen. Diese Möglichkeit gibt die Zentralbank auf, indem sie sich in Form einer Selbstbindung dazu verpflichtet, den Wechselkurs konstant zu halten. Es wird dabei vorläufig unterstellt, daß die Wirtschaftssubjekte der Zentralbank glauben und ihre Erwartungen entsprechend anpassen. Die Frage, ob eine solche Ankündigung glaubwürdig ist oder ob mit der Wechselkursfixierung ein Zeitinkonsistenzproblem verbunden ist, wird erst im Unterabschnitt 3.3. untersucht.

Wenn die Zentralbank eine Festkurspolitik betreibt, gilt $w_{f i x}=0$. Da die Wirtschaftssubjekte der Ankündigung dieser Politik Glauben schenken, erwarten sie für

69 Der Parameter $\gamma$ ist grøßer, kleiner oder gleich Eins, je nachdem, ob $\lambda$ großer, kleiner oder gleich $1-\delta \mu$ ist. Es gilt $\beta<1$, weil $[(1-\mu) \delta] /[1-\delta \mu]<1$, denn $(1-\mu) \delta<1-\delta \mu \Leftrightarrow \delta<1$. An dieser Stelle kann auch die Aussage aus Unterabschnitt 3.1.2. erlăutert werden, daß bei $\delta=1$ die Wechselkurspolitik keine Auswirkung auf den realen Wechselkurs hat. Wenn $\delta=1$ ist, gilt auch $\beta=1$. Berlicksichtigt man letzteres in (7') und beachtet (6'), dann gilt immer $w^{r}=w-\pi_{N}=-\gamma \pi_{a d m}$. 
die handelbaren Güter keine Preisänderungen. Die Anhebung der Preise im Sektor der nicht-handelbaren Güter resultiert dann ausschließlich aus einem direkten und indirekten Effekt der Erhöhung der administrativ festgelegten Preise. Der direkte Effekt ergibt sich dadurch, daß die Güter, deren Preise staatlich reguliert werden, nationale Güter sind und daher die Preisanhebungen einen Teil des Preisanstiegs nicht-handelbarer Güter ausmachen. Der indirekte Effekt wirkt über die von den Wirtschaftssubjekten erwartete Auswirkung der Anhebung staatlich festgelegter Preise auf das gesamtwirtschaftliche Preisniveau. Die Arbeitnehmer im nationalen Sektor werden höhere Löhne fordern, die sich ebenfalls in einem Preisanstieg für die nicht-handelbaren Güter niederschlagen. Beide Effekte werden durch den $\mathrm{Pa}$ rameter $\gamma$ in Gleichung (7') erfaßt. ${ }^{70}$ Unter Berücksichtigung von $w=0$ folgt aus Gleichung (7')

$$
\pi_{N f f x}=\gamma \pi_{a d m} .
$$

Einsetzen von $w_{f i x}=0$ und $\pi_{N}=\gamma \pi_{a d m}$ in Gleichung (2') liefert für die Preisentwicklung bei fixiertem nominalem Wechselkurs

$$
\pi_{f i x}=\mu \gamma \pi_{a d m} .
$$

Aus Gleichung (9) ist unmittelbar ersichtlich, daß das gesamtwirtschaftliche Preisniveau nicht so stark ansteigt wie die Preise der nicht-handelbaren Güter. Da durch die Wechselkursbindung die Preise internationaler Güter konstant gehalten werden, erhöht die Inflation nicht-handelbarer Güter das gesamtwirtschaftliche Preisniveau nur um den Anteil $(\mu)$, den diese Güter am Warenkorb des Preisindexes haben. Für die Veränderung des realen Wechselkurses ergibt sich unter Verwendung von $w_{f i x}=0$ und $\pi_{N}=\gamma \pi_{a d m}$ in Gleichung (6')

$$
w_{f i x}^{r}=-\gamma \pi_{a d m} .
$$

Da der nominale Wechselkurs konstant gehalten wird, kommt es - bei konstanten Preisen internationaler Güter in Auslandswährung - zu einer realen Aufwertung, die aufgrund der hier verwendeten Definition für den realen Wechselkurs betragsmäßig der Inflationsrate der Preise nicht-handelbarer Güter entspricht.

Als Ergebnis einer Festkurspolitik bleibt festzuhalten, daß sich eine positive gesamtwirtschaftliche Inflationsrate einstellt, obwohl die Zentralbank den nominalen Wechselkurs fixiert und die Wirtschaftssubjekte diese Politik für glaubwürdig halten. Dieser Preisanstieg resultiert aus der Preisanpassung im Sektor der nicht-

70 Das Zusammenspiel dieser beiden Effekte ist die ökonomische Erklărung dafür, daß $\gamma$ auch größer als Eins sein kann. 
handelbaren Güter. Solange der Prozeß der Anpassung administrativ festgelegter Preise noch nicht abgeschlossen ist, ergibt sich in diesem Modell eine positive Inflationsrate und - wie aus Gleichung (10) hervorgeht - aufgrund des Anstiegs der Preise nationaler Güter eine reale Aufwertung der heimischen Währung.

Durch Einsetzen der Gleichungen (9) und (10) in Gleichung (1') erhält man für die wirtschaftspolitische Zielfunktion bei festem Wechselkursregime einen Verlust in Höhe von

$$
K_{f i x}=\frac{\mu^{2}+\alpha}{2} \gamma^{2} \pi_{a d m}^{2}
$$

der daraus resultiert, daß beide Ziele $\left(\hat{\pi}=0, \hat{w}^{r}=0\right)$ verfehlt werden. ${ }^{71}$ Denn die Zentralbank erreicht durch die Wechselkursfixierung weder das Ziel der Preisstabilität noch das Ziel, den realen Wechselkurs konstant zu halten.

\subsubsection{Stabilisierung bei flexiblen Wechselkursen}

In diesem Unterabschnitt wird der Frage nachgegangen, welche Ergebnisse sich unter einem System flexibler Wechselkurse einstellen, bevor im Unterabschnitt 3.2.3. die beiden Wechselkurssysteme miteinander verglichen werden. Die zentrale Frage ist zunächst, welche nominale Wechselkursänderung die Zentralbank anstrebt, wenn sie sich nicht zu einem festen Wechselkurs verpflichtet, sondern diskretionär die für sie optimale nominale Wechselkursänderung festlegen kann. Bei flexiblen Wechselkursen ist die Zentralbank in der Lage, den Wechselkurs anzupassen, nachdem die Preisentscheidungen im nationalen Sektor getroffen wurden. Wie sich zeigt, ist es in diesem Fall optimal, den nominalen Wechselkurs im Aus$\mathrm{ma}$

$$
w_{\text {flex }}=\frac{\alpha-(1-\mu) \mu}{\psi} \gamma \pi_{a d m}, \text { mit } \psi=\alpha(1-\beta)+(1-\mu)(1-\mu+\mu \beta)>0,
$$

zu ändern. ${ }^{72}$ Entscheidend für die Richtung der Wechselkursänderung ist das Vorzeichen des Bruches. Da der Nenner immer größer als Null ist, kommt es auf das Vorzeichen des Zählers an. Wie unmittelbar aus Gleichung (12) ablesbar ist, nimmt der Zähler negative Werte an, wenn gilt $\alpha<(1-\mu) \mu$. Wenn $\alpha>(1-\mu) \mu$, dann ist der Zähler positiv. ${ }^{73}$ Für den ersten Fall, in dem $\alpha$ kleiner ist als

71 Für die allgemeine Formulierung des wirtschaftspolitischen Verlustes bei $\hat{\pi}, \hat{w}^{r} \neq 0$ siehe Gleichung (A5) im Anhang VI.1.1.

72 Zur Bestimmung der optimalen Wechselkursănderungsrate siehe die Herleitung der Gleichung (A8) im Anhang VI.1.2.

73 Insofern stellt die Parameterkonstellation $\alpha=(1-\mu) \mu$ einen „kritischen Wert" dar, bei dem die Zentralbank auch im diskretionären Fall keine Wechselkursănderung anstrebt. Für diesen Spezialfall sind die Ergebnisse bei festen und flexiblen Wechselkursen identisch. 
$(1-\mu) \mu$, wird die Zentralbank den Wechselkurs senken, also eine nominale Aufwertung betreiben, weil sie eine sehr starke Präferenz für Preisstabilität hat. ${ }^{74}$ Mit der Senkung des nominalen Wechselkurses wird eine Senkung der Preise handelbarer Güter in heimischer Währung und ein geringerer Anstieg der Preise im Sektor der nicht-handelbaren Güter erreicht. Beide Effekte bewirken, daß das gesamtwirtschaftliche Preisniveau langsamer steigt und damit das stark bevorzugte Ziel besser erreicht wird. Im umgekehrten Fall, in dem die Zentralbank dem Ziel der Preisstabilität eine nicht ganz so hohe Priorität einräumt, d.h. $\alpha>(1-\mu) \mu$, ist bei flexiblen Wechselkursen eine nominale Abwertung optimal, weil diese zu einer besseren Zielerreichung im Hinblick auf einen konstanten realen Wechselkurs führt.

In diesem Zusammenhang soll auf eine wichtige Implikation des Modells hingewiesen werden, die auf den ersten Blick paradox erscheint. Auch bei Präferenzen der Zentralbank, die bedeuten, daß diese in ihrer wirtschaftspolitischen Zielfunktion das Ziel der Preisstabilität stärker gewichtet als das reale Wechselkursziel $(\alpha<1)$, kann es im diskretionären Fall optimal sein, eine nominale Abwertung zu betreiben, die zu Preissteigerungen führt. ${ }^{75}$ Der Grund hierfür ist darin zu sehen, daß in dem Modell mit der Einflußgröße $\gamma \pi_{a d m}$ über die Preisentwicklung im Sektor der nicht-handelbaren Güter eine Tendenz sowohl zur realen Aufwertung als auch zu Preissteigerungen eingebaut ist. Der Einfluß auf den realen Wechselkurs ist jedoch stärker als auf die gesamtwirtschaftliche Inflationsrate, weil der Einfluß auf die Preisentwicklung in Gleichung (2') nur abgeschwächt mit dem Faktor $\mu<1$ eingeht, während er sich beim realen Wechselkurs in voller Höhe auswirkt (Gleichung (6')). Da $\hat{\pi}=0$ und $\hat{w}^{r}=0$ gilt, ist die Zielverfehlung beim realen Wechselkursziel größer. Höhere Abweichungen vom Zielwert gehen aber aufgrund der Quadrierung in der Zielfunktion mit einem größeren Gewicht in die Bewertung ein, so daß auch bei Präferenz für Preisstabilität eine nominale Abwertung optimal sein kann, weil das - wenn auch schwächer gewichtete - Ziel der Konstanz des realen Wechselkurses stärker verfehlt wird. Die nominale Abwertung bewirkt, daß diese mit hohen Verlusten verbundene Zielverfehlung reduziert wird. Der sich aus der Wechselkursänderung ergebende Anstieg des Verlustes, der aus dem Verfehlen des Preisstabilitätsziels resultiert, fällt nicht so hoch aus wie die Verlustreduktion bei der realen Wechselkurskomponente, so daß sich insgesamt durch die Anhebung des nominalen Wechselkurses ein niedrigerer Verlustwert einstellt.

Für die Preisentwicklung im Sektor der nicht-handelbaren Güter bei flexiblen Wechselkursen ist entscheidend, daß die Wirtschaftssubjekte rationale Erwartun-

74 Wegen $0<\mu<1$ gilt: $(1-\mu) \mu \leq 0,25$. Die Zentralbank muß also ein deutlich höheres Gewicht auf das Preisziel als auf das reale Wechselkursziel legen, damit dieser Fall eintritt.

Dieser Fall ist durch die Parameterkonstellation $(1-\mu) \mu<\alpha<1$ gekennzeichnet. 
gen über die gesamtwirtschaftliche Preisentwicklung bilden. Dies impliziert, daß sie auch die von der Zentralbank angestrebte Wechselkursänderungsrate korrekt antizipieren und in ihrem Preissetzungskalkül berücksichtigen. Die Preise nichthandelbarer Güter steigen daher in einem System flexibler Wechselkurse im Aus$\mathrm{ma}$

$$
\pi_{N \text { flex }}=\frac{\alpha+(1-\mu)^{2}}{\psi} \gamma \pi_{a d m} .76
$$

Da sowohl der Zähler als auch der Nenner des Bruches vor $\gamma \pi_{a d m}$ positiv sind, kommt es in jedem Fall zur Anhebung der Preise im Sektor nicht-handelbarer Güter. Also auch wenn die Zentralbank den nominalen Wechselkurs senkt, ergibt sich im Sektor der nicht-handelbaren Güter noch eine positive Inflationsrate. Richtet man den Blick nur auf die Gleichung (7'), erscheint es denkbar, daß eine entsprechend deutliche Senkung des nominalen Wechselkurses zu einem Rückgang der Preise nationaler Güter führt. Tatsächlich wird die Zentralbank den Wechselkurs aber nicht so stark absinken lassen, denn die nominale Aufwertung betreibt sie, um ihrem Ziel der Preisstabilität näherzukommen. Würde sie den Wechselkurs so stark senken, daß die Preise im Sektor der nicht-handelbaren Güter zurückgingen, schösse sie über ihr Ziel hinaus, und das gesamtwirtschaftliche Preisniveau fiele. ${ }^{77}$ Der stark ansteigende Verlust aufgrund der großen Zielverfehlung beim realen Wechselkursziel und der Deflation verhindert eine so starke nominale Aufwertung, daß auch die Preise nationaler Güter sinken.

Nachdem die Entwicklung des nominalen Wechselkurses und der Preise im Sektor der nicht-handelbaren Güter bestimmt ist, lassen sich unter Verwendung der Gleichungen (6') und (2') sowohl die Änderungsrate des realen Wechselkurses als auch die gesamtwirtschaftliche Inflationsrate ermitteln. Es ergibt sich

$$
w_{\text {flex }}^{r}=-\frac{1-\mu}{\psi} \gamma \pi_{a d m}<0
$$

und

$$
\pi_{\text {flex }}=\frac{\alpha}{\psi} \gamma \pi_{a d m}>0.78
$$

Aus den Gleichungen (14) und (15) läßt sich ablesen, daß die Politik mit flexiblen Wechselkursen im Hinblick auf die Richtung der Preisänderung und der Entwick-

76 Zum Beweis siehe die Herleitung der Gleichung (A7) im Anhang VI.1.2.

77 Bei $\pi_{N}<0$ und $w<0$ folgt aus Gleichung (2') $\pi<0$.

78 Die Herleitung der Ergebnisse erfolgt wiederum im Anhang VI.1.2. 
lung des realen Wechselkurses qualitativ die gleichen Ergebnisse liefert wie eine Festkurspolitik (siehe die Gleichungen (9) und (10)). Auch unter einem System flexibler Wechselkurse kommt es zu einer realen Aufwertung und einer positiven Inflationsrate, so daß ebenfalls weder das Ziel der Preisstabilität noch das Ziel eines konstanten realen Wechselkurses erreicht wird. Deshalb entsteht auch bei flexiblen Wechselkursen ein wirtschaftspolitischer Verlust, der auf eine Zielverfehlung beider Zielwerte zurückzuführen ist. Einsetzen von (14) und (15) in Gleichung ( $\left.1^{\prime}\right)$ liefert als Wert für die Verlustfunktion

$$
K_{\text {flex }}=\frac{\alpha}{2} \frac{\alpha+(1-\mu)^{2}}{\psi^{2}} \gamma^{2} \pi_{a d m}^{2}
$$

\subsubsection{Vergleich der Ergebnisse beider Wechselkurssysteme}

Nach der Darstellung der Ergebnisse unter alternativen Wechselkurssystemen werden die Resultate in diesem Unterabschnitt einem Vergleich unterzogen und analysiert, ob und unter welchen Bedingungen sich ein Regime als vorteilhaft erweist. Die Ausführungen im Unterabschnitt 3.2.2. deuten bereits an, daß eine Fallunterscheidung danach vorgenommen werden muß, ob $\alpha>(1-\mu) \mu .79$ Es wird zunächst untersucht, wie sich die nominale und reale Wechselkursänderung und die Preisentwicklungen bei alternativen Wechselkurssystemen unterscheiden, bevor ein Vergleich der Verlustwerte eine Antwort darauf liefert, welches Wechselkursregime unter welchen Bedingungen vorteilhafter ist.

Im Hinblick auf die Entwicklung des nominalen Wechselkurses wurde bereits ausführlich erläutert, daß die Zentralbank unter einem flexiblen Wechselkurssystem eine nominale Abwertung (Aufwertung) verfolgt, wenn $\alpha$ größer (kleiner) ist als $(1-\mu) \mu$. Während die Zentralbank im Festkurssystem den nominalen Wechselkurs konstant hält, hebt oder senkt sie ihn bei flexiblen Wechselkursen in Abhängigkeit von der Parameterkonstellation.

Bei der Betrachtung der Inflation im Sektor der nicht-handelbaren Güter ist zu berücksichtigen, daß die Wirtschaftssubjekte rationale Erwartungen über die Preisentwicklung haben. Sie berücksichtigen daher einen aus einer Abwertung resultierenden Anstieg der Preise ebenso wie einen Rückgang aufgrund einer Senkung des nominalen Wechselkurses. Die Berechnungen zeigen, $80 \mathrm{da} \beta \pi_{N \text { fex }}<\pi_{N \text { fix }}$, wenn $\alpha<(1-\mu) \mu$. Das heißt, daß die Preise im Sektor der nicht-handelbaren Güter bei flexiblen Wechselkursen weniger stark als im Festkurssystem steigen, wenn die

79 Wie bereits erwăhnt, sind fur den Grenzfall $\alpha=(1-\mu) \mu$ die Ergebnisse identisch. Er wird deshalb nicht năher betrachtet. Siehe hierzu bereits die Fußnote 73.

Die mathematische Herleitung erfolgt im Anhang VI.1.3.1. 
Zentralbank nominal aufwertet. Umgekehrt gilt $\pi_{N \text { fex }}>\pi_{N f i x}$, wenn $\alpha>(1-\mu) \mu$. Das heißt, daß bei flexiblen Wechselkursen die Preise stärker als bei einer Wechselkursfixierung steigen, wenn die Zentralbank die Währung nominal abwertet. Der stärkere Anstieg der Preise nationaler Güter resultiert zum einen daraus, daß die Arbeitnehmer im Sektor nicht-handelbarer Güter höhere Lohnforderungen stellen, weil sie die abwertungsbedingten Preissteigerungen der handelbaren Güter korrekt vorhersehen. Zum anderen antizipieren die Anbieter nationaler Güter die steigende Nachfrage nach ihren Produkten, weil diese in Relation zu den internationalen Gütern günstiger werden. Es stellt sich also ein kosten- und nachfrageinduzierter Preisauftrieb im Sektor der nicht-handelbaren Güter ein.

Für die beiden wirtschaftspolitischen Zielgrößen „gesamtwirtschaftliche Inflation“ und „realer Wechselkurs" wurde bereits festgestellt, daß sich die Ergebnisse in qualitativer Hinsicht nicht unterscheiden, da sich in beiden Wechselkurssystemen ein Anstieg des gesamtwirtschaftlichen Preisniveaus und eine reale Aufwertung einstellen. Im folgenden werden die quantitativen Unterschiede analysiert, d.h. es wird untersucht, in welchem System die entsprechenden Änderungen stärker ausfallen. Dabei wird zuerst der Fall betrachtet, in dem die Zentralbank eine sehr hohe Präferenz für Preisstabilität hat, d.h. $\alpha$ ist kleiner als $(1-\mu) \mu$.

Ob die reale Aufwertung bei flexiblen Wechselkursen stärker oder schwächer ausfällt als im Festkurssystem, hängt von der nominalen Wechselkursänderung und von der Inflation im Sektor der nicht-handelbaren Güter ab. Wie oben ausgeführt, senkt die Zentralbank im Fall sehr hoher Präferenz für Preisstabilität den Wechselkurs $\left(w_{\text {flex }}<0\right)$, wodurch die Preise im Sektor der nicht-handelbaren Güter weniger stark steigen als beim festen Wechselkurs $\left(\pi_{N \text { flex }}<\pi_{N \text { fix }}\right)$. Auf die reale Wechselkursänderung wirken diese beiden Effekte gegenläufig ein. Wie aus Gleichung (6') ersichtlich, verstärkt die Senkung des nominalen Wechselkurses die reale Aufwertung. Der geringere Preisanstieg hingegen schwächt die reale Aufwertung ab. Allerdings geht die Preissteigerung wegen $\beta<1$ nicht im gleichen Ausma $ß$ zurück wie der nominale Wechselkurs gesenkt wird. Es kommt in diesem Fall zu einer stärkeren realen Aufwertung als beim festen Wechselkurs, also zu einer stärkeren Zielverfehlung im Hinblick auf $\hat{w}^{r}=0.81$ Die nominale Aufwertung bewirkt über eine Senkung der Preise internationaler Güter und den schwächeren Anstieg der Preise im Sektor nicht-handelbarer Güter, daß der Anstieg des gesamtwirtschaftlichen Preisniveaus geringer ausfällt. ${ }^{82}$ Die Zentralbank kommt ihrem stark gewichteten Ziel $\hat{\pi}=0$ deshalb näher als beim festen Wechselkurs, ohne es jedoch zu erreichen.

81 Es gilt: Aus $\alpha<(1-\mu) \mu$ folgt $\left|w_{\text {fex }}^{r}\right|>\left|w_{f i x}^{r}\right|$. Zum mathematischen Beweis siehe Anhang VI.1.3.2.

82 Zum formalen Beweis, daß $\pi_{\text {fex }}<\pi_{\text {fix }}$ aus $\alpha<(1-\mu) \mu$ folgt, siehe Anhang VI.1.3.3. 
Für den Fall, daß die Zentralbank eine weniger starke Präferenz für Preisstabilität hat, d.h. $\alpha$ ist größer als $(1-\mu) \mu$, ist es einerseits möglich, daß das Preisziel ein höheres Gewicht in der Zielfunktion hat als das reale Wechselkursziel. In diesem Fall gilt $(1-\mu) \mu<\alpha<1$. Andererseits kann das reale Wechselkursziel auch stärker gewichtet sein, d.h. $\alpha>1$. In beiden Fällen kommt es - wie oben gesehen - zu einer nominalen Abwertung $\left(w_{\text {flex }}>0\right)$. Da die Wirtschaftssubjekte im Sektor der nicht-handelbaren Güter die Preise nicht so stark hinaufsetzen, wie der nominale Wechselkurs steigt, erreicht die Zentralbank eine Abschwächung der realen Aufwertung. ${ }^{83}$ Allerdings wirkt sich die nominale Abwertung negativ - d.h. erhöhend - auf die Inflationsrate aus. Da bei flexiblen Wechselkursen sowohl die Anhebung des nominalen Wechselkurses preissteigernd auf die internationalen Güter wirkt als auch die Preise im Sektor der nicht-handelbaren Güter stärker steigen als im Festkurssystem, ergibt sich bei flexiblen Wechselkursen ein stärkerer gesamtwirtschaftlicher Preisanstieg als bei Wechselkursbindung. ${ }^{84}$

Die Ergebnisse für die beiden Wechselkurssysteme sind in der Tabelle 2 nochmals in Abhängigkeit vom Ausmaß der Gewichtung der wirtschaftspolitischen Ziele zusammenfassend gegenübergestellt.

\section{Tabelle 2: Vergleich der Ergebnisse bei alternativen Wechselkurssystemen}

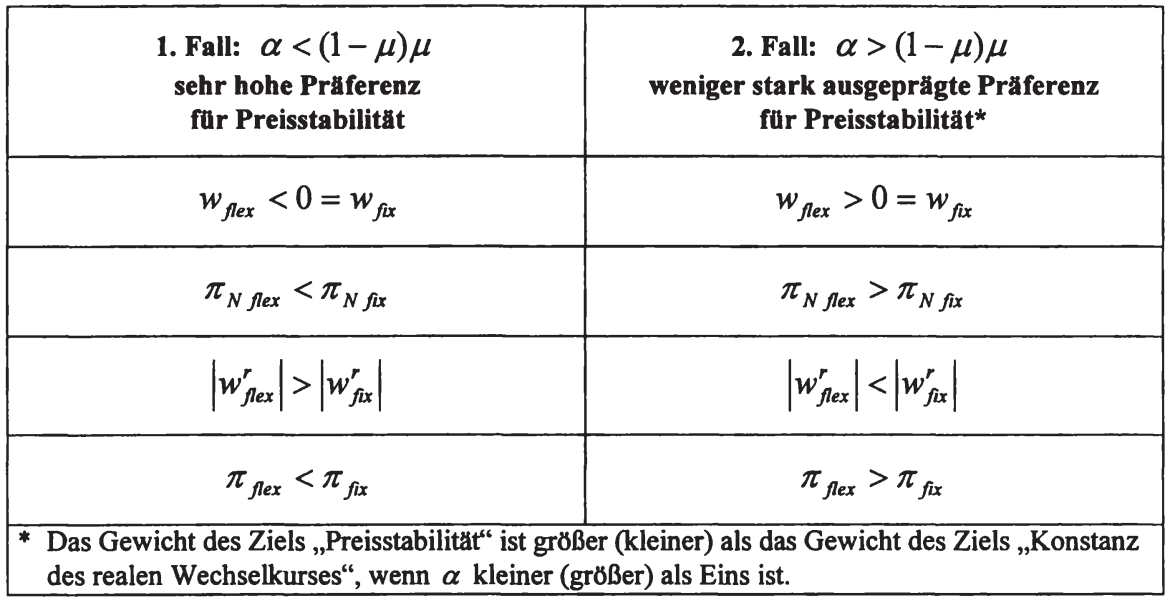

Wie aus den letzten zwei Zeilen der Gegenüberstellung hervorgeht, kommt die Zentralbank bei beiden Parameterkonstellationen jeweils einem wirtschaftspolitischen Ziel auf Kosten einer höheren Zielverfehlung beim anderen Ziel näher, je

83 Aus $\alpha>(1-\mu) \mu$ folgt $\left|w_{f a x}^{r}\right|<\left|w_{f x}^{r}\right|$. Vgl. Anhang VI.1.3.2.

84 Aus $\alpha>(1-\mu) \mu$ folgt $\pi_{f e x}>\pi_{f x}$. Siehe Anhang VI.1.3.3. 
nachdem für welche wechselkurspolitische Strategie sie sich entscheidet. Welches Wechselkursregime vorteilhafter ist, läßt sich aus dieser Aufstellung daher nicht ablesen. Die Antwort hängt von einem Kostenvergleich unter beiden Systemen ab. Also davon, ob

$$
K_{\text {flex }} \stackrel{\geqq}{\gtrless} K_{f i x}
$$

bzw. unter Berücksichtigung der Gleichungen (11) und (16), ob

$$
\frac{\alpha}{2} \frac{\alpha+(1-\mu)^{2}}{\psi^{2}} \stackrel{\mu^{2}+\alpha}{2} \text { mit } \psi=\alpha(1-\beta)+(1-\mu)(1-\mu+\mu \beta) .
$$

Aus Gleichung (17) geht hervor, daß die Abwägung, welches der beiden Wechselkurssysteme vorteilhafter ist, von den drei Parametern $\alpha, \beta$ und $\mu$ abhängt. Um einerseits einen Kostenvergleich in übersichtlicher Darstellungsweise zu ermöglichen und andererseits die Berechnungen nicht unnötig zu erschweren, wird als zusätzliche Annahme für den Systemvergleich $\beta=1-\mu$ unterstellt. Es handelt sich um eine Vereinfachung, die die Ergebnisse nicht qualitativ beeinflußt. Zur Begründung dieser Aussage ist zunächst zu beachten, daß die Preise handelbarer Güter in zweierlei Hinsicht auf die allgemeine Preisentwicklung einwirken. Einerseits erhöht ein Preisanstieg internationaler Güter das gesamtwirtschaftliche Preisniveau direkt, da diese Güter einen bestimmten Anteil $(1-\mu)$ am Warenkorb ausmachen. Andererseits wirkt auch ein indirekter Effekt, der darin besteht, daß die Wirtschaftssubjekte bei Preissteigerungen im Sektor der handelbaren Güter einen Anstieg der Lebenshaltungskosten antizipieren, deshalb im nationalen Sektor höhere Löhne fordern und somit zu einem Preisanstieg bei den nicht-handelbaren Gütern beitragen. Wie ein Vergleich der Beziehungen (2') und (7') unter Berücksichtigung von $\beta=1-\mu$ zeigt, bedeutet die vereinfachende Annahme lediglich, $\mathrm{da} ß$ der indirekte Einfluß von Preissteigerungen internationaler Güter auf die Inflationsrate nicht-handelbarer Güter genauso groß ist wie der direkte Einfluß auf die gesamtwirtschaftliche Inflation. In qualitativer Hinsicht ändern sich die Ergebnisse nicht. So gilt nach wie vor, daß der Einfluß von Preisänderungen internationaler Güter auf die Preisentwicklung im Sektor nicht-handelbarer Güter um so stärker ist, je höher der Anteil dieser Produkte am gesamtwirtschaftlichen Warenkorb, je offener also die betrachtete Volkswirtschaft ist. ${ }^{85}$

85 Eine Argumentation anhand von Gleichung (4) liefert das gleiche Ergebnis. Aus $\beta=1-\mu$ folgt $\delta=1 /(1+\mu)$. Auch hier gilt: Je offener eine Volkswirtschaft ist, je kleiner also $\mu$ ist, um so stärker ist der Einfluß eines Preisanstiegs internationaler Guter uber die gesamtwirtschaftliche Inflationsrate auf die Preisentwicklung im Sektor nicht-handelbarer Guter. 
Auch die Auswirkungen staatlicher Deregulierung auf die Preisentwicklung im Sektor nicht-handelbarer Güter sind von der zusätzlichen Annahme nicht betroffen. Bei der Betrachtung der relevanten Gleichung ( (7') ist zu berücksichtigen, daß gilt $\gamma=\lambda(1+\mu)$, wenn $\beta=1-\mu$. Dies bedeutet, daß sich eine Anhebung staatlich regulierter Preise um so stärker auf die Preisentwicklung im Sektor nichthandelbarer Güter auswirkt, je geschlossener eine Volkswirtschaft ist, d.h. je größer $\mu$ ist. Dies ist einsichtig, weil in diesem Fall neben dem direkten Einfluß auf $\pi_{N}$ auch der indirekte Einfluß stärker ausfällt, der über die erwartete gesamtwirtschaftliche Preissteigerung in Gleichung (2') wirkt. Je geschlossener die Volkswirtschaft ist, um so höher ist der Anstieg der Lebenshaltungskosten, mit dem die Wirtschaftssubjekte rechnen. Schließlich hat auch der Vergleich der beiden Wechselkurssysteme gezeigt, daß die Ergebnisse, welche Variablenänderungen stärker ausfallen, nicht vom Parameter $\beta$ abhängig sind. ${ }^{86}$ Deshalb kann davon ausgegangen werden kann, daß das Setzen von $\beta=1-\mu$ die Aussagekraft der nachfolgenden Analyse nicht beeinträchtigt.

Unter Berücksichtigung der Annahme $\beta=1-\mu$ vereinfacht sich die Bedingung (17) $\mathrm{zu}$

$$
\frac{\alpha}{2} \frac{\alpha+(1-\mu)^{2}}{\left.\alpha \mu+(1-\mu)\left(1-\mu^{2}\right)\right]^{2}} \stackrel{\mu^{2}+\alpha}{2} .
$$

Nach einigen Umformungen läßt sich zeigen, ${ }^{87} \mathrm{da} ß$

$$
K_{\text {flex }} \stackrel{\geqq}{\gtrless} K_{\text {fix }},
$$

wenn

$$
\begin{aligned}
& \alpha^{3}-\xi_{1} \alpha^{2}-\xi_{2} \alpha+\xi_{3} \leqq 0 \\
& \xi_{1}=\frac{\left(1-\mu^{2}\right)\left(1-2 \mu+3 \mu^{2}\right)}{\mu^{2}} \\
& \xi_{2}=(1-\mu)^{2}\left(2-2 \mu-3 \mu^{3}\right) \\
& \xi_{3}=(1-\mu)^{2}\left(1-\mu^{2}\right)^{2}
\end{aligned}
$$

86 Die allein ausschlaggebende Konstellation ist $\alpha_{<}^{>}(1-\mu) \mu$.

87 Zur Herleitung der Bedingung siehe Anhang VI.1.3.4. 
Die Auswertung der Ungleichung (18) erfolgt durch die Darstellung der Ergebnisse für verschiedene Parameterkonstellationen. Um die Interpretation der Ergebnisse zu erleichtern, erfolgt die Illustration nicht in einer $\alpha-\mu$-Tabelle, sondern in Abhängigkeit von $\alpha$ (= Gewicht des realen Wechselkursziels) und $1-\mu$, weil letzteres als ein Maß für die Offenheit der betrachteten Volkswirtschaft aufgefaßt werden kann. Die in der Tabelle 3 eingetragenen Aussagen „nein" und ,ja“ sind Antworten auf die Frage, ob der Wert der Verlustfunktion bei Regelbindung (Wahl eines festen Wechselkurses) niedriger ist als bei flexiblen Wechselkursen, also ob $K_{\text {flex }}>K_{f i x}$ ist. Anders ausgedrückt bedeutet ein , ja " in der Tabelle, daß ein Festkurssystem vorteilhafter ist, während ein „nein“ eine Konstellation beschreibt, in der ein System flexibler Wechselkurse aus Sicht der Zentralbank einem Festkurssystem überlegen ist.

\section{Tabelle 3: Ist ein Festkurssystem vorteilhafter als ein System flexibler Wechselkurse?}

\begin{tabular}{|c|c|c|c|c|c|c|c|c|c|}
\hline \multirow{2}{*}{$\begin{array}{l}\text { Gewichtung } \\
\text { des Wk-ziels } \\
(\alpha)\end{array}$} & \multicolumn{9}{|c|}{ Offenheitsgrad $(1-\mu)$} \\
\hline & 0,1 & 0,2 & 0,3 & 0,4 & 0,5 & 0,6 & 0,7 & 0,8 & 0,9 \\
\hline 0,05 & nein & nein & nein & nein & nein & nein & nein & nein & nein \\
\hline 0,06 & nein & nein & nein & nein & nein & nein & nein & nein & nein \\
\hline 0,07 & nein & nein & nein & nein & nein & nein & nein & nein & nein \\
\hline 0,08 & nein & nein & nein & nein & nein & nein & nein & nein & nein \\
\hline 0,09 & nein & nein & nein & nein & nein & nein & nein & nein & nein \\
\hline 0,1 & ja & nein & nein & nein & nein & nein & nein & nein & $\mathrm{ja}$ \\
\hline 0,2 & ja & ja & nein & nein & nein & nein & nein & ja & ja \\
\hline 0,3 & $\mathrm{ja}$ & ja & ja & $\mathrm{ja}$ & ja & $\mathrm{ja}$ & ja & ja & ja \\
\hline 0,4 & nein & $\mathrm{ja}$ & $\mathrm{ja}$ & $\mathrm{ja}$ & ja & $\mathrm{ja}$ & ja & $\mathrm{ja}$ & $\mathrm{ja}$ \\
\hline 0,5 & nein & ja & $\mathrm{ja}$ & $\mathrm{ja}$ & ja & ja & ja & ja & ja \\
\hline 0,6 & nein & $\mathrm{ja}$ & $\mathrm{ja}$ & ja & $\mathrm{ja}$ & $\mathrm{ja}$ & ja & $\mathrm{ja}$ & ja \\
\hline 0,7 & nein & nein & $\mathrm{ja}$ & $\mathrm{ja}$ & $\mathrm{ja}$ & $\mathrm{ja}$ & $\mathrm{ja}$ & ja & ja \\
\hline 0,8 & nein & nein & $\mathrm{ja}$ & ja & $\mathrm{ja}$ & ja & $\mathrm{ja}$ & ja & $\mathrm{ja}$ \\
\hline 0,9 & nein & nein & ja & $\mathrm{ja}$ & ja & ja & ja & ja & ja \\
\hline 1,0 & nein & nein & $\mathrm{ja}$ & $\mathrm{ja}$ & $\mathrm{ja}$ & $\mathrm{ja}$ & ja & $\mathrm{ja}$ & $\mathrm{ja}$ \\
\hline 1,11 & nein & nein & nein & ja & ja & $\mathrm{ja}$ & $\mathrm{ja}$ & $\mathrm{ja}$ & $\mathrm{ja}$ \\
\hline 1,25 & nein & nein & nein & ja & ja & ja & ja & ja & $\mathrm{ja}$ \\
\hline 1,43 & nein & nein & nein & ja & ja & ja & $\mathrm{ja}$ & $\mathrm{ja}$ & $\mathrm{ja}$ \\
\hline 1,67 & nein & nein & nein & nein & ja & ja & ja & ja & ja \\
\hline 2,0 & nein & nein & nein & nein & $\mathrm{ja}$ & ja & $\mathrm{ja}$ & $\mathrm{ja}$ & $\mathrm{ja}$ \\
\hline 2,5 & nein & nein & nein & nein & nein & $\mathrm{ja}$ & $\mathrm{ja}$ & ja & ja \\
\hline 3,33 & nein & nein & nein & nein & nein & ja & ja & ja & ja \\
\hline 5,0 & nein & nein & nein & nein & nein & nein & ja & ja & ja \\
\hline 10,0 & nein & nein & nein & nein & nein & nein & nein & ja & ja \\
\hline
\end{tabular}


Wie aus der Tabelle sehr anschaulich hervorgeht, lassen sich drei verschiedene Bereiche identifizieren. Betrachtet man zunächst den Fall, daß $\alpha$ sehr klein ist, genauer: daß $\alpha<(1-\mu) \mu$, dann zeigt sich, daß die Preisstabilität so stark gewichtet wird, daß eine nominale Aufwertung gewünscht wird. Ein flexibles Wechselkurssystem ist vorteilhafter, da die gewünschte Senkung des nominalen Wechselkurses bei einem Festkurssystem nicht möglich ist. Diese Politik ist zwar mit einer höheren Zielverfehlung beim realen Wechselkursziel verbunden, allerdings wird diese so gering bewertet, daß ein System flexibler Wechselkurse optimal ist. Es gilt $K_{f l e x}<K_{f i x}$.

Spiegelbildlich dazu ist der linke, untere Bereich in der Tabelle $3 \mathrm{zu}$ sehen, in dem $\alpha$ im Vergleich zu $1-\mu$ relativ groß ist. In diesem Fall ist der Zentralbank sehr stark daran gelegen, den realen Wechselkurs konstant zu halten. Um dies zu erreichen, ist eine nominale Abwertung erforderlich. Die damit verbundene höhere Inflationsrate und entsprechend starke Verfehlung des Preisstabilitätsziels erscheint der Zentralbank weniger wichtig, weil ihr nur ein sehr geringes Gewicht beigemessen wird. Es gilt wiederum $K_{\text {fex }}<K_{f i x}$. Aus dem linken, unteren Bereich der Tabelle läßt sich außerdem eine Abhängigkeit dieses Ergebnisses von der Offenheit der Volkswirtschaft ablesen. Bei gegebenem Wert für das Gewicht des realen Wechselkursziels $\alpha$ ist das flexible Wechselkursregime um so eher dem Festkurssystem unterlegen, je offener die Volkswirtschaft ist. Dies resultiert daraus, daß die Abwertung um so stärker preissteigernd wirkt, je offener die betrachtete Volkswirtschaft ist, m.a.W. je größer der Anteil der handelbaren Güter am Warenkorb der gesamtwirtschaftlichen Inflationsrate ausfällt. In einer relativ geschlossenen Volkswirtschaft wird dementsprechend das Ziel der Preisstabilität bei gleich hoher Abwertungsrate nicht so stark verfehlt wie in einer relativ offenen Volkswirtschaft.

Der zwischen den bisher beschriebenen Fällen liegende - in der Tabelle dunkel hinterlegte - Bereich beschreibt Situationen, in denen ein festes Wechselkursregime vorteilhafter ist. Durch die Fixierung des Wechselkurses wird der Anstieg der Preise im Sektor der nicht-handelbaren Güter abgeschwächt. In Verbindung mit dem konstanten Wechselkurs $(w=0)$ bedeutet dies, daß eine niedrigere Inflationsrate als bei flexiblen Wechselkursen erreicht werden kann. Offenbar führt in diesen Situationen die bessere Zielerreichung des Preisziels durch den Verzicht auf eine nominale Abwertung zu einem stärkeren Rückgang des wirtschaftspolitischen Verlustes, als die stärkere reale Aufwertung diesen dadurch erhöht, daß auf die nominale Abwertung verzichtet wird. Das Festkurssystem ist vorteilhafter; es gilt $K_{f l e x}>K_{f i x}$. Da auch in diesem Fall der Preiseffekt wieder um so stärker ausfällt, je größer $1-\mu$ ist, wird eine Regelbindung in Form eines festen Wechselkurses einem Flexkurssystem unter sonst gleichen Umständen um so eher vorgezogen, je offener die Volkswirtschaft ist. 
Der Vorteil des festen Wechselkurses besteht darin, daß die Zentralbank durch die Selbstbindung den Wirtschaftssubjekten signalisiert, auf die nominale Abwertung zu verzichten, die sie bei flexiblen Wechselkursen und der Parameterkonstellation $\alpha>(1-\mu) \mu$ betreiben würde. Diese Tendenz zur nominalen Abwertung kann man als „devaluation bias“ des Modells bezeichnen. Durch die Wechselkursbindung erreicht die Zentralbank eine niedrigere Inflationsrate bei etwas stärkerer realer Aufwertung und damit - bei den in der Tabelle dunkel hinterlegten Konstellationen - auch einen niedrigeren wirtschaftspolitischen Verlust.

Bevor darauf eingegangen wird, inwiefern die Ergebnisse die Beobachtungen in den Transformationsländern widerspiegeln und daher eine Übertragbarkeit der Ergebnisse gegeben ist, wird im nächsten Unterabschnitt zunächst der Frage nachgegangen, welche Probleme im Hinblick auf die Glaubwürdigkeit einer Bindung des nominalen Wechselkurses bestehen. Im Unterabschnitt 3.2.1. wurde die Problematik ausgeklammert, ob die Zentralbank in der Lage ist, den Wechselkurs glaubwürdig zu fixieren. Diese Fragestellung wird nun aufgegriffen und daran anschließend diskutiert, welche Möglichkeiten sich den verantwortlichen Wirtschaftspolitikern bieten, die Glaubwürdigkeit einer Wechselkursbindung zu erhöhen, wenn sie sich für ein Festkurssystem entscheiden.

\subsection{Glaubwürdigkeitsprobleme einer Wechselkurs- fixierung}

Aus der geldtheoretischen Literatur ist bekannt, daß mit einer Regelbindung ein Glaubwürdigkeitsproblem bzw. Zeitinkonsistenzproblem verbunden sein kann. ${ }^{88}$ Eine Politik ist zeitlich inkonsistent, wenn sie zu einem Zeitpunkt $t_{0}$ unter Berücksichtigung aller verfügbaren Informationen in $t_{0}$ für künftige Zeitpunkte angekündigt ist, zum Zeitpunkt der geplanten Durchführung aber nicht wie beabsichtigt umgesetzt wird, weil sie nach Realisierung der dafür erforderlichen Bedingungen nicht mehr optimal ist. ${ }^{89} \mathrm{Im}$ Unterabschnitt 3.2.1. wurde angenommen, daß bei einer Wechselkursbindung die Wirtschaftssubjekte den Wirtschaftspolitikern glauben und letztere ihre angekündigte Politik auch tatsächlich implementieren. Es ist aber denkbar, daß für die Zentralbank ein Anreiz besteht, entgegen ihrer Ankündigung doch den Wechselkurs zu ändern, nachdem die Wirtschaftssubjekte ihre Erwartungen gebildet und die Preise im Sektor der nicht-handelbaren Güter festgelegt haben. Ob im Rahmen des vorgestellten Modells ein solcher Anreiz besteht, wird im folgenden untersucht.

88 Vgl. zur Zeitinkonsistenz u.a. den grundlegenden Aufsatz von Kydland/Prescott (1977), S. 473 ff., sowie die fruhen Arbeiten von Calvo (1978), S. 1411 ff., und Fischer (1980), S. 93 ff., zu diesem Thema. Siehe auch Jarchow (1993), S. 145 ff., und den Übersichtsaufsatz von Blackburn/Christensen (1989), S. 1 ff.

89 Vgl. zu dieser Definition Loef/Ziemes (1989), S. 446, und Jarchow (1993), S. 148. 
Wenn die Wirtschaftssubjekte der Zentralbank glauben, daß sie den Wechselkurs nicht verändert, setzen sie die Preise im gleichen Ausmaß herauf wie im Fall mit glaubwürdig fixiertem Wechselkurs, d.h.

$$
\pi_{N T}=\gamma \pi_{a d m} .90
$$

Entscheidend ist, daß die Preise festgelegt werden, bevor die tatsächliche Wechselkursänderung beobachtet wird. Die Preissetzung für die betrachtete Periode erfolgt nach der Ankündigung der Regierung über die Anhebung der staatlich festgelegten Preise und aufgrund der Erwartungen der Wirtschaftssubjekte über die Wechselkurspolitik der Zentralbank. Diese wird die Preissetzung in ihrem Kalkül über die Wechselkurspolitik berücksichtigen, d.h. die Zentralbank minimiert die wirtschaftspolitische Zielfunktion - wie auch im flexiblen Wechselkurssystem für gegebene Werte von $\pi_{N}$. Da es ihr aber gelingt, die Wirtschaftssubjekte zu täuschen, rechnen diese weiterhin mit einem fixierten Wechselkurs und können ihre Erwartungen und Preisentscheidungen nicht einer eventuellen Wechselkursänderung anpassen. Bei diesem Szenario ist es für die Zentralbank optimal, den Wechselkurs wie folgt zu ändern:

$$
w_{T}=\frac{\alpha-(1-\mu) \mu}{\alpha+(1-\mu)^{2}} \gamma \pi_{a d m} .91
$$

Man erkennt, daß die Wirkung auf die Richtung der nominalen Wechselkursänderung wiederum von der Parameterkonstellation $\alpha>(1-\mu) \mu$ abhängt. Besteht eine sehr starke Präferenz der Zentralbank für Preisstabilität, wird die Zentralbank entgegen ihrer Ankündigung, den nominalen Wechselkurs konstant zu halten, eine nominale Aufwertung durchführen. Ist die Präferenz für Preisstabilität weniger stark ausgeprägt, besteht ein Anreiz, den Wechselkurs anzuheben. Wenn $\alpha=(1-\mu) \mu$, wird die Zentralbank nicht von der angekündigten Politik abweichen. Nur bei dieser Parameterkonstellation ist es optimal, die Wirtschaftssubjekte nicht zu täuschen und die Wechselkursfixierung beizubehalten. ${ }^{92}$ Es ist jedoch zu beachten, daß der Fall $\alpha<(1-\mu) \mu$ für die Betrachtung der Täuschungslösung eher theoretischer Natur ist. Wie beim Vergleich der Wechselkurssysteme im Unterabschnitt 3.2.3. gezeigt, wird bei dieser Parameterkonstellation aller Voraussicht nach ein flexibles Wechselkurssystem gewählt. Für ein Festkurssystem wird sich die Zentralbank in der Regel nur bei $\alpha>(1-\mu) \mu$ entscheiden, wobei dann ein Anreiz zur Abwertung bei erfolgreicher Täuschung besteht.

90 Der Index „T“ steht fur „Täuschung“.

91 Zur Herleitung des Ergebnisses siehe Anhang VI.1.4.

92 Fur diesen Sonderfall wurde bereits gezeigt, daß die Ergebnisse bei festen und flexiblen Wechselkursen identisch sind. Siehe die Fußnoten 73 und 79. 
Im Hinblick auf die Richtung der Ergebnisse der realen Wechselkursänderung und des gesamtwirtschaftlichen Preisniveaus ergibt sich, wie auch schon bei den beiden zuvor betrachteten Systemen, eine reale Aufwertung und eine positive gesamtwirtschaftliche Inflationsrate, genauer gilt

$$
w_{T}^{r}=-\frac{1-\mu}{\alpha+(1-\mu)^{2}} \gamma \pi_{a d m}
$$

und

$$
\pi_{T}=\frac{\alpha}{\alpha+(1-\mu)^{2}} \gamma \pi_{a d m} \cdot 93
$$

Die Richtung der beiden Ergebnisse hängt nicht von der Präferenzstruktur der Zentralbank ab. Die reale Aufwertung und der gesamtwirtschaftliche Preisanstieg stellen sich unabhängig davon ein, ob die Zentralbank die Wirtschaftssubjekte durch eine Senkung oder Anhebung des nominalen Wechselkurses täuscht.

Für die Zentralbank besteht ein Anreiz, von der von ihr verkündeten wechselkurspolitischen Strategie abzuweichen, wenn sie bei Täuschung der privaten Wirtschaftsakteure einen geringeren Verlust realisiert. Es läßt sich zeigen, daß der Verlust im Falle der Täuschung durch die Gleichung

$$
K_{T}=\frac{1}{2} \frac{\alpha}{\alpha+(1-\mu)^{2}} \gamma^{2} \pi_{a d m}^{2}
$$

beschrieben wird. ${ }^{94}$ Die Kosten einer Wechselkursfixierung werden durch die schon aus dem Unterabschnitt 3.2.1. bekannte Gleichung

$$
K_{f i x}=\frac{\mu^{2}+\alpha}{2} \gamma^{2} \pi_{a d m}^{2}
$$

wiedergegeben. Ob die Kosten bei Täuschung höher oder niedriger ausfallen als bei Aufrechterhaltung der Wechselkursbindung, d.h. ob

$$
K_{T} \stackrel{\geqq}{<} K_{f i x},
$$

ist deshalb davon abhängig, ob

93 Die Berechnung erfolgt im Anhang VI.1.4.

94 Gleichung (23) ergibt sich aus Gleichung (A18) im Anhang VI.1.4., wenn $\hat{\pi}=\hat{w}^{r}=0$ gesetzt wird. 


$$
\frac{\alpha}{\alpha+(1-\mu)^{2}} \stackrel{\geqq}{\gtrless} \mu^{2}+\alpha
$$

Dieser Ausdruck läßt sich umformen zu

$$
0 \stackrel{\gtrless}{\gtrless}\left(\frac{\alpha}{1-\mu}-\mu\right)^{2} \cdot .95
$$

Daraus läßt sich ablesen, daß immer gilt

$$
K_{T} \leqq K_{f i x}
$$

weil die rechte Seite der Gleichung (24) nicht negativ werden kann. Die Zentralbank erzielt also im allgemeinen einen geringeren Verlust, wenn es ihr gelingt, die privaten Wirtschaftssubjekte zu täuschen. ${ }^{96}$ Es ist also vorteilhaft, von der Festkursstrategie abzuweichen, so daß sich diese Politik als zeitinkonsistent herausstellt. Eine Wechselkursbindung ist nicht glaubwürdig, weil die Öffentlichkeit erkennt, daß für die Zentralbank ein Anreiz besteht, ihre Ankündigung nicht einzuhalten.

Wenn die Wirtschaftssubjekte rationale Erwartungen haben, werden sie von vornherein der Ankündigung einer Festkursstrategie keinen Glauben schenken. Sie passen ihre Erwartungen dergestalt an, daß die Möglichkeit zur Täuschung ausgeschlossen wird. ${ }^{97}$ Im Rahmen des Modells bedeutet dies, daß die Preise im nationalen Sektor nicht auf das bei einer glaubwürdigen Wechselkursfixierung ermittelte niedrige Niveau festgelegt werden (siehe Gleichung (8)). Statt dessen werden die Preise im gleichen Ausmaß wie bei einem flexiblen Wechselkurssystem heraufgesetzt (siehe Gleichung (13)). ${ }^{98}$ Die Zentralbank kann dann nicht mehr die niedrigere gesamtwirtschaftliche Inflationsrate erreichen, die sich bei einer glaubwürdigen Wechselkursbindung einstellen würde.

In der Literatur werden verschiedene Möglichkeiten diskutiert, die der Zentralbank zur Verfügung stehen, um die Glaubwürdigkeit einer stabilitätsorientierten Politik zu erhöhen. Dies sind unter anderem eine von außen auferlegte Regelbindung, die

95 Zur Herleitung siehe Anhang VI.1.5.

96 Das Gleichheitszeichen in den Gleichungen (24) und (25) gilt wieder für den Spezialfall $\alpha=(1-\mu) \mu$. Da bei dieser Konstellation die Ergebnisse der Tăuschungslösung denen unter den beiden anderen Systemen entsprechen, besteht kein Zeitinkonsistenzproblem. Allerdings gibt es auch gar keinen Anreiz, eine Wechselkursbindung vorzunehmen.

Vgl. Barro/Gordon (1983b), S. 101.

8 Daß die Inflationsrate bei nationalen Gütern im Fall der Gleichung (13) höher ist als im Fall der Gleichung (8), ist aus der zweiten Spalte der Tabelle 2 auf Seite 114 ablesbar. 
Ernennung eines konservativen Zentralbankchefs und eine Disziplinierung durch einen längeren Zeithorizont. Auf diese Möglichkeiten wird im folgenden eingegangen.

Bisher wurde unterstellt, daß die Zentralbank zwar einen festen Wechselkurs ankündigt, ihre Strategie aber jederzeit ändern kann. Von dieser Selbstbindung ist eine Regelbindung zu unterscheiden, bei der die Notenbank aufgrund institutioneller Regelungen dazu verpflichtet wird, sich an die Wechselkursbindung zu halten. ${ }^{99}$ Eine solche exogene Regelbindung kann zum Beispiel in einer internationalen Vereinbarung bestehen, die nicht oder nur sehr schwer gelöst werden kann. Die Wirtschaftspolitiker sind dann durch völkerrechtliche Verträge an die Aufrechterhaltung des festen Wechselkurses gebunden. Die Europäische Währungsunion stellt hierfür ein gutes Beispiel dar. Eine schwächere Form der exogenen Regelbindung besteht darin, die Zentralbank durch gesetzliche Bestimmungen zur Beibehaltung des festen Wechselkurses zu zwingen. Prominentestes Beispiel für eine solche inländische Regelung ist ein Currency Board. ${ }^{100}$ Im Rahmen eines Currency Boards ist die Zentralbank per Gesetz dazu verpflichtet, die Geldpolitik am Wechselkursziel auszurichten, wobei diese Verpflichtung dadurch unterstrichen wird, daß die Geldbasis zu 100 v.H. durch Devisenreserven gedeckt sein muß. Eine Änderung der festgelegten Parität erfordert in der Regel eine Gesetzesänderung, so daß die Öffentlichkeit rechtzeitig über eine geplante Aufgabe der Festkursstrategie informiert wird. Weil Überraschungen bzw. Täuschungen im Rahmen eines Currency Boards sehr unwahrscheinlich sind, besitzt diese Art der Wechselkursfixierung in der Regel eine hohe Glaubwürdigkeit.

Der in der Literatur vorgeschlagene Weg der Ernennung einer ultrakonservativen Zentralbankleitung, die ausschließlich das Ziel der Preisstabilität verfolgt, ${ }^{101}$ scheidet hingegen zur Lösung des Glaubwürdigkeitsproblems im Rahmen des hier vorgestellten Modells aus. Wie der Vergleich der beiden Wechselkurssystem deutlich gemacht hat, würde ein ultrakonservativer Zentralbankchef keine Wechselkursbindung wählen, sondern im Rahmen eines flexiblen Wechselkurssystems eine nominale Aufwertung anstreben.

Schließlich ist noch zu bedenken, daß es sich bei der Modellanalyse um eine Einperiodenbetrachtung handelt. Tatsächlich wird aber der Zeithorizont der Zentral-

99 Siehe zur Unterscheidung zwischen Selbstbindung und exogener Regelbindung im Rahmen einer Festkursstrategie Bofinger et al. (1996), S. 325.

100 Zur Funktionsweise und Ausgestaltung von Currency Boards siehe Balino et al. (1997), S. 1 ff.

101 Der Vorschlag zur Ernennung eines konservativen Zentralbankers geht zuruck auf Rogoff (1985), S. 1169 ff. Siehe hierzu auch Illing/fecht (1998), S. 89 f. 
bank mehrere Perioden umfassen. 102 Bei einer Mehrperiodenbetrachtung berücksichtigt die Notenbank, daß ihre Politikmaßnahmen in der laufenden Periode auch Auswirkungen auf die Erwartungsbildung der Wirtschaftssubjekte in den Folgeperioden haben. Während sie durch ein Abweichen von der Festkursstrategie kurzfristig einen niedrigeren Verlust realisieren kann, muß die Zentralbank in Kauf nehmen, daß die Wirtschaftssubjekte ihr künftig keinen Glauben mehr schenken. Sie kann dann zukünftig nur eine höhere Inflationsrate wie bei einem flexiblen Wechselkurssystem realisieren. Demgegenüber kann die Zentralbank eine Reputation aufbauen, wenn sie über mehrere Perioden die Wechselkursbindung beibehält. Die konkreten Ergebnisse sind davon abhängig, wie lang der Planungshorizont ist, wie stark die Zentralbank künftige Verlustwerte abdiskontiert und welcher Art die Sanktionen der Öffentlichkeit sind. So kommt es zum Beispiel darauf an, wieviel Zeit vergeht, bis die Wirtschaftssubjekte einer Ankündigung der Zentralbank wieder Glauben schenken. Auf die Ausweitung der Analyse auf einen Mehrperiodenansatz wird an dieser Stelle verzichtet, weil die Abhängigkeit des Stabilisierungserfolgs vom Wechselkurssystem, die im Mittelpunkt der vorliegenden Arbeit steht, bereits bei der Einperiodenbetrachtung deutlich hervortritt.

\subsection{Zusammenfassung und Übertragbarkeit der Ergebnisse}

Als ein wichtiges Ergebnis der Modellauswertung ist zunächst festzuhalten, daß bei sehr starker Präferenz für Preisstabilität der feste Wechselkurs als nominaler Anker nicht optimal ist. Verfolgt die Zentralbank fast ausschließlich das Ziel, das Preisniveau zu stabilisieren, ohne sich um die Aufrechterhaltung der internationalen Wettbewerbsfähigkeit zu sorgen, dann ist es optimal, den Wechselkurs zu senken. Bei annahmegemäß konstanten Preisen handelbarer Güter in ausländischer Währung bewirkt die nominale Aufwertung eine Senkung der Preise im internationalen Sektor und einen geringeren Anstieg der Preise im Sektor der nichthandelbaren Güter. ${ }^{103}$ Die Zentralbank kann daher ihrem sehr stark gewichteten Ziel der Preisstabilität über die nominale Aufwertung näher kommen, als wenn sie den Wechselkurs konstant hält. Diese Erkenntnis wird in den meisten Beiträgen vernachlässigt, die im Rahmen der Diskussion um das optimale Wechselkurssystem die Ankerfunktion der Wechselkursbindung betonen und in diesem Zusam-

102 Vgl. zu den Ausfuhrungen zum Mehrperiodenansatz Jarchow (1998a), S. 289 ff.

103 Wird die Annahme der Preisstabilităt internationaler Guter in Auslandswăhrung aufgegeben und durch eine positive Inflationsrate ersetzt, ergibt sich die gleiche Schlußfolgerung. Bei unverăndertem Ziel der Preisstabilităt im Inland $(\hat{\pi}=0)$ verstärkt sich sogar der Wunsch der Zentralbank nach einer Senkung des nominalen Wechselkurses, weil die ausländischen Preissteigerungen durch den Anteil der handelbaren Guter am Warenkorb zusătzlich preiserhöhend wirken. 
menhang von einem „Import von Preisstabilität“ sprechen.104 Es zeigt sich zwar auch im Rahmen des hier vorgestellten Modells, daß ein festes Wechselkurssystem zu niedrigeren Inflationsraten führen kann als ein System flexibler Wechselkurse. Allerdings ist ein Festkurssystem aus Sicht der wirtschaftspolitischen Entscheidungsträger nur dann optimal, wenn sie neben dem Ziel der Inflationsreduzierung auch die internationale Wettbewerbsfähigkeit der Volkswirtschaft beachten. Hat das zuletzt genannte Ziel hingegen nur ein zu vernachlässigendes Gewicht, läßt sich die Preisstabilität besser durch eine Senkung des nominalen Wechselkurses erreichen.

In der wirtschaftswissenschaftlichen Diskussion um die Vorteilhaftigkeit einer Wechselkursbindung wurde dieser Aspekt bisher nicht nur unzureichend berücksichtigt, sondern seine Vernachlässigung hat auch zu falschen Interpretationen geführt. So setzt Edwards (1998) zum Beispiel irrtümlich zur Beschreibung des Falles einer Wechselkursfixierung das Gewicht vor dem ersten Term der Zielfunktion gleich Eins und das Gewicht vor der realen Wechselkurskomponente gleich Null. ${ }^{105}$ Dies spiegelt zwar den Grenzfall einer ausschließlichen Präferenz der Wirtschaftspolitiker für Preisstabilität wider, ist jedoch nicht mit einer Wechselkursfixierung identisch. Solange die Preissteigerungen in Auslandswährung nicht Null sind (wie die positive ausländische Inflation bei Edwards (1998)) oder andere preiserhöhend wirkende Einflüsse im Modell berücksichtigt werden (wie im hier vorgestellten Modell in Form von $\gamma \pi_{a d m}$ ), werden die Wirtschaftspolitiker bei ausschließlicher Präferenz für Preisstabilität den nominalen Wechselkurs senken, um bei $\pi=0$ eine Minimierung der Kosten zu erreichen. Wie die Auswertung im Unterabschnitt 3.2.3. gezeigt hat, ist eine nominale Aufwertung sogar nicht nur im Extremfall ausschließlicher Präferenz für Preisstabilität optimal. Dieses Ergebnis stellt sich auch ein, wenn die Gewichtung des realen Wechselkursziels hinreichend gering ist; konkret, wenn $\alpha<(1-\mu) \mu$. Wie bereits bei der Vorstellung der wirtschaftspolitischen Zielfunktion erwähnt, kann auch im vorliegenden Modell der Fall abgebildet werden, in dem die Zentralbank ausschließlich das Ziel der Preisstabilität verfolgt. Dazu muß $\alpha$ in den Gleichungen für das System flexibler

104 Vgl. exemplarisch zu dieser Position Aghevli et al. (1991), S. 7, Schăfer (2000), S. 217, und Weber (1995), S. 251 f. Auch die Aussage von Krajnyák/Zettelmeyer (1998), S. 312, daß die Wechselkurspolitik in der Anfangsphase der Transformation überwiegend in den Dienst der Stabilisierung gestellt wurde, muß im Lichte des Partialmodells dieser Arbeit kritisch gesehen werden. Die Analyse hat gezeigt, daß ein Festkurssystem gewählt wird, wenn die Preisstabilisierung und das außenwirtschaftliche Gleichgewicht wichtige wirtschaftspolitische Zielsetzungen sind.

105 Vgl. Edwards (1998), S. 687. Er verwendet eine Zielfunktion in der Form $K=\alpha \pi_{1}^{2}+(1-\alpha)\left(w^{r}-\hat{w}^{r}\right)^{2}$, wobei die realen Wechselkursgrößen als Niveaus in die Verlustfunktion eingehen und im Modell eine positive ausländische Inflationsrate unterstellt wird. Siehe S. 685; die Notation wurde aus Grunden der Vergleichbarkeit der in dieser Arbeit verwendeten Symbolik angepaßt. 
Wechselkurse gleich Null gesetzt werden. Es ergibt sich dann ebenfalls eine nominale Aufwertung als optimale Lösung. ${ }^{106} \mathrm{Da}$ die Zentralbank jedoch nur noch ein wirtschaftspolitisches Ziel mit einem Instrument - in diesem Fall dem nominalen Wechselkurs - verfolgt, kann sie ihr Ziel auch erreichen, d.h. es ergibt sich gesamtwirtschaftliche Preisstabilität $(\pi=0)$ und kein Verlust, da $K$ in diesem Fall den Wert Null annimmt. ${ }^{107}$

Die Ergebnisse des Modells stimmen hingegen mit der Literatur in der Hinsicht überein, daß ein fester Wechselkurs eher dann gewählt wird, wenn ein relativ hohes Gewicht auf Preisstabilität gelegt wird. ${ }^{108}$ In der Tabelle 3 sind die Situationen, in denen ein Festkurssystem vorteilhafter ist, durch die schattierten Felder gekennzeichnet. Wenn man beachtet, daß bei $\alpha=1$ beide Ziele gleich stark gewichtet sind, wird die Aussage insbesondere für weniger offene Volkswirtschaften sehr anschaulich bestätigt. Die schattierte Fläche erstreckt sich im größeren Ausmaß über Felder oberhalb der Zeile $\alpha=1$, also in Bereichen mit $\alpha<1$, die mit einer stärkeren Präferenz für Preisstabilität verbunden sind. Wichtig ist die Erkenntnis, daß nicht ein „zu großes“ Gewicht auf die Preisstabilität gelegt werden darf, denn dann ist die Wechselkursfixierung nicht mehr optimal. Solche Situationen werden durch den oberen, nicht schattierten Bereich in der Tabelle 3 markiert. In Übereinstimmung mit den Ergebnissen aus der Diskussion um die Abgrenzung eines optimalen Währungsraums ergibt sich zudem, daß ceteris paribus ein fester Wechselkurs um so eher für ein Land zu empfehlen ist, je offener seine Volkswirtschaft ist. 109

Für die Übertragbarkeit der Ergebnisse auf die mittel- und osteuropäischen Transformationsländer ist zu berücksichtigen, daß eine Mehrzahl diese Länder zumindest für einen gewissen Zeitraum eine Wechselkursbindung betrieben hat. Die Modellergebnisse legen die Vermutung nahe, daß diese Länder einerseits zwar den festen Wechselkurs als Instrument zur Reduzierung hoher Inflationsraten benutzten, daß sie andererseits aber auch um die internationale Wettbewerbsfähigkeit besorgt waren. Dies erscheint plausibel, da die Länder zu Transformationsbeginn -

106 Wie sich unter Berucksichtigung von $\alpha=0$ in Gleichung (12) sehr leicht zeigen läßt, ergibt sich fur die nominale Wechselkursănderung genauer $w=-[\mu /(1-\mu+\mu \beta)] \gamma \pi_{a d m}$.

107 Fur die Variablen $\pi_{N}$ und $w^{r}$ ergeben sich fur diesen Spezialfall die folgenden Ergebnisse: Wenn $\alpha=0$ ist, folgt fur die Preisentwicklung im Sektor der nicht-handelbaren Guter aus Gleichung (13)

$\pi_{N}=[(1-\mu) /(1-\mu+\mu \beta)] \gamma \pi_{\text {odm }}$

und fur die reale Wechselkursănderung aus Gleichung (14)

$w^{r}=-[1 /(1-\mu+\mu \beta)] \gamma \pi_{\text {odm }}$.

108 Siehe hierzu den Unterabschnitt II.3.2.1. und die darin angegebene Literatur.

109 Vgl. zur Bedeutung des Offenheitsgrads einer Volkswirtschaft fur das Wechselkursregime McKinnon (1963), S. 717 ff., sowie Jarchow/Ruhmann (1997), S. 306 ff., und Rose/Sauernheimer (1999), S. 310 f. 
wie im zweiten Kapitel ausführlich erläutert - eine unvermeidbare Preisliberalisierung mit stark steigenden Inflationsraten durchführen mußten und daher mit der Notwendigkeit einer zügigen Preisstabilisierung konfrontiert waren. Wie ebenfalls im vorangegangenen Kapitel erläutert, standen die Länder zudem vor der Aufgabe, ihre Volkswirtschaften in den internationalen Handel zu integrieren. Insbesondere die massiven Abwertungen der meisten Reformländer zu Beginn ihrer Transformation deuten darauf hin, daß dem Ziel der Sicherung der internationalen Wettbewerbsfähigkeit ein nicht unbedeutendes Gewicht bei der wirtschaftspolitischen Zielsetzung beigemessen wurde. Auch die Entscheidungen Polens und Ungarns für einen aktiven Crawling Peg stützen die These, daß beide Zielsetzungen für die Transformationsländer von Bedeutung waren. Bei einem Crawling Peg besteht einerseits die Möglichkeit, den Wechselkurs als nominalen Anker für die Inflationserwartungen zu nutzen. Andererseits eröffnet ein solches Wechselkursregime die Möglichkeit, die mit einer Wechselkursfixierung verbundene reale Aufwertung abzuschwächen, wenn im Inland über einen längeren Zeitraum höhere Inflationsraten herrschen als im Ausland.

Auch im Hinblick auf die Glaubwürdigkeitsproblematik einer Wechselkursbindung liefert die Modellauswertung wichtige Ergebnisse. Wie im Unterabschnitt 3.3. gezeigt, besteht für die Zentralbank in der Regel ein Anreiz, die Wechselkursbindung aufzugeben, nachdem die Wirtschaftssubjekte ihre Inflationserwartungen nach unten angepaßt haben. ${ }^{110}$ Darüber hinaus wird ein besonderes Problem von Stabilisierungsprogrammen mit festem Wechselkurs deutlich. Ein Festkurssystem wird nur dann gewählt, wenn sowohl das Preisstabilitätsziel als auch die außenwirtschaftliche Komponente in der Zielfunktion beachtet werden; denn bei ausschließlicher oder starker Präferenz für Preisstabilität wäre eine Aufwertung im Rahmen eines Systems flexibler Wechselkurse zielkonform. Das Modell zeigt, daß die Argumentation, die Zentralbank fixiere deshalb den Wechselkurs, weil ihr fast ausschließlich an einer Preisstabilisierung gelegen sei, nicht korrekt ist. Mit der Wahl des festen Wechselkurses erreicht die Zentralbank zwar eine Reduzierung der Inflationsrate gegenüber einem flexiblen Wechselkurssystem, allerdings signalisiert sie gleichzeitig, daß sie auch Wert auf die internationale Wettbewerbsfähigkeit legt. Dieses Ziel wird jedoch bei einem Festkurssystem stärker verfehlt als bei einem System flexibler Wechselkurse, in dem die Zentralbank nominal abwertet. 111

110 Dieses Glaubwürdigkeitsproblem entspricht - auf die Wechselkurspolitik bezogen - dem aus der geldtheoretischen Literatur bekannten Täuschungsanreiz, der sich aus der Zeitinkonsistenz der Regelbindung ergibt. Siehe hierzu Barro/Gordon (1983b), S. 107 f., und Jarchow (1998a), S. $283 \mathrm{ff}$.

111 Der Vergleich zwischen den Systemen mit festen und flexiblen Wechselkursen hat folgendes gezeigt: Die Parameterkonstellation $\alpha>(1-\mu) \mu$ ist eine notwendige, aber nicht hinreichende Bedingung dafur, daß der Vergleich der wirtschaftspolitischen Kosten seitens der Zentralbank 
Aus dieser Konstellation resultiert ein besonderes Glaubwürdigkeitsproblem, das über den oben beschriebenen Anreiz zur Täuschung hinausgeht. Es wird dasjenige Ziel stärker verfehlt, dessen Relevanz durch die Entscheidung für das feste Wechselkursregime signalisiert wird. In der Literatur wird insbesondere auf die mit einer Wechselkursfixierung verbundene Gefahr hingewiesen, daß die Inflationsdifferenz zum Ausland zu einer realen Aufwertung führe. Dies könne die wirtschaftspolitischen Entscheidungsträger früher oder später dazu veranlassen, protektionistische Maßnahmen zu ergreifen oder die Wechselkursbindung aufzugeben, weil die Kosten der Überbewertung die Vorteile des festen Wechselkurses übersteigen. ${ }^{112}$ Die Ergebnisse dieses Abschnitts bestätigen diese Schlußfolgerung. Allerdings erweitert das Modell diesen Aspekt um die Erkenntnis, daß die Entscheidung für eine Wechselkursbindung gerade ein Indiz für die nicht zu vernachlässigende Bedeutung der außenwirtschaftlichen Komponente in der Zielsetzung der Wirtschaftspolitiker ist.

Da eine Täuschung nach Ankündigung einer Wechselkursfixierung vorteilhaft ist, bietet das Modell eine Erklärung dafür, warum einige Länder Mittel- und Osteuropas ihre Währungen in Form eines Currency Boards gebunden haben. Wie erwähnt, ist ein entsprechend starkes Binden der eigenen Hände in Form der gesetzlichen Verankerung der Wechselkursbindung durch ein Currency Board eine Möglichkeit, um die Glaubwürdigkeit der Festkursstrategie zu erhöhen. Auch die Beobachtung, daß viele Transformationsländer nach einer anfänglichen Fixierung zu einer flexibleren Handhabung der Wechselkurspolitik übergegangen sind, ist mit den Resultaten der Modellauswertung kompatibel. Um die Eignung des Modellansatzes für die Analyse der Wechselkurspolitik im Transformationsproze $\beta \mathrm{zu}$ überprüfen, müssen jedoch noch zwei weitere Ergebnisse des Modells mit den Erfahrungen der Reformländer verglichen werden. Einerseits ergibt sich unabhängig vom Wechselkursregime in allen Fällen eine reale Aufwertung der heimischen Währung, wobei die Aufwertung bei flexiblen Wechselkursen geringer ausfällt als bei einer Wechselkursbindung, wenn die Währung im Rahmen des Flexkurssystems nominal abgewertet wird. ${ }^{113}$ Zum anderen legt der Vergleich der Inflationsraten zwischen einem Festkurssystem und einem System flexibler Wechselkurse die Vermutung nahe, daß Länder, die einen festen Wechselkurs gewählt haben, niedrigere Preissteigerungsraten aufweisen als Länder, die sich für flexible Wech-

zu einer Entscheidung für ein Festkurssystem fuhrt. Bei dieser Parameterkonstellation gilt $\left|w_{\text {fex }}^{r}\right|<\left|w_{\text {Nxx }}^{r}\right|$ und $\pi_{\text {fex }}>\pi_{\text {fix }}$, so daß bei einem festen Wechselkurs eine stärkere Abweichung von der außenwirtschaftlichen Zielsetzung hingenommen werden muß als bei flexiblen Wechselkursen. Vgl. Tabelle 2 im Unterabschnitt 3.2.3.

112 Siehe hierzu exemplarisch Edwards (1989), S. 77 f., und Schweickert et al. (1992), S. $11 \mathrm{ff}$.

113 In einem Flexkurssystem mit nominaler Aufwertung fallt hingegen die reale Aufwertung stärker aus als bei Fixierung des nominalen Wechselkurses. Siehe hierzu die erste Spalte der Tabelle 2 auf Seite 114. 
selkurse entschieden - es sei denn, das Land mit flexiblem Wechselkurs hat nominal aufgewertet. Diesen beiden Aspekten wird im folgenden vierten Kapitel ausführlich nachgegangen, wobei auch weitere Einflußfaktoren analysiert werden, die auf die wirtschaftliche Entwicklung der Transformationsländer unter Umständen einen nicht unerheblichen Einfluß gehabt haben, die aber nicht in die Modellformulierung aufgenommen wurden. 
Axel Gerloff - 978-3-631-75700-0

Downloaded from PubFactory at 01/11/2019 02:46:37AM

via free access 


\section{Wechselkurs- und stabilitätspolitische Erfahrungen der zehn mittel- und osteuropäischen EU-Beitrittskandidaten}

Nach der theoretischen Analyse der Rolle der Wechselkurspolitik im dritten Kapitel werden diesen Überlegungen im vierten Kapitel die Erfahrungen in den zehn mittel- und osteuropäischen EU-Beitrittskandidaten gegenübergestellt. Der erste Abschnitt gibt einen Überblick darüber, für welche wechselkurspolitischen Optionen sich diese Länder zu Beginn ihrer Transformation entschieden und wie die Wechselkurspolitik im Zeitablauf modifiziert wurde.

Daran schließt sich im zweiten Abschnitt eine Auswertung der empirischen Literatur zur Rolle der Wechselkurspolitik im Hinblick auf zwei wichtige Aspekte an. Erstens wird untersucht, wie sich der reale Wechselkurs im Transformationsprozeß entwickelt hat und inwieweit der Verlauf vom gewählten Wechselkursregime abhängt. Diese Auswertung liefert eine Antwort auf die Frage, ob das im dritten Kapitel vorgestellte Partialmodell die reale Wechselkursentwicklung im Transformationsprozeß korrekt beschreibt. Zweitens werden empirische Studien dahingehend ausgewertet, welche Aussagen sie über die Relevanz des Wechselkurssystems für die Entwicklung der beiden zentralen makroökonomischen Größen Wachstum und Inflation treffen. Anhand dieser Literaturübersicht und des dritten Abschnitts, der den Verlauf von Wirtschaftswachstum und Inflation in den zehn betrachteten Ländern beschreibt, wird untersucht, ob das Ergebnis des Partialmodells im Hinblick auf die Inflationsentwicklung bestätigt werden kann. Die Modellanalyse läßt erwarten, daß die Länder, die entweder eine nominale Aufwertung betrieben oder ein Festkurssystem wählten, größere Erfolge bei der Preisstabilisierung erreichten als Länder, deren Währungen nominal abgewertet wurden. Zusätzlich zur Inflation wird auch das Wirtschaftswachstum in die Betrachtung einbezogen, um zu überprüfen, ob eine erfolgreiche Reduzierung der Preissteigerungsraten gegebenenfalls die wirtschaftliche Entwicklung beeinträchtigt hat. Neben der Wahl des Wechselkurssystems werden weitere mögliche Einflußfaktoren analysiert, um Gemeinsamkeiten in der Entwicklung von Wirtschaftswachstum und Inflation zu erläutern und zu klären, welche Rolle der Wechselkurspolitik im Rahmen eines Stabilisierungsprogramms beigemessen werden kann.

Der vierte Abschnitt über die mittelfristigen wechselkurspolitischen Perspektiven der zehn Beitrittskandidaten rundet das Kapitel IV ab, indem er einen Ausblick auf den beitrittsbedingten wechselkurspolitischen Handlungsbedarf gibt. Der Beitritt zur EU stellt für die Länder eine neue währungspolitische Heraus- 
forderung dar, weil er als mittelfristige Zielsetzung die Teilnahme am Europäischen Wechselkursmechanismus EWS II vorsieht sowie in der Endstufe die Einführung des Euro und die Teilnahme an der Europäischen Währungsunion beinhaltet.

\section{Wechselkurspolitische Maßnahmen}

Die zehn Beitrittskandidaten haben eine Vielzahl unterschiedlicher wechselkurspolitischer Strategien gewählt. Während einige Länder zunächst eine Bindung der heimischen Währung an eine ausländische Währung oder einen Währungskorb vornahmen, entschieden sich andere für einen flexiblen Wechselkurs. Von denjenigen Ländern, die mit einem Festkurssystem begannen, gingen einige zu flexibleren Wechselkursregelungen über, während andere die feste Bindung auch gegenwärtig noch beibehalten. Diejenigen Länder, die sich zunächst für die Option eines flexiblen Wechselkurses entschieden, modifizierten ebenfalls ihre Politik, indem sie zum Beispiel für einen bestimmten Zeitraum eine Wechselkursstabilisierung betrieben oder sogar ganz zu einem Festkurssystem übergingen.

Die folgenden Ausführungen geben einen Überblick über die vielfältigen Wechselkurspolitiken, die in Mittel- und Osteuropa praktiziert wurden, und stützen sich auf den Anhang VI.2., der für alle zehn Beitrittskandidaten eine detaillierte Chronik der währungspolitischen Maßnahmen enthält. Dabei wird nicht nur ein reines Floating, sondern auch ein Managed Floating als flexibles Wechselkurssystem bezeichnet. Alle betrachteten Länder, die ein flexibles Wechselkursregime wählten, haben gelegentlich am Devisenmarkt interveniert. Ein reines Floating war und ist in den Transformationsökonomien nicht $\mathrm{zu}$ beobachten. Die Tabelle 4 am Ende des Abschnitts faßt die Ergebnisse zusammen. Weiterführende Angaben zu den wechselkurspolitischen Maßnahmen in den einzelnen Ländern finden sich im genannten Anhang VI.2. Die in diesem Abschnitt und im Anhang verwendeten Währungsbezeichnungen sind im Abkürzungsverzeichnis der Arbeit aufgeführt.

$\mathrm{Zu}$ den Ländern, die am Anfang ihrer Transformation einen festen Wechselkurs wählten, gehören Estland, Polen, die Tschechoslowakei und Ungarn. Nach dem Ausscheiden aus der Rubelzone führte Estland im Juni 1992 eine neue Währung ein. Die Estnische Krone wurde von Beginn an in Form eines Currency Board Systems im Verhältnis 8 EEK zu 1 DEM an die Deutsche Mark gebunden. ${ }^{1}$ Dieses Währungssystem wurde bei unveränderter Wechselkursrelation während des gesamten Reformprozesses beibehalten.

1 Zur Ausgestaltung des estnischen Currency Boards siehe Bennett (1993), S. 451 ff., und Balino et al. (1997), S. $1 \mathrm{ff}$. 
Polen hat Anfang 1990 den Zloty an den US-Dollar gebunden, ist aber sukzessive zu flexibleren Wechselkursregelungen übergegangen. Die Wechselkursbindung zu Transformationsbeginn war - wie auch in allen anderen mittel- und osteuropäischen Ländern - mit einer drastischen nominalen Abwertung verbunden, ${ }^{2}$ und zwar von 6500 auf 9500 Zloty pro US-Dollar. Die Regierung kündigte an, das neue Wechselkursniveau auf jeden Fall ein Vierteljahr aufrecht zu erhalten. Nach diesem Zeitraum könnte, wenn erforderlich, eine Anpassung erfolgen. ${ }^{3}$ Tatsächlich wurde die Bindung bis zum Mai 1991 beibehalten. In diesem Monat wurde der Zloty einmalig abgewertet und an einen aus fünf Währungen bestehenden Währungskorb gebunden. ${ }^{4}$ Noch im Oktober des gleichen Jahres erfolgte der Wechsel zu einem aktiven Crawling Peg mit einer angekündigten monatlichen Abwertungsrate von anfänglich 1,8 v.H. Dies entsprach einer Abwertung auf Jahresbasis in Höhe von 23,9 v.H. und lag deutlich unter der Inflationsrate, die 1991 im Jahresdurchschnitt 70,3 v.H. betrug. Um die nominale Ankerfunktion des Wechselkurses zu erhalten, wurde mit fortschreitenden Erfolgen bei der Disinflation die monatliche Abwertungsrate sukzessive gesenkt. Darüber hinaus erfolgten aber auch mehrfach diskretionäre Wechselkursanpassungen. In den Jahren 1992 und 1993 wurde je einmal nominal abgewertet, während 1995 den starken Kapitalzuflüssen mit einer nominalen Aufwertung Rechnung getragen wurde. Im Jahr 1995 wurde außerdem das Wechselkursband um die gleitende Parität zunächst im März von $\pm 0,5$ v.H. auf \pm 2 v.H. und dann im Mai auf \pm 7 v.H. ausgeweitet, so daß man ab diesem Zeitpunkt von einem Crawling Band sprechen kann. Die Bandbreite wurde in drei weiteren Schritten erhöht und betrug zuletzt \pm 15 v.H. Der ursprüngliche Währungskorb aus fünf Währungen wurde bis Ende 1998 beibehalten und im Januar 1999 durch einen Korb ersetzt, der nur noch aus dem Euro (55 v.H.) und dem US-Dollar (45 v.H.) bestand. Im April 2000 ist Polen zu einem flexiblen Wechselkurs übergangen. Die polnische Wechselkurspolitik stellt insofern ein Beispiel für einen kontinuierlichen, krisenfreien Übergang von einer festen Wechselkursbindung zu einem flexiblen Wechselkurssystem dar.

Der Wechsel von einem Festkurssystem zu flexibleren Wechselkursregelungen in den Nachfolgestaaten der Tschechoslowakei verlief hingegen nicht so problemlos. Nach der Vereinheitlichung des Wechselkurses und drei diskretionären Abwertungen der Tschechoslowakischen Krone im Laufe des Jahres 1990 wur-

2 Nicht nur im Rahmen der Entscheidungen fur feste Wechselkurse wurden die nominalen Wechselkurse stark angehoben. Auch in den Lăndern, die mit einem flexiblen Wechselkurssystem in die Transformation starteten, stellten sich anfangs deutliche nominale Abwertungen ein.

3 Vgl. Wellisz (1997), S. 158.

4 Der Wăhrungskorb bestand aus folgenden Wăhrungen mit entsprechender Gewichtung: USD 45 v.H., DEM 35 v.H., GBP 10 v.H., FRF 5 v.H. und CHF 5 v.H. 
de die Währung Ende Dezember 1990 nach einer weiteren Abwertung an einen Korb aus fünf Währungen gebunden. Die Zusammensetzung des Korbes wurde im Januar 1992 leicht modifiziert, der Korb bestand aber weiterhin aus fünf Währungen. ${ }^{5}$ Nach der Aufspaltung der Tschechoslowakei in die Slowakische und Tschechische Republik zerbrach im Februar 1993 die Währungsunion zwischen den beiden neuen Staaten. Die neu eingeführte Tschechische Krone wurde zunächst auf unverändertem Niveau gegenüber dem gleichen Währungskorb wie die Tschechoslowakische Krone fixiert. Bereits ein Vierteljahr später im Mai 1993 - wurde dieser Währungskorb durch eine Bindung gegenüber der Deutschen Mark (65 v.H.) und dem US-Dollar (35 v.H.) ersetzt. Nachdem im Februar 1996 zunächst eine Ausweitung des Bandes um die Parität von \pm 0,5 v.H. auf \pm 7,5 v.H. erfolgte, war Tschechien im Mai 1997 im Rahmen einer Währungskrise gezwungen, den Kurs freizugeben. Seither ist der Wechselkurs flexibel.

Nach der Auflösung der Währungsunion mit Tschechien behielt auch die Slowakische Republik zunächst die Wechselkursbindung bei. Die Slowakische Krone wurde ebenfalls auf dem gleichem Niveau wie die Tschechoslowakische Krone an den bisherigen Währungskorb gebunden. Im Juli 1993 erfolgte eine Abwertung um 10 v.H. Ein Jahr später - im Juli 1994 - wurde die Zusammensetzung des Währungskorbes geändert. Von diesem Zeitpunkt an bestand der neue Korb nur noch aus der Deutschen Mark (60 v.H.) und dem US-Dollar (40 v.H.). Das Wechselkursband wurde in mehreren Schritten von ursprünglich \pm 0,5 v.H. auf schließlich \pm 7 v.H. im Jahre 1996 ausgeweitet. Aus verschiedenen Gründen erhöhte sich im Laufe des Jahres 1998 die Unsicherheit über den Fortbestand der Wechselkursfixierung. ${ }^{6}$ Der zunehmende Abwertungsdruck führte schließlich dazu, daß die slowakische Nationalbank den Kurs Anfang Oktober 1998 freigab. Seit der Aufgabe der Wechselkursbindung läßt die Nationalbank die Slowakische Krone floaten und interveniert nur gelegentlich auf dem Devisenmarkt.

Von den bisher beschriebenen Länderbeispielen weicht Ungarn dergestalt ab, $\mathrm{da} ß$ es zwar auch zunächst eine Wechselkursbindung wählte, von Anfang an aber ein sehr viel höheres Gewicht auf die Erhaltung der internationalen Wett-

5 Bis 1991 war die Zusammensetzung wie folgt: 45,52 v.H. DEM, 31,34 v.H. USD, 12,35 v.H. ATS, 6,55 v.H. CHF und 4,24 v.H. GBP. Ab Januar 1992 bestand der Korb aus 49,07 v.H. USD, 36,15 v.H. DEM, 8,07 v.H. ATS, 3,79 v.H. CHF und 2,92 v.H. FRF.

6 Insbesondere drei Faktoren fuhrten zur Unsicherheit uber den Fortbestand des festen Wechselkurses. Erstens geriet die Slowakische Krone - wie auch andere mittel- und osteuropäische Wăhrungen - im Zuge der Rußlandkrise unter Abwertungsdruck. Zweitens wurde die Slowakei von den internationalen Ratingagenturen 1998 zuruckgestuft und verlor im September 1998 das Investment Grade. Als dritter Faktor erhöhten die bevorstehenden Parlamentswahlen die Unsicherheit. Vgl. Krzak (1998), S. 17. 
bewerbsfähigkeit legte, während in den anderen Ländern der Wechselkurs als nominaler Anker verwendet wurde. Bis 1991 wurde der feste, aber anpassungsfähige Wechselkurs an einen Währungskorb gebunden, der aus verschiedenen Währungen wichtiger Außenhandelspartner bestand und dessen Zusammensetzung jährlich überprüft wurde. Im Dezember 1991 wurde der Forint an einen Korb gebunden, der zu gleichen Teilen aus der ECU und dem US-Dollar bestand. ${ }^{7}$ Im Zeitraum von 1990 bis 1994 wurde der Forint unregelmäßig in mehreren Schritten pro Jahr abgewertet, wobei sich die Gesamthöhe der jährlichen Abwertungen zwischen 5,1 v.H. und 21,7 v.H. bewegte. Während 1990, 1991 und 1992 jeweils zwei oder drei nominale Abwertungen vorgenommen wurden, stieg die Zahl der diskretionären Wechselkursanpassungen in 1993 und 1994 auf fünf bzw. sieben an. Einen wesentlichen Bestandteil des Stabilisierungsprogramms vom März 1995 bildete - neben einer weiteren einmaligen Abwertung im Ausmaß von 9 v.H. - ein aktives Crawling Peg System mit im voraus angekündigten Abwertungsschritten. Nachdem das Ziel der häufigen ad hoc Anpassungen des Wechselkurses insbesondere die Aufrechterhaltung der internationalen Wettbewerbsfähigkeit gewesen war, setzte ab 1995 auch Ungarn den Wechselkurs als Anker für die Inflationserwartungen ein. ${ }^{8}$ Der Währungskorb bestehend aus der ECU (70 v.H.) und dem US-Dollar (30 v.H.) - blieb zunächst unverändert. Im Januar 1997 wurde die ECU durch die Deutsche Mark ersetzt, die wiederum im Januar 1999 vom Euro abgelöst wurde. Seit Januar 2000 erfolgt die Bindung ausschließlich an den Euro. Die monatliche Abwertungsrate wurde von den ursprünglichen monatlichen 1,9 v.H. in mehreren, im voraus angekündigten Schritten auf 0,3 v.H. ab April 2000 reduziert. Um die gleitende Parität besteht seit der Einführung des Systems ein Interventionsband von \pm 2,25 v.H.

Die Ländergruppe, die mit flexiblen Wechselkurssystemen ihre Transformation begann, wird von Bulgarien, Lettland, Litauen, Rumänien und Slowenien gebildet. Während die beiden zuletzt genannten Länder an den flexiblen Wechselkursregelungen festgehalten haben, wählten die anderen drei Länder zwischenzeitlich einen festen Wechselkurs. Wie auch Estland führten die beiden anderen baltischen Staaten nach ihrem Ausscheiden aus der Rubelzone eine neue Währung ein. Anders als in Estland erfolgte die Währungsumstellung in Lettland und Litauen jeweils in zwei Schritten. Lettland ersetzte 1992 zunächst den Russischen Rubel durch den Lettischen Rubel, bevor der Lats 1993 stufenweise eingeführt wurde. In Litauen löste der Litauische Talonas im September 1992

7 Im August 1993 wurde im Zusammenhang mit den Turbulenzen innerhalb des Europäischen Währungssystems die ECU für kurze Zeit durch die Deutsche Mark ersetzt. Im Mai 1994 wurde jedoch wieder die ECU in den Währungskorb genommen, nunmehr mit von 50 v.H. auf 70 v.H. gestiegener Gewichtung.

8 Vgl. Moghadam (1998), S. 60. 
den Russischen Rubel ab, bevor im Sommer des darauffolgenden Jahres der Litas als neue Landeswährung an dessen Stelle trat. Sowohl Lettland als auch Litauen ließen ihre neuen Währungen zunächst für kurze Zeit floaten. Im Februar 1994 entschieden sich die lettischen Behörden, den Lats an einen Währungskorb in der Zusammensetzung des Sonderziehungsrechts des Internationalen Währungsfonds im Verhältnis 1 LVL zu 1,25 SDR zu binden. Litauen folgte im April 1994 dem Beispiel Estlands und führte ein Currency Board ein. Der Litas ist jedoch nicht an die Deutsche Mark, sondern im Verhältnis 4 LTL zu 1 USD an den US-Dollar gebunden. ${ }^{9}$ Dieses Wechselkurssystem wird zur Zeit noch aufrechterhalten. Allerdings hat die litauische Zentralbank bereits in ihrem geldpolitischen Programm für den Zeitraum 1997-1999 eine Strategie für den Ausstieg aus dem Currency Board entworfen. ${ }^{10}$ Aufgrund der schwierigen internationalen Rahmenbedingungen, die durch Krisen in anderen Schwellenländern bedingt waren, entschied sich die Notenbank dazu, dieses Vorhaben zu verschieben. Nunmehr ist eine Beibehaltung des Currency Boards in der gegenwärtigen Form bis 2001 und ein sich anschließender Wechsel zum Euro als neuer Ankerwährung vorgesehen. ${ }^{11}$

Auch Bulgarien vollzog nach einer Phase flexibler Wechselkurse den Übergang zu einem Currency Board. Die Wechselkursflexibilität wurde jedoch deutlich länger beibehalten, und zwar bis Mitte 1997. Auslöser für den Politikwechsel war eine schwere Wirtschaftskrise. Nach zwei Jahren, in denen Bulgarien positive Wachstumsraten verzeichnete, ging das reale Bruttoinlandsprodukt 1996 um mehr als 10 v.H. zurück. Die Inflationsrate stieg im Januar 1997 (im Vorjahresvergleich) auf 500 v.H. und im März 1997 auf über 2000 v.H. an. 12 Zur Überwindung dieser schwierigen wirtschaftlichen Situation wurde in der ersten Jahreshälfte 1997 ein Stabilisierungsprogramm verabschiedet, das als einen zentralen Bestandteil die Errichtung eines Currency Boards vorsah. ${ }^{13} \mathrm{Im}$ Juli 1997 wurde der Bulgarische Lew im Verhältnis 1000 BGL zu 1 DEM an die Deutsche Mark gebunden. Nach einer Währungsredenomination ${ }^{14}$ und eines durch die Einführung der einheitlichen europäischen Währung bedingten Wech-

9 Zu weiteren Informationen uber das litauische Currency Board siehe Balino et al. (1997), S. $1 \mathrm{ff}$.

10 Vgl. Bank of Lithuania (1997), Abschnitt 2.

11 Wahrend der ursprüngliche Plan explizit einen Ausstieg aus dem Currency Board System vorsah (vgl. Bank of Lithuania (1997), S. 7), ist nicht ganz klar, ob die neue Strategie eine Anbindung an den Euro in Form eines Currency Boards oder einer konventionellen Bindung vorsieht. Laut der Bank of Lithuania (1999), S. 1, soll ein „repegging of the litas to the euro" stattfinden.

12 Vgl. zu den Zahlenangaben Gulde (1999), S. 2.

13 Für weitere Komponenten des Programms siehe Backé (1997), S. 21 f.

14 Im Juli 1999 wurden drei Nullen der bulgarischen Wăhrung gestrichen. Ein „neuer“ Lew entspricht damit 1000 ,alten“ Lew. 
sels der Ankerwährung ist der Lew nunmehr im Verhältnis 1,95583 BGL zu 1 EUR an den Euro gebunden.

Im Gegensatz zu Bulgarien, Lettland und Litauen, die nach einer Phase flexibler Wechselkurse zu einem festen Wechselkursregime übergingen, behielten Rumänien und Slowenien die flexiblen Wechselkurse bei. Rumänien hat Anfang des Jahres 1991 ein duales Wechselkurssystem einführt, in dem zwischen einem offiziellen Kurs und einem Marktkurs unterschieden wurde. Bereits Ende des gleichen Jahres wurden die beiden Wechselkurse jedoch wieder vereinheitlicht. Seit November 1991 besteht ein flexibles Wechselkurssystem, wobei jedoch mehrfach versucht wurde, durch administrative Eingriffe Einfluß auf die Wechselkursentwicklung zu nehmen. Mit Ausnahme von vier staatlichen Banken wurden zum Beispiel im März 1996 allen Devisenhändlern die Lizenzen für den Fremdwährungshandel entzogen, so daß die Kursbildung einer weitgehenden staatlichen Kontrolle unterlag. Anfang 1997 erhielten die Devisenhändler ihre Lizenzen zurück. Der Kurs des Rumänischen Leu bildet sich seitdem wieder am Devisenmarkt, auf dem die rumänische Zentralbank jedoch häufig interveniert, um die Wechselkursentwicklung zu beeinflussen.

Nach der Abspaltung von Jugoslawien im Oktober 1991 führte Slowenien eine neue Währung ein und läßt den Slowenischen Tolar seither floaten. Allerdings hat die slowenische Notenbank häufiger am Devisenmarkt interveniert, um den Wechselkurs zu stabilisieren. Von Mitte 1994 bis Mitte 1995 nutzte die slowenische Zentralbank den Wechselkurs als nominalen Anker, indem sie den Kurs des Tolar zur Deutschen Mark nahezu konstant hielt. Auch danach griff sie regelmäßig in die Kursbildung am Devisenmarkt ein, um den Wechselkurs des Tolar gegenüber der Deutschen Mark für längere Zeiträume konstant zu halten, ohne jedoch explizit ein bestimmtes, von ihr verfolgtes Wechselkursziel zu nennen.

Zusammenfassend läßt sich festhalten, daß in den mittel- und osteuropäischen EU-Beitrittskandidaten das gesamte Spektrum wechselkurspolitischer Strategien von einem Currency Board bis zu flexiblen Wechselkursen mit gelegentlichen Interventionen am Devisenmarkt zum Einsatz kam. Darüber hinaus hat ein Großteil der Länder im Zeitablauf die Wechselkurspolitik modifiziert und zum Teil drastische Politikwechsel vollzogen. Die folgende Tabelle gibt einen zusammenfassenden Überblick über die Wechselkursregime in den zehn betrachteten Ländern. 
Tabelle 4: Wechselkurssysteme in Mittel- und Osteuropa ${ }^{a}$

\begin{tabular}{|c|c|c|}
\hline Land & Zeitraum & Wechselkurssystem \\
\hline Bulgarien & $\begin{array}{l}1990 \text { - Juni } 1997 \\
\text { seit Juli } 1997\end{array}$ & $\begin{array}{l}\text { flexibler Wechselkurs } \\
\text { Currency Board } \\
\text { Bindung an die DEM, seit } 1999 \text { an den EUR } \\
\end{array}$ \\
\hline Estland & $\begin{array}{l}\text { Juni } 1992 \\
\text { seit Juni } 1992\end{array}$ & $\begin{array}{l}\text { Austritt aus der Rubelzone, } \\
\text { Einfuhrung der Estnischen Krone } \\
\text { Currency Board } \\
\text { Bindung an die DEM, seit } 1999 \text { an den EUR }\end{array}$ \\
\hline Lettland & $\begin{array}{l}1992 \\
1993 \\
1992-\text { Jan } 1994 \\
\text { seit Feb } 1994\end{array}$ & $\begin{array}{l}\text { Austritt aus der Rubelzone, } \\
\text { Einfuhrung des Lettischen Rubel } \\
\text { stufenweise Einführung des Lats } \\
\text { flexibler Wechselkurs } \\
\text { fester Wechselkurs } \\
\text { Bindung an das SDR des Internationalen Wäh- } \\
\text { rungsfonds } \\
\end{array}$ \\
\hline Litauen & $\begin{array}{l}\text { Sept } 1992 \\
\text { Juni/Juli } 1993 \\
\text { 1992 - März } 1994 \\
\text { seit April } 1994\end{array}$ & $\begin{array}{l}\text { Austritt aus der Rubelzone, } \\
\text { Einfuhrung des Litauischen Talonas } \\
\text { Einführung des Litas } \\
\text { flexibler Wechselkurs } \\
\text { Currency Board } \\
\text { Bindung an den USD } \\
\end{array}$ \\
\hline Polen & $\begin{array}{l}\text { Mai } 1995 \text { - Apr } 2000 \\
\text { seit Apr } 2000\end{array}$ & $\begin{array}{l}\text { fester Wechselkurs } \\
\text { Bindung an den USD } \\
\text { Bindung an einen Währungskorb aus } 5 \text { Währungen } \\
\text { Crawling Peg } \\
\text { gegenüber dem unveränderten Währungskorb aus } 5 \\
\text { Währungen; schrittweise Reduzierung der ange- } \\
\text { kündigten monatlichen Abwertungsrate von } 1,8 \\
\text { v.H. auf } 1,2 \text { v.H.; im März } 1995 \text { Ausweitung des } \\
\text { Bandes um die Parität von } \pm 0,5 \text { v.H. auf } \pm 2 \text { v.H. } \\
\text { Crawling Band } \\
\text { gegenüber dem unveränderten Währungskorb aus } 5 \\
\text { Währungen; schrittweise Reduzierung der ange- } \\
\text { kündigten monatlichen Abwertungsrate von } 1,2 \\
\text { v.H. auf } 0,3 \text { v.H.; Ausweitung des Bandes in } 3 \\
\text { Schritten von } \pm 7 \text { v.H. auf } \pm 15 \text { v.H.; ab Jan } 1999 \\
\text { Bindung an Währungskorb aus EUR und USD } \\
\text { flexibler Wechselkurs }\end{array}$ \\
\hline Rumänien & $\begin{array}{l}\text { Feb } 1991 \\
\text { Nov } 1991 \\
\text { seit Nov } 1991 \\
\end{array}$ & $\begin{array}{l}\text { Einfuhrung eines dualen Wechselkurssystems } \\
\text { Vereinheitlichung des offiziellen und des } \\
\text { Marktkurses } \\
\text { flexibler Wechselkurs }\end{array}$ \\
\hline
\end{tabular}




\begin{tabular}{|c|c|c|}
\hline Slowakei & Feb 1993 & $\begin{array}{l}\text { Auflosung der Wăhrungsunion mit Tschechien, } \\
\text { Einfuhrung der Slowakischen Krone } \\
\text { fester Wechselkurs } \\
\text { Bindung an einen Wăhrungskorb aus } 5 \text { Währungen, } \\
\text { ab Juli } 1994 \text { Bindung an Wahrungskorb aus DEM } \\
\text { und USD, Ausweitung des Bandes um die Parităt in } \\
3 \text { Schritten von } \pm 1,5 \text { v.H. auf } \pm 7 \text { v.H. } \\
\text { flexibler Wechselkurs }\end{array}$ \\
\hline Slowenien & $\begin{array}{l}\text { Okt } 1991 \\
\text { seit Okt } 1991\end{array}$ & $\begin{array}{l}\text { Einfuhrung des Slowenischen Tolar } \\
\text { flexibler Wechselkurs }\end{array}$ \\
\hline Tschechien & $\begin{array}{l}\text { Ende } 1990 \\
\text { Dez } 1990 \text { - Jan } 1993 \\
\text { Feb } 1993 \\
\text { Feb } 1993 \text { - Mai } 1997\end{array}$ & $\begin{array}{l}\text { Vereinheitlichung des Wechselkurses der } \\
\text { Tschechoslowakischen Krone } \\
\text { fester Wechselkurs } \\
\text { Bindung an einen Wăhrungskorb aus } 5 \text { Währungen } \\
\text { Auflösung der Wăhrungsunion mit der Slowakei, } \\
\text { Einfuhrung der Tschechischen Krone } \\
\text { fester Wechselkurs } \\
\text { bis April } 1993 \text { unverănderter Wăhrungskorb aus } 5 \\
\text { Wăhrungen, ab Mai } 1993 \text { Bindung an Wăhrungs- } \\
\text { korb aus DEM und USD, Feb } 1996 \text { Ausweitung des } \\
\text { Bandes um die Parităt von } \pm 0,5 \text { v.H. auf } \pm 7,5 \text { v.H. } \\
\text { flexibler Wechselkurs }\end{array}$ \\
\hline Un & $\begin{array}{l}\text { Dez } 1991 \text { - Juli } 1993 \\
\text { Aug } 1993 \text { - Mai } 1994 \\
\text { Mai } 1994 \text { - Mărz } 1995\end{array}$ & $\begin{array}{l}\text { fester Wechselkurs } \\
\text { Bindung an einen Wăhrungskorb, bis } 1991 \text { jăhrli- } \\
\text { che Revision der Zusammensetzung in Abhängig- } \\
\text { keit von der Struktur des Außenhandels } \\
\text { Bindung an Währungskorb aus ECU und USD } \\
\text { Bindung an Wăhrungskorb aus DEM und USD } \\
\text { Bindung an Währungskorb aus ECU und USD } \\
1991 \text { bis } 95 \text { häufige, unregelmäßige Abwertungen } \\
\text { (ad hoc Anpassungen der Parităt) } \\
\text { Crawling Peg } \\
\text { gegenuber dem unveränderten Wăhrungskorb aus } \\
\text { ECU und USD; Band um die Parităt von } \pm 2,25 \\
\text { v.H.; Juni 1995 Reduzierung der angekündigten } \\
\text { monatlichen Abwertungsrate von 1,9 v.H. auf 1,3 } \\
\text { v.H., danach Reduzierung der monatlichen Abwer- } \\
\text { tungsrate in 0,1 v.H.-Schritten auf 0,3 v.H.; im Jan } \\
\text { 1997 Bindung an einen Wahrungskorb aus DEM } \\
\text { und USD, im Jan } 1999 \text { aus EUR und USD, seit Jan } \\
2000 \text { Bindung an den EUR }\end{array}$ \\
\hline \multicolumn{3}{|c|}{$\begin{array}{l}\text { Anmerkung: }{ }^{\text {a }} \text { Stand: Dezember 2000. Die Tabelle ist eine zusammenfassende Klassifikation } \\
\text { der Wechselkurssysteme. Detailliertere Angaben zu den wechselkurspolitischen Maßnahmen } \\
\text { finden sich im Anhang VI.2. }\end{array}$} \\
\hline
\end{tabular}

Quelle: Zusammengestellt aus den Angaben im Anhang VI.2. 


\section{Auswertung der empirischen Literatur zur Rolle der Wechselkurspolitik im Transforma- tionsprozeß}

Es gibt inzwischen eine reichhaltige empirische Literatur, die den Transformationsprozeß und die ihn prägenden Einflußfaktoren untersucht. Neben Länderstudien sind in den zurückliegenden Jahren viele vergleichende empirische Studien erschienen, die die Erfahrungen der Länder im Transformationsprozeß untersuchen und mögliche Ursachen für die verschiedenen Ergebnisse aufzeigen. Bei der überwiegenden Mehrheit der Studien steht dabei die Frage im Vordergrund, welche Faktoren die Entwicklung des Wirtschaftswachstums bestimmen. ${ }^{15}$ Die empirische Literatur zur Rolle der Wechselkurspolitik im Transformationsprozeß ist zwar weniger umfangreich, zwei wichtige Aspekte werden jedoch eingehender betrachtet: Erstens wird untersucht, wie sich der reale Wechselkurs entwickelt hat, weil davon die internationale Wettbewerbsfähigkeit der Transformationsländer abhängt. Zweitens wird analysiert, ob die Wahl des Wechselkurssystems einen Einfluß auf die Erfolge der Stabilisierungsbemühungen in den Ländern hatte. $\mathrm{Zu}$ welchem Ergebnis die empirische Literatur im Hinblick auf diese beiden zentralen Fragestellungen kommt, erläutern die beiden folgenden Unterabschnitte.

\subsection{Entwicklung des realen Wechselkurses}

Als allgemeines Muster des realen Wechselkursverlaufs zeigt sich eine deutliche reale Abwertung zu Beginn der Transformation und eine sich anschließende, kontinuierliche Aufwertung des realen Wechselkurses. ${ }^{16}$ Beide Entwicklungen sind sowohl in Transformationsländern mit flexiblen Wechselkursen als auch in Ländern, die eine Wechselkursbindung gewählt haben, zu beobachten. Die anfängliche reale Abwertung ist insbesondere auf die starken nominalen Abwertungen beim Übergang zu konvertiblen Währungen zurückzuführen, während der nachfolgende Prozeß der realen Aufwertung aus den höheren Preissteigerungen im Vergleich zum Ausland resultiert. Das konkrete Ausmaß der realen Wechselkursentwicklung in den betrachteten Ländern ist allerdings davon abhängig, welches Konzept man der Berechnung des realen Wechselkurses zugrunde legt.

15 Siehe zum Beispiel Christoffersen/Doyle (1998), S. 1 ff., de Melo et al. (1997b), S. 17 ff., Havrylyshyn et al. (1999), S. 22 ff., und Krueger/Ciolko (1998), S. 718 ff., sowie die darin angegebene Literatur.

16 Vgl. Brada (1998), S. 614, und Stolze (1997), S. 5 f. 
Vom theoretischen Standpunkt aus gesehen, wäre es wünschenswert, ein Maß für das Verhältnis der Preise handelbarer Güter zu den Preisen nichthandelbarer Güter zu verwenden. Allerdings sind entsprechende Preisindizes häufig nicht verfügbar. ${ }^{17}$ Statt dessen wird der reale Wechselkurs in der Regel als das Verhältnis eines ausländischen Preisindexes (multipliziert mit dem nominalen Wechselkurs) zu einem inländischen Preisindex definiert. Um einen sogenannten realen effektiven Wechselkurs zu ermitteln, wird der ausländische Preisindex als handelsgewichteter Durchschnitt von Preisindizes bedeutender Außenhandelspartner gebildet. Die Ergebnisse variieren in Abhängigkeit davon, ob bei der Berechnung Konsumgüterpreis-, Produzentenpreis- oder Großhandelspreisindizes verwendet werden. Ein weiteres Konzept zur Messung der internationalen Wettbewerbsfähigkeit besteht darin, einen Vergleich von Lohnkosten oder Lohnstückkosten vorzunehmen. ${ }^{18}$

Zwei Studien, die die reale Wechselkursentwicklung in der Transformation untersuchen und das zuletzt genannte Konzept verwenden, sind Halpern/Wyplosz (1997) und Krajnyák/Zettelmeyer (1998). ${ }^{19}$ Halpern und Wyplosz schätzen sogenannte gleichgewichtige Dollarlöhne und vergleichen diese mit der tatsächlichen Lohnentwicklung in den untersuchten Ländern. Sie stellen fest, daß die reale Aufwertung im Transformationsprozeß einerseits die Umkehr einer anfänglichen Unterbewertung bewirkt und insofern eine Annäherung an den realen gleichgewichtigen Wechselkurs darstellt. Andererseits ermitteln die Autoren einen im Zeitablauf ansteigenden realen Gleichgewichtswechselkurs, den sie unter anderem auf Produktivitätszuwächse in den Transformationsländern zurückführen. Sowohl diese Studie als auch Krajnyák und Zettelmeyer kommen zu dem Ergebnis, daß die deutlichen realen Aufwertungen in den untersuchten Ländern Mitte der 1990er Jahre (noch) nicht zu einer Überbewertung der Währungen geführt hatten. 20

Rosati (1997) und Drabek/Brada (1998) hingegen verwenden für die Messung des realen Wechselkurses in Mittel- und Osteuropa jeweils den Konsumgüterpreisindex und den Produzentenpreisindex. ${ }^{21}$ Für alle sechs betrachteten Länder - Bulgarien, Polen, Rumänien, die Slowakei, Tschechien und Ungarn - ergeben sich in diesen Studien für beide Meßkonzepte deutliche reale Aufwertungen für die Zeiträume 1991-1995 bei Rosati bzw. 1992-1997 bei Drabek und Brada. Bei Verwendung des Produzentenpreisindexes zur Berechnung des realen Wechselkurses verzeichnen Tschechien und die Slowakei in beiden Studien die

17 Vgl. Aghevli/Montiel (1991), S. 213.

18 Siehe z.B. Koch (1997), S. 31, und Rosati (1997), S. 494.

19 Vgl. Halpern/Wyplosz (1997), S. 430 ff., und Krajnyák/Zettelmeyer (1998), S. 309 ff.

20 Vgl. Halpern/Wyplosz (1997), S. 458, und Krajnyák/Zettelmeyer (1998), S. 316.

21 Siehe Rosati (1997), S. 490, und Drabek/Brada (1998), S. 650 ff. 
stärkste reale Aufwertung. Da es sich um die zwei Länder handelt, die im Betrachtungszeitraum ein festes Wechselkurssystem unterhielten, ${ }^{22}$ scheint diese Beobachtung die These des Partialmodells im dritten Kapitel zu stützen, daß ein Festkurssystem mit einer höheren realen Aufwertung verbunden ist als ein Flexkurssystem, in dem nominal abgewertet wird. ${ }^{23}$ Allerdings führt eine Verwendung des Konsumgüterpreisindexes zu einer Änderung der Reihenfolge. In diesem Fall liegen Bulgarien und Tschechien, also ein Land mit flexiblem und ein Land mit festem Wechselkurs, mit den stärksten realen Aufwertungen an der Spitze. ${ }^{24}$ Während der generelle Trend einer realen Aufwertung in Mittelund Osteuropa unabhängig von der Wahl des Wechselkursregimes ist, lassen die Ergebnisse der beiden Studien keine eindeutige Aussage darüber zu, ob die Wahl eines festen Wechselkurses zu einer stärker ausgeprägten realen Aufwertung der entsprechenden Währung geführt hat.

Für den Zeitraum 1993 bis 1998 betrachtet Kopits (1999) die nominale und reale Wechselkursentwicklung in Estland, Polen, Slowenien, Tschechien und Ungarn. ${ }^{25}$ In seiner Studie verzeichnet Slowenien (mit flexiblem Wechselkurs) eine deutlich geringere reale Aufwertung als Tschechien und Estland, zwei Länder mit festen Wechselkurssystemen bis 1997 im Falle Tschechiens bzw. während des gesamten Betrachtungszeitraums im Falle Estlands. Dieses Ergebnis stellt sich sowohl bei Verwendung des Konsumgüterpreisindexes als auch bei Verwendung von Lohnstückkosten ein.

Generell besteht in der Literatur also Einvernehmen über das Verlaufsmuster des realen Wechselkurses im Transformationsprozeß. Es wird einheitlich festgestellt, daß sich das beobachtete Phänomen der anfänglichen realen Abwertung, gefolgt von einer anschließenden deutlichen realen Aufwertung, unabhängig vom gewählten Wechselkurssystem einstellt. Es bestehen aber unterschiedliche Auffassungen über das Ausmaß der realen Aufwertung und der Abweichung des tatsächlichen realen Wechselkurses vom Gleichgewichtswert. Die aus den modelltheoretischen Überlegungen im dritten Kapitel abgeleitete Frage, ob die reale Aufwertung unter allen Wechselkurssystemen die Realität im

22 Polen und Ungarn hatten im Zeitraum 1991-1997 ebenfalls zunächst feste Wechselkurssysteme, die aber 1991 in Polen und 1995 in Ungarn von aktiven Crawling Pegs abgelöst wurden. Wie in Abschnitt IV.1. gezeigt, war die relativ lange Phase der offiziellen Wechselkursbindung in Ungarn außerdem durch hăufige nominale Abwertungen gekennzeichnet.

23 Die in den Studien genannten Lănder, die ein flexibles Wechselkurssystem hatten, verzeichneten jeweils deutliche nominale Abwertungen.

24 Auch bei Fröhlich (1994), S. 181 f., der die Entwicklungen in Polen, der Tschechoslowakei und Ungarn von Ende 1989 bis Ende 1992 untersucht, hăngen die Ergebnisse sehr stark vom verwendeten Meßkonzept ab.

Vgl. Kopits (1999), S. 19 ff. 
Transformationsprozeß korrekt abbildet, kann also eindeutig positiv beantwortet werden. Die Aussagen über die reale Wechselkursentwicklung in Abhängigkeit vom Wechselkurssystem fallen demgegenüber nicht so eindeutig aus. ${ }^{26}$ Aus diesem Grund wird die Literaturauswertung durch einen Blick auf die jüngste Entwicklung in den EU-Beitrittskandidaten in Form der Tabelle 5 ergänzt. Sie ermöglicht einen Vergleich der realen Wechselkursänderungsraten für alle betrachteten Länder in der zweiten Hälfte der 1990er Jahre.

Tabelle 5: Entwicklung des realen Wechselkurses in der zweiten Hälfte der 1990er Jahre ${ }^{2}$

\begin{tabular}{|c|c|c|c|c|c|c|}
\hline & 1995 & 1996 & 1997 & 1998 & 1999 & $\varnothing^{b}$ \\
\hline Bulgarien & 19,6 & $-0,6$ & 135,1 & 14,1 & 3,3 & 26,9 \\
\hline Estland & 28,5 & 17,1 & 5,5 & 7,7 & 2,1 & 11,8 \\
\hline Lettland & 17,0 & 13,4 & 13,3 & 3,5 & 7,1 & 10,8 \\
\hline Litauen & 23,7 & 25,8 & 20,1 & 5,2 & 4,6 & 15,5 \\
\hline Polen & 8,8 & 8,2 & 3,7 & 4,0 & $-1,1$ & 4,7 \\
\hline Rumånien & $-2,1$ & $-11,3$ & 15,7 & 31,0 & $-13,1$ & 2,7 \\
\hline Slowakei & 6,2 & 0,6 & 3,9 & 0,0 & $-3,7$ & 1,3 \\
\hline Slowenien & 8,7 & $-3,9$ & 1,9 & 4,8 & 0,3 & 2,3 \\
\hline Tschechien & 6,3 & 7,8 & 1,8 & 7,3 & $-1,0$ & 4,4 \\
\hline Ungarn & $-5,1$ & 2,3 & 6,4 & $-0,2$ & 3,8 & 1,4 \\
\hline \multicolumn{7}{|c|}{ 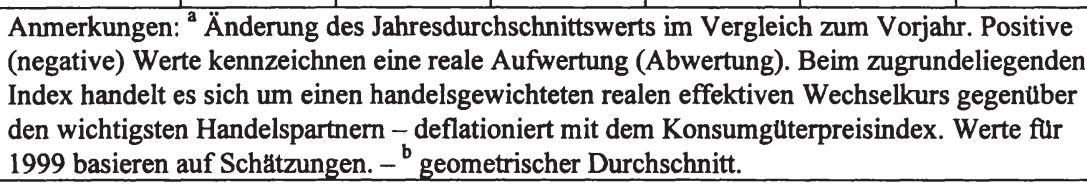 } \\
\hline
\end{tabular}

Quelle: Eigene Berechnungen auf Grundlage der Indizes von DB Research (2000a).

In der letzten Spalte der Tabelle 5 ist der Durchschnitt für alle fünf Jahre angegeben. Es zeigt sich, daß die drei baltischen Länder, die über den gesamten Betrachtungszeitraum ein festes Wechselkurssystem hatten, im Vergleich zu den anderen Ländern - mit Ausnahme Bulgariens - eine stärkere reale Aufwertung verzeichneten. ${ }^{27}$ Eine höhere reale Aufwertung bei festen im Gegensatz zu fle-

26 Auch Halpern und Wyplosz versuchen zwar, den Einfluß des Wechselkursregimes auf die reale Wechselkursentwicklung zu testen, kommen jedoch nicht zu statistisch abgesicherten Ergebnissen. Vgl. Halpern/Wyplosz (1997), S. 455.

27 Der bulgarische Durchschnitt ist insbesondere durch den hohen Wert fur 1997 verzerrt. Wie bereits erwăhnt, ging Bulgarien im Sommer 1997 im Rahmen eines Stabilisierungsprogramms zu einem Currency Board System uber. Dies trug zwar zu einer schnellen Re- 
xiblen Wechselkursen weisen auch die Entwicklungen in der tschechischen und der slowakischen Republik auf. Während Tschechien 1997 vom Festkurssystem zu flexiblen Wechselkursen überging, vollzog die Slowakei den Wechsel im Jahr 1998. Beide Länder verzeichnen seit dem Übergang zu einem flexiblen Wechselkurssystem tendenziell eine nominale Abwertung verbunden mit einer geringeren realen Aufwertung. ${ }^{28}$ Allerdings ist die allgemeine Aussage nur mit Einschränkungen gültig. So sind zum Beispiel die Werte für Rumänien, das ein flexibles Wechselkurssystem mit starker nominaler Abwertung der Währung unterhält, in den Jahren 1997 und 1998 wesentlich höher als während der Festkursperioden in Tschechien oder der Slowakei. Des weiteren fiel im Jahr 1998 die reale Aufwertung in Lettland, das seine Währung an das Sonderziehungsrecht gebunden hat, deutlich niedriger aus als in Slowenien und Tschechien, die flexible Wechselkurssysteme hatten und im Jahresdurchschnitt 1998 sowohl gegenüber dem US-Dollar als auch gegenüber der Europäischen Währungseinheit eine nominale Abwertung verzeichneten. ${ }^{29}$

Zusammenfassend läßt sich folgendes sagen: Eine detaillierte Länderbetrachtung weist zwar darauf hin, daß offensichtlich neben dem Wechselkursregime auch andere Faktoren eine wichtige Rolle gespielt haben und deshalb Länder mit Festkurssystem nicht generell eine stärkere reale Aufwertung erfuhren als Länder mit nominaler Abwertung bei flexiblem Wechselkurs. Allerdings läßt die Tabelle 5 die Schlußfolgerung $\mathrm{zu}$, daß zumindest tendenziell diejenigen Länder, die eine Wechselkursbindung vorgenommen haben, eine stärkere reale Aufwertung verzeichneten als Länder, die in einem flexiblen Wechselkurssystem nominal abwerteten. Insbesondere eine Betrachtung des mehrjährigen Durchschnitts bestätigt diese Hypothese des Partialmodells im dritten Kapitel. Da keines der betrachteten Länder in der zweiten Hälfte der 1990er Jahre eine trendmäßige nominale Aufwertung verzeichnete, kann hingegen die nominale Aufwertungsvariante - wie sie in der ersten Spalte der Tabelle 2 im Unterabschnitt III.3.2.3. dargestellt ist - nicht überprüft werden. Danach würde sich in einem System flexibler Wechselkurse bei nominaler Aufwertung eine stärkere reale Aufwertung der Währung ergeben als in einem Festkurssystem.

duzierung der Inflation bei. Da es sich bei den Indexwerten, die der Tabelle zugrunde liegen, aber um Jahresdurchschnittswerte handelt, spiegelt sich die extrem hohe Inflation zu Jahresbeginn in einer entsprechend starken realen Aufwertung wider.

28 Zur nominalen Wechselkursentwicklung in Mittel- und Osteuropa gegenüber dem USDollar und der Europăischen Wăhrungseinheit - bzw. ab 1999 dem Euro - siehe DB Research (2000a).

Siehe ebenda. 


\subsection{Ergebnisse empirischer Studien zur Auswirkung des Wechselkursregimes auf Wachstum und Inflation}

Während sich viele Studien mit der Ursachenanalyse für die Rückkehr zu frühem Wirtschaftswachstum befassen, ist die Anzahl derjenigen empirischen Studien geringer, die den Einfluß unterschiedlicher Komponenten der Stabilisierungspolitik im allgemeinen und der Wechselkurspolitik im besonderen auf die Disinflationsfortschritte analysieren. So untersuchen zum Beispiel Havrylyshyn et al. (1998) die Bestimmungsfaktoren des Wirtschaftswachstums und verwenden als erklärende Variable unter anderem auch die Inflationsrate. ${ }^{30}$ Ziel der Autoren ist es, anhand der Preisentwicklung den Einfluß der Stabilisierungsbemühungen auf das Wachstum zu erfassen, weil sie die Disinflation als notwendige, aber nicht hinreichende Bedingung für Wirtschaftswachstum ansehen. Es ist zwar einsichtig, daß eine erfolgreiche Stabilisierungspolitik durch eine niedrige Inflationsrate gemessen wird, während eine verfehlte makroökonomische Politik durch hohe Inflationsraten gekennzeichnet ist. Diese Vorgehensweise ermöglicht aber keine Aussage darüber, wie eine erfolgreiche Stabilisierungspolitik aussehen sollte und durch welchen makroökonomischen Policy Mix man eine Senkung der Inflationsrate erreichen kann.

Gerade dies ist aber die zentrale Fragestellung, wenn man den Einfluß des Wechselkursregimes auf die Stabilisierungserfolge untersuchen möchte. Die aus den modelltheoretischen Überlegungen abgeleitete Frage lautet, ob die Entscheidung für ein bestimmtes Wechselkurssystem eine wichtige Rolle dabei gespielt hat, eine zügige Disinflation zu erreichen. Falls das Ziel erreicht wurde, die Inflationsrate schnell zu senken, muß für eine objektive Bewertung außerdem geklärt werden, ob die Entscheidung für ein bestimmtes Wechselkurssystem zu Lasten einer frühzeitigen Rückkehr zu positiven gesamtwirtschaftlichen Wachstumsraten ging. Studien, die sich diesen Fragen widmen, lassen sich grob in drei Gruppen einteilen. Die erste Gruppe untersucht die Auswirkungen der Wechselkurspolitik auf den Wachstumsprozeß, während eine zweite Gruppe die Determinanten einer erfolgreichen Disinflation analysiert. Die dritte Gruppe bilden schließlich jene Studien, die den Einfluß sowohl auf die Wachstums- als auch die Inflationsentwicklung untersuchen.

Zur ersten Gruppe zählt die Arbeit von Hernández-Catá (1997), die Faktoren analysiert, die die Entwicklung des Bruttoinlandsprodukts während der Transformation beeinflussen. Die Studie kommt zu dem Ergebnis, daß Länder, die einen festen Wechselkurs wählten, durch ein höheres reales Einkommensniveau

30 Vgl. Havrylyshyn et al. (1998), S. 13. 
gekennzeichnet sind. ${ }^{31}$ Das positive Vorzeichen für den festen Wechselkurs ist allerdings nicht signifikant. Hernández-Catá führt dies zum Teil auf Meßprobleme zurück. In seinem Schätzansatz werden als erklärende Variablen sowohl die Inflationsrate als auch eine Dummyvariable für das Wechselkursregime berücksichtigt. Der Einfluß des festen Wechselkurses geht dadurch einerseits direkt, andererseits aber auch - über die fallende Inflationsrate - indirekt in die Regression ein, wenn man unterstellt, daß der nominale Wechselkursanker über reduzierte Inflationserwartungen zu einem beschleunigten Rückgang der Inflation beigetragen hat. Diese Vermutung wird dadurch gestützt, daß bei einer Eliminierung der Inflationsvariablen der Koeffizient für die Dummyvariable des Wechselkurssystems ansteigt und der Standardfehler sinkt. ${ }^{32}$

Christoffersen/Doyle (1998) hingegen ermitteln einen negativen Einfluß von Wechselkursbindungen auf das Wirtschaftswachstum in Stabilisierungsprogrammen von Transformationsländern. Wenn moderate Inflationsraten im Rahmen einer Wechselkursbindung innerhalb eines Jahres mehr als halbiert werden, hat dies negative Auswirkungen auf das Wirtschaftswachstum. ${ }^{33}$ Die Autoren schränken aber ein, daß einerseits die Kosten der Wechselkursfixierung durch Meßprobleme überzeichnet sein könnten. Andererseits spiegele dieses Ergebnis eventuell eher die Probleme einer Stabilisierung im Rahmen eines unterbewerteten festen Wechselkurses als einer Wechselkursbindung an sich wider. Die Erklärung dafür liegt laut Christoffersen und Doyle darin, daß bei einem festen Wechselkurs und einer starken Unterbewertung der Währung die Anpassung des realen Wechselkurses über einen Anstieg des Preisniveaus erfolgen muß. Wenn die Wirtschaftspolitiker in dieser Situation eine Senkung der Inflationsraten anstreben, kann dies zu einer Rezession führen. Da die Autoren aber keine Kosten in Form eines geringeren Wirtschaftswachstums bei flexiblen Wechselkursen feststellen, deuten ihre Ergebnisse eher auf einen negativen Einfluß einer Wechselkursbindung hin. Der signifikante Einfluß des Wechselkurssystems läßt sich allerdings nicht mehr nachweisen, wenn weniger drastische Stabilisierungsprogramme in die Untersuchung einbezogen werden, in denen die Inflationsrate innerhalb eines Jahres nicht mindestens um die Hälfte, sondern „nur“ um mehr als ein Fünftel reduziert wurde. ${ }^{34}$ Die Ergebnisse hängen in dieser Studie sehr stark von der konkreten Formulierung des Schätzansatzes ab.

31 Siehe Hernández-Catá (1997), S. 420 und 426. Die Studie stellt insofern eine Ausnahme dar, daß sie den Einfluß auf das Outputniveau in den Transformationsländern untersucht. Alle anderen empirischen Studien analysieren die Faktoren für die Entwicklung des Wirtschaftswachstums.

32 Vgl. Hernández-Catá (1997), S. 420.

33 Siehe hierzu und zu dem folgenden Gedankengang Christoffersen/Doyle (1998), S. 30.

34 Vgl. ebenda, S. 21. 
Eine weitere Studie, die - neben dem Budgetdefizit und der Inflationsrate explizit eine Dummyvariable für das Wechselkursregime als makroökonomische Variable zur Erklärung des Wirtschaftswachstums berücksichtigt, ist der Beitrag von Berg et al. (1999). ${ }^{35}$ Außerdem werden von den Autoren unter anderem Indizes für Strukturreformen und die Ausgangsbedingungen als erklärende Variablen berücksichtigt. Im Rahmen des in dieser Studie verwendeten general-to-specific-Ansatzes läßt sich jedoch kein statistisch signifikanter Einfluß des Wechselkurssystems auf das Wirtschaftswachstum feststellen, so daß die entsprechende Dummyvariable als nicht signifikante Größe im Laufe der Untersuchung eliminiert wird.

$\mathrm{Zu}$ der zweiten Gruppe der empirischen Studien, die die Determinanten einer erfolgreichen Disinflation in der Transformation untersuchen, gehören Coorey et al. (1997, 1998). ${ }^{36}$ Neben dem Einfluß der Geldmenge, der Nominallohnentwicklung und der relativen Preisanpassungen berücksichtigen sie auch die Wahl des Wechselkursregimes. Laut ihren Untersuchungen hat ein expliziter Wechselkursanker nur eine statistisch schwach signifikante, aber positive Wirkung auf eine geringere Inflation. Wie bei Hernández-Catá (1997) stellt auch in dieser Studie die Erfassung des Einflusses der Wechselkurspolitik auf die Antiinflationspolitik ein erhebliches Problem dar. Die entsprechende Dummyvariable mißt nur den Effekt für ein gegebenes Wachstum von Löhnen und nominaler Geldmenge. Die Autoren weisen darauf hin, daß ein Wechselkursanker aber gerade über eine Politikdisziplinierung und über eine Senkung der Inflationserwartungen zu einer geringeren Geldmengenwachstumsrate und einem verminderten Lohndruck führt. ${ }^{37}$ Der positive Effekt einer Wechselkursbindung kann deshalb schon in diesen Variablen enthalten sein.

Hernández-Catá (1999) untersucht ebenfalls, welche Faktoren das Verhalten der Konsumgüterpreise in der Transformation bestimmen. Neben der Liberalisierung der Wirtschaft, der Preisderegulierung und des Geldmengenwachstums berücksichtigt er dabei auch eine Dummyvariable für das Wechselkursregime. Der Koeffizient dieser Variablen ist instabil und nicht signifikant von Null verschieden. ${ }^{38}$ Allerdings hat der Wechselkursdummy einen signifikanten Einfluß auf die Geldmengenexpansion: Länder mit festem Wechselkurs weisen eine niedrigere Geldmengenwachstumsrate auf als Länder mit flexiblem Wechselkurs.

35 Siehe Berg et al. (1999), S. 20.

36 Siehe Coorey et al. (1997), S. 4 ff., und Coorey et al. (1998), S. $240 \mathrm{ff}$.

37 Vgl. Coorey et al. (1997), S. 13.

38 Siehe Hernández-Catá (1999), S. 10. 
Die dritte Gruppe von Studien, die den Einfluß der Wechselkurspolitik auf das Wirtschaftswachstum und auf die Inflation analysieren, wird von de Melo et al. (1997a) und Fischer et al. $(1996,1997)$ gebildet. De Melo et al. folgern aus ihren Untersuchungen, daß die Ursache einer erfolgreichen Transformation eher eine frühe und weitreichende Liberalisierung als die Wahl des richtigen nominalen Ankers ist. Im Rahmen des Transformationsprozesses kann laut ihrer Auffassung Glaubwürdigkeit - von der der Erfolg eines Stabilisierungsprogramms in erster Linie abhängt - nicht ohne weitreichende Liberalisierung erreicht werden. 39

Eindeutig positive Auswirkungen der Wechselkurspolitik auf Wirtschaftswachstum und Inflation ermitteln Fischer et al. $(1996,1997) .40$ In ihren Arbeiten, die neben dem Wechselkurssystem auch die Fiskalpolitik, das Ausmaß der Strukturreformen und die Ausgangsbedingungen als erklärende Variablen berücksichtigen, hat ein fester Wechselkurs einen eindeutigen, signifikant positiven Einfluß auf die Stabilisierungserfolge der Länder. Staaten mit festem Wechselkurssystem erreichten eine schnelle Inflationssenkung und wuchsen schneller als diejenigen Länder, die ein flexibles Wechselkursregime unterhielten. Neben der Beseitigung fundamentaler fiskalischer Ungleichgewichte sehen sie in der Wechselkursbindung deshalb eine „Schlüsselkomponente“ von erfolgreichen Stabilisierungsprogrammen. ${ }^{41}$

In nahezu allen Studien wird die Frage der Kausalität aufgeworfen. So argumentiert Hernández-Catá, daß sich unter Umständen nur die Länder für einen festen Wechselkurs entschieden, in denen ein politischer Konsens für eine Disinflation bestand und die einen ausreichend hohen Grad an institutioneller Entwicklung aufwiesen. ${ }^{42}$ Auch Begg (1998) argumentiert anhand eines medizinischen Gleichnisses, daß nur denjenigen Ländern, die er als die stärkeren Patienten bezeichnet, ein fester Wechselkurs als Arznei verschrieben wurde. Den Ländern, die ungünstigere Ausgangsbedingungen aufwiesen, sei hingegen ein flexibler Wechselkurs empfohlen worden. Man könne deshalb nicht schlußfolgern, daß die Wahl eines festen Wechselkurses die überlegenere Strategie gewesen sei. 43

Zusammenfassend läßt sich feststellen, daß nicht nur in der theoretischen Literatur die Rolle des Wechselkursregimes im Transformationsprozeß umstritten ist, sondern auch in der empirischen Literatur der Einfluß der Wechselkurspoli-

39 Vgl. de Melo et al. (1997a), S. 65.

40 Vgl. Fischer et al. (1996), S. 45 ff., und Fischer et al. (1997), S. 79 ff.

41 Siehe Fischer et al. (1996), S. 63.

42 Vgl. Hernández-Catá (1997), S. 420, und Hernández-Catá (1999), S. 22.

43 Vgl. Begg (1998), S. 107. 
tik auf die Entwicklung von Wachstum und Inflation nicht eindeutig beantwortet wird. Während einige Autoren eine positive Wirkung einer Wechselkursbindung ermitteln, bleibt bei der Mehrzahl der Studien das Ergebnis offen, weil entweder Fragen hinsichtlich der korrekten Messung des Einflusses aufgeworfen werden oder aber die gefundenen Koeffizienten nicht oder nur schwach signifikant sind. Des weiteren unterscheiden alle Studien nur zwischen einem festen und einem flexiblen Wechselkurssystem. Es wird nicht danach differenziert, ob im Rahmen eines Flexkurssystems eine nominale Auf- oder Abwertung stattgefunden hat. Aus diesem Grund kann die Hypothese des Partialmodells im Kapitel III, daß die Länder mit festem Wechselkurs oder nominaler Aufwertung der Währung bei der Disinflation erfolgreicher waren als die Länder, die in einem Flexkurssystem nominal abwerteten, durch die Auswertung der empirischen Literatur weder bestätigt noch widerlegt werden. Alle hier genannten Studien arbeiten außerdem mit einem Ländersample, das mehr als zwanzig Transformationsländer umfaßt. Die im ersten Kapitel dieser Arbeit genannten Gründe lassen jedoch vermuten, daß für die relativ homogene Gruppe der zehn mittel- und osteuropäischen EU-Beitrittskandidaten eventuell Aussagen getroffen werden können, die für eine größere Ländergruppe nicht oder nur sehr eingeschränkt gelten. $\mathrm{Ob}$ dies für die Entwicklungen von Wirtschaftswachstum und Inflation sowie die sie bestimmenden Faktoren zutrifft, untersucht der folgende Abschnitt.

\section{Stabilitätspolitische Erfolge}

Nachdem im vorangegangenen Abschnitt gezeigt wurde, daß die empirischen Arbeiten zu unterschiedlichen Ergebnissen im Hinblick auf die Auswirkungen der Wechselkurspolitik auf Wirtschaftswachstum und Inflation im Transformationsprozeß kommen, untersucht dieser Abschnitt zunächst, welche Entwicklungen dieser beiden makroökonomischen Größen in den Ländern der Beitrittskandidaten beobachtbar sind und welche Gemeinsamkeiten existieren. Im Anschluß daran werden verschiedene Einflußgrößen daraufhin untersucht, welche Rolle sie bei der Erklärung der beobachteten Entwicklungen spielen. Neben der hier besonders interessierenden Wechselkurspolitik werden fünf weitere Faktoren berücksichtigt, bevor ein Zwischenfazit bezüglich der wechselkursund stabilitätspolitischen Erfahrungen gezogen wird. Da im Rahmen der vorliegenden Arbeit eine zehn Staaten umfassende Ländergruppe betrachtet wird, kann die Analyse der Ländererfahrungen nicht so detailliert ausfallen wie in Studien, die sich nur auf ein Land oder wenige Länder konzentrieren. Bei der Betrachtung des Verlaufs von Wachstum und Inflation liegt der Schwerpunkt daher auf der Identifikation von Gemeinsamkeiten im Transformationsprozeß der EU-Beitrittskandidaten und auf der Analyse, welchen Einfluß die Wechsel- 
kurspolitik und die anderen betrachteten Komponenten auf die Entwicklung und dabei insbesondere die Reduzierung der Inflation - hatten.

\subsection{Verlauf von Wirtschaftswachstum und Inflation}

\subsubsection{Vorbemerkungen}

Wenn man gemeinsame Entwicklungen im Transformationsproze $ß$ herausarbeiten möchte, besteht ein Problem darin, daß die Länder zu unterschiedlichen Zeitpunkten den Reformprozeß begonnen haben. Also selbst wenn es Gemeinsamkeiten im Reformprozeß gibt, treten sie unter Umständen nicht hervor, wenn man die Entwicklungen im Zeitablauf (mit Zeitachse) betrachtet, weil sich bei einer Mehrländerbetrachtung unterschiedliche Verläufe überlagern. Um ein einheitliches Muster in der Darstellung im Zeitablauf zu erhalten, muß man deshalb „umskalieren“. In der Literatur wurden unterschiedliche Verfahren angewendet, um dieses Problem zu lösen. Die Entwicklung wird nicht im chronologischen Zeitablauf dargestellt, sondern es wird für alle Länder ein Zeitpunkt $T=0$ bestimmt, in dem entweder der Transformationsproze $ß$ oder ein Stabilisierungsprogramm begann. Fischer et al. (1996) gehen dabei so vor, daß sie ein Jahr bestimmen, in dem mit einem Stabilisierungsprogramm begonnen wurde. Die Autoren bezeichnen dieses Vorgehen als eine Betrachtung in ,stabilization time“. 44 Während für die meisten Transformationsländer die Implementierung eines Stabilisierungsprogramms mit dem Reformbeginn übereinstimmt, ist dieses Verfahren für diejenigen Länder problematisch, in denen die Stabilisierungsbemühungen später einsetzten. Auch die Behandlung der Fälle, in denen das erste Stabilisierungsprogramm scheiterte und erst in einem zweiten Anlauf eine Stabilisierung der Wirtschaft gelang, ist schwierig. Schließlich lassen sich mit dieser Methode auch Länder, die einen graduellen Reformansatz wählten, nur unzureichend erfassen.

De Melo et al. (1997a) lösen das Problem der unterschiedlichen Startzeitpunkte, indem sie einen normalisierten Liberalisierungsindex als Maßstab verwenden. Die Autoren weisen dem Wert des von ihnen entwickelten kumulativen Liberalisierungsindex für Polen im Jahr 1994 den Wert 5,0 zu, weil sich Polen 1994 im fünften Jahr der Transformation befand. Da der tatsächliche Wert für Polen jedoch nur 4,14 betrug, werden die Indizes für alle Länder mit 5,0/4,12 = 1,2 multipliziert. Durch Rundung auf ganze Zahlen ermitteln de Melo et al., seit wie vielen Jahren sich das entsprechende Land im Transformationsprozeß be-

44 Siehe Fischer et al. (1996), S. 54 f. Christoffersen/Doyle (1998), S. 6, wăhlen die gleiche Vorgehensweise und bezeichnen ihre Skalierung als „disinflation time“. Andere Autoren, die auf den Transformationsbeginn abstellen, sprechen von „transition time“. Vgl. z.B. Berg et al. (1999), S. 5. 
findet, wenn die Reformbemühungen in „Polen-äquivalenten Reformjahren“ gemessen werden. ${ }^{45}$ Die mit Hilfe dieses Verfahrens bestimmten Reformzeitpunkte zielen nicht auf Stabilisierungsprogramme ab, sondern auf das Ausmaß der Liberalisierungsanstrengungen. An diesem Vorgehen ist aber problematisch, daß nicht der eigentliche Reformbeginn erfaßt wird, sondern eine Standardisierung erfolgt, die polnische Erfahrungen als Maßstab zugrunde legt.

Auch wenn die Vorgehensweisen grundsätzlich einsichtig sind, entbehren die Verfahren aus den genannten Gründen nicht einer gewissen Willkür. Das hier gewählte Vorgehen vermeidet dieses Problem. Es erfolgt eine graphische Darstellung in Wachstums-Inflations-Diagrammen, für die es keiner Festlegung eines Reformzeitpunktes bedarf. Damit wird das Problem umgangen, mit Hilfe welcher Kriterien ein solcher Zeitpunkt bestimmt werden soll. Es wird keine Zeitachse verwendet, sondern es werden in den Diagrammen zu den Kombinationen aus Wirtschaftswachstum und Inflation die entsprechenden Jahreszahlen angegeben. Wenn es ähnliche Verläufe im Transformationsprozeß gegeben hat, müßte sich anhand des Verlaufes der beiden Größen der Reformzeitpunkt aus den Graphiken ablesen lassen. Auch bei wiederholten Stabilisierungsversuchen ist zu erwarten, daß die Entwicklungen von Wachstum und Inflation diese widerspiegeln.

Im Vergleich zu statistischen Schätzverfahren handelt es sich bei den hier verwendeten Diagrammen um eine relativ grobe Methode. Neben dem Vorzug, daß kein Reformzeitpunkt festgelegt werden muß, hat die graphische Analyse aber auch den Vorteil, daß sie ein sehr robustes Verfahren ist. Dies trägt dem Aspekt Rechnung, daß die Daten in den mittel- und osteuropäischen Ländern mit großer Unsicherheit behaftet sind. ${ }^{46} \mathrm{Da}$ es sich außerdem bei den genannten Meßproblemen um systematische Fehler handelt, die in allen Transformationsländern auftreten, beeinträchtigen sie den graphischen Ländervergleich nur in geringem Umfang. Es wird zum Beispiel allgemein vermutet, daß die offiziellen Daten den Wachstumseinbruch in den Reformländern überzeichnen. Die Darstellungen werden deshalb für alle Länder in der Weise verzerrt sein, daß sie zu niedrige Wachstumsraten abbilden. Für einen Vergleich der Verläufe ist dies aber nur von untergeordneter Bedeutung, weil von der ungenauen Erfassung des Wirtschaftswachstums alle Graphiken - in unterschiedlichem Ausmaß aber in der gleichen Richtung - betroffen sind.

45 Vgl. de Melo et al. (1997a), S. 36 f.

46 Auf die Schwierigkeiten bei der korrekten Erfassung der wirtschaftlichen Aktivităt wurde bereits im Kapitel II im Unterschnitt 1.2. eingegangen. Auch mit der Messung der Inflationsrate sind nicht unerhebliche Probleme verbunden. Siehe Fischer et al. (1996), S. 48 f. 
Die Darstellung in Wachstums-Inflations-Diagrammen greift einen Ansatz von Bruno (1993) auf, der entsprechende Graphiken für lateinamerikanische Länder und für einige Transformationsländer zu Reformbeginn verwendet. ${ }^{47}$ Indem Bruno die Stabilisierungspolitik in Bulgarien, der Tschechoslowakei, Polen, Rumänien und Rußland analysiert, versucht er, Gemeinsamkeiten der makroökonomischen Daten zu identifizieren. Er vergleicht die Stabilisierungsbemühungen mit den Erfahrungen von fünf lateinamerikanischen Staaten und Israel. ${ }^{48}$ Selbstverständlich bestehen große Unterschiede zwischen den beiden Ländergruppen. Wie im zweiten Kapitel ausführlich dargestellt, standen die Reformländer vor besonderen Herausforderungen zu Beginn ihrer Transformation. Trotz offensichtlicher Unterschiede zwischen den beiden Ländergruppen haben beide aber auch gemeinsame wirtschaftspolitische Zielsetzungen. Sowohl die mittel- und osteuropäischen als auch die lateinamerikanischen Staaten und Israel haben wichtige Schritte unternommen, um eine Integration ihrer Volkswirtschaften in die Weltwirtschaft zu erreichen. Darüber hinaus haben beide Regionen starke Anstrengungen zur Bekämpfung hoher Inflationsraten und zur Erlangung eines internen und externen wirtschaftlichen Gleichgewichts unternommen. Als stilisierte Entwicklung von Krise, Anpassung und Reform hat Bruno einen in vier Phasen unterteilten Verlauf ermittelt, der in Abbildung 4 wiedergegeben ist.

Nach einer Periode mit sinkenden Wachstumsraten unternehmen die Länder eine Preisliberalisierung, die zu einem deutlichen Inflationsanstieg führt. Während von der Stabilisierungspolitik erwartet wird, daß sie den erwarteten Erfolg im Hinblick auf die Inflationsreduzierung bringt, ist sie mit negativem Wirtschaftswachstum verbunden. Positive Wachstumsraten stellen sich erst ein, nachdem umfassende Strukturreformen durchgeführt wurden. Während die Abbildung 4 hauptsächlich auf beobachteten Entwicklungen in Lateinamerika und Israel beruht, stellte sie Anfang der 1990er Jahre für die Transformationsökonomien eine Prognose dar. Die beiden folgenden Unterabschnitte stellen die Entwicklungen in den zehn betrachteten mittel- und osteuropäischen Staaten dar und prüfen, ob es in diesen Ländern zu einem Verlauf von Inflation und Wachstum gekommen ist, wie er in der Abbildung 4 vorhergesagt wird.

47 Siehe Bruno (1993), S. $306 \mathrm{ff}$.

48 Die untersuchten Länder sind Argentinien, Bolivien, Brasilien, Chile, Mexiko und Israel. Lateinamerika ist in der Literatur hăufiger als Referenz furr die Politikgestaltung in den Transformationsländern herangezogen worden. Vgl. zum Beispiel Schweickert (1993), S. 205 ff., und Edwards (1996a), S. 133, für Folgerungen aus den geld- und wechselkurspolitischen Erfahrungen Lateinamerikas für die Transformationslănder. 


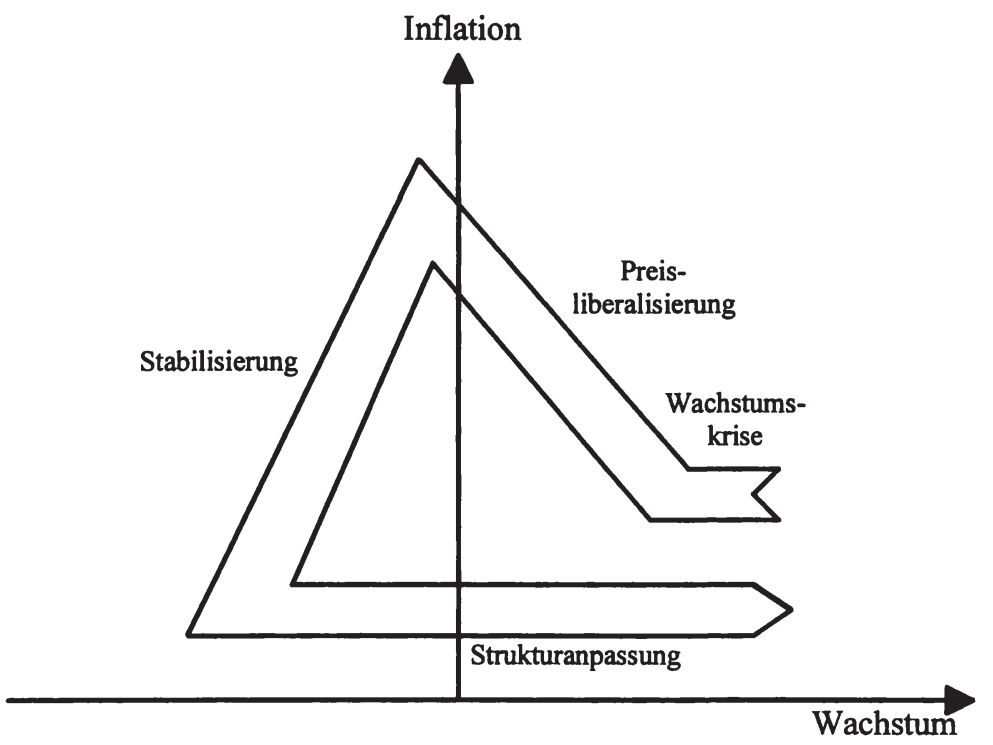

Quelle: Bruno (1993), S. 310.

\subsubsection{Entwicklungen in den zehn Transformationsländern}

Die zehn Diagramme der Abbildung 5 stellen die Entwicklung von Wachstum und Inflation in den zehn betrachteten Ländern dar. Bevor auf die Länderentwicklungen eingegangen wird, sollen kurz die verwendeten Daten erläutert werden, die verschiedenen Ausgaben des World Economic Outlook vom Internationalen Währungsfonds und der Transition Reports und Transition Report Updates von der Europäischen Bank für Wiederaufbau und Entwicklung entnommen sind. Bei den Wachstumsraten handelt es sich um jährliche Veränderungen des realen Bruttoinlandsprodukts, während die Inflation durch den jahresdurchschnittlichen Anstieg des Konsumgüterpreisindexes gemessen wird. 49 Durch die Beschränkung auf Jahresdaten ist zwar die Anzahl der Beobachtungen geringer als zum Beispiel bei der Verwendung von Quartalsdaten, allerdings wird auch die Volatilität der Werte reduziert. Insbesondere der Konsumgüterpreisindex unterliegt in den Transformationsländern innerhalb eines Kalenderjahres starken Schwankungen. Dies resultiert vor allem aus dem relativ

49 Fur fruhe Jahre werden die Wachstumsraten zum Teil in realen Änderungsraten des sogenannten „Net Material Products“ und Inflationsraten auf der Basis des „Retail Price Index“ gemessen. 
hohen Gewicht, das Nahrungsmittel an den Warenkörben einnehmen. Saisonal bedingte Veränderungen von Lebensmittelpreisen können deshalb die monatlichen oder vierteljährlichen Inflationsraten insgesamt beeinflussen. ${ }^{50}$ Eine Verwendung von Jahresdaten blendet diese kurzfristigen Schwankungen aus und erlaubt eine Konzentration auf die mittel- bis längerfristigen Entwicklungen der Preissteigerungsraten, die sich aus den Stabilisierungsbemühungen ergeben. Aufgrund der großen Bandbreite beobachteter Inflationsraten werden diese auf einer logarithmierten Skala abgetragen. Der Beobachtungszeitraum reicht vom Ende der 1980er Jahre bis zum Jahr 1999, wobei die Daten für 1999 Schätzungen der Europäischen Bank für Wiederaufbau und Entwicklung sind. Da der Schwerpunkt der Betrachtung auf den Stabilisierungsbemühungen im Transformationsprozeß liegt, werden die Wachstums- und Inflationsraten nur für wenige Jahre vor Reformbeginn mit aufgenommen, sofern entsprechende Zahlenangaben verfügbar sind. Allerdings müssen diese Angaben mit besonderer Vorsicht interpretiert werden, da es sich um Daten aus sozialistischen Statistiken für Zentralverwaltungswirtschaften handelt. Sie wurden hier berücksichtigt, um einerseits einige Informationen über den Verlauf in der Endphase der Planwirtschaft zu liefern und andererseits nicht von vornherein einen bestimmten Startzeitpunkt für den Transformationsprozeß vorgeben zu müssen.

Bei der Betrachtung der Abbildung 5 fällt auf, daß sich die Entwicklungen in Bulgarien und Rumänien deutlich von den Verläufen in den anderen acht Staaten unterscheiden. Es werden daher zunächst die Entwicklungen in diesen acht Ländern betrachtet, bevor näher auf Bulgarien und Rumänien eingegangen wird.

Von Slowenien abgesehen fiel in den anderen sieben Ländern zu Reformbeginn der größte Rückgang des Bruttoinlandsprodukts mit dem höchsten Preisanstieg zusammen. Als weitere Gemeinsamkeit läßt sich erkennen, daß in diesen Ländern die stärksten negativen Wachstumsraten überwiegend zwischen -10 v.H. und -15 v.H. lagen. Nur in Lettland und Litauen war der wirtschaftliche Einbruch größer. In Polen war das Jahr 1990 durch diese Kombination aus stärkstem wirtschaftlichem Rückgang und höchster Inflationsrate geprägt. Die slowakische und tschechische Republik sowie Ungarn folgten 1991 und die baltischen Länder im Jahre 1992. Die Abbildung 5 zeigt weiterhin, daß nach diesen Jahren die Wachstumsraten zwar zunächst negativ blieben, aber das Bruttoinlandsprodukt nicht mehr in so starkem Ausmaß zurückging. Zwei bis drei Jahre später erreichten alle Länder positive Wachstumsraten. Slowenien weicht von diesem Muster etwas ab, da der größte Wirtschaftseinbruch im Jahre $1991 \mathrm{zu}$ verzeichnen war, nachdem die Inflationsrate bereits von über 1000 v.H. auf 
Abbildung 5a: Verlauf von Wirtschaftswachstum und Inflation in den zehn mittel- und osteuropäischen EU-Beitrittskandidaten
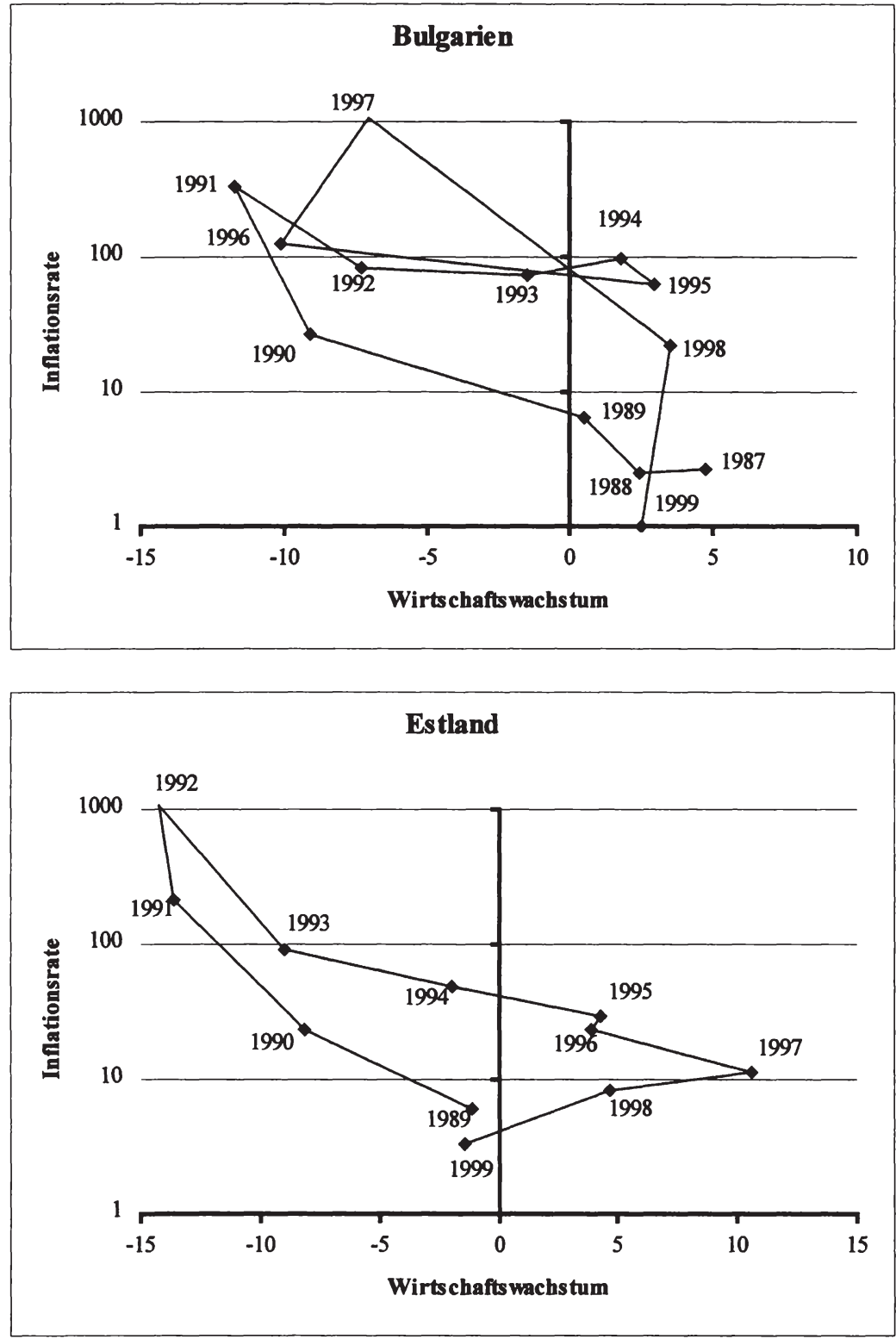
Abbildung 5b: Verlauf von Wirtschaftswachstum und Inflation in den zehn mittel- und osteuropäischen EU-Beitrittskandidaten
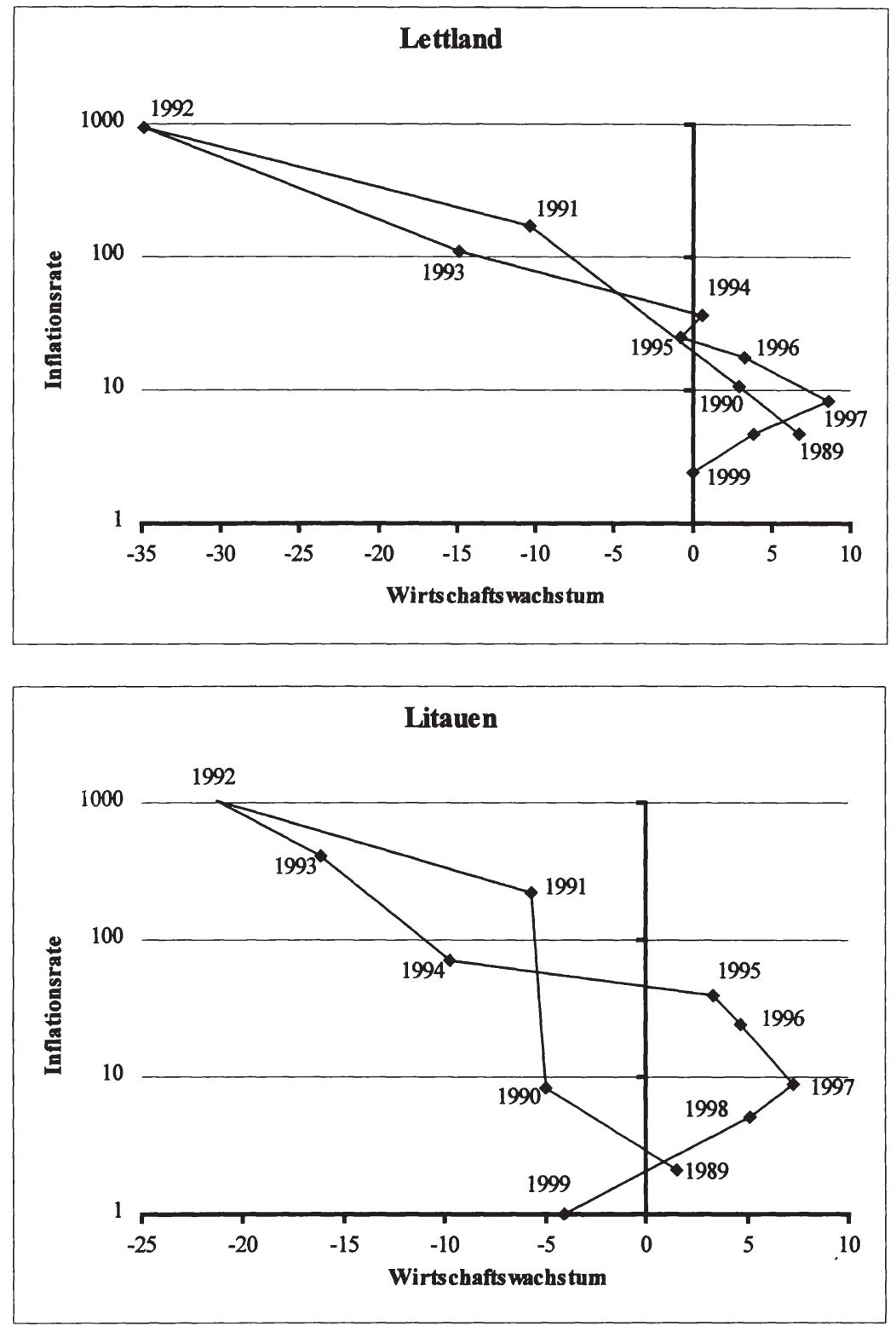
Abbildung 5c: Verlauf von Wirtschaftswachstum und Inflation in den zehn mittel- und osteuropäischen EU-Beitrittskandidaten
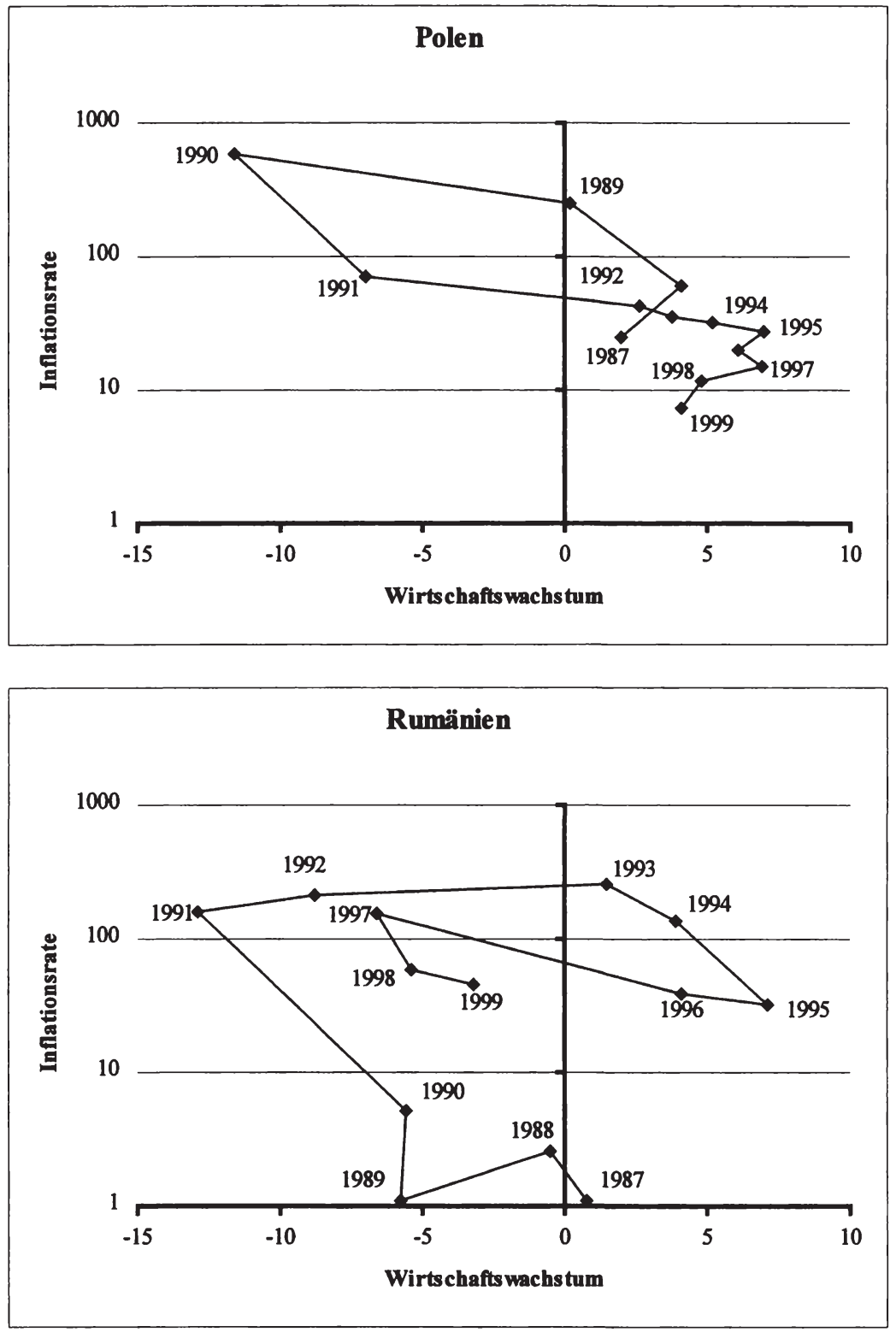
Abbildung 5d: Verlauf von Wirtschaftswachstum und Inflation in den zehn mittel- und osteuropäischen EU-Beitrittskandidaten
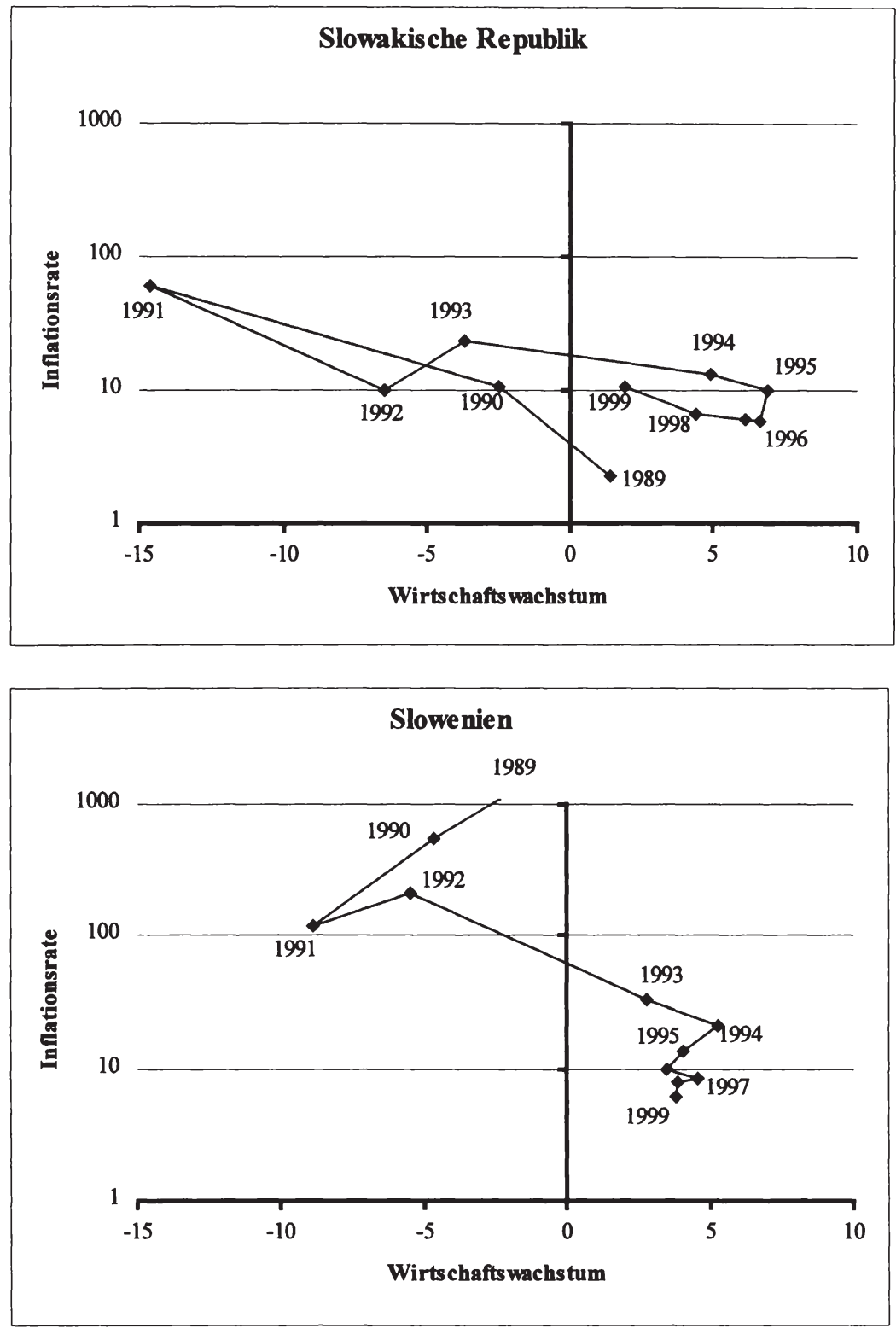
Abbildung 5e: Verlauf von Wirtschaftswachstum und Inflation in den zehn mittel- und osteuropäischen EU-Beitrittskandidaten
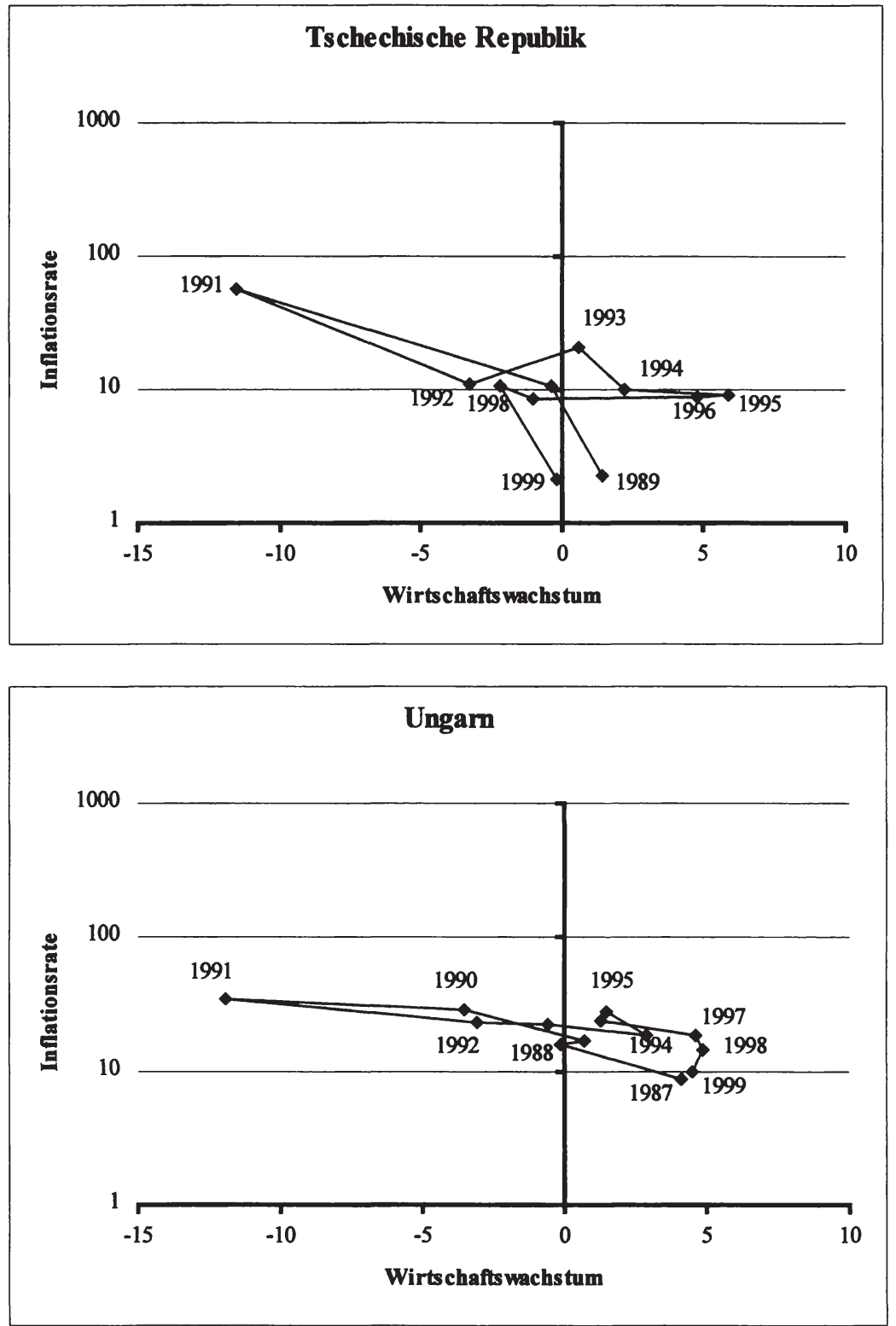

Quelle: IMF, EBRD (verschiedene Jahrgănge) 
einen unteren dreistelligen Betrag zurückgeführt werden konnte. Außerdem ist die Wachstumsrate nicht unter den Wert von -10 v.H. gefallen. Im Hinblick auf die wirtschaftliche Erholung erfüllt Slowenien jedoch das gerade beschriebene Muster, weil sich 1993 positive Wachstumsraten einstellten, d.h. zwei Jahre nachdem der stärkste Rückgang des Bruttoinlandsprodukts zu verzeichnen war.

Während die meisten Länder seit dem Übergang zu positiven Wachstumsraten diese beibehalten konnten, wiesen Tschechien sowie Estland und Litauen in letzter Zeit wieder negative Wachstumsraten auf. Noch bis 1998 hatten die beiden baltischen Länder Wachstumsraten von über 4 v.H. erreicht. Die negative Wirtschaftsentwicklung im Jahr 1999 ist in erster Linie auf die Auswirkungen der russischen Finanzkrise im August 1998 zurückzuführen. ${ }^{51}$ Trotz der verstärkten Westorientierung des Außenhandels bestanden im Baltikum bis 1998 enge Handelsbeziehungen zu dem großen Nachbarland, die ausgeprägter waren als in den anderen betrachteten Staaten. Die Rußlandkrise wirkte sich zwar auf die ganze Region aus, das Baltikum war aber am stärksten von ihr betroffen. Für das Jahr 2000 wird jedoch bereits in allen drei baltischen Ländern wieder mit einem deutlichen Anstieg des Bruttoinlandsprodukts gerechnet. ${ }^{52}$ Tschechien erlebte 1997-1999 eine Rezession. Unzureichende Strukturreformen verbunden mit stark ansteigenden Löhnen und mit einer realen Aufwertung der Währung führten bis Anfang 1997 in Tschechien zu einer sich verschlechternden Wettbewerbsfähigkeit der Unternehmen, die im Mai 1997 in eine Währungskrise mündete. ${ }^{53}$ Auf diese Entwicklung wurde mit einer makroökonomischen Politik reagiert, die bis Ende 1998 sehr restriktiv blieb, und zwar zum Teil auch dadurch bedingt, weil negative Auswirkungen der Rußlandkrise auf die tschechische Wirtschaft befürchtet wurden.

Für alle acht Länder zeigt die Abbildung 5 extrem hohe Inflationsraten zu Beginn der Transformation. Diese hohen Preissteigerungsraten ergaben sich - wie im Kapitel II geschildert - durch die Preisliberalisierung und die Beseitigung des Geldüberhangs durch offene Inflation. Während die slowakischen, tschechischen und ungarischen Inflationsraten unter 100 v.H. blieben, verzeichneten die anderen Länder drei- oder sogar vierstellige Preissteigerungsraten. Seit dem Erreichen dieser Höchstwerte sind die Inflationsraten in den drei baltischen Staaten und Polen kontinuierlich gefallen, wobei im Baltikum deutlich früher als in Polen einstellige Preissteigerungsraten erreicht wurden.

51 Die drastische Abwertung des Rubels und die daraus resultierende Halbierung der russischen Importe fuhrte zu einem Export- und Wirtschaftseinbruch in den baltischen Staaten. Vgl. Gulde et al. (2000), S. 10. Auch Lettland war von den Entwicklungen in Rußland stark betroffen, allerdings stellte sich 1999 noch eine knapp positive Wachstumsrate ein. Vgl. DB Research (2000d), S. 20, und EBRD (2000), S. 4.

$53 \mathrm{Zu}$ den Hintergrunden der tschechischen Rezession siehe IMF (2000), S. 6. 
Auch Slowenien verzeichnet seit 1989 eine deutliche Disinflation. Eine Ausnahme unter den ansonsten kontinuierlich fallenden Preissteigerungsraten bildet lediglich das Jahr 1992, in dem die Inflation höher ausfiel als im Vorjahr. Dieser Anstieg resultiert vor allem aus der Tatsache, daß die slowenische Regierung im Januar 1992 die Preiskontrollen für 80 v.H. aller Güter aufhob. ${ }^{54}$ In der Slowakei und Tschechien führten unter anderem steuerpolitische Maßnahmen zu einem Anstieg der Inflation im Jahre 1993. In beiden Ländern wurde in diesem Jahr die Mehrwertsteuer eingeführt, was zu dem Preisanstieg entscheidend beitrug. 55 In der Slowakei hat sich zusätzlich die einmalige nominale Abwertung in Höhe von 10 v.H. im Juli 1993 preissteigernd ausgewirkt. Mit Ausnahme dieses einen Jahres verzeichneten aber beide Länder bis 1997 ebenfalls eine deutliche Disinflation. In Tschechien stieg die Inflationsrate 1998 kurzfristig auf einen zweistelligen Wert an, der insbesondere durch die Abwertung der Tschechischen Krone im Jahr 1997 und einige starke Anhebungen regulierter Preise hervorgerufen wurde. ${ }^{56}$ Bereits 1999 ging die Preissteigerung jedoch auf einen niedrigen einstelligen Wert zurück. In der Slowakei stieg in den letzten Jahren die Inflation, was insbesondere auf Preisderegulierungen der neuen slowakischen Regierung seit dem Herbst 1998 und die Abwertung der Slowakischen Krone nach dem Übergang zum flexiblen Wechselkurssystem im Oktober 1998 zurückzuführen ist. 57

In Ungarn war der Trend bei der Rückführung hoher Preissteigerungsraten insbesondere in der ersten Hälfte der 1990er Jahre weniger stark ausgeprägt als in den anderen Ländern. Es ist das dritte Land neben Tschechien und der Slowakei, das keine dreistelligen Inflationsraten aufwies. Allerdings wurde die Inflation zunächst nicht deutlich reduziert. Nach einem langsamen Rückgang in den Jahren von 1991 bis 1994 stieg die Inflationsrate im Jahr 1995 wieder deutlich über das Niveau von 1992 an. Erst seit 1995 fällt die Inflationsrate kontinuierlich und erreichte 1999 erstmalig einen Wert unter 10 v.H.

Während die Entwicklungen in den bisher behandelten Ländern sich nur geringfügig unterscheiden, weichen die Verläufe in Bulgarien und Rumänien grundlegend vom Muster in den anderen Ländern ab. Nach den ersten großen Stabilisierungsbemühungen in beiden Ländern, d.h. in Bulgarien im Februar 1991 und

54 Siehe EBRD (1995), S. 59. Einige Preisfreigaben wurden allerdings 1993 wieder zuruckgenommen.

55 In Tschechien werden 8,5 Prozentpunkte der Inflationsrate dieses Jahres in Høhe von insgesamt 20 v.H. auf den Übergang zum Mehrwertsteuersystem zuruckgefuhrt. Vgl. Janácková (1995), S. 37.

57 Vgl. OECD (1999b), S. 42 f. 
in Rumänien im Oktober 1993,58 schien es zunächst, als würden die Länder eine ähnliche Entwicklung mit rückläufigen Inflationsraten und positiven Wachstumsraten nehmen. Bulgarien verzeichnete 1994 erstmals wieder ein positives Wachstum. Die Inflationsrate stieg zwar im gleichen Jahr auf einen fast dreistelligen Wert an, nachdem sie im Zeitraum 1991-93 deutlich gesenkt worden war. Allerdings konnte sie im Folgejahr bei weiter steigender Wachstumsrate wieder reduziert werden. Diese Entwicklung kehrte sich 1996 um, indem die Inflation auf deutlich über 100 v.H. stieg und die Wirtschaft um 10 v.H. schrumpfte. 1997 verschärfte sich die wirtschaftliche Krise und die Preissteigerung erreichte im Vorjahresvergleich einen vierstelligen Wert. ${ }^{59} \mathrm{Im}$ Frühjahr 1997 handelte Bulgarien mit dem Internationalen Währungsfonds ein Stabilisierungsprogramm aus, dessen zentraler Bestandteil die Einführung eines Currency Boards war. Wie aus Abbildung 5 hervorgeht, führte dieses Programm innerhalb kurzer Zeit zu einer deutlichen Reduzierung der Inflationsraten und zu positiven Wachstumsraten.

Demgegenüber befindet sich Rumänien nach wie vor in einer Situation mit negativem Wachstum und Preissteigerungsraten, die im Jahresdurchschnitt über 40 v.H. liegen. Ebenso wie Bulgarien erzielte Rumänien mit dem ersten Stabilisierungsprogramm in den Jahren 1994 und 1995 Erfolge bei der Rückführung der hohen Inflationsraten, wobei diese Periode der Disinflation sogar mit positiven Wachstumsraten verbunden war. Allerdings wurden kaum Strukturreformen in Angriff genommen; und bereits 1996 stieg die Inflationsrate wieder an. Im Jahr 1997 begann dann die im Herbst des Vorjahres neugewählte Regierung ein umfassendes Reformprogramm zur Umstrukturierung und Stabilisierung der rumänischen Wirtschaft. ${ }^{60}$ Die lange verschleppten Strukturreformen führten zu einem starken Rückgang der Wirtschaftsleistung; und die erneute Preisliberalisierung bewirkte eine weitere Zunahme der Preissteigerung. Seither ist die Inflation rückläufig, betrug aber 1999 immer noch 45,8 v.H.

\subsubsection{Stilisierte Darstellung der Gemeinsamkeiten}

Selbstverständlich gibt es keinen einheitlichen Verlauf der beiden makroökonomischen Größen, der auf alle Länder zutrifft. Dazu waren die Ausgangsbedingungen sowie die gewählten Reformansätze und Politikstrategien zu unterschiedlich. Wie Bruno (1993) es in Form der ersten beiden Phasen der Abbildung 4 prognostiziert hat, ist allerdings in allen Transformationsländern eine

58 Die Daten stammen von Fischer et al. (1997), S. 90.

59 Zur Inflationsdynamik zu Beginn des Jahres 1997 siehe auch die Ausfuhrungen über Bulgarien im Abschnitt IV.1. Für die Ursachen der Krise vgl. OECD (1997a), S. 1 ff.

60 Das Programm sah vor, bereits 1997 uber 100 Gesetze zu verabschieden, um eine zugige Reformierung zu erreichen. Siehe OECD (1998), S. 3 und $152 \mathrm{ff}$. 
schwere Wachstumskrise mit außergewöhnlich hohen Inflationsraten zu Beginn des Reformprozesses eingetreten. Die Stabilisierungsbemühungen waren hingegen von unterschiedlich starken Erfolgen geprägt. Im Hinblick auf Gemeinsamkeiten zwischen den zehn betrachteten mittel- und osteuropäischen EUBeitrittskandidaten lassen sich die Länder grob in zwei Gruppen einteilen. Die erste Gruppe wird von folgenden acht Ländern gebildet: den drei baltischen Staaten, Polen, Slowakei, Slowenien, Tschechien und Ungarn. Die zweite Gruppe besteht aus Bulgarien und Rumänien. Während die Länder der ersten Gruppe bereits im Zuge der Reduzierung hoher Preissteigerungsraten die negativen Wachstumsraten verringern und dann ein positives Wirtschaftswachstum erreichen konnten, weisen Bulgarien und Rumänien nicht eine solche klare Tendenz auf. Für die erste Gruppe läßt sich ein Verlauf von Wirtschaftswachstum und Inflation entwickeln, wie er in der Abbildung 6 dargestellt ist.

\section{Abbildung 6: Stilisierte Darstellung von Wirtschaftswachstum und Inflation im Transformationsprozeß}

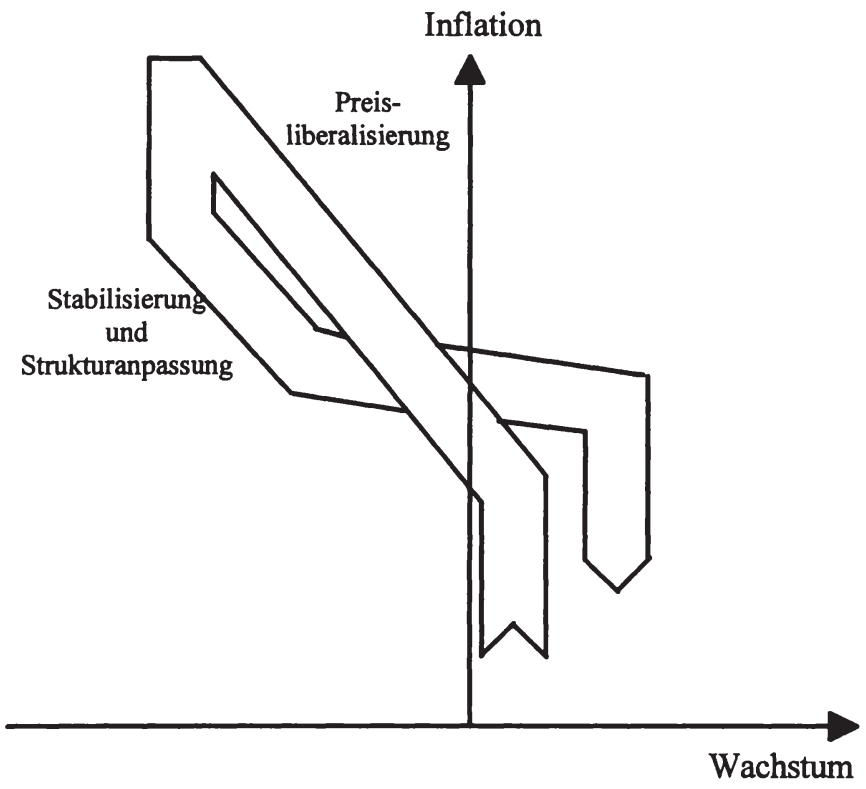

Quelle: Gerloff (2000), S. 136.

Bei aller Vorsicht, die bei Ländervergleichen angebracht ist, zeigt sich in dieser Gruppe ein relativ einheitliches Bild, obwohl die konkreten Wachstumseinbrüche, Inflationsschübe und Stabilisierungsansätze von Land zu Land stark variierten. Ungefähr zwei Jahre nach Reformbeginn erzielten die Länder ein positi- 
ves Wirtschaftswachstum bei fallenden Preissteigerungsraten. Beide Größen Wirtschaftswachstum und Inflation - folgen in den acht Ländern in etwa dem gleichen Verlauf, wobei die Entwicklung bei den Preissteigerungsraten noch ähnlicher ist als bei den Wachstumsraten. Der entscheidende Unterschied zwischen den Abbildungen 4 und 6 liegt darin, daß die erfolgreichen Transformationsländer sehr viel schneller zu positiven Wachstumsraten zurückkehrten, als Bruno (1993) dies prognostiziert hat. Die Reduzierung der Inflationsraten war nicht mit rückläufigen, negativen Wachstumsraten verbunden. Die radikalen Politikansätze, die eine restriktive Stabilisierungspolitik mit gleichzeitiger Liberalisierung der Wirtschaft und Strukturreformen verbanden, erwiesen sich offenbar als sehr erfolgreich im Hinblick auf eine zügige Stabilisierung von Inflation und Wachstum.

Während in entwickelten Volkswirtschaften in der Regel davon ausgegangen wird, daß mit der Disinflation Kosten im Sinne eines temporären Rückgangs der Beschäftigung und des Sozialprodukts verbunden sind, ${ }^{61}$ gilt dieser Zusammenhang - zumindest bezüglich des Sozialprodukts - in den Transformationsländern nicht. Dieses Ergebnis unterstreicht die im zweiten Kapitel ausführlich analysierten Besonderheiten der Ausgangslage in den Reformländern. Eine schnelle Reduzierung hoher Preissteigerungsraten ist nicht zu Lasten der wirtschaftlichen Entwicklung gegangen, sondern führte ganz im Gegenteil eher zu einem frühen Anstieg des Sozialprodukts. Rumänien und Bulgarien erreichten zwar 1993 bzw. 1994 positive Wachstumsraten, obwohl die Preissteigerungsraten noch nicht deutlich zurückgeführt worden waren. Allerdings stieg das Sozialprodukt in beiden Fällen nur für einen kurzen Zeitraum, bevor es erneut deutlich zurückging und die Inflationsraten kräftig anstiegen. Wenn im Rahmen des Transformationsprozesses von einer gelungenen Stabilisierung der Volkswirtschaften gesprochen wird, bedeutet dies deshalb nicht nur eine erfolgreiche Rückführung der hohen Inflationsraten zu Reformbeginn, sondern gleichzeitig eine Rückkehr zu einem wieder ansteigenden Sozialprodukt.

Daten für die Entwicklung der Arbeitslosigkeit, die nicht aus den Graphiken ablesbar sind, enthält die Tabelle 4 in Fischer/Sahay (2000). ${ }^{62}$ Die Höhe der Arbeitslosenquoten ist von Land zu Land sehr verschieden, aber in allen zehn EU-Beitrittskandidaten lag die durchschnittliche Arbeitslosenquote im Zeitraum 1995-97 über dem Durchschnittswert für den Zeitraum 1989-94. Die Arbeitslosenquoten in den Transformationsländern haben sich also auch in den erfolgreich stabilisierten Volkswirtschaften trotz des wieder zunehmenden Sozialprodukts erhöht. De Melo et al. (1997a) ermitteln ebenfalls einen positiven $\mathrm{Zu}$ sammenhang zwischen registrierter Arbeitslosigkeit und Wirtschaftswachstum

61 Siehe de Melo et al. (1997a), S. 34, und Jarchow (1998a), S. $321 \mathrm{f}$.

62 Vgl. Fischer/Sahay (2000), S. 38 f. 
und nennen als einen Erklärungsansatz höhere Anreize in fortgeschrittenen Ländern, sich arbeitslos zu melden. ${ }^{63}$ Während des Reformprozesses gilt also offensichtlich nicht das sogenannte Okunsche Gesetz, das einen inversen $\mathrm{Zu}$ sammenhang zwischen Unterbeschäftigung und realem Sozialprodukt unterstellt. ${ }^{64}$ Bei dieser Aussage handelt es sich um ein gemeinsames Kennzeichen der Transformationsländer, das auch auf Bulgarien und Rumänien zutrifft.

Die in diesem Unterabschnitt erfolgte Einteilung der Beitrittskandidaten in eine Gruppe erfolgreicher Stabilisierer und eine Gruppe, die in den ersten Jahren der Systemtransformation keine nachhaltige Stabilisierung erreichen konnte, bildet die Grundlage für die Analyse der Ursachen, die zu den unterschiedlichen Stabilisierungserfolgen geführt haben. In diesem Zusammenhang wird einerseits untersucht, welche Faktoren, die nicht im Partialmodell des dritten Kapitels berücksichtigt wurden, eine wichtige Rolle bei der Stabilisierung gespielt haben. Andererseits wird überprüft, ob für die Gruppe der zehn mittel- und osteuropäischen Staaten die Hypothese des Modells bestätigt werden kann, daß ein festes Wechselkursregime eher als ein flexibles Wechselkurssystem zur Reduzierung der Inflation beiträgt, es sei denn, in einem Flexkurssystem wird nominal aufgewertet.

\subsection{Mögliche Einflußfaktoren}

In diesem Unterabschnitt werden sechs Faktoren analysiert, die eventuell dazu beitragen können, die unterschiedlichen Entwicklungen in den zehn Ländern zu erklären. Es werden die Ausgangsbedingungen, die Liberalisierungspolitik und makroökonomische Politikvariablen betrachtet, weil diese Faktoren in den meisten empirischen Studien untersucht werden und ihr Beitrag zu einer erfolgreichen Stabilisierung unterschiedlich bewertet wird. ${ }^{65}$ Die Behandlung in diesem Abschnitt konzentriert sich auf die Unterschiede zwischen der Untergruppe der acht erfolgreich stabilisierenden Länder auf der einen Seite sowie Bulgarien und Rumänien auf der anderen Seite, die in den ersten Jahren der Transformation bei der Stabilisierung ihrer Volkswirtschaften deutlich weniger erfolgreich waren. Nach der Betrachtung des Einflusses der Ausgangslage wird die Bedeutung der Liberalisierungspolitik analysiert. Daran schließen sich Untersuchungen der Zentralbankgesetzgebung sowie der Fiskal- und Geldpolitik an, bevor auf die Bedeutung der Wahl des Wechselkurssystems eingegangen wird. Bei

63 Vgl. de Melo et al. (1997a), S. 44 ff. und 65.

64 Zum Okunschen Gesetz siehe Okun (1970), S. 136, und Jarchow (1998a), S. 262. Eine Diskussion möglicher Ursachen für den positiven Zusammenhang zwischen Unterbeschätigung und Sozialprodukt geht uber den Rahmen der vorliegenden Arbeit hinaus. Fur verschiedene Ansatzpunkte siehe o.V. (1996), S. 306 f.

Siehe Fischer/Sahay (2000), S. 15. 
der Betrachtung des Einflusses der Wechselkurspolitik wird neben den Unterschieden zwischen Bulgarien und Rumänien im Vergleich zu den anderen acht Ländern insbesondere der Frage nachgegangen, ob diejenigen Länder, die sich für eine Wechselkursbindung oder die nominale Aufwertungsvariante entschieden, größere Erfolge bei der Inflationsbekämpfung aufweisen, wie es vom Modell im Kapitel III prognostiziert wird.

\subsubsection{Unterschiedliche Ausgangsbedingungen}

Die Rolle, die die Ausgangsbedingungen für den Reformprozeß gespielt haben, gehört zu den umstrittensten Aspekten der Transformation. ${ }^{66}$ Es stimmen alle Autoren darin überein, daß die Ausgangsbedingungen einen Einfluß auf die Transformation hatten. Aber während ihnen einige Wissenschaftler eine große Bedeutung beimessen, meinen andere, sie hätten nur geringen Einfluß gehabt und die Bedeutung ginge im Zeitablauf zurück. Wie bereits erwähnt, ist die $\mathrm{Zu}-$ sammensetzung des Ländersamples dieser Arbeit gewählt worden, weil die

Tabelle 6: Unterschiedliche Ausgangsbedingungen in Mittel- und Osteuropa

\begin{tabular}{|c|c|c|c|c|c|c|}
\hline Land & $\begin{array}{c}\text { Pro- } \\
\text { Kopf- } \\
\text { Einkom- } \\
\text { men } \\
1989^{a}\end{array}$ & $\begin{array}{l}\text { Anteil } \\
\text { RGW- } \\
\text { Handel } \\
\text { am BIP } \\
1990^{b}\end{array}$ & $\begin{array}{l}\text { Anteil } \\
\text { Landwirt- } \\
\text { schaft am } \\
\text { BIP } 1989^{c}\end{array}$ & $\begin{array}{c}\text { Entfernung } \\
\text { zu } \\
\text { Zentral- } \\
\text { europa } \\
\text { in } \mathbf{k m}^{\mathbf{d}}\end{array}$ & $\begin{array}{c}\text { Jahre } \\
\text { unter } \\
\text { kommuni- } \\
\text { stischer } \\
\text { Herrschaft }\end{array}$ & $\begin{array}{l}\text { Auslandsver- } \\
\text { schuldung } \\
\text { vor Reform- } \\
\text { beginn }^{\mathrm{e}}\end{array}$ \\
\hline Bulgarien & 5.740 & 15 & 11 & 1.574 & 43 & 50,6 \\
\hline Estland & 6.475 & 27 & 20 & 1.449 & 51 & 0,0 \\
\hline Lettland & 5.204 & 31 & 19 & 1.293 & 51 & 0,0 \\
\hline Litauen & 3.603 & 34 & 27 & 1.299 & 51 & 0,2 \\
\hline Polen & 5.687 & 17 & 13 & 995 & 42 & 63,4 \\
\hline Rumänien & 3.535 & 3 & 14 & 1.637 & 43 & 2,9 \\
\hline Slowakei & 6.969 & 10 & 7 & 824 & 43 & 6,8 \\
\hline Slowenien & 11.525 & 5 & 5 & 815 & 44 & 0,0 \\
\hline Tschechien & 8.207 & 10 & 7 & 559 & 43 & 12,2 \\
\hline Ungarn & 6.081 & 10 & 14 & 1.002 & 41 & 64,0 \\
\hline \multicolumn{7}{|c|}{$\begin{array}{l}\text { Anmerkungen: }{ }^{\mathrm{a}} \text { In US-Dollar-Kaufkraftparităten umgerechnetes BIP geteilt durch die gesamte } \\
\text { Bevolkerung. }-{ }^{b} \text { Anteil in v.H.; für das Baltikum Handel innerhalb der ehemaligen Sowjetuni- } \\
\text { on. - }{ }^{\mathrm{c}} \text { Anteil in v.H. }-{ }^{\mathrm{d}} \text { Gemessen als Entfernung zwischen der jeweiligen Hauptstadt und } \\
\text { Dussseldorf. - }{ }^{\mathrm{e}} \text { Anteil am BIP in v.H. im Jahr vor Reformbeginn. }\end{array}$} \\
\hline
\end{tabular}

Quelle: Fischer/Sahay (2000), Tabelle 3, S. 36.

66 Vgl. Havrylyshyn/van Rooden (2000), S. 21. 
Staaten gemeinsame Charakteristika aufweisen, und zwar vor allem die Westorientierung und das gemeinsame Ziel eines EU-Beitritts. Trotzdem waren die Ausgangssituationen in den Ländern sehr unterschiedlich. Es stellt sich deshalb auch hier die Frage, ob dies die Ergebnisse erklären kann.

In der Literatur wird eine Vielzahl verschiedener Ausgangsbedingungen diskutiert. Dazu gehören unter anderem der Entwicklungsstand zu Beginn der Transformation, der Anteil der städtischen Bevölkerung an der gesamten Bevölkerung, die Handelsabhängigkeit vom RGW, der Anteil der Landwirtschaft an der Wertschöpfung oder Beschäftigung sowie die räumliche Entfernung zu Westeuropa. ${ }^{67}$ Die Tabelle 6 zeigt sechs häufig genannte Merkmale für die zehn betrachteten Länder.

Aus der Tabelle geht hervor, daß sich die EU-Beitrittskandidaten zu Reformbeginn in sehr unterschiedlichen Ausgangspositionen befanden. Allerdings zeigt sich für fast alle genannten Faktoren keine klare Tendenz in der Art, daß Bulgarien und Rumänien in dieser Kategorie die ungünstigsten Werte einnehmen und dies deshalb erklären könnte, warum diese beiden Länder weniger erfolgreich bei der Stabilisierung ihrer Volkswirtschaften waren. ${ }^{68}$ Das einzige Merkmal, in dem beide Länder gemeinsam am Ende der Skala stehen, ist die geographische Entfernung zu Zentraleuropa. Diese Beobachtung ist kompatibel mit der Aussage von Lipton/Sachs (1990), die feststellen, daß ,the prospects appear to be brightest in the most westward countries: ... Poland, Czechoslovakia, Hungary, and Yugoslavia. In Bulgaria and Romania, the conditions are less favorable, both economically and politically."69 Allerdings erscheint es nicht angemessen, die unterschiedlichen Stabilisierungserfolge allein auf eine etwas größere geographische Entfernung zu Europa zurückzuführen. So sind Bulgarien und $\mathrm{Ru}-$ mänien räumlich nicht wesentlich weiter von Westeuropa entfernt als das Baltikum. Auch wenn die baltischen Staaten an ihre guten Beziehungen zu Skandinavien aus vorsozialistischer Zeit anknüpfen konnten und die Situation zu Transformationsbeginn vorteilhafter war als in den meisten anderen ehemaligen Sowjetrepubliken, ist zu berücksichtigen, daß die Nachfolgestaaten der ehemaligen Sowjetunion generell von einer schlechteren Ausgangsbasis starteten als die Länder in Mittel- und Osteuropa. Dies zeigt sich auch in den stärker negati-

67 Für weitere Merkmale der Ausgangssituation siehe de Melo et al. (1997b), S. 9 ff., und EBRD (1999), S. 28.

68 Ein weiterer, häufig genannter Faktor ist die Große der Volkswirtschaft. Dieses Merkmal scheidet jedoch ebenfalls als Erklärungsmöglichkeit aus, weil Polen - gemessen an der Bevollkerung und der Staatsflăche großtes der betrachteten Länder - ebenso zu der Gruppe der erfolgreichen Stabilisierer gehört wie Estland und Slowenien, die die beiden kleinsten Staaten im Hinblick auf diese Kennzahlen sind. Siehe Gerloff (1999), S. 12.

Lipton/Sachs (1990), S. 78. 
ven Wachstumsraten und den höheren Inflationsraten zu Beginn des Transformationsprozesses. Daß die baltischen Staaten zu der Gruppe mit kontinuierlicher Inflationsreduzierung und früher Rückkehr zu positiven Wachstumsraten gehören, deutet daher darauf hin, daß die Durchführung einer konsistenten Reformpolitik einen größeren Einfluß ausgeübt hat als die Ausgangssituation. Dieses Ergebnis wird auch von vielen empirischen Studien bestätigt, die eine größere Anzahl an Ländern mit noch stärker differierenden Ausgangsbedingungen in die Analyse einbeziehen. ${ }^{70}$

In der Tabelle 6 fällt hingegen das hohe Pro-Kopf-Einkommen Sloweniens positiv auf. Dies deutet auf eine relativ vorteilhafte Ausgangslage dieses Landes im Vergleich zu den anderen neun Staaten hin, was durch weitere Fakten belegt werden kann. So waren in Slowenien zum Beispiel kleine Unternehmen bereits vor Transformationsbeginn überwiegend in Privatbesitz. ${ }^{71}$ Auch die außenwirtschaftliche Situation stellte sich in Slowenien deutlich günstiger dar als in anderen mittel- und osteuropäischen Ländern. Jugoslawien unterhielt schon in den 1980er Jahren enge Handelsbeziehungen zur Europäischen Gemeinschaft. Bereits vor Reformbeginn wickelte Slowenien über Zweidrittel seines Außenhandels mit Westeuropa ab, während der Handel mit RGW-Staaten nur 16 v.H. des Außenhandels ausmachte. ${ }^{72}$ Unter Berücksichtigung der Ausführungen im Unterabschnitt II.1.3., der die Probleme im Zusammenhang mit dem Zusammenbruch des RGW und der Neuausrichtung der Handelsbeziehungen beschreibt, wird deutlich, daß sich Slowenien in einer deutlich vorteilhafteren Ausgangslage befand als die anderen betrachteten Länder. Mit Blick auf die besondere Stellung Jugoslawiens gibt auch die vorletzte Spalte der Tabelle 6 ein etwas falsches Bild. Fischer und Sahay, auf deren Angaben die Tabelle basiert, unterscheiden mit der Angabe „Jahre unter kommunistischer Herrschaft" nicht zwischen der sozialistischen Planwirtschaft und dem jugoslawischen System. Das jugoslawische Wirtschaftssystem hob sich aber deutlich von den Zentralverwaltungswirtschaften durch einen geringeren Grad an zentraler Planung und eine größere Autonomie der Wirtschaftssubjekte ab. ${ }^{73}$

Während also die Analyse der unterschiedlichen Ausgangssituationen - mit Ausnahme einer etwas größeren räumlichen Entfernung zu Zentraleuropa - keinen Anhaltspunkt dafür liefert, warum es Bulgarien und Rumänien in den ersten Jahren der Transformation nicht gelang, ihre Volkswirtschaften zu stabilisieren,

70 Vgl. Havrylyshyn et al. (1998), S. 32, und Berg et al. (1999), S. 53. Für eine Gegenposition siehe Denizer (1997), S. 17.

71 Vgl. Westin (1998), S. 69.

72 Siehe OECD (1997b), S. 17.

73 Das jugoslawische Modell der Arbeiterselbstverwaltung wird auch als ,sozialistische Marktwirtschaft“ bezeichnet. Vgl. Hagemann/Klemencic (1974), S. 10. 
ergibt sich für Slowenien in positiver Hinsicht eine herausgehobene Position. Die ehemalige jugoslawische Teilrepublik dürfte sich innerhalb des Ländersamples mit Abstand in der günstigsten Ausgangslage zu Transformationsbeginn befunden haben.

\subsubsection{Bedeutung der Liberalisierungspolitik}

Es ist allgemein akzeptiert, daß Stabilisierung allein nicht ausreichend ist, um eine erfolgreiche Transformation der Wirtschaft zu erreichen. Die Stabilisierungspolitik muß von einer Liberalisierungspolitik und von mikroökonomischen Reformen begleitet werden, wie z.B. einer umfassenden Privatisierung und institutionellen Reformen. Deshalb muß auch analysiert werden, welche Anstrengungen die Länder unternommen haben, um ihre Wirtschaften zu liberalisieren, und ob diese einen entscheidenden Einfluß auf die verschiedenen Ergebnisse haben. Zur Messung des Liberalisierungsgrades wird in vielen empirischen Studien der sogenannte kumulative Liberalisierungsindex (cumulative liberalization index) verwendet, der von de Melo et al. (1996) entwickelt wurde. ${ }^{74}$ Sie haben einen jährlichen Liberalisierungsindex für mehr als 25 Transformationsländer für die Jahre 1989 bis 1994 ermittelt. Dieser Index mißt den Fortschritt der Reformen in drei Bereichen: Liberalisierung des Binnenmarktes, Erleichterung der Marktzutrittsbedingungen im privaten Sektor und Liberalisierung des außenwirtschaftlichen Sektors. Die Addition der jährlichen Liberalisierungsindizes über die Beobachtungsperiode liefert einen kumulierten Wert für jedes Land zwischen 0 und 6. Da insbesondere argumentiert wird, daß es beim Übergang von der Plan- zur Marktwirtschaft auf eine frühzeitige Liberalisierung ankommt, um den Reformwillen zu dokumentieren, ist zur Erfassung der frühen Liberalisierungsanstrengungen der Transformation der kumulative Liberalisierungsindex für das Jahr 1994 in der zweiten Spalte von Tabelle 7 wiedergegeben.

Für die zehn betrachteten Länder ergibt sich nach de Melo et al. (1997a), die in der dritten Spalte angegebene Rangfolge. Theoretische Überlegungen lassen erwarten, daß diejenigen Länder, die ihre Wirtschaft am stärksten liberalisiert haben, auch die größten Erfolge bei der Stabilisierung erzielten. Auf den ersten Rängen in der dritten Spalte der Tabelle stehen tatsächlich Länder, die große Fortschritte bei der Inflationsbekämpfung und dem Erzielen eines frühen Wirtschaftswachstums erzielt haben, und zwar Slowenien, Polen, Ungarn und Tschechien. Allerdings scheinen die niedrigen Ränge für Rumänien, Lettland und Litauen der Erkenntnis zu widersprechen, daß das Ausmaß der Liberalisierung zur Erklärung der Unterschiede zwischen den Ländern beiträgt. Gerade die baltischen Staaten sind zusammen mit Polen diejenigen vier Länder, die seit

74 Siehe de Melo et al. (1996), S. 1 ff. 
Beginn der Stabilisierungsbemühungen kontinuierlich fallende Preissteigerungsraten verzeichnen.

\section{Tabelle 7: Indikatoren für Strukturreformen und die Liberalisierung der Wirtschaft}

\begin{tabular}{|c|c|c|c|c|}
\hline \multirow[t]{2}{*}{ Land } & \multicolumn{2}{|c|}{$\begin{array}{c}\text { kumulativer } \\
\text { Liberalisierungsindex (1994) }\end{array}$} & \multicolumn{2}{|c|}{$\begin{array}{l}\text { durchschnittlicher } \\
\text { Transformationsindikator (1999) }\end{array}$} \\
\hline & Wert & Rang & Wert & Rang \\
\hline Bulgarien & 2,90 & 7 & 2,9 & 9 \\
\hline Estland & 2,93 & 6 & 3,6 & 4 \\
\hline Lettland & 2,45 & 9 & 3,2 & 7 \\
\hline Litauen & 2,72 & 8 & 3,2 & 7 \\
\hline Polen & 4,14 & 2 & 3,7 & 2 \\
\hline Rumănien & 2,29 & 10 & 2,8 & 10 \\
\hline Slowakei & 3,47 & 5 & 3,5 & 5 \\
\hline Slowenien & 4,16 & 1 & 3,4 & 6 \\
\hline Tschechien & 3,61 & 4 & 3,7 & 2 \\
\hline Ungarn & 4,11 & 3 & 3,9 & 1 \\
\hline
\end{tabular}

Quelle: de Melo et al. (1997a), Tabelle 2, S. 28, fur den kumulativen Liberalisierungsindex, eigene Berechnungen auf Grundlage der Tabelle 2.1 von EBRD (1999), S. 24, fur den durchschnittlichen Transformationsindikator.

Es muß allerdings beachtet werden, daß der kumulative Liberalisierungsindex sowohl die Intensität als auch die Dauer der Reformen mißt. ${ }^{75}$ Durch letzteres kann es vorkommen, daß ein Land, das in den zurückliegenden Jahren einen graduellen Reformweg beschritten hat, höher bewertet wird als ein Land, das erst zu einem späteren Zeitpunkt sehr weitreichende Liberalisierungsschritte umgesetzt hat. Auch wenn frühen Maßnahmen eine große Bedeutung zukommt, spricht diese Überlegung dafür, daß die Kumulierung jährlicher Indizes bis einschließlich 1994 die radikalen Reformen der baltischen Staaten nicht angemessen erfaßt. Es muß ein anderer Indikator herangezogen werden, der auch die Entwicklung in der zweiten Hälfte der 1990er Jahre berücksichtigt. Ein längerer Beobachtungszeitraum reduziert die Meßprobleme, die mit der gleichzeitigen Erfassung von Dauer und Intensität der Reformen verbunden sind. Je mehr Jah-

75 Vgl. Ickes (1996), S. 300. 
re bei der Bildung des Indexes herangezogen werden, um so geringer ist das Gewicht eines einzelnen Reformjahres und um so geringer sind die Unterschiede, die darauf zurückzuführen sind, daß die Länder ihre Transformationsprozesse zu unterschiedlichen Zeitpunkten begannen.

Die Tabelle 7 enthält deshalb auch Werte für einen Index, der auf Daten von 1999 basiert. Dieser Index gibt den Fortschritt in drei Bereichen der Transformation wieder, die im Transition Report der Europäischen Bank für Wiederaufbau und Entwicklung genannt werden: Unternehmenssektor, Märkte und Handel sowie Finanzsektor. ${ }^{76}$ Der Index ist so konstruiert, daß alle acht Kategorien gleich gewichtet sind, für die die EBRD numerische Werte von 1 bis 4+ angibt. Der Klassifizierung 4+ wurde ein Wert von 5 zugewiesen. Diese Bewertung entspricht einem Stand der Transformation, der mit entwickelten Marktwirtschaften vergleichbar ist, ${ }^{77}$ während ein Wert von 1 für nur sehr geringe Fortschritte in der entsprechenden Kategorie steht. Auch dieser Index ist kumulativer Natur, aber im Gegensatz zum kumulativen Liberalisierungsindex werden nicht Jahreswerte zu einem Gesamtwert addiert. Vielmehr repräsentiert er den Stand der Entwicklung in einem bestimmten Jahr, in diesem Fall im Jahr 1999. Dies impliziert, daß der Index fallen würde, wenn ein Land Reformen zurücknähme. Der kumulative Liberalisierungsindex hingegen würde in diesem Fall nicht sinken. Der Wert des Transformationsindikators signalisiert, wie weit sich das entsprechende Land von einer Zentralverwaltungswirtschaft hin zu einem marktwirtschaftlich organisierten System entwickelt hat. Er reflektiert nicht nur die Änderungen im Laufe des Jahres 1999. Die Werte und Ränge für die Länder sind in den letzten beiden Spalten der Tabelle 7 angegeben. Es ergibt sich folgende Rangliste: Ungarn, Tschechien und Polen, Estland, Slowakei, Slowenien, Lettland und Litauen, Bulgarien sowie Rumänien. Nach diesem Index werden Bulgarien und Rumänien als diejenigen Länder identifiziert, die die geringsten Fortschritte auf dem Weg zu einer Marktwirtschaft erreicht haben.

Eine Betrachtung der Reformanstrengungen im weiteren Sinne unter Einbeziehung der mikroökonomischen Reformen und der Liberalisierungspolitik läßt den Schluß zu, daß die Stabilisierungsprogramme in Bulgarien (bis zum Jahr 1996) und in Rumänien unter anderem deshalb nicht erfolgreich waren, weil die Stabilisierungsbemühungen nicht in ausreichendem Maße von komplementären Liberalisierungsschritten begleitet wurden. Dieses Ergebnis stimmt mit den Resultaten der meisten empirischen Studien überein, die ebenfalls einen starken

76 Vgl. EBRD (1999), S. 24 f.

77 Alle anderen Plus- und Minuszeichen aus Tabelle 2.1 von EBRD (1999), S 24, wurden so in numerische Werte uberfuhrt, daß vom Grundwert jeweils 0,3 subtrahiert bzw. addiert wurde. Der maximal erreichbare Wert fur den Transformationsindikator ist 5. Ein Land mit dieser Bewertung entsprăche auf allen Gebieten einer Marktwirtschaft. 
positiven Einfluß der Liberalisierung auf eine erfolgreiche Transformation feststellen. ${ }^{78}$

Die im Rahmen der vorliegenden Arbeit gefundenen Ergebnisse deuten an, daß strukturelle Anpassung und makroökonomische Stabilisierung in einem engen Zusammenhang stehen. Ungarn befindet sich - in Abhängigkeit vom verwendeten Index - auf dem dritten bzw. ersten Rang. Dieser hohe Rang reflektiert zum Teil den frühen Beginn der Transformation in Ungarn. Aber obwohl die frühe und graduelle Liberalisierung die ungarische Wirtschaft vor einer Hyperinflation bewahrt hat, deuten die makroökonomischen Daten für die erste Hälfte der 1990er Jahre darauf hin, daß diese Liberalisierungspolitik nicht $\mathrm{zu}$ einer ausgeprägten Inflationsreduzierung beigetragen hat. Strukturreformen und Liberalisierung scheinen deshalb eine notwendige, aber nicht hinreichende Bedingung für eine erfolgreiche Stabilisierung zu sein.

\subsubsection{Zentralbankgesetzgebung}

In diesem Unterabschnitt wird die Zentralbankgesetzgebung als spezieller Aspekt der institutionellen Reformen im Transformationsprozeß näher betrachtet. ${ }^{79}$ Für Industrieländer wird in der Regel eine positive Korrelation zwischen einer niedrigen Inflationsrate und einem hohen Grad an Zentralbankunabhängigkeit ermittelt. Außerdem haben Loungani/Sheets (1997) und Lybek (1999) auch für Transformationsländer eine entsprechende signifikant positive Korrelation festgestellt. ${ }^{80} \mathrm{Es}$ ist deshalb zu erwarten, daß die gesetzliche Verankerung der Zentralbankunabhängigkeit für eine erfolgreiche Disinflation von großer Bedeutung ist. Allerdings ist es schwierig, den Grad der Unabhängigkeit korrekt zu messen. Die wissenschaftliche Diskussion, welche institutionellen Regelungen zentral für die Messung der Zentralbankunabhängigkeit sind, ist nicht abgeschlossen. 81

Obwohl rechtliche Regelungen, die Zentralbankunabhängigkeit garantieren sollen, nicht zwangsläufig auch tatsächliche Unabhängigkeit gewährleisten,

78 Vgl. z.B. Sachs (1996b), S. 129, und Hernández-Catá (1999), S. 16 ff. Für eine gegenteilige Meinung siehe Åslund et al. (1996), S. 232 f.

79 Andere institutionelle Aspekte schlagen sich im Transformationsindikator nieder, der im vorangegangenen Unterabschnitt 3.2.2 vorgestellt wurde. Dazu gehören z.B. die Privatisierung, eine wettbewerbliche Gesetzgebung und Reformen des Finanzsektors.

80 Vgl. Loungani/Sheets (1997), S. 397, und Lybek (1999), S. 17.

81 Siehe z.B. Banaian et al. (1998), S. 1 ff., furr eine Kritik an dem facettenreichen Cukierman-Index. Sie schlagen einen einfacheren Index vor, der sich allein auf die „Politikunabhängigkeit" bezieht und ihrer Meinung nach die Zentralbankunabhăngigkeit besser abbildet. Des weiteren können die empirischen Studien zur Analyse des Einflusses der Zentralbankunabhăngigkeit auf die Inflation nicht die Frage der Kausalităt klären. 
stellen sie eine entscheidende Vorbedingung für eine unabhängige Geldpolitik der Notenbank dar. Konzentriert man sich zunächst wieder auf die frühen Jahre der Transformation - bis zur Mitte der 1990er Jahre -, dann können die Aspekte der Zentralbankgesetzgebung in den zehn betrachteten Ländern wie folgt zusammengefaßt werden. ${ }^{82} \mathrm{Zu}$ Beginn der Transformation haben die Länder ein zweistufiges Bankensystem eingeführt, eine neue Zentralbank eingerichtet sowie ein neues Zentralbankgesetz verabschiedet oder das alte Gesetz grundlegend modifiziert. 83 Obwohl die Zentralbanken in der Regel dazu verpflichtet waren, die Wirtschaftspolitik der Regierungen zu unterstützen, genossen die meisten Notenbanken bereits in den frühen Jahren des Reformprozesses ein relativ hohes Maß an Autonomie. Im Jahre 1997 waren fast alle Zentralbanken in den betrachteten Ländern rechtlich unabhängig. Nur in Polen und Rumänien enthielten die Zentralbankgesetze keine Rechtsnormen im Hinblick auf die Unabhängigkeit in der Formulierung der Geldpolitik. Das Hauptziel aller Zentralbanken war die Sicherung der Währungsstabilität; und die Amtszeiten aller Gouverneure waren länger als die Wahlperioden in dem entsprechenden Land.

Radzyner/Riesinger (1997) vergleichen die rechtliche und die tatsächliche Zentralbankunabhängigkeit in fünf hier betrachteten Ländern. ${ }^{84}$ Sie kommen zu dem Schluß, daß die schwächste Stelle der Zentralbankgesetzgebung in der Regel die direkte Kreditvergabe an die Regierung ist. In den ersten Jahren nach dem Transformationsbeginn enthielten fast alle Zentralbankgesetze einen Artikel, der solche Kredite zwar erlaubte, die Höhe aber auf einen bestimmten Betrag begrenzte. ${ }^{85}$ Die beiden Ausnahmen sind Estland und Litauen. Der estnischen Nationalbank ist seit ihrer Neugründung im Jahre 1992 jegliche Kreditvergabe an die Regierung verboten. Das Gesetz über die litauische Zentralbank enthält hingegen keine Angaben über die Kreditgewährung an den öffentlichen Sektor. ${ }^{86}$ In diesem Zusammenhang ist bemerkenswert, daß bis zur Änderung des Notenbankgesetzes im Jahre 1998 das polnische Parlament regelmäßig den Artikel 34 des Gesetzes über die polnische Nationalbank aussetzte, der den Höchstbetrag spezifizierte, bis zu dem die Nationalbank auf dem Primärmarkt Staatsanleihen ankaufen durfte.

In der jüngeren Vergangenheit sind in einigen Ländern die Zentralbankstatuten geändert worden, um die rechtlichen Voraussetzungen für einen späteren EU-

82 Vgl. Hochreiter (1995), S. $127 \mathrm{ff}$., und Hochreiter/Riesinger (1995), S. $17 \mathrm{ff}$.

83 In Polen wurde zum Beispiel das alte Recht beibehalten, allerdings im Laufe der Zeit mehrfach reformiert.

84 Es handelt sich um Polen, die Slowakei, Slowenien, Tschechien und Ungarn. Siehe Radzyner/Riesinger (1997), S. $57 \mathrm{ff}$.

85 Vgl. Hochreiter/Riesinger (1995), S. 19 f.

86 Siehe Hochreiter/Kowalski (1999), S. 25. 
Beitritt zu schaffen. So verbieten die 1998 in Kraft getretenen Gesetzesänderungen in Lettland und Polen nunmehr die Kreditvergabe an die Regierung. ${ }^{87}$ Rumänien hat seine Zentralbankgesetzgebung 1998 ebenfalls geändert. Seitdem darf die rumänische Nationalbank dem Staat nur noch Kredite mit einer Laufzeit von maximal 180 Tagen zu Marktkonditionen gewähren, um vorübergehende Finanzierungsdefizite zu überbrücken. ${ }^{88}$

Ungeachtet differierender nationaler Gesetzgebungen haben alle zehn Länder relativ unabhängige Zentralbanken errichtet. Das bulgarische und rumänische Notenbankgesetz weichen nicht wesentlich von den rechtlichen Regelungen in den anderen Ländern ab. Die Unterschiede zwischen den Notenbankstatuten einschließlich dem erlaubten Ausmaß der Finanzierung von Budgetdefiziten sind so gering, daß sie die unterschiedlichen Ergebnisse im Hinblick auf die Stabilisierung nicht zu erklären vermögen. Es kann zwar nicht ausgeschlossen werden, daß die tatsächliche Zentralbankunabhängigkeit von der gesetzlich garantierten so stark abweicht, daß die Gemeinsamkeiten in der Gesetzgebung überlagert werden. Eine detaillierte Analyse dieser Möglichkeit geht jedoch über den Rahmen der vorliegenden Arbeit hinaus.

\subsubsection{Einfluß der Fiskalpolitik}

Die zentrale Aufgabe der Transformationspolitik ist die Rückführung der staatlichen Aktivitäten und die Schaffung eines funktionsfähigen Privatsektors. Trotzdem bestimmt auch etwa zehn Jahre nach dem Zusammenbruch der sozialistischen Systeme der öffentliche Sektor in fast allen Transformationsländern weiterhin einen großen Teil der Wirtschaftstätigkeit. Seit Transformationsbeginn verharren die Anteile des staatlichen Sektors auf relativ hohem Niveau. Die Länderseiten der Transition Reports der Europäischen Bank für Wiederaufbau und Entwicklung zeigen, daß die Anteile hartnäckig hoch sind und in keinem der betrachteten Länder ein klar abnehmender Trend zu erkennen ist. Der Anteil des öffentlichen Sektors - gemessen als Anteil aller Staatsausgaben am Bruttoinlandsprodukt - liegt mehrheitlich über 40 v.H. In einigen Ländern nimmt die Staatsaktivität sogar ungefähr die Hälfte des Wirtschaftslebens ein. Nur Litauen und Rumänien verzeichneten in der zweiten Hälfte der 1990er Jahre geringere Anteile des Staatssektors mit Werten unter 40 v.H. des BIP. 89 Die unterschiedliche Höhe der Anteile scheint daher nicht korreliert zu sein mit der Gruppierung in Abhängigkeit vom Erfolg bei der Stabilisierung.

\footnotetext{
87 In Polen wurde die Unabhängigkeit der Zentralbank sogar in der 1997 geänderten Verfassung festgeschrieben. Auch in der slowenischen Verfassung ist die Unabhăngigkeit der Notenbank verankert. Für einen Überblick über die gesetzlichen Regelungen in den zehn betrachteten Ländern Ende der 1990er Jahre siehe Hochreiter/Kowalski (1999), S. 1 ff.

Vgl. National Bank of Romania (1998), S. 8.

Vgl. EBRD (1999), S. 245 und S. 257.
} 
Die dominierende Rolle des öffentlichen Sektors deutet aber auf eine wichtige Rolle der Fiskalpolitik als Komponente der Stabilisierungspolitik hin. Die Tabelle 8 gibt die Budgetsalden der vergangenen neun Jahre wieder. Die letzte Spalte gibt den Durchschnitt für alle Jahre an, für die Daten verfügbar sind. Die fettgedruckten Zahlen markieren ein Budgetdefizit, das das sogenannte Maastricht-Kriterium von $-3,0$ v.H. des BIP übersteigt. Obwohl dieser Referenzwert eher willkürlich gewählt ist, veranschaulicht er die Unterschiede zwischen den Ländern, die eine restriktive Finanzpolitik betrieben haben, und jenen Ländern, in denen es an fiskalischer Disziplin mangelte.

\section{Tabelle 8: Budgetsalden in den 1990er Jahren"}

\begin{tabular}{|c|c|c|c|c|c|c|c|c|c|c|}
\hline Land & 1991 & 1992 & 1993 & 1994 & 1995 & 1996 & 1997 & $1998^{b}$ & $1999^{b}$ & $\varnothing$ \\
\hline Bulgarien & k.A. & $-5,2$ & $-10,9$ & $-5,8$ & $-6,4$ & $-10,4$ & $-3,0$ & 1,0 & k.A. & $-5,8$ \\
\hline Estland & 5,2 & $-0,3$ & $-0,7$ & 1,3 & $-1,3$ & $-1,9$ & 2,2 & $-0,3$ & $-3,0$ & 0,1 \\
\hline Lettland $^{c}$ & k.A. & $-0,8$ & 0,6 & $-4,0$ & $-3,9$ & $-1,7$ & 0,1 & $-0,8$ & $-3,8$ & $-1,8$ \\
\hline Litauen $^{c}$ & 2,7 & 0,5 & $-3,3$ & $-5,5$ & $-4,5$ & $-4,5$ & $-1,8$ & $-5,8$ & $-7,0$ & $-3,2$ \\
\hline Polen $^{c}$ & $-6,7$ & $-6,7$ & $-3,1$ & $-3,1$ & $-2,8$ & $-3,3$ & $-3,1$ & $-3,0$ & $-3,0$ & $-3,9$ \\
\hline Rumănien & 3,3 & $-4,6$ & $-0,4$ & $-1,9$ & $-2,6$ & $-4,0$ & $-3,6$ & $-3,3$ & $-2,7$ & $-2,2$ \\
\hline Slowakei & k.A. & k.A. & $-7,0$ & $-1,3$ & 0,2 & $-1,9$ & $-4,4$ & $-5,8$ & $-3,2$ & $-3,3$ \\
\hline Slowenien & 2,6 & 0,2 & 0,1 & $-0,3$ & $-0,5$ & $-0,2$ & $-1,7$ & $-1,4$ & $-1,0$ & $-0,2$ \\
\hline Tschechien $^{c}$ & $-1,9$ & $-3,1$ & 0,5 & $-1,1$ & $-1,8$ & $-1,1$ & $-2,1$ & $-2,6$ & $-5,0$ & $-2,0$ \\
\hline Ungarn & $-3,7$ & $-7,6$ & $-8,9$ & $-8,6$ & $-6,2$ & $-3,1$ & $-4,9$ & $-4,6$ & $-4,5$ & $-5,8$ \\
\hline \multicolumn{11}{|c|}{$\begin{array}{l}\text { Anmerkungen: }{ }^{\mathrm{a}} \text { Angaben in v.H. des Bruttoinlandsprodukts. Das Budget umfaßt den Natio- } \\
\text { nalstaat, die Kommunen und außerbudgetăre Fonds (state, municipalities and extrabudgetary } \\
\text { funds). Fettdruck bei Budgetdefiziten, die }-3 \text { v.H. des BIP ubersteigen. }-{ }^{b} \text { Geschătzt. }-{ }^{c} \text { Der } \\
\text { Saldo enthalt keine Privatisierungserlöse. - k.A. = keine Angaben verfugbar. }\end{array}$} \\
\hline
\end{tabular}

Quelle: Lănderseiten von EBRD (1999).

Die Tabelle zeigt, daß die zehn Transformationsländer im allgemeinen relativ geringe Budgetdefizite aufwiesen, und zwar auch, wenn man sie mit Ländern der Europäischen Union vergleicht. Die Mehrheit der EU-Mitgliedstaaten verzeichnete in den 1990er Jahren Budgetdefizite, die diesen Schwellenwert über- 
schritten. ${ }^{90}$ Nur fünf der hier betrachteten mittel- und osteuropäischen Länder hatten Haushaltsdefizite, die im Durchschnitt über -3,0 v.H. lagen. Im Gegensatz dazu wiesen Estland und Slowenien im Durchschnitt der betrachteten Jahre einen nahezu ausgeglichenen Staatshaushalt auf, gefolgt von Lettland und Tschechien mit relativ geringen Budgetdefiziten.

Bulgarien und Rumänien sollen etwas detaillierter betrachtet werden. Das bulgarische Budgetdefizit lag in den Jahren bis 1996 jeweils deutlich über $-5,0$ v.H. des BIP. Wie aus Tabelle 8 ersichtlich, war das im ersten Halbjahr 1997 beschlossene Stabilisierungsprogramm, das eine drastische Reduzierung der Inflation und bereits 1998 wieder ein positives Wachstum bewirkte, mit einer deutlichen Verbesserung der Haushaltslage verbunden. ${ }^{91}$ Wie der Vergleich der in Tabelle 8 aufgeführten rumänischen Budgetsalden mit der in Abbildung 5 präsentierten Entwicklung von Wirtschaftswachstum und Inflation in Rumänien zeigt, ${ }^{92}$ war die dreijährige Erholungsphase von 1993 bis 1995 von niedrigeren Defiziten der öffentlichen Hand begleitet. Seit 1997 verzeichnet Rumänien erneut negative Wachstumsraten, und die Inflationsraten sind höher als die Werte der Jahre 1995 und 1996. Diese Entwicklung geht mit Budgetdefiziten einher, die seit 1996 wieder den Referenzwert von -3,0 v.H. des BIP übersteigen, wobei für 1999 allerdings nur mit einem Wert von $-2,7$ v.H. gerechnet wird. Die Analyse der bulgarischen und rumänischen Haushaltsdefizite im Zeitablauf deutet darauf hin, daß niedrigere Budgetdefizite zu einer besseren Inflationsund Wachstumsentwicklung beitragen. Auch die Tatsache, daß diejenigen Länder - Estland, Lettland, Slowenien und Tschechien -, die eine eher restriktive Finanzpolitik verfolgt haben, zur Gruppe der erfolgreichen Stabilisierer gehören, scheint diese Korrelation zu bestätigen.

Allerdings passen in diesem Zusammenhang Polen und Ungarn nicht in das Bild. Im Durchschnitt des letzten Jahrzehnts haben beide Länder höhere Budgetdefizite verzeichnet als Rumänien. Ungarn belegt mit $-5,8$ v.H. sogar zusammen mit Bulgarien den letzten Platz. Diese Daten deuten auf eine weniger restriktive Fiskalpolitik hin, die nach herrschender Meinung potentiell einen

90 Vgl. die Tabellen 6 im Kapitel I von Europăisches Wăhrungsinstitut (1998), S. 43 ff. Allerdings sind die Zahlenangaben nur bedingt vergleichbar, da in den mittel- und osteuropäischen Staaten die statistischen Abgrenzungen sehr unterschiedlich sind und die ausgewiesenen Haushaltsdefizite nicht der Definition von Budgetsalden nach dem EU-Vertrag entsprechen.

91 Zur Entwicklung von Wirtschaftswachstum und Inflation in Bulgarien vgl. die entsprechende Graphik der Abbildung 5a auf Seite 155.

Siehe Seite 157 für das Wachstums-Inflations-Diagramm Rumäniens. 
geringeren Erfolg bei der Stabilisierung erwarten ließe. ${ }^{93}$ Die beiden „Ausreißer" Polen und Ungarn erfordern eine genauere Analyse des staatlichen Ausgabeverhaltens, um zu überprüfen, ob eventuell die Zusammensetzung der Staatsausgaben den Stabilisierungserfolg beider Länder trotz höherer Haushaltsdefizite erklären kann. Insbesondere könnten unterschiedliche Anteile öffentlicher Investitionen - im Gegensatz zu staatlichen Konsumausgaben - einen Erklärungsansatz bieten. Wenn die fiskalischen Defizite durch einen überdurchschnittlich hohen investiven Anteil am Gesamthaushalt geprägt sind, dann tragen die öffentlichen Ausgaben dazu bei, dringend erforderliche Investitionen durchzuführen. So besteht zum Beispiel in allen Transformationsländern nach wie vor ein großer Nachholbedarf in der Infrastruktur. Für diesen Bereich bereitgestellte öffentliche Gelder fördern das Wachstum, indem sie zum Beispiel Transportkosten senken und die Nutzungsmöglichkeiten neuer Kommunikationstechniken verbessern.

Tabelle 9 liefert einen Überblick über einige Ausgabenkategorien der öffentlichen Hand. Dabei fällt zunächst auf, daß Zinszahlungen in einigen Transformationsländern eine wichtige Komponente der Staatsausgaben sind. Besonders hervorzuheben ist der außerordentlich hohe Anteil der Zinszahlungen in Bulgarien. Mehr als ein Drittel der staatlichen Ausgaben mußte 1996 für Zinsen aufgewendet werden. In Ungarn entfielen 17 v.H. und in Polen 7,5 v.H. des Staatshaushaltes auf Zinszahlungen. Während der größte Anteil dieser Zahlungen aus Schulden vor dem Beginn der Transformation resultiert, veranschaulichen die Werte, daß ein großer Teil der finanziellen Ressourcen des öffentlichen Sektors für andere Verwendungen nicht zur Verfügung stand. Die sehr niedrigen Anteile der Zinszahlungen in den baltischen Staaten sind unter anderem darauf zurückzuführen, daß Rußland alle Forderungen und Verbindlichkeiten der ehemaligen Sowjetunion übernommen hat.

Die sozialen Ausgaben stellen in allen betrachteten Ländern eine wichtige Position dar. Im Jahr 1996 hatten die Sozialausgaben (social security) in den meisten Ländern einen Anteil von einem Viertel bis zu einem Drittel an den Gesamtausgaben des Staates. ${ }^{94}$ In Polen und Slowenien machte der Anteil der Sozialausgaben sogar über 40 v.H. des öffentlichen Budgets aus. Die Tabelle 9 präsentiert auch Werte für die investiven staatlichen Ausgaben. Wie aus der letzten Spalte hervorgeht, übersteigen die Anteile nur in vier Ländern 10 v.H. Dies sind Estland, Rumänien, die Slowakei und Tschechien.

93 Die Bedeutung einer restriktiven Fiskalpolitik fur eine erfolgreiche Stabilisierung im Transformationsprozeß wird u.a. von Budina/van Wijnbergen (1997), S. 50, und Fischer et al. (1997), S. 91, betont.

94 Der geringere Anteil Bulgariens laßßt sich auf den dominierenden Einfluß der Zinszahlungen zuruckfuhren, der die Anteile anderer Ausgabenkomponenten entsprechend verringert. 
Tabelle 9: Komponenten der Staatsausgaben 1996

\begin{tabular}{|c|c|c|c|c|}
\hline Land & Zinszahlungen & $\begin{array}{c}\text { Sozialausgaben } \\
\text { (Social Security) }\end{array}$ & Subventionen & $\begin{array}{l}\text { Investive Ausgaben } \\
\text { (Capital Expenditure) }\end{array}$ \\
\hline Bulgarien & 37,2 & 17,5 & 11,2 & 3,0 \\
\hline Estland & 0,7 & 23,2 & 2,1 & 10,9 \\
\hline Lettland & 4,2 & 35,6 & 0,9 & 5,4 \\
\hline Litauen & 2,8 & 29,8 & 2,4 & 8,2 \\
\hline Polen & 7,5 & 42,0 & 4,7 & 7,1 \\
\hline Rumănien ${ }^{\text {b }}$ & 3,7 & 26,3 & 9,3 & 15,7 \\
\hline Slowakei & 4,6 & 30,0 & 7,2 & 15,1 \\
\hline Slowenien & 2,7 & 45,0 & 7,1 & 5,6 \\
\hline Tschechien & 2,5 & 24,6 & 13,5 & 15,6 \\
\hline Ungarn & 17,0 & 28,9 & 7,8 & k.A. \\
\hline
\end{tabular}

Quelle: Eigene Berechnungen auf Grundlage von IMF (1997b, 1998).

Dieser kurze Blick auf die Verwendung der Staatsausgaben vermag nicht die These zu stützen, daß in Polen und Ungarn eine vorteilhaftere Zusammensetzung der öffentlichen Ausgaben trotz relativ hoher Fiskaldefizite zu Stabilisierungserfolgen geführt hat. Zusätzlich zu den relativ hohen Budgetdefiziten hat Polen den zweithöchsten Anteil der Sozialausgaben; und der Anteil investiver Ausgaben in Höhe von 7,1 v.H. ist nur unwesentlich höher als die drei niedrigsten Werte in der Tabelle 9. Mit Blick auf Polen und Ungarn kann man daher nicht schließen, daß niedrigere Inflationsraten und stärkeres Wirtschaftswachstum in der Regel mit niedrigeren Fiskaldefiziten korreliert sind.

Für die Gruppe der zehn mittel- und osteuropäischen EU-Beitrittskandidaten ergibt sich deshalb kein eindeutiges Ergebnis für die Auswirkungen der Fiskalpolitik auf die Stabilisierungserfolge. Während für die Mehrheit der betrachteten Länder ein positiver Zusammenhang zwischen niedrigen Budgetdefiziten und besserer Inflations- und Wachstumsentwicklung zu beobachten ist, läßt sich diese Aussage für Polen und Ungarn nicht bestätigen. 


\subsubsection{Geldpolitische Einflüsse}

Bei der Analyse der Zentralbankunabhängigkeit wurde gezeigt, daß sich die nationalen Notenbankgesetze in den betrachteten Ländern nicht wesentlich voneinander unterscheiden. Hinter der Vermutung, daß eine höhere Zentralbankunabhängigkeit mit niedrigeren Inflationsraten einhergeht, steht die empirische Beobachtung, daß eine unabhängige Notenbank eher eine am Ziel der Preisstabilität ausgerichtete Geldpolitik betreibt. Auch wenn der Grad der gesetzlich garantierten Zentralbankunabhängigkeit in den zehn mittel- und osteuropäischen EU-Beitrittskandidaten relativ gleich ist, können unterschiedlich expansive Geldpolitiken für die Unterschiede bei der Reduzierung der hohen Preissteigerungsraten verantwortlich sein. Coorey et al. (1997) haben zum Beispiel in ihrer empirischen Studie einen dominierenden Einfluß der Geldmengenentwicklung auf die Inflation in 21 Transformationsländern ermittelt. ${ }^{95}$ Auch sind nach Ansicht des Internationalen Währungsfonds die wieder ansteigenden Inflationsraten in Bulgarien und Rumänien Mitte der 1990er Jahre vor allem auf eine expansive Geldpolitik zurückzuführen. ${ }^{96}$ Daher wird in diesem Unterabschnitt analysiert, ob niedrigere Wachstumsraten von Kredit- und Geldmengenaggregaten die niedrigeren Inflationsraten in der Gruppe der acht erfolgreichen Staaten im Vergleich zu Bulgarien und Rumänien erklären können.

Ein Problem bei der Betrachtung von Geldmengenwachstumsraten liegt darin, daß die Staaten zu Beginn ihrer Stabilisierungsbemühungen eine relativ niedrige Monetisierung der Wirtschaft aufwiesen. In den Transformationsländern lag das Verhältnis von M2 zum Bruttoinlandsprodukt zu Reformbeginn deutlich unter der entsprechenden Relation in entwickelten Volkswirtschaften. 97 Wie bereits bei der Diskussion der Geldmengenstrategie im Kapitel II aufgezeigt, wird die heimische Währung bei sinkenden Inflationsraten aufgrund einer erfolgreichen Stabilisierung zunehmend als Transaktionsmedium und Wertaufbewahrungsmittel verwendet. ${ }^{98}$ Die Umlaufgeschwindigkeit des Geldes sinkt, und das Verhältnis von M2 zum Bruttoinlandsprodukt steigt an. Dieses Phänomen der Remonetisierung erfordert unter sonst gleichen Bedingungen eine höhere Wachstumsrate der Geldmenge. Um die daraus resultierende kurzfristige Vereinbarkeit von relativ hohen Geldmengenwachstumsraten mit sinkender Inflation so weit wie möglich auszuklammern und der unsicheren Länge der geldpolitischen Time Lags Rechnung zu tragen, erfolgt in diesem Unterabschnitt eine längerfristige Betrachtung. Die Tabelle 10 enthält die jährlichen Wachstumsraten der Geldmenge und des inländischen Kreditvolumens von 
1991 bis 1999 sowie in der letzten Spalte den geometrischen Durchschnitt für alle Jahre, für die Werte verfügbar sind.

Tabelle 10: Geldmengen- und Kreditwachstum ${ }^{\text {a, }}$

\begin{tabular}{|c|c|c|c|c|c|c|c|c|c|c|c|}
\hline Land & & 1991 & 1992 & 1993 & 1994 & 1995 & 1996 & 1997 & 1998 & $1999^{c}$ & $\varnothing^{d}$ \\
\hline \multirow{2}{*}{ Bulgarien } & $m$ & 110,0 & 53,7 & 47,6 & 78,6 & 39,6 & 124,5 & 359,3 & 9,7 & 11,4 & 74,5 \\
\hline & $k$ & 148,0 & 57,2 & 56,0 & 37,1 & 16,8 & 216,8 & 156,8 & $-15,3$ & $-3,1$ & 59,0 \\
\hline \multirow{2}{*}{ Estland } & $m$ & k.A. & 59,0 & 93,3 & 40,1 & 34,5 & 35,6 & 42,3 & 0,1 & 23,6 & 38,9 \\
\hline & $k$ & k.A. & 29,6 & 53,4 & 42,3 & 41,0 & 132,8 & 86,2 & 23,1 & 10,4 & 48,4 \\
\hline \multirow{2}{*}{ Lettland } & $m$ & k.A. & 169,9 & 84,1 & 47,4 & $-23,1$ & 19,9 & 38,7 & 5,9 & 8,0 & 34,5 \\
\hline & $k$ & k.A. & 303,8 & 146,0 & 72,3 & $-28,2$ & 6,0 & 39,3 & 30,6 & 15,2 & 51,2 \\
\hline \multirow{2}{*}{ Litauen } & $m$ & k.A. & 245,9 & 100,2 & 63,0 & 28,9 & $-3,5$ & 34,1 & 14,5 & 7,7 & 48,2 \\
\hline & $k$ & k.A. & k.A. & 109,4 & 78,1 & 10,7 & 1,8 & 37,6 & 16,8 & 24,4 & 35,5 \\
\hline \multirow{2}{*}{ Polen } & $m$ & 37,0 & 57,5 & 36,0 & 38,2 & 34,9 & 29,3 & 30,9 & 25,2 & 19,5 & 33,9 \\
\hline & $k$ & 158,7 & 55,6 & 44,2 & 30,1 & 20,8 & 31,9 & 26,5 & 22,1 & 20,2 & 41,2 \\
\hline \multirow{2}{*}{ Rumănien } & $m$ & 101,2 & 79,6 & 141,0 & 138,1 & 71,6 & 66,0 & 104,9 & 48,9 & 44,9 & 85,6 \\
\hline & $k$ & 116,5 & 34,5 & 140,0 & 115,4 & 89,5 & 80,8 & 50,8 & 71,9 & k.A. & 84,4 \\
\hline \multirow{2}{*}{ Slowakei } & $m$ & k.A. & k.A. & 18,5 & 18,6 & 18,9 & 16,7 & 8,9 & 2,7 & 13,0 & 13,8 \\
\hline & $k$ & k.A. & k.A. & k.A. & $-6,4$ & $-1,6$ & 28,9 & 34,4 & 3,1 & 2,5 & 9,1 \\
\hline \multirow{2}{*}{ Slowenien } & $m$ & k.A. & 128,9 & 63,2 & 43,3 & 28,1 & 20,5 & 24,3 & 19,8 & 14,1 & 39,1 \\
\hline & $k$ & k.A. & 90,1 & 101,4 & 27,2 & 35,1 & 13,2 & 14,2 & 22,4 & 19,0 & 37,0 \\
\hline \multirow{2}{*}{ Tschechien } & $m$ & k.A. & 20,7 & 22,5 & 20,8 & 19,4 & 7,8 & 8,7 & 5,2 & 8,1 & 10,4 \\
\hline & $k$ & k.A. & 14,6 & 19,2 & 16,0 & 12,2 & 12,0 & 8,6 & 3,4 & 0,9 & 10,7 \\
\hline \multirow{2}{*}{ Ungarn } & $m$ & 35,7 & 27,6 & 15,7 & 13,0 & 20,1 & 22,5 & 19,6 & 15,2 & 15,9 & 20,4 \\
\hline & $k$ & 14,9 & 11,8 & 20,8 & 18,1 & 13,7 & 7,6 & 12,0 & 13,9 & $-8,5$ & 11,3 \\
\hline \multicolumn{12}{|c|}{$\begin{array}{l}\text { Anmerkungen: }{ }^{a} \text { Verănderung gegenuber dem Vorjahr in v.H. }-{ }^{b} m=\text { Wachstumsrate des } \\
\text { Geldmengenaggregats „Broad Money“ (Jahresendwerte): für Bulgarien, Rumänien, Slowenien } \\
\text { und Ungarn M3; für Estland und Litauen M2; für Lettland M2X. M2X umfaßt neben M2 auch } \\
\text { Einlagen in ausländischer Wăhrung bei inländischen Banken, vgl. Begg (1998), S. 108. } k= \\
\text { Rate des inländischen Kreditwachstums (Jahresendwerte). }-{ }^{c} \text { Geschätzt. }-{ }^{d} \text { geometrischer } \\
\text { Durchschnitt der vorhandenen Werte. - k.A. = keine Angaben verfügbar. }\end{array}$} \\
\hline
\end{tabular}

Quelle: EBRD (verschiedene Jahrgănge).

Die Betrachtung des durchschnittlichen Geldmengen- und Kreditwachstums in der letzten Spalte der Tabelle zeigt eine deutliche Dreiteilung der betrachteten Länder: Die Slowakei, Tschechien und Ungarn bilden die erste Gruppe mit niedrigen Zuwachsraten im unteren zweistelligen Bereich. Die zweite Gruppe besteht aus den baltischen Staaten, Polen sowie Slowenien und weist Wachstumsraten auf, die im Durchschnitt zwischen 30 v.H. und 50 v.H. jährlich liegen. Die Werte der von Bulgarien und Rumänien gebildeten dritten Gruppe liegen deutlich darüber. Mit Werten in Höhe von ca. 85 v.H. liegt Rumänien 
sowohl beim Geldmengenwachstum als auch bei der Zunahme der inländischen Kreditmenge hinter Bulgarien an letzter Stelle. Im Falle Bulgariens wirkt sich insbesondere das erfolgreiche Stabilisierungsprogramm vom Frühjahr 1997 positiv aus. ${ }^{99}$ Wie aus der Tabelle hervorgeht, waren die durchschnittlichen Zuwachsraten der beiden betrachteten geldpolitischen Aggregate bis 1997 deutlich höher als in den Jahren 1998 und 1999.

Diejenigen drei Länder - die Slowakei, Tschechien und Ungarn -, die während des Transformationsprozesses keine jährlichen Preissteigerungsraten über 100 v.H. verzeichneten, wiesen auch die geringsten Geldmengenwachstumsraten in den 1990er Jahren auf. Wie bereits erwähnt, war in Ungarn bis zur Mitte der 1990er Jahre kein klarer Trend fallender Inflationsraten zu beobachten, während in der zweiten Hälfte des letzten Jahrzehnts eine kontinuierliche Disinflation stattfand. Aus der letzten Zeile der Tabelle 10 geht hervor, daß im Zeitraum 1991 bis 1994 die Wachstumsraten der Geldmenge stetig sanken. Allerdings ergibt sich für diese Periode ein durchschnittlicher jährlicher Anstieg in Höhe von 22,7 v.H. In der Zeit ab 1995 sind ebenfalls rückläufige Wachstumsraten zu beobachten, der Durchschnitt liegt jedoch mit 18,6 v.H. deutlich niedriger. Insofern ist auch nachvollziehbar, daß sich in der zweiten Hälfte der 1990er Jahre eine stärkere Disinflation ergeben hat. Die anderen fünf Länder, die ebenfalls zur Gruppe der erfolgreich stabilisierenden Länder gehören, wiesen Wachstumsraten der Geld- und Kreditmenge im mittleren zweistelligen Bereich auf und heben sich insofern zusammen mit der ersten Gruppe deutlich von Bulgarien und Rumänien $a b$.

Die Betrachtung der Geldmengenentwicklung bestätigt, daß offensichtlich auch in den mittel- und osteuropäischen Transformationsländern die Inflation letztlich ein monetäres Phänomen ist. Trotz der Problematik, daß eine erfolgreiche Stabilisierung mit einer Remonetisierung der Wirtschaft verbunden ist und dieses Ausmaß nur schwer von der Zentralbank abgeschätzt werden kann, ist über einen längeren Zeitraum hinweg eine positive Korrelation zwischen einem stärkeren Anstieg der Geldmengenaggregate und einer höheren Inflation zu beobachten. Ein Vergleich der Jahresdaten in Tabelle 10 mit den Inflationsverläufen, wie sie in der Abbildung 5 wiedergegeben sind, läßt zwar noch keine Schlußfolgerung über die Kausalität zwischen den beiden Größen zu. Allerdings ermitteln Coorey et al. (1997) unter Verwendung von Quartalsdaten einen um drei Monate verzögerten, signifikant positiven Einfluß des Geldmengenwachstums auf die Inflationsrate. ${ }^{100}$ Dies ist ein Hinweis dafür, daß die Geldmengenexpansion für die Inflation ursächlich ist.

99 Im Zeitraum von 1991 bis 1997 lag der durchschnittliche Anstieg der Geld- bzw. Kreditmenge in Bulgarien bei 98,7 v.H. bzw. 86,8 v.H.

100

Vgl. Coorey et al. (1997), S. 8. 
Im Unterabschnitt II.3.1.2. wurden die Probleme bei der Wahl einer geldpolitischen Zwischenzielgröße diskutiert. Dabei wurde festgestellt, daß in der Anfangsphase der Transformation unter Umständen ein Wechselkursziel insbesondere wegen seiner "Einfachheit" anderen Zwischenzielen überlegen ist. Der folgende Unterabschnitt untersucht deshalb, ob für das Wechselkurssystem ein ähnlich eindeutiger Einfluß festgestellt werden kann wie für die Geldmengenentwicklung. In diesem Zusammenhang wird auch die Hypothese des Partialmodells aus Kapitel III überprüft, daß Länder mit festen Wechselkursen größere Erfolge bei der Disinflation verzeichnen, es sei denn, die Währung des Landes mit flexiblem Wechselkurs wird nominal aufgewertet.

\subsubsection{Wahl des Wechselkursregimes}

Im ersten Abschnitt dieses Kapitels wurden die wechselkurspolitischen Maßnahmen in den zehn betrachteten Ländern dargestellt und in der Tabelle 4 zusammengefaßt. Für die Analyse des Einflusses des Wechselkurssystems auf die Stabilisierungserfolge der Länder erscheint es zweckmäßig, die Systeme in zwei Extreme einzuteilen, und zwar entweder in ein festes oder ein flexibles Wechselkursregime. Bei der Klassifizierung steht im Vordergrund, ob der Wechselkurs als geldpolitischer Anker verwendet wurde. So kann zum Beispiel einerseits ein aktiver Crawling Peg mit einem engen Band um die gleitende Parität als ein Festkurssystem aufgefaßt werden, weil die wirtschaftspolitischen Entscheidungsträger im voraus eine Abwertungsrate festlegen, die kleiner ist als die Inflationsdifferenz zum Ausland. Aus diesem Grund werden zum Beispiel die Crawling Peg Systeme in Polen (bis 1995) und Ungarn als Festkurssysteme klassifiziert. Andererseits entspricht ein festes Wechselkurssystem mit häufigen diskretionären Abwertungen oder mit einem sehr weiten Wechselkursband, innerhalb dessen die Währung frei schwanken kann, eher einem flexiblen Wechselkurssystem. Obwohl zum Beispiel in Ungarn von 1990 bis 1994 formal ein festes Wechselkursregime bestand, wurde die Währung in diesen fünf Jahren insgesamt zwanzig Mal diskretionär abgewertet. Dieser Zeitraum wird deshalb im folgenden nicht als Festkursperiode gewertet.

Im Hinblick auf eine Bandbreite bei festen Wechselkursen werden Regelungen in diesem Unterabschnitt als Festkurssystem aufgefaßt, solange die erlaubten Schwankungen bis zu \pm 5 v.H. betragen. Systeme mit größeren Wechselkursbändern werden als flexible Regime eingestuft. ${ }^{101}$ Eine diskretionäre Wechselkursanpassung beendet eine Festkursepisode. Wird zum Beispiel im Anschluß an die einmalige nominale Abwertung der Wechselkurs erneut fixiert, beginnt

101 Ein hőherer Grenzwert würde die letzten drei Festkursperioden in Polen, der Slowakei und Tschechien um einige Monate verlängern. Die Ergebnisse der Untersuchung wären davon jedoch nicht betroffen. 
eine neue Periode. Die Tabelle 11 enthält für die zehn mittel- und osteuropäischen Staaten alle Zeiträume bis Ende 1999, die nach den angegebenen Kriterien als eine Festkursperiode klassifiziert werden können.

Tabelle 11: Festkursperioden ${ }^{2}$ in Mittel- und Osteuropa 1990 - 1999

\begin{tabular}{|c|c|c|c|c|}
\hline Land & \multicolumn{4}{|c|}{ Festkursperioden } \\
\hline Bulgarien & \multicolumn{4}{|c|}{ seit Juli $1997^{b}$} \\
\hline Estland & \multicolumn{4}{|c|}{ seit Juni $1992^{b}$} \\
\hline Lettland & \multicolumn{4}{|c|}{ seit Feb $1994^{b}$} \\
\hline Litauen & \multicolumn{4}{|c|}{ seit April $1994^{\mathrm{b}}$} \\
\hline Polen & $\begin{array}{c}\text { Jan } 1990- \\
\text { Mai } 1991\end{array}$ & $\begin{array}{c}\text { Mai } 1991- \\
\text { Feb } 1992\end{array}$ & $\begin{array}{c}\text { Feb } 1992- \\
\text { Aug } 1993\end{array}$ & $\begin{array}{c}\text { Aug } 1993- \\
\text { Mai } 1995\end{array}$ \\
\hline Rumănien & \multicolumn{4}{|c|}{ (keine) } \\
\hline Slowakei & \multicolumn{2}{|c|}{ Jan 1991 - Juli 1993} & \multicolumn{2}{|c|}{ Juli 1993 - Dez 1996} \\
\hline Slowenien & \multicolumn{4}{|c|}{ (keine) } \\
\hline Tschechien & \multicolumn{4}{|c|}{ Jan 1991 - Feb 1996} \\
\hline Ungarn & \multicolumn{4}{|c|}{ seit Mărz $1995^{\mathrm{b}}$} \\
\hline
\end{tabular}

Quelle: Zusammengestellt aus den Angaben im Anhang IV.2.

Ein Vergleich der Tabelle 11 mit den Stabilisierungsverläufen in der Abbildung 5 zeigt, daß ein Zusammenhang zwischen Festkursperioden und Phasen mit einer deutlichen Reduzierung der Inflationsraten besteht. Alle drei baltischen Staaten, die sich 1992 bzw. 1994 für feste Wechselkurssysteme entschieden, verzeichnen seit dieser Zeit einen stetigen Rückgang der Preissteigerungsraten. Die gleiche Aussage gilt für Ungarn seit dem Übergang zum aktiven Crawling Peg im März 1995, während in der ersten Hälfte der 1990er Jahre kein klarer Disinflationstrend zu erkennen war. Auch die tschechischen und die slowakischen Wechselkursbindungen waren jeweils - mit der bereits erwähnten Ausnahme des Jahres 1993 - von deutlichen Rückgängen der Inflationsraten begleitet. In der Slowakei fällt der einmalige höhere Preisanstieg mit einer nominalen Abwertung in Höhe von 10 v.H. zwischen den beiden Festkursperioden 
im Juli 1993 zusammen. Dies ist mit dem modelltheoretischen Zusammenhang kompatibel, daß eine nominale Abwertung preissteigernd wirkt. Die Wechselkurspolitik in Polen, neben dem Baltikum viertes Land mit kontinuierlich fallender Inflation, ist durch mehrere Festkursperioden gekennzeichnet. Allerdings wurden diese Episoden durch drei nominale Abwertungen unterbrochen. ${ }^{102}$ Diese schlugen sich zwar in Polen nicht in einem Anstieg der Preissteigerungsraten nieder. Allerdings bieten diese diskretionären Abwertungen und der Übergang zu einem Crawling Peg System einen Erklärungsansatz dafür, daß die polnischen Preissteigerungsraten nicht so schnell wie im Baltikum zurückgeführt werden konnten. ${ }^{103}$ Die Betrachtung der Festkursperioden bestätigt das Ergebnis der modelltheoretischen Analyse im Kapitel III, daß eine Wechselkursbindung ein Instrument zur Reduzierung hoher Inflationsraten sein kann. Für eine Beurteilung, ob die theoretischen Ergebnisse über den Zusammenhang zwischen der Inflationsentwicklung und dem Wechselkurssystem zutreffend sind, ist jedoch eine genauere Analyse der Erfahrungen in den Ländern erforderlich, die ein flexibles Wechselkurssystem unterhielten. Insbesondere muß analysiert werden, ob es im Rahmen der Flexkurssysteme zu nominalen Auf- oder Abwertungen kam.

Rumänien und Slowenien sind zwei Länder, die im Betrachtungszeitraum nicht auf den festen Wechselkurs zurückgegriffen haben, während Bulgarien bis Mitte 1997 ein flexibles Wechselkurssystem hatte. Die Stabilisierungserfahrungen dieser drei Länder sind sehr unterschiedlich. Rumänien und Bulgarien sind die beiden Länder, die nicht $\mathrm{zu}$ den erfolgreichen Stabilisierern gehören. Slowenien erlebt dagegen seit 1992 kontinuierlich fallende Inflationsraten und ist bereits $1993 \mathrm{zu}$ positiven Wachstumsraten übergegangen. Während sich in Bulgarien und Rumänien die Landeswährungen im Laufe der 1990er Jahre jedoch massiv abwerteten, fiel die nominale Wechselkursentwicklung in Slowenien deutlich moderater aus. ${ }^{104}$ Zwar verzeichnet auch der Slowenische Tolar seit seiner Einführung eine trendmäßige nominale Abwertung, allerdings ist diese Kursentwicklung auch von Phasen relativer Stabilität oder sogar von Phasen nominaler Aufwertungen gekennzeichnet.

Für die zehn mittel- und osteuropäischen Transformationsländer gilt offenbar, daß die nicht erfolgreich stabilisierenden Länder - Bulgarien und Rumänien ein flexibles Wechselkurssystem hatten. Allerdings ist der Umkehrschluß, daß

102 Der Polnische Zloty wurde im Mai 1991 um 14,4 v.H., im Februar 1992 in Höhe von 12,0 v.H. und im August 1993 um 8,1 v.H. gegenüber dem Wăhrungskorb abgewertet.

103 Trotz des deutlich früheren Transformationsbeginns in Polen verzeichneten alle vier Länder erst 1995 bzw. 1996 Inflationsraten von weniger als 30 v.H. p.a.

$104 \mathrm{Zu}$ den nominalen Wechselkursentwicklungen in Bulgarien, Rumänien und Slowenien siehe DB Research (1999a), S. 48, und DB Research (2000a). 
sich alle erfolgreichen Stabilisierer für ein Festkurssystem entschieden, nicht zulässig. Die überwiegende Mehrheit der Länder dieser Gruppe weist zwar mindestens eine Festkursperiode auf, allerdings zeigt das Beispiel Sloweniens, daß eine Stabilisierung auch bei flexiblen Wechselkursen möglich ist.

Im folgenden werden einige Länder etwas genauer untersucht, die im Laufe der Transformation einen Regimewechsel in der Wechselkurspolitik vollzogen haben. Zuerst werden die drei Länder Bulgarien, Lettland und Litauen betrachtet, die anfangs den Wechselkurs flexibel gehandhabt haben und dann zu festen Wechselkursen übergegangen sind. Im Anschluß daran erfolgt die Analyse der Slowakei, Tschechiens und Polens, in denen die Entwicklung in entgegengesetzter Richtung verlief.

Ein besonders interessanter Fall ist.Bulgarien. Bis 1997 konnten dort unter einem flexiblen Wechselkurs keine anhaltenden Erfolge bei der Reduzierung der Inflationsraten und der Rückkehr zu dauerhaftem Wirtschaftswachstum erzielt werden. Das Stabilisierungsprogramm mit festem Wechselkurs hat hingegen mit Blick auf beide Variablen beeindruckende Fortschritte gebracht. Es bleibt abzuwarten, ob Bulgarien in der Lage sein wird, die niedrigen Inflationsraten und das positive Wirtschaftswachstum auch längerfristig zu erhalten. Zumindest aber bildet das Land ein Gegenbeispiel zu der These von Begg (1998), daß nur die Länder mit vorteilhafteren Ausgangsbedingungen eine Wechselkursbindung wählten und insbesondere deshalb Stabilisierungsprogramme mit festem Wechselkurs erfolgreich waren. ${ }^{105}$ Des weiteren bleibt festzuhalten, daß Bulgarien mit dem Currency Board System die negativen Auswirkungen des Kosovokrieges, von dem das Land ebenso wie Rumänien als südöstlicher Nachbar Serbiens besonders stark betroffen war, besser verkraftet hat, als ursprünglich erwartet worden war. 106

Litauen und Lettland sind zwei weitere Staaten, die zunächst ihre Währungen floaten ließen, bevor sie sich 1994 für eine Wechselkursbindung entschieden. Wie aus der Abbildung 5 hervorgeht, verzeichneten sowohl Litauen als auch Lettland bereits ab 1993 deutlich sinkende Preissteigerungsraten, wobei der Rückgang in Lettland wesentlich stärker war als in Litauen. ${ }^{107} \mathrm{Da}$ die lettische Zentralbank bis zum Ende des Jahres 1993 eine nominale Aufwertung der Wäh-

105 Vgl. Begg (1998), S. 107 und 112.

106 Für 1999 war zum Beispiel aufgrund des Kosovokonfliktes ein negatives Wirtschaftswachstum befurchtet worden. Siehe IMF (1999).

107 Durch die logarithmische Skalierung der Ordinate in Abbildung 5 tritt dieser Unterschied in der graphischen Darstellung nicht so anschaulich hervor wie im Zahlenvergleich. Nachdem beide Staaten 1992 eine Preissteigerung von ca. 1.000 v.H. erfuhren, betrug die Inflationsrate 1993 in Lettland nur noch 109,2 v.H., wăhrend die Preise in Litauen noch um 410,4 v.H. stiegen. 
rung zuließ, ist auch diese Beobachtung mit den Ergebnissen des Partialmodells im Kapitel III kompatibel. Die litauische Währung wertete bis zum Sommer des Jahres 1993 zunächst nominal ab. ${ }^{108}$ In der zweiten Jahreshälfte kam es dann ebenfalls zu einer nominalen Aufwertung, die aber nicht so stark ausfiel wie in Lettland. Die Entwicklungen in den beiden baltischen Ländern sind daher Beispiele für die Konstellation des Partialmodells, bei der die Zentralbank über eine nominale Aufwertung niedrige Preissteigerungsraten erreicht. ${ }^{109}$ Es ist deshalb nicht überraschend, daß die Rückführung der Inflation in Estland und in Lettland in etwa im gleichen Ausmaß gelang, während in Litauen, wo es in der ersten Jahreshälfte 1993 zu einer deutlichen nominalen Abwertung kam, die Reduzierung der Preissteigerungsrate schwächer ausfiel.

Nach dem Ende der Festkursperioden in Tschechien und der Slowakei führten neben anderen Faktoren auch die deutlichen nominalen Abwertungen zu steigenden Inflationsraten. In relativ kurzer Zeit nach den Systemwechseln stabilisierten sich die Kurse jedoch, und sowohl die Tschechische als auch die Slowakische Krone erlebten in den Jahren 1999 und 2000 Phasen nominaler Aufwertungen, die die Zentralbanken zum Teil durch Interventionen abzuschwächen versuchten. ${ }^{110}$ Der Übergang zu größerer Wechselkursflexibilität in Polen führte hingegen nicht zu einer Unterbrechung des kontinuierlichen Disinflationsprozesses. Allerdings ist dabei zu berücksichtigen, daß die polnischen $\mathrm{Be}-$ hörden nicht nur die sukzessive Ausweitung des Wechselkursbandes bis hin zur vollständigen Freigabe betrieben, sondern zum Beispiel im Jahre 1995 den Zloty gegenüber dem Währungskorb auch diskretionär aufwerteten.

Im Hinblick auf die Gruppierung der zehn Länder in erfolgreiche und nicht erfolgreiche Stabilisierer läßt sich feststellen, daß Rumänien und Bulgarien, die die zuletzt genannte Gruppe bilden, über die meiste Zeit ein flexibles Wechselkurssystem hatten, während die anderen Länder zumindest für einen längeren Zeitraum eine Wechselkursbindung vorgenommen haben. Eine Ausnahme bildet Slowenien, das zu keinem Zeitpunkt eine Wechselkursbindung vorgenommen hat, aber sehr erfolgreich bei der Rückführung der Inflation und der frühen Rückkehr zu wirtschaftlichem Wachstum war. Während also ein fester Wechselkurs offensichtlich ein hilfreiches Instrument in Stabilisierungsprogrammen war, zeigt der Transformationsprozeß Sloweniens und die Entwicklung in den

$108 \mathrm{Zu}$ den nominalen Wechselkursentwicklungen der lettischen und litauischen Wăhrungen gegenuber dem US-Dollar im Jahr 1993 vgl. Lainela/Sutela (1994), S. 81, Korhonen (1999a), S. 18, und Korhonen (1999b), S. 8 f.

109 Diese Situation wird im Unterabschnitt III.3.2. durch die Parameterkonstellation $\alpha<(1-\mu) \mu$ beschrieben.

110 Vgl. DB Research (1999b), S. 7, DB Research (2000b), S. 3, und DB Global Markets Research (2000), S. 26 f. 
frühen Jahren in Lettland und Litauen, daß eine erfolgreiche Stabilisierung auch mit flexiblen Wechselkursen möglich ist.

Der Vergleich der Stabilisierungserfahrungen bei unterschiedlichen Wechselkurssystemen mit den Ergebnissen des Partialmodells im dritten Kapitel zeigt, $\mathrm{da} ß$ die aus der Modellauswertung abgeleiteten Vermutungen grundsätzlich bestätigt werden können: Im Rahmen von Festkurssystemen wurden deutliche Fortschritte bei der Inflationsreduzierung durch den Verzicht auf nominale Abwertungen erzielt. Bei flexiblen Wechselkursen konnten in der Regel dann Stabilisierungserfolge verzeichnet werden, wenn diese von nominalen Aufwertungen begleitet waren.

\subsection{Zwischenfazit}

Die in diesem Abschnitt verwendete Darstellung der Stabilisierungserfahrungen in Wachstums-Inflations-Diagrammen hat gezeigt, daß die Mehrheit der betrachteten Länder ein ähnliches Muster für die Entwicklung dieser beiden makroökonomischen Größen im Reformprozeß aufweist. ${ }^{111}$ Die erfolgreichen Stabilisierungsprogramme waren dadurch gekennzeichnet, daß einerseits die Preissteigerungsraten deutlich gesenkt und andererseits ungefähr zwei bis drei Jahre nach dem stärksten wirtschaftlichen Einbruch wieder positive Wachstumsraten erreicht wurden. Diejenigen Länder, die sehr schnell die Inflationsraten zurückführen konnten, kehrten früh auf den Wachstumspfad zurück. Die wichtige Erkenntnis ist, daß die Disinflation in den Ländern positiv mit einem steigenden Sozialprodukt korreliert ist.

Nur zwei Länder weisen Entwicklungen auf, die sich deutlich von den Verläufen der anderen EU-Beitrittskandidaten abheben, und zwar Bulgarien und Rumänien. Die entsprechende Graphik für Bulgarien zeigt aber, daß das Stabilisierungsprogramm des Jahres 1997 offensichtlich so erfolgreich war, daß sich in den folgenden Jahren ein deutlicher Rückgang der Preissteigerung verbunden mit positivem Wirtschaftswachstum einstellte, wie ihn auch die anderen Länder erlebt haben. Allerdings ist der Zeitraum zu kurz, um schon beurteilen zu können, ob es sich um eine nachhaltige Reduzierung der Inflationsraten handelt.

Die Graphiken Bulgariens und Rumäniens in den Abbildungen 5a und 5c (siehe S. 155 ff.) zeigen außerdem, daß die gewählte Darstellung die Zeitpunkte verschiedener Reformansätze sehr deutlich hervorhebt. Die jeweiligen „Spitzen“ der Verläufe im Jahr 1997 markieren in beiden Ländern den Beginn neuer Stabilisierungsbemühungen, wobei diese in Bulgarien offensichtlich erfolgreicher

111 Siehe Abbildung 5 auf S. 155 ff. für die Entwicklungen in den zehn betrachteten Ländern und Abbildung 6 auf S. 163 fur einen stilisierten Verlauf von Wirtschaftswachstum und Inflation im Transformationsprozeß. 
waren als in Rumänien. Es bestätigt sich also, daß sich die Zeitpunkte größerer Reformanstrengungen aus den Graphiken ablesen lassen und daß die Verläufe der beiden makroökonomischen Größen auch die wiederholten Stabilisierungsversuche sehr anschaulich abbilden.

Die Analyse von sechs Faktoren zur Erklärung der Verläufe kommt zu dem Ergebnis, daß die Ausgangsbedingungen vermutlich keine entscheidende Rolle für die verschiedenen Muster spielen. Die Situationen zu Transformationsbeginn waren sehr unterschiedlich, aber Bulgarien und Rumänien hoben sich nicht in besonderer Weise von den anderen Ländern ab. Slowenien befand sich zwar in der günstigsten Ausgangslage, aber die Stabilisierungserfahrungen weichen nicht markant von denen anderer erfolgreich stabilisierender Transformationsökonomien ab. Es ist deshalb zu vermuten, daß die betriebene Politik wichtiger war als die Startbedingungen.

Von den fünf betrachteten Politikfeldern stellen sich die Zentralbankgesetzgebung und die Fiskalpolitik als zwei Bereiche heraus, die nicht dazu beitragen können, die unterschiedlichen Erfolge zu erklären. Im Hinblick auf den Grad an gesetzlich garantierter Zentralbankunabhängigkeit ähneln sich die Länder so sehr, daß dieser Aspekt institutioneller Reformpolitik keinen Ansatzpunkt für eine Erklärung bietet. Bei der Fiskalpolitik bestehen erkennbare Unterschiede zwischen den zehn EU-Beitrittskandidaten, aber weder bei der Höhe der Budgetdefizite noch bei der Zusammensetzung der Staatsausgaben lassen sich Bulgarien und Rumänien als die ,schlechtesten“ Kandidaten identifizieren. Vielmehr sind Polen und Ungarn zwei Länder mit vergleichsweise hohen Budgetdefiziten, die aber zu den erfolgreichen Stabilisierern gehören. Während die Betrachtung einzelner Ländererfahrungen anzudeuten scheint, daß höhere Budgetdefizite eine Stabilisierung behindern, bleibt das Bild insgesamt doch eher unscharf.

In Übereinstimmung mit Theorie und Empirie anderer Arbeiten zeigt sich aber, daß sowohl die Liberalisierung als auch die Geldpolitik wichtige Komponenten einer erfolgreichen Transformationspolitik sind. Die Auswertung potentieller Einflußfaktoren auf die Stabilisierungserfahrungen der mittel- und osteuropäischen EU-Beitrittskandidaten legt die Schlußfolgerung nahe, daß sowohl eine umfassende Liberalisierungspolitik als auch eine weniger expansive Geldpolitik in entscheidendem Maße zur Stabilisierung beitragen. Die große Bedeutung dieser beiden Faktoren zeigt, daß eine erfolgreiche Stabilisierung im Transformationsprozeß offensichtlich vom komplementären Einsatz von Strukturreformen und geldpolitischer Stabilisierungspolitik abhängt. ${ }^{112}$

112 Es wird damit die Aussage von Pujol/Griffiths (1998), S. 227, bestătigt, daß „the combination of tighter monetary policy and active restructuring has the potential to reduce inflation in the least costly and most lasting way." 
Im Hinblick auf die in dieser Arbeit im Vordergrund stehende Wechselkurspolitik ergibt sich kein so eindeutiger Zusammenhang. Sieben von acht Ländern, die ihre Volkswirtschaften erfolgreich stabilisiert haben, hatten über einen längeren Zeitraum hinweg einen festen Wechselkurs. Auch die Stabilisierungserfolge Bulgariens in den vergangenen Jahren fanden unter einem Festkursregime statt. Zwar deutet diese Beobachtung darauf hin, daß ein fester Wechselkurs einen positiven Einfluß ausgeübt hat, aber Slowenien bildet mit einer erfolgreichen Stabilisierung bei flexiblen Wechselkursen im gesamten Reformprozeß eine Ausnahme von dieser Regel. ${ }^{113}$

Während für die unterschiedlichen Ausgangsbedingungen in den Ländern kein Einfluß auf die Stabilisierungserfolge insgesamt festgestellt werden konnte, ist es denkbar, daß sie für die Wahl der geldpolitischen Strategie von Bedeutung sind. In Slowenien konnte unter Umständen deshalb von Anfang an eine Geldmengensteuerung erfolgreich durchgeführt werden, weil sich das Land in einer relativ günstigen Ausgangslage befand. Als auf den Außenhandel mit Westeuropa spezialisierte jugoslawische Teilrepublik war Slowenien nicht so stark vom Zusammenbruch des RGW betroffen wie die anderen betrachteten Länder. Auch die Koordinationsmechanismen waren schon vor der Transformation zum Teil privatwirtschaftlich. ${ }^{114}$ Bei der Betrachtung des Verlaufs von Wirtschaftswachstum und Inflation hat sich diese relativ günstige Ausgangssituation darin widergespiegelt, daß Slowenien als einziges Land keinen Rückgang des Sozialprodukts von mehr als $10 \mathrm{v}$.H. erfahren hat. Es ist also denkbar, daß die vorteilhaftere Ausgangslage in Slowenien bereits von Reformbeginn an eine Geldmengensteuerung erlaubte, die in den anderen Ländern aufgrund größerer wirtschaftlicher Veränderungen und damit verbundener Unsicherheiten nicht möglich war.

Diese Vermutung wird einerseits dadurch gestützt, daß Ungarn und Bulgarien denen in der ersten Hälfte der 1990er Jahre mit flexibel gehandhabten Wechselkursregimen keine deutliche Disinflation gelang - zu festeren Wechselkurssystemen wechselten. Offensichtlich gelang es den Zentralbanken in diesen beiden Ländern bei flexiblen Wechselkursen nicht, eine stabilitätskonforme Geldpolitik zu betreiben, so daß sich die wirtschaftspolitischen Entscheidungsträger für den

113 Auch die Erfahrungen Lettlands und Litauens von Ende 1992 bis Anfang 1994 sind Beispiele dafur, daß eine Stabilisierung mit flexiblen Wechselkursen gelang. Allerdings sind die Perioden von ca. anderthalb Jahren sehr kurz, so daß nur Slowenien als Beispiel fur eine lăngerfristige Stabilisierung mit flexiblen Wechselkursen herangezogen werden kann.

114 Die besondere Ausgangslage der ehemaligen jugoslawischen Teilrepubliken durfte auch die Ursache dafur sein, daß Burton und Fischer in ihrer Studie Kroatien und Slowenien nicht als Transformationsländer klassifizieren. Siehe Burton/Fischer (1998), Tabelle 4, S. $29 \mathrm{ff}$. 
Einsatz des Wechselkurses als nominalen Anker zur Inflationsbekämpfung entschieden. In Ungarn geschah dies 1995 durch den Übergang zu einem aktiven Crawling Peg, während in Bulgarien 1997 ein Currency Board eingeführt wurde. Andererseits gingen einige Länder mit anfänglichem Festkurssystem zu flexibleren Wechselkursregelungen über, nachdem sie deutliche Fortschritte bei der Inflationsbekämpfung mit Hilfe des festen Wechselkurses erzielt hatten. Dies sind Polen, Tschechien und die Slowakei. Die Zentralbanken dieser drei Länder betreiben inzwischen eine Geldpolitik mit Hilfe eines Inflation Targeting, wobei sie Veränderungen des nominalen Wechselkurses aufmerksam beobachten, weil diese einen starken Einfluß auf die Preisentwicklung ausüben. $\mathrm{Ob}$ diese geldpolitische Strategie langfristig erfolgreich sein wird, muß sich erst noch zeigen. ${ }^{115}$ Es liegt aber die Vermutung nahe, daß aufgrund von Unsicherheiten im frühen Transformationsprozeß zunächst eine Wechselkursstrategie gewählt wurde, während inzwischen eine stärker eigenständige Geldpolitik für möglich gehalten wird.

Durch die EU-Beitrittsperspektive ist allerdings bereits eine Entwicklung zu weniger flexiblen Regelungen in den Ländern vorgezeichnet. Mit den künftigen Herausforderungen an die währungspolitischen Entscheidungsträger in den EUBeitrittskandidaten befaßt sich daher der folgende Abschnitt.

\section{Mittelfristige wechselkurspolitische Perspektiven}

Das entscheidende Abgrenzungskriterium für die Länderauswahl der vorliegenden Arbeit ist die angestrebte Mitgliedschaft in der Europäischen Union. Eine Analyse der Wechselkurspolitik in den betrachteten Ländern wäre daher unvollständig, wenn sie nicht auch einen Ausblick auf die neuen wechselkurspolitischen Aufgaben gäbe, die mit der Erreichung dieses Ziels verbunden sind. Zwar ist die Fähigkeit zur Teilnahme an der Währungsunion kein Kriterium, das die Länder für einen EU-Beitritt erreichen müssen. Auch die Erfüllung der Maastricht-Kriterien ist (noch) nicht erforderlich. Ein Beitritt zur EU erfordert jedoch von den neuen Mitgliedstaaten, daß sie sich zu den Zielen der EWU bekennen.

115 Die tschechische Zentralbank legte erstmals fur 1998 ein Inflationsziel in Form eines Zielkorridors fest, die polnischen und slowakischen Währungsbehörden für das Jahr 1999. Die slowakische Nationalbank betreibt allerdings eine Mischstrategie, indem sie gleichzeitig ein Geldmengenziel verfolgt. In Tschechien lag die tatsächliche Inflationsrate in den Jahren 1998 und 1999 jeweils unterhalb des angestrebten Zielkorridors. Die polnische Zentralbank erreichte ihre Zielvorgabe nicht, weil die tatsăchliche Inflation uber der Spanne fur den Zielwert blieb. Nur in der Slowakei lag die tatsăchliche Preissteigerungsrate 1999 im vorgegebenen Zielbereich. Siehe Backé/Wójcik (2000), S. 13, 20 und 24. 
Laut Artikel 124 des EU-Vertrags ist jeder EU-Mitgliedstaat dazu verpflichtet, seine Wechselkurspolitik als eine Angelegenheit von gemeinsamem Interesse zu behandeln. ${ }^{116}$

Für die Wechselkurspolitik in den mittel- und osteuropäischen Staaten ergeben sich deshalb mit dem EU-Beitritt neue Fragen und Herausforderungen, auf die in diesem vierten Abschnitt eingegangen wird. Nach einem kurzen Überblick über den Prozeß und den Stand der EU-Osterweiterung wird erläutert, welche neuen Rahmenbedingungen sich durch die Schaffung der Europäischen Währungsunion ergeben und mit welchen wechselkurspolitischen Maßnahmen die Beitrittskandidaten auf den Beginn der EWU reagiert haben. Daran anschlieBend wird diskutiert, welche Chancen und Risiken mit der Wechselkurspolitik nach einem EU-Beitritt verbunden sind.

\subsection{Schritte auf dem Weg zu einer EU-Osterweiterung - eine Bestandsaufnahme}

Eine EU-Beitrittsperspektive wurde den Ländern bereits in der ersten Hälfte der 1990er Jahre mit dem Abschluß der Europa-Abkommen eröffnet. Im Zentrum dieser Abkommen stand die Regelung handelspolitischer Fragen. Darüber hinaus sollten sie jedoch auch den Demokratisierungsproze $B$ in den Partnerländern unterstützen und eine engere politische, rechtliche und kulturelle Bindung an die EU bewirken. ${ }^{117}$ Im Juni 1993 fand die Tagung des Europäischen Rates in Kopenhagen statt, auf der die Bedingungen für einen EU-Beitritt formuliert wurden. Nach dem Tagungsort werden diese als „Kopenhagener Kriterien“ bezeichnet. Danach muß ein beitrittswilliges Land als Voraussetzung für die Mitgliedschaft die notwendige institutionelle Stabilität besitzen, um eine demokratische und rechtsstaatliche Ordnung, die Wahrung der Menschenrechte sowie einen angemessenen Minderheitenschutz garantieren zu können. Es wird des weiteren eine funktionsfähige Marktwirtschaft sowie die Fähigkeit gefordert, dem Wettbewerbsdruck und den Marktkräften innerhalb der Union standzuhalten. Schließlich setzt eine Mitgliedschaft auch voraus, daß die Beitrittsländer die aus einer Mitgliedschaft erwachsenden Verpflichtungen übernehmen und sich die Ziele der politischen Union sowie der Wirtschafts- und Währungsunion $\mathrm{zu}$ eigen machen. ${ }^{118}$ Von den neuen Mitgliedsländern wird insbesondere gefor-

116 Alle Verweise auf Artikel des EU-Vertrags beziehen sich auf den Vertrag uber die Europäische Union in der am 2. Oktober 1997 in Amsterdam unterzeichneten Fassung. Zu den Vertragstexten siehe Europäische Kommission (2000).

117 Vgl. Plotz/Ritter (1998), S. 3.

$118 \mathrm{Zu}$ den Kopenhagener Kriterien siehe Europăische Kommission (1997), S. 43. Die Anforderungen sind relativ vage formuliert und lassen zum Beispiel offen, was unter einer funktionsfahigen Marktwirtschaft zu verstehen ist. Lavigne (1998) argumentiert, daß die For- 
dert, daß sie den gesamten Bestand an EU-Rechtsnormen - den sogenannten Acquis Communautaire - in nationales Recht umsetzen.

Bereits 1994 stellten Ungarn und Polen die offiziellen Anträge auf Mitgliedschaft in der EU. Die baltischen Staaten, Rumänien und die Slowakei folgten 1995, Slowenien und Tschechien 1996. Auf dem Madrider Gipfeltreffen des Europäischen Rates im Dezember 1995 wurde die Kommission aufgefordert, so bald wie möglich nach dem Abschluß der geplanten Regierungskonferenz ihre Stellungnahmen zu den Beitrittsgesuchen zu veröffentlichen. Die Regierungskonferenz endete im Juni 1997 mit der Unterzeichnung des Amsterdamer Vertrags, ohne daß es zu einer Einigung über die institutionellen Regelungen für die Zeit nach einer Erweiterung kam. Trotzdem präsentierte die Europäische Kommission im Juli 1997 die Agenda 2000 und ihre Stellungnahmen zu den Beitrittsanträgen aller Kandidaten. Darin schlug sie die Aufnahme von Verhandlungen mit fünf mittel- und osteuropäischen Beitrittskandidaten sowie Zypern vor. Der Europäische Rat bestätigte im Dezember 1997 in Luxemburg die Empfehlungen der Kommission, so daß im März 1998 mit Estland, Polen, Slowenien, Tschechien, Ungarn und Zypern Verhandlungen über den EU-Beitritt beginnen konnten. Diese sechs Staaten werden daher auch als „Länder der ersten Runde" bezeichnet. Allen Staaten, die einen Beitrittsantrag gestellt hatten, wurden sogenannte Beitrittspartnerschaften angeboten, die mit finanziellen Hilfen der EU verbunden sind und jährliche Überprüfungen der Entwicklungen in diesen Ländern beinhalten.

Während die Kommission im November 1998 bei der Vorlage der ersten regelmäßigen Berichte über den Fortschritt der Kandidaten auf dem Weg zum Beitritt noch keine Ausdehnung der Beitrittsverhandlungen auf weitere Staaten vorsah, schlug sie im Oktober 1999 vor, ab dem Frühjahr 2000 mit allen Beitrittskandidaten in Verhandlungen über den Beitritt einzutreten. Nach der Bestätigung dieser Empfehlung auf dem Gipfel der Staats- und Regierungschefs in Helsinki im Dezember 1999 wurden im Februar 2000 mit fünf weiteren mittelund osteuropäischen Staaten sowie Malta offiziell Beitrittsverhandlungen aufgenommen. ${ }^{119}$ Sie bilden die Gruppe der „Zweiten Runde“. Die Europäische Kommission hat allerdings wiederholt betont, daß ein EU-Beitritt von den Fort-

mulierungen bewußt wenig konkret sind, da die Entscheidung, welche Länder wann Mitgliedstaaten werden, letztlich eine politische Entscheidung sein wird. Vgl. Lavigne (1998), S. 55.

119 Malta hatte sein Beitrittsgesuch zunächst zurulckgezogen, zwischenzeitlich aber wieder aufleben lassen, so daß es in die zweite Runde der Beitrittskandidaten mit aufgenommen werden konnte. Auf dem Gipfeltreffen in Helsinki wurde auch die Turkei in den Kreis der Kandidaten fur eine EU-Erweiterung aufgenommen. Mit ihr werden jedoch (noch) keine Beitrittsverhandlungen gefuhrt. 
schritten der einzelnen Länder bei der Umsetzung des Acquis Communautaire abhängig ist und mit der Aufnahme von Beitrittsverhandlungen zu zwei verschiedenen Zeitpunkten keine zeitliche Abfolge bei der Aufnahme in die Europäische Union vorherbestimmt ist. Einen Überblick über die Daten der einzelnen Beitrittsetappen gibt die Tabelle 12.

\section{Tabelle 12: Formale Beziehungen der mittel- und osteuropäischen Staaten} mit der EU

\begin{tabular}{|c|c|c|c|c|}
\hline Land & $\begin{array}{l}\text { Unterzeichnung } \\
\text { des Europa- } \\
\text { Abkommens }\end{array}$ & $\begin{array}{l}\text { Inkrafttreten } \\
\text { des Europa- } \\
\text { Abkommens }\end{array}$ & $\begin{array}{l}\text { Antrag auf EU- } \\
\text { Mitgliedschaft }\end{array}$ & $\begin{array}{l}\text { Beginn der } \\
\text { Beitrittsver- } \\
\text { handlungen }\end{array}$ \\
\hline Bulgarien & Mărz 1993 & Februar $1995^{b}$ & Dezember 1995 & Februar 2000 \\
\hline Estland & Juni 1995 & Februar 1998 & November 1995 & Mărz 1998 \\
\hline Lettland & Juni 1995 & Februar 1998 & Oktober 1995 & Februar 2000 \\
\hline Litauen & Juni 1995 & Februar 1998 & Dezember 1995 & Februar 2000 \\
\hline Polen & Dezember 1991 & Februar $1994^{c}$ & April 1994 & Mărz 1998 \\
\hline Rumănien & Februar 1995 & Februar $1995^{c}$ & Juni 1995 & Februar 2000 \\
\hline Slowakei & Dezember $1991^{a}$ & Februar $1995^{c}$ & Juni 1995 & Februar 2000 \\
\hline Slowenien & funi 1996 & Februar $1999^{c}$ & Juni 1996 & Mărz 1998 \\
\hline Tschechien & Dezember $1991^{a}$ & Februar $1995^{c}$ & Januar 1996 & Mărz 1998 \\
\hline Ungarn & Dezember 1991 & Februar $1994^{c}$ & Mărz 1994 & Mărz 1998 \\
\hline \multicolumn{5}{|c|}{$\begin{array}{l}\text { Anmerkungen: }{ }^{a} \text { Datum der Unterzeichnung des Europa-Abkommens mit der Tschechoslo- } \\
\text { wakei. Mit der Slowakei und Tschechien wurden im Oktober } 1993 \text { entsprechende Anschluß- } \\
\text { abkommen unterzeichnet. }-{ }^{b} \text { Ein vorläufiges Abkommen uber wirtschaftliche Aspekte trat } \\
\text { im Dezember } 1993 \text { in Kraft. }-{ }^{c} \text { Die Handelspolitik betreffende vorlăufige Abkommen traten } \\
\text { bereits fruher in Kraft: mit Polen, der Slowakei, Tschechien und Ungarn im März 1992, mit } \\
\text { Rumänien im Mai } 1993 \text { sowie mit Slowenien im Januar } 1997 .\end{array}$} \\
\hline
\end{tabular}

Quelle: Europäische Kommission (2000).

Aber nicht nur die Beitrittskandidaten müssen einen gesellschaftlichen und wirtschaftlichen Wandel vollziehen, damit die EU-Osterweiterung stattfinden kann. Parallel dazu entwickelt sich die EU nicht nur weiter, sondern muß ebenfalls reformiert werden. So ist zum Beispiel unstrittig, daß die Abstimmungsregeln innerhalb des Ministerrates geändert werden müssen, damit die EU bei einer Erweiterung um bis zu zwölf neue Mitglieder handlungsfähig bleibt. Die- 
ser Prozeß der internen Reformen wird, inklusive der notwendigen Ratifizierung durch alle Mitgliedstaaten, voraussichtlich nicht vor Ende 2002 abgeschlossen sein, so daß das Jahr 2003 den frühesten Zeitpunkt für die nächste Erweiterung der EU markiert. Eine wichtige Veränderung innerhalb der EU war der Beginn der Europäischen Währungsunion im Januar 1999, denn durch ihn haben sich das währungspolitische Umfeld und die mit dem EU-Beitritt verbundenen Perspektiven für die Beitrittskandidaten verändert. Den Auswirkungen der EWU auf die mittel- und osteuropäischen Staaten gehen die beiden folgenden Unterabschnitte nach.

\subsection{Neue Rahmenbedingungen durch die Schaffung der Europäischen Währungsunion}

\subsubsection{Vom EU-Beitritt über das EWS II zur Währungsunion}

Wie bereits erwähnt, erfordert ein EU-Beitritt, daß die neuen Mitglieder ihre Wechselkurspolitik als eine Angelegenheit von gemeinsamem Interesse behandeln und sie sich die Ziele der Europäischen Währungsunion zu eigen machen. Aus währungspolitischer Sicht ist deshalb der EU-Beitritt als eine Etappe auf dem Weg zur Teilnahme an der Währungsunion anzusehen. Dies gilt vor allem deshalb, weil die Europäische Union beschlossen hat, daß für neue Mitgliedsländer keine sogenannten „opt-out"-Klauseln mehr möglich sind, wie sie Dänemark und Großbritannien gewährt wurden. ${ }^{120}$ Nach dem Beitritt zur Europäischen Union werden die Staaten nach Artikel 122 „Mitgliedstaaten, für die eine Ausnahmeregelung gilt". Im Vergleich zu den am Euro-Währungsgebiet teilnehmenden Staaten gelten deshalb gewisse Verpflichtungen noch nicht für die neuen Mitgliedsländer. Es wird aber zum Beispiel gewünscht, daß sie so bald wie möglich am EWS II teilnehmen. ${ }^{121}$ Die Teilnahme am EWS II bildet eine entscheidende Vorstufe für die Mitgliedschaft in der Währungsunion.

Die formalen Anforderungen für eine Teilnahme an der EWU werden durch die sogenannten Maastricht-Kriterien beschrieben. Danach müssen diejenigen Staaten, die der Währungsunion beitreten wollen, eine hinreichende fiskalische und monetäre Konvergenz aufweisen. Nach Artikel 121 des Amsterdamer Vertrags erfordert dies die Erreichung eines hohen Grades an Preisstabilität, eine auf Dauer tragbare Finanzlage der öffentlichen Hand, eine im Niveau der langfristigen Zinssätze zum Ausdruck kommende Dauerhaftigkeit der Konvergenz sowie die Einhaltung der normalen Bandbreiten des Wechselkursmechanismus

120 Vgl. Europåische Zentralbank (2000a), S. 48, und Masson (1999), S. 10.

$121 \mathrm{Zu}$ den Rechten und Pflichten eines EU-Mitgliedstaates mit Ausnahmeregelung siehe die Tabelle 1 in Ilzkovitz (1996), S. 243, sowie die Tabelle 6 in Temprano-Arroyo/Feldman (1998), S. 29. 
für mindestens zwei Jahre ohne Abwertung. 122 Weil das zuletzt genannte Kriterium eine Teilnahme am EWS II von mindestens zwei Jahren fordert, wird hierdurch der Zeithorizont für den Weg vom EU-Beitritt bis zur Teilnahme an der Währungsunion bestimmt. Selbst wenn ein neues Mitgliedsland von Anfang an am neuen Wechselkursmechanismus teilnähme, wäre ein Eintritt in die Währungsunion - bei strenger Auslegung der Kriterien - erst etwa drei Jahre später möglich, weil zu berücksichtigen ist, daß eine Überprüfung der Erfüllung aller Kriterien erfolgen muß und für die technische Vorbereitung ebenfalls einige Monate zu veranschlagen sind. ${ }^{123}$ Von der Entscheidung, wann die Länder dem EWS II beitreten, ist demnach auch abhängig, wann der Euro die nationalen Währungen in den neuen EU-Mitgliedstaaten frühestens ersetzen kann.

Im folgenden wird zunächst das EWS II vorgestellt. Im Anschluß daran wird aufgezeigt, mit welchen wechselkurspolitischen Maßnahmen die mittel- und osteuropäischen Länder auf den Start der Währungsunion reagiert haben, bevor zum Abschluß des Kapitels die Herausforderungen diskutiert werden, die der EU-Beitritt für die Wechselkurspolitik in den neuen Beitrittsländern mit sich bringt.

\subsubsection{Ausgestaltung des Europäischen Wechselkurs- mechanismus EWS II}

Durch die Schaffung der Europäischen Währungsunion und die Einführung des Euro Anfang des Jahres 1999 wurde das bestehende Europäische Währungssystem außer Kraft gesetzt. Elf der in diesem System verbundenen Währungen gingen in der neuen europäischen Einheitswährung auf, während gleichzeitig ein neuer Wechselkursmechanismus geschaffen wurde, der als EWS II bezeichnet wird. Dieser bietet den noch nicht an der Währungsunion teilnehmenden EU-Staaten die Möglichkeit, ihre Währungen im Rahmen des neuen Mechanismus an den Euro zu binden, der in diesem System die Funktion einer Ankerwährung übernimmt.

$122 \mathrm{Zu}$ den Konvergenzkriterien siehe genauer Jarchow/Ruhmann (1997), S. 332.

$123 \mathrm{Ob}$ die Kriterien tatsăchlich streng ausgelegt werden, ist unsicher, da z.B. bereits zu Beginn der Wăhrungsunion auf eine strikte Einhaltung des Wechselkurskriteriums verzichtet wurde. So nahmen Finnland und Italien zum Zeitpunkt der Überprufung der Konvergenz im Fruhjahr 1998 noch nicht seit zwei Jahren am Europäischen Wăhrungssystem teil. Die Finnmark trat erst im Oktober 1996 dem Wechselkursmechanismus bei, und die Italienische Lira wurde erst im November 1996 erneut aufgenommen. Vgl. Europäisches Wăhrungsinstitut (1998), S. 9. 
Das neue Wechselkurssystem ist wie folgt ausgestaltet. ${ }^{124}$ Die Teilnahme am EWS II ist freiwillig; es wird aber von den noch nicht zum Währungsgebiet gehörenden Staaten erwartet, daß sie möglichst bald teilnehmen. Im Gegensatz zum Paritätengitter des früheren EWS werden die Leit- und Interventionskurse ausschließlich gegenüber dem Euro festgelegt, weshalb das System auch als „Nabe- und Speichen-Ansatz"125 bezeichnet wird. Die generelle Schwankungsbreite um den Leitkurs gegenüber dem Euro beträgt \pm 15 v.H. (= Standardbandbreite). Es kann aber auch - bei schon hinreichend weiten Konvergenzfortschritten - eine engere Schwankungsbreite vereinbart werden. Um spürbare Kursverzerrungen zu vermeiden, kann auf Initiative aller an den Beschlüssen beteiligten Parteien ein vertrauliches Verfahren zur Überprüfung der Leitkurse eingeleitet werden. ${ }^{126}$ An den oberen und unteren Interventionspunkten sind automatische und in der Höhe unbegrenzte Interventionen vorgesehen. Allerdings können die EZB oder die nationalen Notenbanken ihre Interventionen einstellen, wenn durch diese das vorrangige Ziel der Preisstabilität gefährdet wäre. Es besteht ferner die Möglichkeit, koordinierte intramarginale Interventionen zwischen der EZB und der Notenbank des betroffenen Landes zu vereinbaren. Die Interventionen erfolgen in Euro oder in der Währung des noch nicht dem Währungsgebiet angehörenden Staates. Zur Abwicklung dienen „sehr kurzfristige Finanzierungsfazilitäten“.127

Das neue EWS II verfolgt das Ziel, die Konvergenz zwischen dem EuroWährungsgebiet und den daran noch nicht teilnehmenden Staaten zu fördern, so daß Interventionen nur flankierend eingesetzt werden müssen. In erster Linie soll eine stabilitätskonforme Geld- und Fiskalpolitik stabile Kurse sicherstellen. Die Üherwachung des reibungslosen Funktionierens des EWS II obliegt dem Erweiterten Rat der EZB. Er dient auch als Forum für die Koordinierung der Geld- und Wechselkurspolitik. Die noch nicht an der Währungsunion teilnehmenden Länder sollen bei der Umsetzung einer stabilitätsorientierten Wirtschaftspolitik und ihren Anstrengungen zur Einführung des Euro unterstützt werden. 128 Von den vier EU-Mitgliedstaaten, die nicht von Beginn an zum Euro-Währungsraum gehörten, haben in den ersten zwei Jahren des Bestehens nur Griechenland und Dänemark an dem neuen Wechselkursmechanismus teilgenommen. Griechenland ist ab 1. Januar 2001 zwölftes Mitgliedsland der Wäh-

124 Zur Konstruktion und Funktionsweise des EWS II siehe Europåische Kommission (1998), S. $6 \mathrm{ff}$, und Deutsche Bundesbank (1998), S. $19 \mathrm{ff}$.

125 Deutsche Bundesbank (1998), S. 22.

126 Die Initiative kann von den nationalen Notenbanken, von der EZB, von den Finanzministern oder auch von der Europäischen Kommission ausgehen.

127 Fur weitere Details zu den Interventionen und den Finanzierungsfazilităten siehe Deutsche Bundesbank (1998), S. 23 ff.

$128 \mathrm{Vgl}$. Europăische Kommission (1998), S. 6. 
rungsunion. Da Schweden und Großbritannien nicht am EWS II teilnehmen, spielt das System zur Zeit keine große Rolle. Dies könnte sich mit der Aufnahme der mittel- und osteuropäischen Staaten in die EU ändern.

\subsubsection{Auswirkungen der Währungsunion auf die Wechselkurs- politik der Beitrittskandidaten}

Bis zum EU-Beitritt gibt es keine Beschränkungen oder Empfehlungen im Hinblick auf die Ausgestaltung der Wechselkurspolitik in den Beitrittsländern, und eine Teilnahme am EWS II stellt derzeit für die mittel- und osteuropäischen Staaten noch keine wechselkurspolitische Option dar. Trotzdem haben die Beitrittskandidaten schon auf den Beginn der Währungsunion reagiert, indem sie ihre Wechselkurspolitik dem veränderten währungspolitischen Umfeld angepaßt und zum Teil auch schon ihre wechselkurspolitischen Absichten im Hinblick auf die Zeit bis zum und nach dem Beitritt geäußert haben.

Diejenigen Länder, die bei Beginn der EWU ein Managed Floating betrieben, verwenden seit Januar 1999 den Euro als neue (informelle) Referenzwährung. Dies sind Rumänien, die Slowakei, Slowenien und Tschechien. ${ }^{129}$ Es sind in diesen vier Ländern zur Zeit keine Änderungen der Wechselkurssysteme bis zum EU-Beitritt geplant.

In Bulgarien und Estland, die ihre Währungen im Rahmen von Currency Boards gegenüber der Deutschen Mark gebunden hatten, hat der Euro die Deutsche Mark ersetzt. In beiden Fällen ist dies zum unwiderruflichen Umtauschkurs der Deutschen Mark zum Euro geschehen, ohne daß es zu einer Neufestsetzung der Wechselkursrelation kam. Die bulgarische Regierung beabsichtigt, das Currency Board auf unbestimmte Zeit beizubehalten. ${ }^{130}$ In Estland bestehen bereits konkrete Pläne für die Wechselkurspolitik bis zur Teilnahme des Landes an der Europäischen Währungsunion. Die Regierung hat signalisiert, $\mathrm{da} ß$ sie bis zum EU-Beitritt und darüber hinaus am Currency Board festhalten will. Auch als Mitgliedsland der EU ist keine Lockerung vorgesehen, sondern beabsichtigt, ohne den Umweg über die Teilnahme am EWS II direkt das Currency Board System durch die Einführung des Euro zu ersetzen. Der estnische Ministerpräsident Laar hat im Januar 2000 sogar die Vorstellung geäußert, Estland könnte den Euro schon als Zahlungsmittel einführen, bevor es der EU beitritt. ${ }^{131}$ Die estnische Zentralbank hat allerdings zu einem zurückhaltenderen Vorgehen in dieser Angelegenheit geraten.

129 Siehe Europäische Zentralbank (2000a), S. 46.

$130 \mathrm{Vgl}$. OECD (1999a), S. 23.

131 Siehe o.V. (2000), S. 19. 
In Lettland wirkte sich der Beginn der EWU nur dergestalt aus, daß der Euro die Deutsche Mark und den Französischen Franc innerhalb des Sonderziehungsrechts des IWF abgelöst hat. Eine Änderung der Wechselkurspolitik erfolgte nicht. Die lettische Zentralbank plant auch bis zum EU-Beitritt keine Änderung ihrer währungspolitischen Strategie. Laut Aussage des Zentralbankgouverneurs ist das bestehende Wechselkurssystem die beste Variante auf dem Weg in die EU. 132

Im Januar 1999 löste der Euro in Ungarn die ECU im Währungskorb ab. Im Januar 2000 wurde der zu 70 v.H. aus Euro und zu 30 v.H. aus US-Dollar bestehende Währungskorb abgeschafft. Seither wird die monatliche Abwertungsrate innerhalb des Crawling Peg Systems ausschließlich gegenüber dem Euro berechnet. Die ungarischen Behörden planen, die gleitende Parität aufzugeben und zu einer festen Wechselkursbindung gegenüber dem Euro mit einer Bandbreite von \pm 15 v.H. überzugehen. Dies soll jedoch erst erfolgen, nachdem die Inflationsrate im Rahmen des bestehenden Systems bei weiter sinkender monatlicher Abwertungsrate auf unter 5 v.H. reduziert wurde. 133

Mit Beginn der EWU hatte Polen ebenfalls die Zusammensetzung seines Währungskorbes geändert, indem der seit 1991 aus fünf Währungen bestehende Korb durch einen Korb aus Euro und US-Dollar ersetzt wurde. Im neuen Währungskorb hatte der Euro ein Gewicht von 55 v.H.; die Dollargewichtung betrug unverändert 45 v.H. Im April 2000 wurde jedoch das Crawling Peg System aufgegeben und zu einem flexiblen Wechselkurs übergegangen. Bereits im September 1998 hatte die polnische Notenbank angekündigt, daß die gleitende Parität zunächst von einer Phase mit flexiblem Wechselkurs abgelöst werden würde, bevor im Rahmen des Beitritts zur EU und zum EWS II eine erneute Bindung erfolge. ${ }^{134}$ Die Entscheidung zielt darauf ab, über den freien Ausgleich von Devisenangebot und -nachfrage ein angemessenes Wechselkursniveau für den Polnischen Zloty zu ermitteln.

Das Wechselkurssystem in Litauen war von der Einführung des Euro nicht unmittelbar betroffen, weil der Litas an den US-Dollar gebunden ist. Allerdings wirkte sich die Abwertung des Euro gegenüber dem US-Dollar negativ auf die litauische Wirtschaft aus, weil ein großer Teil der Exporte inzwischen in die Europäische Union geliefert wird und die Aufwertung des US-Dollar die preisliche Wettbewerbsfähigkeit der Exporteure verschlechterte. Wie bereits im Abschnitt IV.1. erwähnt, planen die litauische Regierung und die Zentralbank seit längerem einen Wechsel der Reservewährung. Aufgrund des ungünstigen inter-

132 Vgl. Repse (1999).

133 Siehe Corker et al. (2000), S. 21.

134 Vgl. National Bank of Poland (1998), S. 14. 
nationalen Umfeldes wurde die Umstellung verschoben, die ursprünglich bereits für das Ende der 1990er Jahre vorgesehen war. Das Currency Board soll mit der gegenwärtigen US-Dollar-Parität auf jeden Fall bis zum Jahr 2001 beibehalten werden. Danach ist eine Bindung an den Euro als neuer Ankerwährung geplant, wobei nicht eindeutig ist, ob mit dem Wechsel der Reservewährung ein Ausstieg aus dem Currency Board angestrebt wird. ${ }^{135}$ Allerdings hat die litauische Zentralbank wiederholt betont, daß die Umstellung zu der dann gültigen Wechselkursrelation zwischen dem Euro und dem US-Dollar erfolgen soll und auf keinen Fall mit einer Abwertung verbunden sein wird. ${ }^{136}$

\subsection{Wechselkurspolitik nach dem EU-Beitritt}

Es wird zwar von den sogenannten „Mitgliedstaaten, für die eine Ausnahmeregelung gilt" erwartet, daß sie am EWS II teilnehmen. Die Teilnahme ist aber freiwillig; und die Entscheidung liegt in der Verantwortung der nationalen Instanzen. Für die mittel- und osteuropäischen Beitrittsländer wird sich nach der Aufnahme in die EU also die Frage stellen, ob sie möglichst früh eine Mitgliedschaft im EWS II anstreben oder ob sie die Teilnahme möglichst lange aufschieben sollten. Bei dieser Entscheidung sind verschiedene Aspekte zu berücksichtigen. Im folgenden wird insbesondere auf vier Problemfelder eingegangen: Erstens wird analysiert, welche Politikwechsel in Abhängigkeit vom derzeitigen Wechselkursregime erforderlich werden. Zweitens wird untersucht, welche Folgerungen sich aus der Situation vollständig liberalisierter Kapitalmärkte ergeben. Drittens wird auf die Bedeutung des Bankensektors eingegangen, bevor viertens das Spannungsverhältnis zwischen realer und monetärer Konvergenz betrachtet wird.

Da die Länder zur Zeit sehr unterschiedliche Wechselkurssysteme haben und sich dies voraussichtlich auch bis zum EU-Beitritt dieser Staaten nicht ändert, stellen sich auch sehr unterschiedliche Fragen beim Übergang in das EWS II. Für diejenigen Länder, die ein Managed Floating unterhalten, würde die Teilnahme voraussichtlich eine Einschränkung der Flexibilität bedeuten. Allerdings gewährt das EWS II mit einer Bandbreite von \pm 15 v.H. eine relativ große Flexibilität. Für Polen, die Slowakei und Tschechien, die von festen Wechselkurssystemen zu flexibleren Handhabungen übergegangen sind, bedeutet der EUBeitritt, daß sie eine „return to peg“'-Strategie entwickeln müssen. ${ }^{137}$ Für den Fall, daß Ungarn seine Strategie wie geplant umsetzt und bereits vor dem EUBeitritt eine Bindung des Forint gegenüber dem Euro mit einer Bandbreite von \pm 15 v.H. vornimmt, ergäbe sich für die ungarische Wechselkurspolitik im

135 Siehe hierzu die Fußnote 11 in diesem Kapitel.

136 Vgl. Bank of Lithuania (1999), S. 1, und Bank of Lithuania (2000), S. 40.

137 Siehe Orlowski (1998), S. 59. 
Grunde kaum eine Änderung. ${ }^{138}$ Lettland hingegen würde sich durch die Teilnahme am EWS II mit „normalen“ Bandbreiten nicht nur an den Euro anstatt an das Sonderziehungsrecht binden, sondern gleichzeitig einen erheblich höheren Grad an Wechselkursflexibilität erreichen, weil das gegenwärtige Wechselkursband um die Parität zum Sonderziehungsrecht sehr viel enger ist. Dabei ist allerdings $z u$ beachten, daß das EWS II auch die Vereinbarung einer geringeren Schwankungsbreite zwischen der EZB und der lettischen Notenbank zuläßt.

Für alle bisher genannten Länder wäre eine Mitgliedschaft im EWS II ohne einen radikalen Politikwechsel möglich. Solange die Länder am EWS II mit einer weiten Bandbreite von \pm 15 v.H. teilnehmen, ist die Teilnahme bis zu einem gewissen Grad mit einer eigenständigen Geldpolitik vereinbar, d.h. die Länder können zum Beispiel ein Inflation Targeting oder eine Geldmengenstrategie betreiben. Die eigenständige Formulierung von geldpolitischen Zielen würde jedoch mit den vom Wechselkurssystem auferlegten Erfordernissen in Konflikt geraten, wenn sich die Beitrittsländer in ihren geldpolitischen Zielsetzungen nicht prinzipiell an der Geldpolitik der EZB orientierten. Eine Bindung der nationalen Währungen an den Euro erfordert, daß die Inflationsraten in etwa auf das im Euro-Währungsraum herrschende Niveau reduziert werden. Anderenfalls käme es zu realen Aufwertungen, die nicht unbegrenzt durchzuhalten wären und schließlich eine Anpassung der Parität - d.h. eine nominale Abwertung - erforderlich machen würden. ${ }^{139}$ Dies gilt insbesondere dann, wenn ein enges Wechselkursband gewählt wird. Bei einer engen Bandbreite schränkt das Ziel der Aufrechterhaltung der Parität die geldpolitischen Möglichkeiten stark ein, und es bleibt kein Spielraum für eine eigenständige Geldpolitik.

Schwieriger ist die Entscheidung über eine Teilnahme am EWS II für die Länder, die zur Zeit ein Currency Board unterhalten. Die Tatsache, daß es sich beim EWS II nur um ein vorübergehendes System handelt, weil das Ziel schließlich die Übernahme des Euro als Landeswährung ist, macht die Entscheidung besonders kompliziert. ${ }^{140}$ Sollen die Länder für eine gewisse Zeit aus der festen Bindung aussteigen, um über den Umweg des EWS II zu einer unwiderruflichen Fixierung zurückzukehren? Nachdem Estland signalisiert hatte, daß es plant, direkt vom Currency Board in die Währungsunion überzugehen, wurde diese Möglichkeit auch innerhalb der EZB diskutiert. Dabei scheint sich her-

138 Eine Verånderung besteht darin, daß die Teilnahme am EWS II auch die EZB zu Interventionen bei Erreichen des oberen oder unteren Interventionspunktes verpflichtet, es sich also nicht mehr um eine reine einseitige Bindung handelt. Gleichzeitig geht aber auch die Initiative für eine Änderung der Parităt dann nicht mehr nur von der ungarischen Notenbank aus.

139 Vgl. Orlowski (1998), S. 76.

140 Siehe Masson (1999), S. 11. 
auszukristallisieren, daß von den Ländern keine Aufgabe des Currency Boards gefordert wird, sondern lediglich Konsultationen zwischen der EZB und den nationalen Instanzen erfolgen müssen, die den Charakter einer gemeinsamen Festlegung der Parität zum Euro unterstreichen. ${ }^{141}$ Die Länder werden voraussichtlich unter Beibehaltung des Currency Boards am EWS II teilnehmen können, indem sie einseitig die Aufrechterhaltung der Parität in einem sehr engen Band garantieren.

Für Bulgarien und Estland stellt sich in diesem Zusammenhang die Frage, ob die derzeitige Wechselkursrelation zum Euro das angemessene Verhältnis für die unwiderrufliche Fixierung gegenüber dem Euro bei einer späteren Teilnahme an der Währungsunion darstellt. Die litauischen Behörden sind hingegen mit dem Problem konfrontiert, zunächst einen Wechsel der Reservewährung vornehmen zu müssen. Unabhängig davon, ob der Übergang von der US-Dollarzur Euro-Bindung mit einem Ausstieg aus dem Currency Board System verbunden wird oder lediglich der Euro den US-Dollar als Reservewährung im Currency Board ablöst, stellt diese Änderung hohe Anforderungen an die litauischen Behörden. Die geplanten Schritte müssen umfassend begründet und rechtzeitig angekündigt werden, um ein hohes $\mathrm{Ma} ß$ an Transparenz zu gewährleisten. Ob der Übergang spannungsfrei vollzogen werden kann, wird vor allem von der Kursentwicklung des Euro gegenüber dem US-Dollar abhängen, weil diese einen entscheidenden Einfluß darauf hat, ob Litauen aus einer starken oder schwachen Position heraus den Wechsel vollzieht.

Für alle drei Länder mit Currency Board Regelungen kommt es neben der Beurteilung, ob die derzeitige Wechselkursrelation angemessen ist, auch darauf an, daß eine hinreichende Flexibilität in anderen Bereichen gewährleistet ist. Dies gilt einerseits für die Fiskalpolitik und andererseits in besonderem Maße für Preise und Löhne. ${ }^{142}$ Auch an den Bankensektor stellt die Strategie des direkten Übergangs vom Currency Board in die EWU besondere Anforderungen, auf die später noch detaillierter eingegangen wird.

Im Zusammenhang mit der Wechselkurspolitik nach der Aufnahme in die EU ist zu beachten, daß eine Voraussetzung für den EU-Beitritt die vollständige Liberalisierung des Kapitalverkehrs ist. Nach Artikel 56 des EU-Vertrags sind nicht nur Beschränkungen zwischen EU-Mitgliedstaaten verboten, sondern auch zwischen Mitgliedstaaten und Drittländern. Falls die EU-Beitrittskandidaten also keine Übergangsbestimmungen im Vorfeld des Beitritts aushandeln, müssen die Kapitalmärkte zum Zeitpunkt des EU-Beitritts vollständig liberalisiert

141 Siehe Europäische Zentralbank (2000b).

142 Vgl. Corker et al. (2000), S. 19 f., die diese Voraussetzungen im Falle Estlands als erfullt ansehen. 
sein. Auch wenn bereits in vielen Ländern ein großer Teil der Kapitalverkehrsbeschränkungen aufgehoben wurde, ${ }^{143}$ sind die Märkte bisher noch nicht vollständig liberalisiert. Die vollkommene Liberalisierung wird deshalb erhöhte Kapitalbewegungen auslösen. Alle zehn betrachteten Länder haben schon in den vergangenen Jahren umfangreiche Kapitalzuflüsse verzeichnet; und es ist damit zu rechnen, daß die Kapitalzuflüsse sowohl im Vorfeld des EU-Beitritts als auch in dessen Folge weiter zunehmen. Niedrige Lohnkosten, relativ gut ausgebildete Arbeitskräfte und die Teilnahme am gemeinsamen Markt machen die Staaten Mittel- und Osteuropas als Investitionsstandort attraktiv. ${ }^{144}$ Aber es wird nicht nur zu vermehrtem Import langfristigen Kapitals kommen, sondern das im Vergleich zur Europäischen Union höhere Zinsniveau in den Ländern wird auch in starkem Maße kurzfristiges Kapital anziehen. Kurzfristige Kapitalströme sind jedoch durch eine hohe Volatilität gekennzeichnet. Es besteht deshalb die Gefahr, daß es zum Beispiel aufgrund veränderter Risikoeinschätzungen internationaler Investoren auch zu Kapitalabflüssen kommt.

Im Hinblick auf die zu erwartenden, stark ansteigenden Kapitalbewegungen erscheint es daher ratsam, daß die Länder erst einige Erfahrungen mit dem vollkommen freien Kapitalverkehr in ihrer neuen Rolle als EU-Mitgliedstaaten sammeln, bevor sie sich im Rahmen des EWS II an den Euro binden. Dies gilt insbesondere dann, wenn die vollständige Liberalisierung des Kapitalverkehrs erst kurze Zeit vor dem tatsächlichen Beitritt erfolgt. In diesem Fall sollte eine frühe Bindung an den Euro im Rahmen des EWS II vermieden werden, weil noch große Unsicherheiten bestehen, auf welchem Niveau sich der Wechselkurs in dem veränderten Umfeld einpendeln wird.

Die vollständige Liberalisierung des internationalen Kapitalverkehrs erfordert außerdem, daß auch der inländische Kapitalmarkt liberalisiert wird und die Länder wirksame Finanzmarktregulierungen und Bankenaufsichten etablieren. Zur Zeit weist der Finanzsektor in den meisten Transformationsländern noch Schwächen auf, zum Beispiel in Form unzureichenden Wettbewerbs zwischen den Banken oder eines hohen Anteils notleidender Kredite. ${ }^{145}$ Ein funktionierender Bankenwettbewerb ist jedoch erforderlich, damit sich geldpolitische Änderungen auf das Zinsniveau auswirken. Führt eine restriktive Geldpolitik beispielsweise nicht zu einer Erhöhung der Kreditzinsen, wird der Transmissionsmechanismus der Geldpolitik beeinträchtigt.

143 Für eine Kurzdarstellung der bisherigen Liberalisierung des Kapitalverkehrs in Mittel- und Osteuropa siehe Köhler/Wes (1999), S. 305 und S. 315.

144 Vgl. Corker et al. (2000), S. 13.

145 Vgl. Köhler/Wes (1999), S. 298 f., und Kopits (1999), S. 16. 
Für die Länder mit einem Currency Board System stellt die Einführung indirekter geldpolitischer Instrumente ein besonderes Problem dar. Die Geldpolitik ist in diesen Ländern durch die strenge Ausrichtung am Wechselkursziel geprägt. Eine Teilnahme an der EWU setzt aber voraus, daß der geldpolitische Transmissionsmechanismus der EZB auch in diesen Ländern funktioniert, d.h. es müssen zum Beispiel entwickelte Geldmärkte und Wertpapiere für die Refinanzierungsgeschäfte mit der EZB existieren. ${ }^{146}$ Aus diesem Grund muß die Übergangsphase bis zum Beitritt zur EWU - auch wenn das Land beabsichtigt, bis zur Teilnahme an der Währungsunion das Currency Board System beizubehalten - insbesondere für institutionelle Reformen genutzt werden, um sicherzustellen, daß im Finanzsektor die technischen und institutionellen Voraussetzungen für eine Teilnahme an der Währungsunion geschaffen werden. Aber auch in den Ländern mit flexibleren Wechselkursregelungen sind noch umfassende Reformen im Finanzsektor erforderlich, damit im Zuge der angestrebten Mitgliedschaft in der EWU eine Integration in den gesamteuropäischen Geldmarkt und die bestehenden europäischen Zahlungssysteme vollzogen werden kann.

Bei der Frage, wann eine Mitgliedschaft im EWS II angestrebt werden sollte, ist schließlich noch zu berücksichtigen, daß der Transformationsprozeß aller Voraussicht nach auch zum Zeitpunkt des EU-Beitritts der Länder noch nicht abgeschlossen sein wird. Wie erwähnt, erfordern die Konvergenzkriterien, daß die Länder zwei Jahre ohne Abwertung am europäischen Wechselkursmechanismus teilgenommen haben und bestimmte fiskalische und monetäre Kriterien einhalten. Die Probleme, die mit einem EU-Beitritt und einer eventuellen Teilnahme am EWS II verbunden sind, gehen jedoch weit über die Fragen fiskalischer und monetärer Konvergenz hinaus. Für die Beitrittsstaaten ist die „reale“ Konvergenz ein ebenso wichtiger Aspekt, wobei mit realer Konvergenz in einem sehr weiten Sinn die Anpassung der mittel- und osteuropäischen Wirtschaftsstrukturen an die Verhältnisse in der EU beschrieben wird. ${ }^{147}$ Im folgenden soll der Begriff als die Fortsetzung des Transformationsprozesses interpretiert werden, durch den ein Aufholen in bezug auf die Produktivität und das Pro-KopfEinkommen ermöglicht wird. $\mathrm{Daß}$ die Annäherung dieser Größen an den EUDurchschnitt nicht als eine Bedingung in die Maastricht-Kriterien Eingang gefunden hat, ist verständlich, weil diese Kriterien ursprünglich für eine Ländergruppe formuliert wurden, die bereits ein relativ hohes Maß an Konvergenz im

146 So gibt es z.B. in Estland keine Staatsanleihen und auch die estnische Zentralbank hat bisher kaum Wertpapiere emittiert. Siehe Gulde et al. (2000), S. 20.

147 Siehe Europaische Zentralbank (2000a), S. 43 ff. und S. 51, Zeitler (2000), S. 10 f., sowie Janácková (1998), S. 80. Die beiden zuerst genannten Quellen definieren den Begriff sehr weit und erfassen mit ihm z.B. auch den Stand der Liberalisierung des Kapitalverkehrs und die Bedeutung der Landwirtschaft. 
Hinblick auf Produktivität und Lebensstandard aufwies. Zwar bestanden auch zwischen den EU-Mitgliedsländern deutliche Unterschiede, insbesondere zwischen den sogenannten Kernländern und den südeuropäischen Staaten, aber der Beitritt der mittel- und osteuropäischen Transformationsländer wird $\mathrm{zu}$ einer völlig neuen Spannweite unterschiedlicher Einkommensniveaus innerhalb der EU führen. ${ }^{148}$

Im November 1999 organisierten die EZB und die finnische Nationalbank in Helsinki ein Seminar, auf dem Vertreter des Europäischen Systems der Zentralbanken mit hochrangigen Zentralbankbeamten aus den beitrittswilligen Staaten zusammentrafen. Eine Schlußfolgerung dieser Tagung war, daß reale und nominale Konvergenz gleichzeitig verfolgt werden sollten und eine Erfüllung der Maastricht-Kriterien mit erforderlichen Strukturreformen in den Beitrittsländern vereinbar sei. ${ }^{149}$ Demnach hindere eine erfolgreiche Fortsetzung des Transformationsprozesses die mittel- und osteuropäischen Staaten nicht an der Erfüllung der Konvergenzkriterien. Aus der theoretischen Analyse im Kapitel III ergibt sich jedoch, daß der wirtschaftliche Reformprozeß unter Umständen mit den nominalen Zielen Wechselkursstabilität und Preisstabilität in Konflikt geraten kann.

Das Partialmodell zeigt, daß der Reformprozeß mit gesamtwirtschaftlichen Preissteigerungen einhergeht, solange noch eine Anpassung administrativ festgelegter Preise erfolgt. Eine vollkommene Preisliberalisierung ist aber eine Voraussetzung für den vollständigen Übergang zur marktwirtschaftlichen Organisation des Wirtschaftslebens und deshalb ein wichtiger Beitrag zur Vollendung der Transformation. Bis der Preisanpassungsproze $ß$ abgeschlossen ist, kommt es im Zuge der Deregulierung zu einer realen Aufwertung der Währung. 150 Wenn die Reformländer eine zügige Preisliberalisierung betreiben,

$148 \mathrm{Zu}$ den Einkommensniveaus der EU-Mitgliedsländer im Vergleich zum EU-Durchschnitt vor dem Beginn der Europäischen Wăhrungsunion siehe Jarchow (1998b), S. 11. Fur die Niveaus der mittel- und osteuropalischen Staaten im Vergleich zum Euro-Wăhrungsraum siehe Europäische Zentralbank (2000a), S. 42.

149 Vgl. Europăische Zentralbank (2000a), S. 51.

150 Das gleiche Ergebnis stellt sich ein, wenn nicht mit der Anpassung staatlich regulierter Preise, sondern mit unterschiedlichen Produktivitătsentwicklungen im nationalen und internationalen Sektor der Reformländer argumentiert wird. Produktivitătssteigerungen im Sektor der handelbaren Guter fuhren zu höheren Lohnsteigerungen, und zwar durch Arbeitskrăftemobilităt auch im nationalen Sektor, in dem die Produktivităt nicht so stark zunimmt. Dadurch steigen die Preise der nicht-handelbaren Güter stärker als die Preise der handelbaren Guter, und es kommt zu einer realen Aufwertung. Vgl. Kopits (1999), S. 13 f. Es handelt sich bei diesem Zusammenhang um den sogenannten Balassa-SamuelsonEffekt. Siehe Rosati (1997), S. 491. Dieses Phănomen wird vermutlich selbst dann noch zu beobachten sein, wenn die Preisliberalisierung abgeschlossen ist, so daß die nachfolgende Argumentation fur einen relativ langen Zeitraum relevant sein dürfte. 
werden die Inflationsraten deutlich über den Preissteigerungsraten im EuroWährungsraum liegen, so daß in dieser Zeit das Preiskriterium nicht erfüllt wird. Streben die Länder hingegen zu früh, d.h. vor einer weitreichenden Preisliberalisierung, die Erfüllung der Maastricht-Kriterien an, ist es zwar möglich, daß sich die Preissteigerungsraten annähern und die Länder für einen gewissen Zeitraum die Maastricht-Kriterien einhalten. Dieses spiegelt dann aber keine dauerhafte Konvergenz wider, sondern ist lediglich das Resultat einer aufgeschobenen Deregulierung.

Wie ebenfalls anhand des Partialmodells gezeigt wurde, kommt es für die Wechselkurspolitik darauf an, ob der Aufrechterhaltung außen- oder binnenwirtschaftlicher Ziele eine höhere Priorität eingeräumt wird. Wenn das Ziel der Preisstabilität im Vordergrund steht, kann entweder eine nominale Aufwertung oder eine glaubwürdige Wechselkursbindung den Preisanstieg abmildern. Je stärker die Preise der nicht-handelbaren Güter ansteigen, um so wahrscheinlicher ist es, daß auf die Aufwertungsvariante zurückgegriffen werden muß, wenn ein zu starkes Abweichen der inländischen Preissteigerungsrate vom EUNiveau verhindert werden soll. Beide Strategien führen aber zu einer realen Aufwertung, die die Gefahr der Entstehung externer Ungleichgewichte beinhaltet. Wird hingegen größeres Gewicht auf die außenwirtschaftliche Situation gelegt, kann die reale Aufwertung durch eine nominale Abwertung abgeschwächt werden. In diesem Fall steigt allerdings das gesamtwirtschaftliche Preisniveau stärker an, so daß das Preiskriterium verletzt wird.

Solange die mittel- und osteuropäischen Staaten sich noch im Aufholprozeß befinden und dabei in hohem Umfang Kapitalimporte anziehen, besteht bei festen Wechselkursen aufgrund einer frühen EWS II-Teilnahme noch ein weiteres Problem. Wie die Erfahrungen einiger EU-Beitrittskandidaten in den zurückliegenden Jahren zeigen, ist damit zu rechnen, daß das Devisenangebot aufgrund der Kapitalzuflüsse die Devisennachfrage aufgrund der Leistungsbilanzdefizite in den Ländern übersteigt, so daß es zu einer nominalen Aufwertungstendenz kommt. ${ }^{151}$ Bei einer Wechselkursbindung erfordert dies Devisenmarktinterventionen, die aber über eine Ausweitung der monetären Basis längerfristig zu einer Erhöhung der Geldmenge führen. Die so induzierte Geldmengenexpansion bewirkt über sinkende Zinsen zwar unter Umständen eine Abschwächung des Kapitalzustroms, sie führt allerdings zu steigenden Preisen, so daß auch aus diesem Grund das Preiskriterium verfehlt werden kann und eine Konvergenz der Preissteigerungsraten des Beitrittslandes zu den EWU-Staaten verhindert wird.

151 Vgl. hierzu exemplarisch die Ausfuhrungen zu den Erfahrungen Tschechiens und der Slowakei in den Jahren 1999 und 2000 im Unterabschnitt 3.2.6. sowie die Quellenangaben in der Fußnote 110. 
Zusammenfassend läßt sich folgendes feststellen: Bis der Prozeß der Deregulierung abgeschlossen ist, sind in Mittel- und Osteuropa noch Inflationsraten zu erwarten, die über dem Niveau im Euro-Währungsraum liegen. Um die Preisauftriebstendenzen zu dämpfen, steht den wirtschaftspolitischen Instanzen entweder eine nominale Aufwertung oder eine glaubwürdige Wechselkursbindung als wechselkurspolitische Alternative zur Verfügung, die beide zu einer stärkeren realen Aufwertung führen. ${ }^{152}$ Bei festen Wechselkursen bewirken die zu erwartenden Kapitalzuflüsse außerdem einen Anstieg des inländischen Preisniveaus, der das Ziel, den Preisauftrieb einzudämmen, konterkariert. Eine reale Konvergenz - verstanden als die Fortsetzung des Transformationsprozesses, der im Modell durch die Preisderegulierung abgebildet wird - ist deshalb nur mit einer Konvergenz der Preisentwicklungen in den mittel- und osteuropäischen Staaten und im Euro-Währungsraum vereinbar, wenn nominale Aufwertungen stattfinden. Inwieweit dies eine realistische Option ist, hängt davon ab, welches Gewicht die Länder auf die außenwirtschaftliche Zielkomponente legen. Die Ausführungen im Unterabschnitt III.3.4. deuten darauf hin, daß diese Komponente ein nicht zu vernachlässigendes Gewicht in der Zielfunktion der wirtschaftspolitischen Entscheidungsträger hat. Insofern ist eher mit nominalen Abwertungen und einer Verzögerung bei der Angleichung der Inflationsraten zu rechnen. In beiden Fällen besteht noch nominaler Wechselkursanpassungsbedarf, solange der Aufholprozeß in den EU-Beitrittsländern nicht abgeschlossen ist.

Auf die Frage, wann für die Länder der beste Zeitpunkt erreicht sein wird, um dem EWS II beizutreten, kann es keine pauschale Antwort geben. Es kommt auf die speziellen Gegebenheiten in den Ländern und dabei vor allem auf die bis zur Teilnahme verfolgte wechselkurspolitische Strategie an. Nach den Erfolgen bei der Stabilisierung der Volkswirtschaften werden in den nächsten Jahren verstärkt die Argumente aus der Diskussion um optimale Währungsräume in der Wechselkurspolitik zu berücksichtigen sein. Es erscheint daher einsichtig, daß die baltischen Staaten mit ihren kleinen, sehr offenen Volkswirtschaften an ihren festen Wechselkursregelungen festhalten wollen, während größere Länder, wie zum Beispiel Polen, zu flexibleren Wechselkurssystemen übergehen. Wie wichtig eine differenzierte Betrachtungsweise ist, zeigt sich unter anderem aber auch daran, daß Slowenien als ebenfalls sehr kleine und offene Volkswirtschaft nach wie vor am flexiblen Wechselkurssystem festhält. Wann die Länder dem Wechselkursmechanismus beitreten sollten, ist insbesondere davon abhängig, wie weit die Länder zum Zeitpunkt der geplanten EWS II-Teilnahme mit der

152 Die stärkere Verfehlung der außenwirtschaftlichen Zielsetzung kőnnte durch eine nominale Abwertung im Rahmen flexibler Wechselkurse abgeschwăcht werden. Diese wirkt aber zusătzlich preissteigernd, so daß in diesem Fall sowohl das Wechselkurskriterium als auch das Preiskriterium verfehlt werden. 
Transformation vorangeschritten sind, da der Reformprozeß noch mit erheblichen realen Wechselkursänderungen verbunden ist. Wenn in den betrachteten Ländern nicht sehr große Preis- und Lohnflexibilitäten herrschen, ist anzunehmen, daß die erforderlichen Anpassungsprozesse bei nominaler Wechselkursflexibilität leichter vollzogen werden können.

Als generelles Ergebnis der Überlegungen ist festzuhalten, daß sich die Länder schon frühzeitig, d.h. bereits vor der angestrebten EU-Mitgliedschaft, auf die künftigen Herausforderungen einstellen und die entsprechenden Vorbereitungen treffen sollten. Dies gilt nicht nur für die angestrebten Wechselkursregelungen, sondern vor allem auch für die Reformen im Finanzsektor und die Liberalisierung des Kapitalverkehrs. 
Axel Gerloff - 978-3-631-75700-0

Downloaded from PubFactory at 01/11/2019 02:46:37AM

via free access 


\section{Schlußbetrachtung}

Die Ausgangslage der Transformationsländer und der daraus abgeleitete Reformbedarf bildeten die Grundlage für die Analyse der vorliegenden Arbeit. Als Ergebnis des zweiten Kapitels ergab sich, daß die Stabilisierungsbemühungen in den ersten Jahren der Transformation von herausragender Bedeutung waren und daß die Reduzierung der extrem hohen Inflationsraten mit der Zeit eine wirtschaftliche Erholung erwarten ließ, weil sie eine Voraussetzung für die Entstehung marktwirtschaftlicher Koordinationsmechanismen darstellte. Diese Vermutung konnte durch die Auswertung der Erfahrungen in den zehn mittel- und osteuropäischen EUBeitrittskandidaten bestätigt werden. Es ist in den Ländern ein positiver Zusammenhang zwischen der Stabilisierung des Preisniveaus und dem Wirtschaftswachstum zu beobachten. Bei der Rückführung der hohen Inflationsraten verzeichneten die erfolgreich stabilisierenden Länder etwa zwei bis drei Jahre nach dem größten Preisschock wieder positive Wachstumsraten. Sie kehrten eher auf einen nachhaltigen Wachstumspfad zurück als jene Länder, die nur zögerlich Reformen umsetzten und die Inflation nicht deutlich reduzierten.

Das zentrale Anliegen bestand darin, die Rolle der Wechselkurspolitik für die Stabilisierungserfolge unter Verwendung modelltheoretischer Ansätze zu analysieren. Im dritten Kapitel wurde deshalb anhand von zwei Modellrahmen untersucht, welche Erkenntnisse sich aus der Theorie ableiten lassen. Es stellte sich heraus, daß das zuerst betrachtete und in der Literatur häufig verwendete DependentEconomy-Modell auf einige Probleme einer Wechselkursfixierung hinweist. Vor allem der Konflikt zwischen dem Einsatz des Wechselkurses als nominaler Anker in Stabilisierungsprogrammen und der Aufrechterhaltung des außenwirtschaftlichen Gleichgewichts wird betont. Des weiteren veranschaulicht das Modell, daß die Wechselkurspolitik von einer konsistenten makroökonomischen Politik unterstützt werden muß und daß der Erfolg eines Stabilisierungsprogramms letztlich davon abhängt, ob es zur erforderlichen Anpassung der Preise im nationalen Sektor kommt. Allerdings werden in dem Modell Preiszusammenhänge nicht explizit formuliert, so daß es nur bedingt für die Analyse der Wechselkurspolitik in Stabilisierungsprogrammen geeignet ist.

Das anschließend vorgestellte Partialmodell legt dagegen den Schwerpunkt auf die Modellierung von Preisentwicklungen in der Volkswirtschaft und berücksichtigt mit der Deregulierung staatlich festgelegter Preise ein Kernelement des Transformationsprozesses. Die Formulierung einer Zielfunktion, die einerseits das Preisstabilitätsziel und andererseits die Konstanz des realen Wechselkurses beinhaltet, berücksichtigt den Einfluß des Wechselkurses auf das binnen- und außenwirtschaftliche Gleichgewicht. Aus diesem Modellrahmen lassen sich wichtige Ergeb- 
nisse für Entscheidungen über den Einsatz eines festen Wechselkurses in Stabilisierungsprogrammen, die Wahl des Wechselkurssystems in Abhängigkeit vom Offenheitsgrad der Volkswirtschaft und die Glaubwürdigkeit einer Wechselkursbindung ableiten.

Das zentrale Ergebnis der Modellanalyse ist, daß bei sehr starker Präferenz für Preisstabilität ein fester Wechselkurs als nominaler Anker nicht optimal ist. Wenn die Zentralbank primär die Sicherung der inländischen Preisstabilität verfolgt, ist ein flexibles Wechselkurssystem optimal, in dem die Politik der Zentralbank darauf ausgerichtet ist, die Währung nominal aufzuwerten. Dies bewirkt einen geringeren Anstieg der Preise im nationalen und internationalen Sektor der Volkswirtschaft als bei einer Wechselkursbindung. Dieses Ergebnis ist ein in der Literatur häufig nicht ausreichend berücksichtigter Aspekt bei der Bewertung eines festen Wechselkurses als Instrument eines Stabilisierungsprogramms. Viele Autoren unterstellen die Optimalität einer Wechselkursbindung, wenn das vorrangige Ziel der wirtschaftspolitischen Entscheidungsträger Preisstabilität ist. Tatsächlich macht die Modellauswertung aber deutlich, daß eine genauere Differenzierung erforderlich ist. Ein flexibler Wechselkurs erweist sich als vorteilhaft, wenn das Preisstabilitätsziel nur relativ schwach gewichtet ist (Strategie: nominale Abwertung) und wenn das Ziel der Preisstabilität sehr stark gewichtet ist (Strategie: nominale Aufwertung). Dazwischen gibt es einen Bereich, in dem ein fester Wechselkurs die bevorzugte Alternative ist, weil die wirtschaftspolitischen Entscheidungsträger keiner der beiden Komponenten der Zielfunktion im Vergleich zur anderen eine sehr viel höhere Bedeutung beimessen. Im Zusammenhang mit einer Wechselkursbindung kann also nur bedingt von einem „Import von Preisstabilität“" gesprochen werden, weil Preisstabilität eher über eine nominale Aufwertung erreicht wird.

Der konkrete Bereich, in dem ein fester Wechselkurs optimal ist, hängt von der Situation in dem betrachteten Land ab. Neben den Präferenzen der Wirtschaftspolitiker kommt es insbesondere auf den Offenheitsgrad der Volkswirtschaft an. In Übereinstimmung mit den Ergebnissen aus der Diskussion um optimale Währungsräume ergibt sich, daß ein fester Wechselkurs unter sonst gleichen Bedingungen um so eher für ein Land zu empfehlen ist, je offener die betrachtete Volkswirtschaft ist. Die ökonomische Begründung liegt darin, daß sich Wechselkursänderungen in einer offenen Wirtschaft über einen höheren Anteil internationaler Güter am Warenkorb des gesamtwirtschaftlichen Preisindexes entsprechend stark auf die Preisentwicklung im Inland auswirken. Wird der Wechselkurs fixiert, dann stabilisiert er in einer offeneren Volkswirtschaft einen größeren Teil der Preise unmittelbar und wirkt sich damit vorteilhaft auf die gesamtwirtschaftliche Preisentwicklung aus. 
Auch im Hinblick auf die Glaubwürdigkeit einer Wechselkursbindung liefert die Modellauswertung wichtige Ergebnisse. Es besteht für die Zentralbank in der Regel ein Anreiz, die Wechselkursbindung aufzugeben, nachdem die Wirtschaftssubjekte ihre Inflationserwartungen nach unten angepaßt haben. Es handelt sich hierbei um ein Ergebnis, das in der Literatur häufig betont und insbesondere von Kritikern einer Wechselkursfixierung gegen das Argument vorgebracht wird, eine Wechselkursbindung bewirke eine Disziplinierung der Wirtschaftspolitiker. Die Analyse bestätigt die Ansicht, daß eine einseitige Wechselkursbindung in den Transformationsländern wie auch in anderen Ländern nicht glaubwürdig ist, weil die Zentralbank jederzeit von der angekündigten Strategie abweichen kann. In diesem Zusammenhang ist die Unterscheidung zwischen einer Selbstbindung und einer Regelbindung von außerordentlicher Bedeutung. ${ }^{1}$ Bei der Analyse von Festkurssystemen muß danach differenziert werden, ob es sich um eine einseitige Wechselkursbindung (Selbstbindung) oder um eine externe Regelbindung handelt, die nicht oder zumindest nur schwer seitens der inländischen Behörden aufgegeben werden kann (wie z.B. bei einem Currency Board oder einer Währungsunion). Nur eine externe Regelbindung kann eine glaubwürdige Wechselkursfixierung gewährleisten.

Darüber hinaus zeigt das Modell aber ein besonderes Problem von Stabilisierungsprogrammen mit festem Wechselkurs auf. Ein Festkurssystem wird nur dann gewählt, wenn das Preisstabilitätsziel und die außenwirtschaftliche Komponente in der Zielfunktion beachtet werden. Hätte die außenwirtschaftliche Zielsetzung nur ein unbedeutendes Gewicht, wäre ein flexibles Wechselkurssystem optimal, in dem die Zentralbank eine nominale Aufwertung betriebe. Das heißt, die Notenbank signalisiert durch die Wechselkursbindung, daß sie nicht nur der Preisstabilität, sondern auch der Aufrechterhaltung außenwirtschaftlichen Gleichgewichts eine nicht zu vernachlässigende Bedeutung beimißt. Dies führt zu einem besonderen Glaubwürdigkeitsproblem, weil bei einem festen Wechselkurs gerade dasjenige Ziel stärker verfehlt wird, dessen Relevanz durch die Entscheidung für das Festkurssystem signalisiert wird. Da die Kosten einer kontinuierlichen realen Aufwertung im Zeitablauf ansteigen und die Vorteile des festen Wechselkurses irgendwann übersteigen werden, muß frühzeitig eine Strategie entwickelt werden, in welcher Form die Bindung gelockert oder aufgegeben werden soll, wenn es sich nicht um eine dauerhafte Regelung handelt, sondern der nominale Wechselkurs als ein Mittel zur Inflationsbekämpfung eingesetzt wird. Polen bietet in der betrachteten Region ein gutes Beispiel für einen schrittweisen, krisenfreien Übergang von einer Wechselkursfixierung zu flexiblen Wechselkursen.

1 In der angelsächsischen Terminologie entspricht dies einer Differenzierung zwischen fixed und pegged exchange rates. Siehe Schuler (1999), S. 99 f., und Willet/Al-Marhubi (1994), S. 804, zu dieser wichtigen Unterscheidung von Festkurssystemen fur die Disziplinierungswirkung. 
Im vierten Kapitel wurden die modelltheoretischen Ergebnisse den Entwicklungen in den zehn mittel- und osteuropäischen EU-Beitrittskandidaten gegenübergestellt. Es zeigte sich, daß in Übereinstimmung mit den Ergebnissen des Partialmodells unabhängig vom Wechselkursregime in allen Transformationsländern eine reale Aufwertung der Währung zu beobachten war. Zumindest tendenziell konnte auch das Modellergebnis bestätigt werden, daß die reale Aufwertung in flexiblen Wechselkurssystemen mit nominalen Abwertungen geringer ausfällt als bei einer Wechselkursbindung.

Nicht ganz so eindeutig waren die Resultate beim Vergleich der Preisentwicklungen bei unterschiedlichen Wechselkurssystemen. Hier prognostiziert das Modell, daß Länder mit einem Festkurssystem niedrigere Preissteigerungsraten aufweisen als Länder, die sich für flexible Wechselkurse entschieden, es sei denn, das Land mit flexiblem Wechselkurs wertet nominal auf. Im mittel- und osteuropäischen Transformationsproze $ß$ ist eine Vielzahl unterschiedlicher Wechselkurssysteme zum Einsatz gekommen. Zwar läßt sich als Gemeinsamkeit festhalten, daß die Mehrheit der zehn betrachteten Länder zumindest für einen vorübergehenden Zeitraum eine Wechselkursbindung gewählt hat. Auch haben diese Länder größere Fortschritte bei der Stabilisierung gemacht als zum Beispiel Bulgarien und Rumänien in ihren Phasen mit flexiblen Wechselkursen. Allerdings bildet Slowenien eine Ausnahme, weil es mit einem flexiblen Wechselkurssystem ähnlich erfolgreich war wie die Länder mit längeren Festkursperioden.

Die frühen Erfahrungen der baltischen Staaten belegen aber auf eindrucksvolle Weise die Modellergebnisse im Hinblick auf die Rolle einer nominalen Aufwertung bei der Preisstabilisierung. Estland entschied sich gleich zu Beginn des Reformprozesses für einen festen Wechselkurs, während Lettland und Litauen zunächst flexible Wechselkurssysteme hatten. In den beiden zuletzt genannten Ländern ist es 1993 zu nominalen Aufwertungen gekommen, die eine Reduzierung der Preissteigerungsraten ermöglichten, und zwar in Lettland mit stärkerer Senkung des nominalen Wechselkurses und entsprechend deutlicherer Disinflation als in Litauen. Lettland war mit flexiblen Wechselkursen also genauso wie Estland mit glaubwürdiger Fixierung der Währung in Form des Currency Boards erfolgreich bei der Inflationsbekämpfung.

Die Analyse zeigt, daß nicht ein bestimmtes Wechselkursregime einem anderen System immer eindeutig überlegen ist. Genauso wie es generell keine einheitliche Antwort auf die Frage gibt, ob ein festes oder flexibles Wechselkurssystem vorteilhafter ist, kann auch für die mittel- und osteuropäischen Transformationsländer keine eindeutige Aussage gemacht werden. Die theoretische Analyse deutet zwar darauf hin, daß ceteris paribus ein Festkurssystem um so eher gewählt wird, je offener eine Volkswirtschaft ist. Wie wichtig eine differenzierte Betrachtungswei- 
se ist, zeigt aber der Vergleich Estlands und Sloweniens, weil in diesen beiden kleinen, offenen Volkswirtschaften einerseits ein festes und andererseits ein flexibles Wechselkurssystem erfolgreich eingesetzt wurde.

Die Beobachtung, daß einige Länder Mittel- und Osteuropas ihre Währungen in Form eines Currency Boards gebunden haben, läßt sich modelltheoretisch damit begründen, daß mit einer weniger strikten Wechselkursbindung ein Täuschungsanreiz verbunden ist. Eine gesetzliche Verankerung der Wechselkursbindung durch ein Currency Board bietet demgegenüber eine Möglichkeit, die Glaubwürdigkeit der Festkursstrategie zu erhöhen. Allerdings muß bei der Interpretation beachtet werden, daß in der Region nicht nur Currency Boards, sondern sehr häufig feste, aber anpassungsfähige Wechselkurse gewählt wurden. Die modelltheoretische Analyse zeigt auf, daß dies kein Hinweis darauf ist, daß die Länder versuchten, ihren Stabilisierungsbemühungen durch eine Wechselkursbindung eine höhere Glaubwürdigkeit zu verleihen.

Offensichtlich stand bei der Entscheidung für einen festen Wechselkurs nicht die Frage der Glaubwürdigkeit im Vordergrund, sondern ein Aspekt, der im dritten Abschnitt des Kapitels II bei der Analyse des geld- und wechselkurspolitischen Entscheidungsbedarfs dargestellt wurde. Es erscheint plausibel, daß insbesondere die Unsicherheiten über die geldpolitischen Transmissionsmechanismen zu der Entscheidung für einen festen Wechselkurs beigetragen haben. In Polen ist zum Beispiel 1990 die Dauer der Wechselkursbindung nur für drei Monate garantiert worden, während für die tschechoslowakische Wechselkursbindung überhaupt keine Aussage darüber getroffen wurde, wie lange sie beibehalten werden sollte. ${ }^{2}$ Unter Berücksichtigung der Ergebnisse der theoretischen Analyse können deshalb die anfänglichen Wechselkursbindungen in Polen und der Tschechoslowakei nicht mit einer höheren Glaubwürdigkeit oder einer Disziplinierungswirkung begründet werden. Vielmehr dürfte der Aspekt der Unsicherheit in der frühen Transformationsphase eine besondere Rolle gespielt haben. ${ }^{3}$ Es liegt die Vermutung nahe, daß der feste Wechselkurs in der Phase tiefgreifender wirtschaftlicher Veränderungen und unsicherer geldpolitischer Zusammenhänge die überlegene geldpolitische Zwischenzielgröße ist. Zu dieser Vermutung paßt auch die Beobachtung, daß Slowenien bereits von Beginn der Reformen an eine Geldmengenstrategie verfolgt hat. Wie bei der Betrachtung der Ausgangssituationen in den zehn EUBeitrittskandidaten dargestellt, befand sich Slowenien im Vergleich zu den anderen neun Ländern in der günstigsten Ausgangslage, die voraussichtlich die Geldmengenstrategie schon zu einem frühen Zeitpunkt ermöglichte. Die Tatsache, daß die slowenische Zentralbank trotz der Geldmengenstrategie den Wechselkurs über

2 Vgl. Horvath/Jonas (1998), S. 10, und Wellisz (1997), S. 158.

3 Die große Bedeutung von Unsicherheiten im Transformationsprozeß wird auch von Ickes (1996), S. 304, betont. 
längere Zeiträume stabilisierte, deutet ebenfalls darauf hin, daß im Reformprozeß ein fester Wechselkurs eine wichtige Orientierungsgröße darstellen kann. ${ }^{4}$

Bei der Analyse weiterer Faktoren, die neben der Wechselkurspolitik zur Erklärung der Verläufe von Wirtschaftswachstum und Inflation herangezogen wurden, stellte sich heraus, daß die Ausgangsbedingungen am Transformationsbeginn, die Notenbankgesetzgebung und die Fiskalpolitik keinen eindeutigen Einfluß ausgeübt haben. Für die Strukturreformen, d.h. insbesondere die Liberalisierung der Wirtschaft, und die Geldpolitik konnten jedoch eindeutige Wirkungen festgestellt werden. Offensichtlich fördert eine Liberalisierungspolitik nicht nur generell den Übergang von der Plan- zur Marktwirtschaft, sondern wirkt sich auch positiv auf die Stabilisierung im Transformationsprozeß aus. Die Analyse der Geldpolitik hat gezeigt, daß eine weniger expansive Geldpolitik einen entscheidenden positiven Einfluß auf die Stabilisierung ausübt. Dies läßt die Schlußfolgerung zu, daß auch in den Transformationsländern die Inflation letztlich ein monetäres Phänomen ist.

Diese Beobachtung unterstreicht, daß Liberalisierungs- und Stabilisierungspolitik Hand in Hand gehen müssen, d.h. daß ein umfassender Reformansatz erforderlich ist. Dies ist die entscheidende Lehre, die sich aus der Untersuchung für diejenigen Länder ergibt, die noch nicht so große Fortschritte wie die erfolgreichsten mittelund osteuropäischen Transformationsländer erzielen konnten. So kann zum Beispiel auch eine Wechselkursbindung nicht erfolgreich sein, wenn sie nicht von einer sie unterstützenden Geldpolitik und umfassenden Strukturreformen begleitet wird.

In der Zukunft wird für die meisten Länder, die in dieser Arbeit betrachtet wurden, nicht mehr die Disinflation im Vordergrund stehen. Vielmehr gilt es, die bisher erzielten Erfolge langfristig zu sichern und durch die Fortsetzung der Strukturreformen eine Produktivitätssteigerung und Erhöhung des Lebensstandards, d.h. eine reale Konvergenz gegenüber der EU, zu erreichen. Bei dieser veränderten Zielsetzung wird auch die Wechselkurspolitik eine andere Aufgabe haben als in den frühen Jahren der Transformation. Wie im letzten Abschnitt des Kapitels IV ansatzweise diskutiert, besteht im weiteren Verlauf des Reformprozesses vermutlich noch erheblicher nominaler Wechselkursanpassungsbedarf, so daß eher flexible Wechselkurse angeraten erscheinen. Die Mehrheit der betrachteten mittel- und osteuropäischen Staaten dürfte inzwischen in der Lage sein, eine eigenständige Geldpolitik zu betreiben, die nicht auf den nominalen Wechselkurs als Zwischenzielgröße angewiesen ist. Allerdings bedeutet dies nicht, daß für alle Länder ein

4 Dieses Ergebnis zeigt einen entscheidenden Vorteil auf, der mit den in dieser Arbeit verwendeten Wachstums-Inflations-Diagrammen verbunden ist. Die gewăhlte graphische Darstellung erlaubt eine differenzierte Betrachtung einzelner Politikinstrumente und ist in der Lage, die Unterschiede zwischen den Ländern herauszuarbeiten. 
flexibler Wechselkurs das angemessene Wechselkurssystem ist. Bei hinreichend großer Flexibilität der Preis- und Lohnmechanismen kann zum Beispiel in den Ländern mit Currency Boards die Beibehaltung der gegenwärtigen Systeme die optimale Strategie sein. Die konkrete Entscheidung ist von der Situation in dem jeweiligen Land abhängig. Im Hinblick auf die Glaubwürdigkeitsproblematik gilt zwar, daß das EWS II eine externe Regel darstellt, die insofern grundsätzlich die Glaubwürdigkeit erhöhen kann; aber die relativ weite Bandbreite und die Möglichkeit von Realignments dürften dieses Argument deutlich abschwächen. Erst die im Anschluß an die EWS II-Übergangsphase erfolgende EWU-Teilnahme stellt eine externe Regelbindung dar, die aufgrund der Integration in den EuroWährungsraum die Glaubwürdigkeit einer Bindung an den Euro stark erhöht.

Der erfolgreiche Einsatz unterschiedlichster Wechselkurssysteme in Mittel- und Osteuropa - vom Currency Board über feste, aber anpassungsfähige Wechselkurse und Crawling Pegs bis hin zu flexiblen Wechselkursen - führt zu der Schlußfolgerung, daß die Stabilisierung im Transformationsprozeß bei unterschiedlichen Wechselkursregelungen gelingen kann und die Vorteilhaftigkeit eines bestimmten Systems von den speziellen Umständen im jeweiligen Reformland abhängt. Sowohl die theoretische Analyse als auch die Auswertung der Erfahrungen in den zehn EU-Beitrittskandidaten haben deutlich gemacht, wie wichtig eine differenzierte Betrachtungsweise ist. Insofern stellt die Arbeit ein Plädoyer dafür dar, Verallgemeinerungen zu vermeiden und jeweils anhand konkreter Einzelfälle zu prüfen, welche Wechselkurssysteme Bestandteil einer konsistenten Wirtschaftspolitik sein können. Auch wenn die Analyse auf einen gewissen Vorzug eines festen Wechselkurses als geldpolitische Steuerungsgröße in der Frühphase der Transformation hindeutet, wird vor generellen Aussagen gewarnt. Die Arbeit schließt deshalb mit einem Zitat von Barry Eichengreen, der zu Empfehlungen für ein bestimmtes Wechselkurssystem sehr anschaulich feststellt, daß ,the economist is no more convincing than the shoe salesman when he insists that one size fits all." 5

5 Eichengreen (1999), S. C3. 
Axel Gerloff - 978-3-631-75700-0

Downloaded from PubFactory at 01/11/2019 02:46:37AM

via free access 


\section{Anhang}

\section{Mathematischer Anhang}

Dieser Anhang enthält die ausführlichen Herleitungen zu den Ergebnissen des Abschnitts III.3. Die Auswertung des Modells in diesem Anhang ist umfassender als im Textteil, da die Berechnungen überwiegend für den allgemeinen Fall ohne bestimmte Annahmen über die wirtschaftspolitischen Zielgrößen erfolgt, d.h. es gilt $\hat{\pi}, \hat{w} \neq 0$. Durch das Nullsetzen der beiden Zielgrößen in den abgeleiteten Gleichungen erhält man die im Abschnitt III.3. präsentierten Ergebnisse. Ebenso wie im Hauptteil der Arbeit wird jedoch vereinfachend unterstellt, daß im Ausland Preisstabilität herrscht, so daß sich mit $\pi^{a}=0$ die Gleichung (3) zu $\pi_{T}=w$ vereinfacht. Unter dieser Annahme wird das Modell durch die Gleichungen (1), (2'), $\left(6^{\prime}\right)$ und $\left(7^{\prime}\right)$ beschrieben, die hier zur besseren Übersicht nochmals wiedergegeben sind:

(7) $\pi_{N}=\beta w+\gamma \pi_{a d m}$,

$$
0<\beta=\frac{1-\mu}{1-\delta \mu} \delta<1, \gamma=\frac{\lambda}{1-\delta \mu}>0
$$

(6) $\quad w^{r}=w-\pi_{N}$.

\subsection{Berechnungen für ein System mit Wechselkursfixie- rung}

Wenn die Zentralbank eine Festkurspolitik betreibt, gilt

(A1) $w_{f i x}=0$.

Einsetzen dieser Bedingung in ( (7') liefert

(A2) $\pi_{N \text { fix }}=\gamma \pi_{a d m}$.

Berücksichtigt man (A1) und (A2) in (2') und (6') ergibt sich für den gesamtwirtschaftlichen Preisanstieg 

(A3)
$\pi_{f i x}=\mu \gamma \pi_{a d m}$

und für die reale Wechselkursänderung

(A4) $w_{f i x}^{r}=-\gamma \pi_{a d m}$.

Verwendung von (A3) und (A4) in (1) liefert für den Verlust aus der wirtschaftspolitischen Zielfunktion

(A5) $K_{f i x}=\frac{1}{2}\left(\mu \gamma \pi_{a d m}-\hat{\pi}\right)^{2}+\frac{\alpha}{2}\left(\gamma \pi_{a d m}+\hat{w}^{r}\right)^{2}$.

\subsection{Berechnungen für ein System flexibler Wechselkurse}

Bei einem flexiblen Wechselkurssystem legt die Zentralbank die optimale nominale Wechselkursänderung fest, indem sie die wirtschaftspolitische Verlustfunktion bei gegebenem $\pi_{N}$ minimiert. Einsetzen von (2') und (6') in (1) liefert

$$
K=\frac{1}{2}\left[\mu \pi_{N}+(1-\mu) w-\hat{\pi}\right]^{2}+\frac{1}{2} \alpha\left(w-\pi_{N}-\hat{w}^{r}\right)^{2},
$$

woraus sich die Optimalitätsbedingung

$$
\frac{\partial K}{\partial w}=(1-\mu)\left[\mu \pi_{N}+(1-\mu) w-\hat{\pi}\right]+\alpha\left(w-\pi_{N}-\hat{w}^{r}\right)=0
$$

ergibt. ${ }^{1}$ Daraus folgt

$$
\left[\alpha+(1-\mu)^{2}\right] w=[\alpha-(1-\mu) \mu] \pi_{N}+(1-\mu) \hat{\pi}+\alpha \hat{w}^{r} \quad \text { bzw. }
$$

(A6) $\quad w=\frac{\alpha-(1-\mu) \mu}{\alpha+(1-\mu)^{2}} \pi_{N}+\frac{1-\mu}{\alpha+(1-\mu)^{2}} \hat{\pi}+\frac{\alpha}{\alpha+(1-\mu)^{2}} \hat{w}^{r}$.

Durch Einsetzen von (A6) in ( $\left.7^{\prime}\right)$ erhält man für die Inflationsrate der nichthandelbaren Güter

1 Die hinreichende Bedingung fur ein Minimum ist erfullt, denn es gilt

$$
\frac{\partial^{2} K}{\partial w^{2}}=(1-\mu)^{2}+\alpha>0 \text {. }
$$




$$
\begin{gathered}
\pi_{N}=\frac{\alpha \beta-(1-\mu) \mu \beta}{\alpha+(1-\mu)^{2}} \pi_{N}+\gamma \pi_{a d m}+\frac{(1-\mu) \beta}{\alpha+(1-\mu)^{2}} \hat{\pi}+\frac{\alpha \beta}{\alpha+(1-\mu)^{2}} \hat{w}^{r} \\
\Leftrightarrow \frac{\alpha(1-\beta)+(1-\mu)(1-\mu+\mu \beta)}{\alpha+(1-\mu)^{2}} \pi_{N}=\gamma \pi_{a d m}+\frac{(1-\mu) \beta}{\alpha+(1-\mu)^{2}} \hat{\pi}+\frac{\alpha \beta}{\alpha+(1-\mu)^{2}} \hat{w}^{r}
\end{gathered}
$$

bzw.

$$
\begin{aligned}
& \pi_{N \text { flex }}=\frac{\alpha+(1-\mu)^{2}}{\psi} \gamma \pi_{\text {adm }}+\frac{(1-\mu) \beta}{\psi} \hat{\pi}+\frac{\alpha \beta}{\psi} \hat{w}^{r} \\
& \text { mit } \psi=\alpha(1-\beta)+(1-\mu)(1-\mu+\mu \beta)>0 .
\end{aligned}
$$

Wird (A7) in (A6) berücksichtigt, ergibt sich als optimale Wechselkursänderungsrate

$$
\begin{aligned}
w_{\text {flex }} & =\frac{\alpha-(1-\mu) \mu}{\psi} \gamma \pi_{\text {adm }}+\left[\frac{\alpha-(1-\mu) \mu}{\alpha+(1-\mu)^{2}} \cdot \frac{(1-\mu) \beta}{\psi}+\frac{1-\mu}{\alpha+(1-\mu)^{2}}\right] \hat{\pi} \\
& +\left[\frac{\alpha-(1-\mu) \mu}{\alpha+(1-\mu)^{2}} \cdot \frac{\alpha \beta}{\psi}+\frac{\alpha}{\alpha+(1-\mu)^{2}}\right] \hat{w}^{r}
\end{aligned}
$$

$\Leftrightarrow \quad w_{\text {flex }}=\frac{\alpha-(1-\mu) \mu}{\psi} \gamma \pi_{a d m}+\frac{1-\mu}{\alpha+(1-\mu)^{2}} \cdot \frac{\alpha \beta-(1-\mu) \mu \beta+\psi}{\psi} \hat{\pi}$

$$
+\frac{\alpha}{\alpha+(1-\mu)^{2}} \cdot \frac{\alpha \beta-(1-\mu) \mu \beta+\psi}{\psi} \hat{w}^{r} \quad \text { bzw. }
$$

(A8) $w_{\text {flex }}=\frac{\alpha-(1-\mu) \mu}{\psi} \gamma \pi_{a d m}+\frac{1-\mu}{\psi} \hat{\pi}+\frac{\alpha}{\psi} \hat{w}^{r}$, denn $\alpha \beta-(1-\mu) \mu \beta+\psi=\alpha \beta-(1-\mu) \mu \beta+\alpha-\alpha \beta+(1-\mu)^{2}+(1-\mu) \mu \beta=\alpha+(1-\mu)^{2}$.

Einsetzen von (A7) und (A8) in (2') liefert für die gesamtwirtschaftliche Inflationsrate 


$$
\begin{aligned}
\pi_{\text {flex }}= & {\left[\mu \frac{\alpha+(1-\mu)^{2}}{\psi}+(1-\mu) \frac{\alpha-(1-\mu) \mu}{\psi}\right] \gamma \pi_{a d m}+\left[\mu \frac{(1-\mu) \beta}{\psi}+\frac{(1-\mu)^{2}}{\psi}\right] \hat{\pi} } \\
& +\left[\mu \frac{\alpha \beta}{\psi}+\frac{\alpha(1-\mu)}{\psi}\right] \hat{w}^{r} \quad \text { bzw. }
\end{aligned}
$$

(A9) $\pi_{\text {flex }}=\frac{\alpha}{\psi} \gamma \pi_{\text {adm }}+\frac{(1-\mu)(1-\mu+\mu \beta)}{\psi} \hat{\pi}+\frac{\alpha(1-\mu+\mu \beta)}{\psi} \hat{w}^{r}$.

Die reale Wechselkursänderungsrate ergibt sich durch Einsetzen von (A7) und (A8) in (6') in Höhe von

$$
w_{\text {flex }}^{r}=\left[\frac{\alpha-(1-\mu) \mu}{\psi}-\frac{\alpha+(1-\mu)^{2}}{\psi}\right] \gamma \pi_{a d m}+\left[\frac{1-\mu}{\psi}-\frac{(1-\mu) \beta}{\psi}\right] \hat{\pi}+\left[\frac{\alpha}{\psi}-\frac{\alpha \beta}{\psi}\right] \hat{w}^{r}
$$

bzw.

(A10) $w_{\text {flex }}^{r}=-\frac{1-\mu}{\psi} \gamma \pi_{a d m}+\frac{(1-\mu)(1-\beta)}{\psi} \hat{\pi}+\frac{\alpha(1-\beta)}{\psi} \hat{w}^{r}$.

Einsetzen von (A9) und (A10) in Gleichung (1) liefert schließlich als Wert für die wirtschaftspolitische Verlustfunktion

$$
\begin{aligned}
K_{\text {flex }}= & \frac{1}{2}\left[\frac{\alpha}{\psi} \gamma \pi_{a d m}+\frac{(1-\mu)(1-\mu+\mu \beta)}{\psi} \hat{\pi}-\hat{\pi}+\frac{\alpha(1-\mu+\mu \beta)}{\psi} \hat{w}^{r}\right]^{2} \\
& +\frac{\alpha}{2}\left[-\frac{1-\mu}{\psi} \gamma \pi_{a d m}+\frac{(1-\mu)(1-\beta)}{\psi} \hat{\pi}+\frac{\alpha(1-\beta)}{\psi} \hat{w}^{r}-\hat{w}^{r}\right]^{2} \\
\Leftrightarrow \quad K_{\text {flex }}= & \frac{1}{2}\left[\frac{\alpha}{\psi} \gamma \pi_{a d m}-\frac{\alpha(1-\beta)}{\psi} \hat{\pi}+\frac{\alpha(1-\mu+\mu \beta)}{\psi} \hat{w}^{r}\right]^{2} \\
& +\frac{\alpha}{2}\left(-\frac{1-\mu}{\psi}\right)^{2}\left[\gamma \pi_{a d m}-(1-\beta) \hat{\pi}+(1-\mu+\mu \beta) \hat{w}^{r}\right]^{2} \quad \text { bzw. }
\end{aligned}
$$

(A11) $K_{\text {flex }}=\frac{\alpha}{2} \frac{\alpha+(1-\mu)^{2}}{\psi^{2}}\left[\gamma \pi_{a d m}-(1-\beta) \hat{\pi}+(1-\mu+\mu \beta) \hat{w}^{r}\right]^{2}$. 


\subsection{Vergleich des Festkurssystems mit dem System flexibler Wechselkurse}

Für den Vergleich der beiden Wechselkurssysteme wird angenommen, daß die Zentralbank Preisstabilität und einen konstanten realen Wechselkurs anstrebt, d.h. für die Auswertung gilt $\hat{\pi}=0$ und $\hat{w}^{r}=0$.

\subsubsection{Vergleich der Inflationsraten im Sektor der nicht-handelbaren Güter}

Für Aussagen über die Höhe der Inflationsraten im nationalen Sektor in Abhängigkeit vom Wechselkursregime werden die Gleichungen (A2) und (A7) miteinander verglichen:

(A2) $\pi_{N f i x}=\gamma \pi_{a d m}$.

Unter Berücksichtigung von $\hat{\pi}=0$ und $\hat{w}^{r}=0$ ergibt sich aus (A7)

(A7') $\pi_{N \text { flex }}=\frac{\alpha+(1-\mu)^{2}}{\psi} \gamma \pi_{a d m}$.

Aus (A2) und (A7') folgt, daß $\pi_{N \text { flex }} \underset{<}{\geqq} \pi_{N \text { fix }}$, wenn $\frac{\alpha+(1-\mu)^{2}}{\psi} \stackrel{\geqq}{\gtrless}$.

Unter Beachtung von $\psi=\alpha(1-\beta)+(1-\mu)(1-\mu+\mu \beta)$ läßt sich dieser Ausdruck umformen zu

$$
\begin{aligned}
& \alpha+(1-\mu)^{2} \stackrel{\geqq}{\gtrless} \alpha(1-\beta)+(1-\mu)(1-\mu+\mu \beta) \\
& \Leftrightarrow \quad \alpha \beta \underset{<}{\geqq}(1-\mu)(1-\mu+\mu \beta)-(1-\mu)^{2} \\
& \Leftrightarrow \quad \alpha \beta \underset{<}{\geqq}(1-\mu)(1-\mu+\mu \beta-1+\mu) \\
& \Leftrightarrow \quad \alpha \stackrel{\gtrless}{\geqq}(1-\mu) \mu .
\end{aligned}
$$

Es gilt also $\pi_{N \text { flex }} \geqq \pi_{N \text { fix }}$, wenn $\alpha \stackrel{\geqq}{\gtrless}(1-\mu) \mu$. 


\subsubsection{Vergleich der realen Wechselkursänderungsraten}

Für Aussagen über das Ausmaß der realen Wechselkursänderung in Abhängigkeit vom Wechselkursregime werden die Gleichungen (A4) und (A10) miteinander verglichen:

(A4) $w_{f i x}^{r}=-\gamma \pi_{a d m}$.

Unter Berücksichtigung von $\hat{\pi}=0$ und $\hat{w}^{r}=0$ ergibt sich aus (A10)

$\left(\mathrm{A} 10^{\prime}\right) w_{\text {flex }}^{r}=-\frac{1-\mu}{\psi} \gamma \pi_{a d m}$.

Aus (A4) und (A10') folgt, daß $\left|w_{f l e x}^{r}\right| \geqq\left|w_{f f x}^{r}\right|$, wenn $\frac{1-\mu}{\psi} \underset{<}{\geqq} 1$.

Unter Beachtung von $\psi=\alpha(1-\beta)+(1-\mu)(1-\mu+\mu \beta)$ läßt sich dieser Ausdruck umformen zu

$$
\begin{aligned}
& \quad 1-\mu \stackrel{\geqq}{\geqq} \alpha(1-\beta)+(1-\mu)(1-\mu+\mu \beta) \\
& \Leftrightarrow \quad(1-\mu)(1-1+\mu-\mu \beta) \stackrel{\geqq}{\gtrless} \alpha(1-\beta) \\
& \Leftrightarrow \quad(1-\mu) \mu \stackrel{\geqq}{\gtrless} \alpha .
\end{aligned}
$$

Es gilt also $\left.\left|w_{f l e x}^{r}\right|\right|_{<} ^{\geqq}\left|w_{f f x}^{r}\right|$, wenn $\alpha \leqq(1-\mu) \mu$.

\subsubsection{Vergleich der gesamtwirtschaftlichen Inflationsraten}

Für Aussagen über das Ausmaß des gesamtwirtschaftlichen Preisanstiegs in Abhängigkeit vom Wechselkursregime werden die Gleichungen (A3) und (A9) miteinander verglichen:

(A3) $\pi_{f i x}=\mu \gamma \pi_{a d m}$.

Unter Berücksichtigung von $\hat{\pi}=0$ und $\hat{w}^{r}=0$ ergibt sich aus (A9)

(A9') $\pi_{\text {flex }}=\frac{\alpha}{\psi} \gamma \pi_{a d m}$. 
Aus (A2) und (A9') folgt, daß $\pi_{f l e x} \geqq \pi_{f x}$, wenn $\frac{\alpha}{\psi} \stackrel{\gtrless}{\gtrless} \mu$.

Unter Beachtung von $\psi=\alpha(1-\beta)+(1-\mu)(1-\mu+\mu \beta)$ läßt sich dieser Ausdruck umformen zu

$$
\begin{aligned}
\alpha & \geqq \alpha \mu(1-\beta)+\mu(1-\mu)(1-\mu+\mu \beta) \\
& <\quad \alpha(1-\mu+\mu \beta) \stackrel{\geqq}{\gtrless} \mu(1-\mu)(1-\mu+\mu \beta) \\
\Leftrightarrow \quad \alpha & \geqq(1-\mu) \mu . \\
\Leftrightarrow & <
\end{aligned}
$$

Es gilt also $\pi_{\text {flex }} \stackrel{\geqq}{\gtrless} \pi_{f i x}$, wenn $\alpha \stackrel{\geqq}{\geqq}(1-\mu) \mu$.

\subsubsection{Vergleich der wirtschaftspolitischen Kosten}

Für den Vergleich der Kosten bei einer Wechselkursbindung mit den Kosten bei einem System flexibler Wechselkurse wird neben $\hat{\pi}=0$ und $\hat{w}^{r}=0$ zusätzlich $\beta=1-\mu$ unterstellt. ${ }^{2}$ Unter Berücksichtigung von $\hat{\pi}=0$ und $\hat{w}^{r}=0$ vereinfacht $\operatorname{sich}(\mathrm{A} 5) \mathrm{zu}$

(A5') $K_{f i x}=\frac{\mu^{2}+\alpha}{2} \gamma^{2} \pi_{a d m}^{2}$.

Bei Verwendung der drei genannten Annahmen läßt sich (A11) als

(A12) $K_{\text {flex }}=\frac{\alpha}{2} \frac{\alpha+(1-\mu)^{2}}{\left[\alpha \mu+(1-\mu)\left(1-\mu^{2}\right)\right]^{2}} \gamma^{2} \pi_{a d m}^{2}$

schreiben. Ein Vergleich von (A5') und (A12) zeigt, daß

$$
K_{\text {flex }} \underset{<}{\gtrless} K_{\text {fix }} \text {, }
$$

wenn

2 Diese Annahme wird im Unterabschnitt III.3.2.3. ausfuhrlich erlautert, wobei auch gezeigt wird, daß die Vereinfachung die okonomischen Zusammenhange nicht qualitativ beeinflußt. 


$$
\frac{\alpha^{2}+\alpha(1-\mu)^{2}}{\left[\alpha \mu+(1-\mu)\left(1-\mu^{2}\right)\right]^{2}} \stackrel{\gtrless}{\gtrless} \mu^{2}+\alpha .
$$

Diese Ungleichung läßt sich umformen zu

$$
\alpha+(1-\mu)^{2} \stackrel{\geqq}{\gtrless}\left(1+\frac{\mu^{2}}{\alpha}\right)\left[\alpha^{2} \mu^{2}+2 \alpha \mu(1-\mu)\left(1-\mu^{2}\right)+(1-\mu)^{2}\left(1-\mu^{2}\right)^{2}\right]
$$

$\Leftrightarrow$

$$
\alpha+(1-\mu)^{2} \stackrel{\gtrless}{\gtrless} \alpha^{2} \mu^{2}+\alpha \mu^{4}+\left(2 \alpha \mu+2 \mu^{3}\right)(1-\mu)\left(1-\mu^{2}\right)+\left(1+\frac{\mu^{2}}{\alpha}\right)(1-\mu)^{2}\left(1-\mu^{2}\right)^{2}
$$

$\Leftrightarrow$

$$
\alpha\left(1-\mu^{4}\right) \underset{<}{\geqq} \alpha^{2} \mu^{2}+\left(2 \alpha \mu+2 \mu^{3}\right)(1-\mu)\left(1-\mu^{2}\right)+\left(1+\frac{\mu^{2}}{\alpha}\right)(1-\mu)^{2}\left(1-\mu^{2}\right)^{2}-(1-\mu)^{2}
$$

$\Leftrightarrow$

$$
\alpha\left(1+\mu^{2}\right) \underset{<1-\mu^{2}}{\geqq} \frac{\alpha^{2} \mu^{2}}{<}+\left(2 \alpha \mu+2 \mu^{3}\right)(1-\mu)+\left(1+\frac{\mu^{2}}{\alpha}\right)(1-\mu)^{2}\left(1-\mu^{2}\right)-\frac{(1-\mu)^{2}}{1-\mu^{2}}
$$

$\Leftrightarrow$

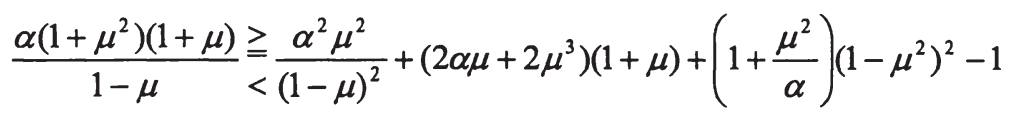

$\Leftrightarrow$

$$
-\frac{\alpha^{2} \mu^{2}}{(1-\mu)^{2}}+\frac{\alpha\left(1+\mu^{2}\right)(1+\mu)}{1-\mu}-2 \alpha \mu(1+\mu)-\frac{\mu^{2}}{\alpha}\left(1-\mu^{2}\right)^{2} \stackrel{\geqq}{\underset{<}{<}} 2 \mu^{3}(1+\mu)+\left(1-\mu^{2}\right)^{2}-1
$$

$\Leftrightarrow$

$$
\frac{\alpha^{2} \mu^{2}}{(1-\mu)^{2}}-\frac{\alpha(1+\mu)\left(1-2 \mu+3 \mu^{2}\right)}{1-\mu}+\frac{\mu^{2}}{\alpha}\left(1-\mu^{2}\right)^{2} \leqq \mu^{2}\left(2-2 \mu-3 \mu^{3}\right)
$$

$\Leftrightarrow$

$$
\begin{aligned}
& \frac{\alpha^{3} \mu^{2}}{(1-\mu)^{2}}-\frac{\alpha^{2}(1+\mu)\left(1-2 \mu+3 \mu^{2}\right)}{1-\mu}+\mu^{2}\left(1-\mu^{2}\right)^{2} \leqq \alpha \mu^{2}\left(2-2 \mu-3 \mu^{3}\right) \\
& \Leftrightarrow
\end{aligned}
$$




$$
\begin{aligned}
& \frac{\alpha^{3}}{(1-\mu)^{2}}-\frac{\alpha^{2}(1+\mu)\left(1-2 \mu+3 \mu^{2}\right)}{(1-\mu) \mu^{2}}-\alpha\left(2-2 \mu-3 \mu^{3}\right)+\left(1-\mu^{2}\right)^{2} \leqq 0 \\
& \Leftrightarrow \\
& \alpha^{3}-\frac{\left(1-\mu^{2}\right)\left(1-2 \mu+3 \mu^{2}\right)}{\mu^{2}} \alpha^{2}-(1-\mu)^{2}\left(2-2 \mu-3 \mu^{3}\right) \alpha+(1-\mu)^{2}\left(1-\mu^{2}\right)^{2} \leqq 0 \\
& >0
\end{aligned}
$$

bzw.

(A13) $\alpha^{3}-\xi_{1} \alpha^{2}-\xi_{2} \alpha+\xi_{3} \stackrel{\leqq}{>}$

mit $\quad \xi_{1}=\frac{\left(1-\mu^{2}\right)\left(1-2 \mu+3 \mu^{2}\right)}{\mu^{2}}$,

$$
\begin{aligned}
& \xi_{2}=(1-\mu)^{2}\left(2-2 \mu-3 \mu^{3}\right), \\
& \xi_{3}=(1-\mu)^{2}\left(1-\mu^{2}\right)^{2} .
\end{aligned}
$$

Es gilt also

$$
K_{\text {flex }} \geqq K_{f i x}, \text { wenn } \alpha^{3}-\xi_{1} \alpha^{2}-\xi_{2} \alpha+\xi_{3} \stackrel{\leqq}{>} 0 .
$$

Ist der Ausdruck $\alpha^{3}-\xi_{1} \alpha^{2}-\xi_{2} \alpha+\xi_{3}$ negativ, führt eine Wechselkursbindung zu niedrigeren Verlustwerten für die wirtschaftspolitische Zielfunktion als ein flexibler Wechselkurs. Ist der Ausdruck $\alpha^{3}-\xi_{1} \alpha^{2}-\xi_{2} \alpha+\xi_{3}$ hingegen positiv, dann ist aus Sicht der Zentralbank ein System flexibler Wechselkurse vorteilhafter.

In der folgenden Tabelle sind die Werte für den Ausdruck $\alpha^{3}-\xi_{1} \alpha^{2}-\xi_{2} \alpha+\xi_{3}$ für verschiedene Parameterkonstellationen angegeben. Um die Interpretation der Ergebnisse zu erleichtern, sind dabei die Werte nicht in einer $\alpha-\mu$-Tabelle dargestellt, sondern in Abhängigkeit von $\alpha$ und $1-\mu$ angegeben, weil letzteres als ein Maß für die Offenheit der betrachteten Volkswirtschaft aufgefaßt werden kann. Zur Veranschaulichung sind darüber hinaus die negativen Werte, die eine Vorteilhaftigkeit einer Wechselkursfixierung anzeigen, in der Tabelle dunkel hinterlegt. 
Tabelle 13: Wertetabelle zum Kostenvergleich bei festen und flexiblen Wechselkursen

\begin{tabular}{|c|c|c|c|c|c|c|c|c|c|}
\hline \multirow{2}{*}{$\alpha$} & \multicolumn{10}{|c|}{$\mathbf{1}-\boldsymbol{\mu}$} \\
\cline { 2 - 10 } & $\mathbf{0 , 1}$ & $\mathbf{0 , 2}$ & $\mathbf{0 , 3}$ & $\mathbf{0 , 4}$ & $\mathbf{0 , 5}$ & $\mathbf{0 , 6}$ & $\mathbf{0 , 7}$ & $\mathbf{0 , 8}$ & $\mathbf{0 , 9}$ \\
\hline $\mathbf{0 , 0 5}$ & 0,00052 & 0,0057 & 0,02 & 0,06 & 0,13 & 0,23 & 0,36 & 0,50 & 0,52 \\
\hline $\mathbf{0 , 0 6}$ & 0,00039 & 0,0055 & 0,02 & 0,06 & 0,12 & 0,22 & 0,34 & 0,47 & 0,41 \\
\hline $\mathbf{0 , 0 7}$ & 0,00022 & 0,0051 & 0,02 & 0,06 & 0,12 & 0,21 & 0,33 & 0,43 & 0,29 \\
\hline $\mathbf{0 , 0 8}$ & 0,00002 & 0,0046 & 0,02 & 0,05 & 0,11 & 0,20 & 0,31 & 0,40 & 0,15 \\
\hline $\mathbf{0 , 0 9}$ & 0,00000 & 0,0040 & 0,02 & 0,05 & 0,11 & 0,19 & 0,29 & 0,36 & 0,00 \\
\hline $\mathbf{0 , 1}$ & $-0,00048$ & 0,0033 & 0,02 & 0,05 & 0,10 & 0,18 & 0,27 & 0,32 & $-0,17$ \\
\hline $\mathbf{0 , 2}$ & $-0,00296$ & $-0,0074$ & 0,01 & 0,01 & 0,03 & 0,05 & 0,01 & $-0,30$ & $-2,78$ \\
\hline $\mathbf{0 , 3}$ & $-0,00109$ & $-0,0210$ & $-0,04$ & $-0,06$ & $-0,08$ & $-0,15$ & $-0,37$ & $-1,24$ & $-7,01$ \\
\hline $\mathbf{0 , 4}$ & 0,01 & $-0,03$ & $-0,08$ & $-0,13$ & $-0,22$ & $-0,40$ & $-0,87$ & $-2,51$ & $-12,87$ \\
\hline $\mathbf{0 , 5}$ & 0,04 & $-0,03$ & $-0,11$ & $-0,21$ & $-0,38$ & $-0,69$ & $-1,49$ & $-4,11$ & $-20,35$ \\
\hline $\mathbf{0 , 6}$ & 0,09 & $-0,02$ & $-0,14$ & $-0,30$ & $-0,55$ & $-1,03$ & $-2,20$ & $-6,02$ & $-29,44$ \\
\hline $\mathbf{0 , 7}$ & 0,17 & 0,02 & $-0,15$ & $-0,38$ & $-0,73$ & $-1,41$ & $-3,02$ & $-8,24$ & $-40,15$ \\
\hline $\mathbf{0 , 8}$ & 0,28 & 0,08 & $-0,15$ & $-0,44$ & $-0,91$ & $-1,81$ & $-3,93$ & $-10,76$ & $-52,45$ \\
\hline $\mathbf{0 , 9}$ & 0,44 & 0,17 & $-0,11$ & $-0,49$ & $-1,09$ & $-2,24$ & $-4,93$ & $-13,59$ & $-66,34$ \\
\hline $\mathbf{1 , 0}$ & 0,64 & 0,31 & $-0,05$ & $-0,52$ & $-1,27$ & $-2,68$ & $-6,01$ & $-16,70$ & $-81,83$ \\
\hline $\mathbf{1 , 1 1}$ & 0,92 & 0,51 & 0,06 & $-0,52$ & $-1,44$ & $-3,18$ & $-7,30$ & $-20,49$ & $-100,90$ \\
\hline $\mathbf{1 , 2 5}$ & 1,38 & 0,85 & 0,28 & $-0,46$ & $-1,62$ & $-3,82$ & $-9,03$ & $-25,72$ & $-127,46$ \\
\hline $\mathbf{1 , 4 3}$ & 2,16 & 1,47 & 0,72 & $-0,25$ & $-1,76$ & $-4,63$ & $-11,43$ & $-33,20$ & $-166,06$ \\
\hline $\mathbf{1 , 6 7}$ & 3,60 & 2,65 & 1,62 & 0,31 & $-1,74$ & $-5,64$ & $-14,86$ & $-44,46$ & $-225,25$ \\
\hline $\mathbf{2 , 0}$ & 6,51 & 5,13 & 3,65 & 1,76 & $-1,17$ & $-6,75$ & $-19,98$ & $-62,55$ & $-322,80$ \\
\hline $\mathbf{2 , 5}$ & 13,29 & 11,10 & 8,78 & 5,85 & 1,31 & $-7,34$ & $-27,93$ & $-94,31$ & $-500,78$ \\
\hline $\mathbf{3 , 3 3}$ & 32,86 & 28,94 & 24,81 & 19,64 & 11,66 & $-3,59$ & $-39,98$ & $-157,7$ & $-880,02$ \\
\hline $\mathbf{5 , 0}$ & 115,54 & 106,67 & 97,37 & 85,83 & 68,11 & 34,19 & $-47,19$ & $-311,5$ & $-1935,7$ \\
\hline $\mathbf{1 0 , 0}$ & 962,0 & 926,2 & 889,0 & 843,4 & 773,6 & 639,6 & 316,5 & $-737,5$ & $-7230,7$ \\
\hline
\end{tabular}

\subsection{Berechnungen für die Täuschungslösung}

In dem Fall der Täuschung glauben die Wirtschaftssubjekte der Ankündigung der Zentralbank, daß sie den nominalen Wechselkurs konstant hält. Nachdem die Wirtschaftssubjekte jedoch ihre Erwartungen gebildet und dementsprechend die Preise im Sektor der nicht-handelbaren Güter festgelegt haben, weicht die Zentralbank von der verkündeten Festkursstrategie ab und ändert den nominalen Wechselkurs. Da die Wirtschaftssubjekte an die Wechselkursbindung glauben, folgt aus Gleichung (7'), daß die Preise im Sektor der nicht-handelbaren Güter genau im gleichen Ausmaß wie bei fixiertem Wechselkurs steigen:

(A14) $\pi_{N T}=\gamma \pi_{a d m}$.

Wird (A14) in (A6) eingesetzt, ergibt sich mit $\hat{\pi}, \hat{w}^{r} \neq 0$ für den allgemeinen Fal] als optimale Wechselkursänderung 
(A15) $w_{T}=\frac{\alpha-(1-\mu) \mu}{\alpha+(1-\mu)^{2}} \gamma \pi_{a d m}+\frac{1-\mu}{\alpha+(1-\mu)^{2}} \hat{\pi}+\frac{\alpha}{\alpha+(1-\mu)^{2}} \hat{w}^{r}$.

Aus (A14) und (A15) in (6') folgt für die reale Wechselkursänderung

(A16) $w_{T}^{r}=-\frac{1-\mu}{\alpha+(1-\mu)^{2}} \gamma \pi_{a d m}+\frac{1-\mu}{\alpha+(1-\mu)^{2}} \hat{\pi}+\frac{\alpha}{\alpha+(1-\mu)^{2}} \hat{w}^{r}$

und mit (A14) und (A15) in (2') für die gesamtwirtschaftliche Inflationsrate

$$
\pi_{T}=\left[\mu+(1-\mu) \frac{\alpha-(1-\mu) \mu}{\alpha+(1-\mu)^{2}}\right] \gamma \pi_{a d m}+\frac{(1-\mu)^{2}}{\alpha+(1-\mu)^{2}} \hat{\pi}+\frac{\alpha(1-\mu)}{\alpha+(1-\mu)^{2}} \hat{w}^{r}
$$

$\Leftrightarrow \quad \pi_{T}=\frac{\alpha \mu+(1-\mu) \alpha}{\alpha+(1-\mu)^{2}} \gamma \pi_{a d m}+\frac{(1-\mu)^{2}}{\alpha+(1-\mu)^{2}} \hat{\pi}+\frac{\alpha(1-\mu)}{\alpha+(1-\mu)^{2}} \hat{w}^{r} \quad$ bzw.

(A17) $\pi_{T}=\frac{\alpha}{\alpha+(1-\mu)^{2}} \gamma \pi_{\alpha d m}+\frac{(1-\mu)^{2}}{\alpha+(1-\mu)^{2}} \hat{\pi}+\frac{\alpha(1-\mu)}{\alpha+(1-\mu)^{2}} \hat{w}^{r}$.

Einsetzen von (A16) und (A17) in (1) liefert für die Verlustfunktion einen Wert in Höhe von

$$
\begin{aligned}
K_{T}= & \frac{1}{2}\left[\frac{\alpha}{\alpha+(1-\mu)^{2}} \gamma \pi_{a d m}+\frac{(1-\mu)^{2}}{\alpha+(1-\mu)^{2}} \hat{\pi}-\hat{\pi}+\frac{\alpha(1-\mu)}{\alpha+(1-\mu)^{2}} \hat{w}^{r}\right]^{2} \\
& +\frac{\alpha}{2}\left[-\frac{1-\mu}{\alpha+(1-\mu)^{2}} \gamma \pi_{a d m}+\frac{1-\mu}{\alpha+(1-\mu)^{2}} \hat{\pi}+\frac{\alpha}{\alpha+(1-\mu)^{2}} \hat{w}^{r}-\hat{w}^{r}\right]^{2} \\
\Leftrightarrow \quad K_{T}= & \frac{1}{2} \frac{\alpha^{2}}{\left[\alpha+(1-\mu)^{2}\right]^{2}}\left[\gamma \pi_{a d m}-\hat{\pi}+(1-\mu) \hat{w}^{r}\right]^{2} \\
& +\frac{\alpha}{2}\left(-\frac{1-\mu}{\alpha+(1-\mu)^{2}}\right)^{2}\left[\gamma \pi_{a d m}-\hat{\pi}+(1-\mu) \hat{w}^{r}\right]^{2}
\end{aligned}
$$

(A18) $K_{T}=\frac{1}{2} \frac{\alpha}{\alpha+(1-\mu)^{2}}\left[\gamma \pi_{a d m}-\hat{\pi}+(1-\mu) \hat{w}^{r}\right]^{2}$. 


\subsection{Kostenvergleich zwischen der Wechselkursbindung und der Täuschungslösung}

Für den Kostenvergleich wird wieder unterstellt, daß die Zentralbank Preisstabilität und einen konstanten realen Wechselkurs anstrebt. Unter Berücksichtigung von $\hat{\pi}=0$ und $\hat{w}^{r}=0$ gilt für die Kosten bei Wechselkursfixierung

(A5') $K_{f i x}=\frac{\mu^{2}+\alpha}{2} \gamma^{2} \pi_{a d m}^{2}$,

und (A18) läßt sich schreiben als

(A19) $K_{T}=\frac{1}{2} \frac{\alpha}{\alpha+(1-\mu)^{2}} \gamma^{2} \pi_{a d m}^{2}$.

Ein Vergleich von (A5') und (A19) zeigt, daß

$$
K_{T} \sum_{<}, \quad \text { wenn } \quad \frac{\alpha}{\alpha+(1-\mu)^{2}} \stackrel{\geq}{\gtrless} \mu^{2}+\alpha .
$$

Es gilt $K_{T} \leqq K_{f i x}$, denn

$$
\begin{aligned}
\alpha & \leqq \alpha^{2}+\alpha(1-\mu)^{2}+\alpha \mu^{2}+\mu^{2}(1-\mu)^{2} \\
\Leftrightarrow \quad 0 & \leqq \frac{\alpha^{2}}{(1-\mu)^{2}}+\frac{\alpha(1-\mu)^{2}-\alpha+\alpha \mu^{2}}{(1-\mu)^{2}}+\mu^{2} \\
\Leftrightarrow \quad 0 & \leqq \frac{\alpha^{2}}{(1-\mu)^{2}}+\frac{\alpha(1-\mu)^{2}-\alpha\left(1-\mu^{2}\right)}{(1-\mu)^{2}}+\mu^{2} \\
\Leftrightarrow \quad 0 & \leqq \frac{\alpha^{2}}{(1-\mu)^{2}}+\frac{\alpha(1-\mu)-\alpha(1+\mu)}{1-\mu}+\mu^{2} \\
\Leftrightarrow \quad 0 & \leqq \frac{\alpha^{2}}{(1-\mu)^{2}}-\frac{2 \alpha \mu}{1-\mu}+\mu^{2} \\
\Leftrightarrow \quad 0 & \leqq\left(\frac{\alpha}{1-\mu}-\mu\right)^{2} .
\end{aligned}
$$




\section{Wechselkurspolitische Chroniken ${ }^{1}$}

\subsection{Wechselkurspolitik in Bulgarien $1990-2000^{2}$}

Anfang 1990 Abwertung des Lew um 20 v.H. gegenüber dem US-Dollar Vereinheitlichung des kommerziellen und des nicht-kommerziellen Kurses

Februar 1991 Einführung eines flexiblen Wechselkurses

Die Einführung des flexiblen Wechselkurses führt unmittelbar zu einer Abwertung um über 400 v.H. gegenüber dem US-Dollar. Die bulgarische Nationalbank verkündet kein Wechselkursziel, interveniert in der Folgezeit aber wiederholt am Devisenmarkt, um den Wechselkurs zu beeinflussen.

März 1994 Nach einer längeren Zeit der Wechselkursstabilisierung gibt die bulgarische Nationalbank die Verteidigung des Wechselkurses auf. Die Währung wertet sich daraufhin im März um fast 30 v.H. und im April um 17 v.H. gegenüber dem US-Dollar ab.

Juli 1997

Einfuihrung eines Currency Boards

Parität: 1000 BGL $=1$ DEM

September 1998 formale Anerkennung des Artikels VIII des IWF-Abkommens

Januar 1999 Der Euro löst die Deutsche Mark als Reservewährung ab.

Umrechnung der Parität zum unwiderruflich fixierten Umtauschverhältnis der Deutschen Mark gegenüber dem Euro;

neue Parität: 1.955,83 BGL = 1 EUR

Juli 1999 Währungsredenomination

1000 ,alte“ Lew $=1$ „neuer“ Lew

1 Alle Chroniken sind aus Angaben des Internationalen Wăhrungsfonds, der Europăischen Kommission und der nationalen Zentralbanken zusammengestellt. Weitere Quellen zu den einzelnen Lăndern sind jeweils gesondert angegeben.

2 Zur Wechselkurspolitik in Bulgarien siehe u.a. OECD (1997a), Hamacher (1992) und Borensztein et al. (1993). 


\subsection{Wechselkurspolitik in Estland $1992-2000^{3}$}

Juni 1992 Währungsreform

Einführung der Estnischen Krone

Die Estnische Krone ist alleiniges gesetzliches Zahlungsmittel.

Einführung eines Currency Boards

Parität: 8 EEK = 1 DEM

Schwankungen des Marktkurses von \pm 3 v.H. werden zugelassen.

August 1994 formale Anerkennung des Artikels VIII des IWF-Abkommens

Januar 1999 Der Euro ersetzt de facto die Deutsche Mark als Reservewährung. Eine formale Anpassung der gesetzlichen Bestimmungen über das Currency Board System erfolgt jedoch nicht.

\subsection{Wechselkurspolitik in Lettland $1992-2000^{4}$}

Mai 1992 Einführung des Lettischen Rubel als Interimswährung - die neben dem Russischen Rubel gesetzliches Zahlungsmittel ist - zu einem Umtauschverhältnis von 1:1

flexibler Wechselkurs gegenüber konvertiblen Währungen und dem Russischen Rubel

Juli 1992 Der Lettische Rubel ist alleiniges gesetzliches Zahlungsmittel.

August 1992 Einführung eines gespaltenen Wechselkurses für Buchgeld-Rubel aus anderen ehemaligen Sowjetrepubliken, um die Wirtschaft vor einer Flut einströmender Rubel aus diesen Ländern zu schützen.

März 1993 Beginn der stufenweisen Einführung des Lats

Das Umtauschverhältnis zwischen Lettischem Rubel und Lats beträgt $200: 1$.

Oktober 1993 Der Lats ist alleiniges gesetzliches Zahlungsmittel.

Februar 1994 Bindung des Lats an das Sonderziehungsrecht des Internationalen Währungsfonds im Verhältnis $1 \mathrm{LVL}=1,25 \mathrm{SDR}$

3 Zur Wechselkurspolitik in Estland siehe u.a. Bennett (1993) und Lainela/Sutela (1994).

4 Zur Wechselkurspolitik in Lettland siehe u.a. Lainela/Sutela (1994), Viksnins/Rimshevitchs (1995) und Repse (1999). 
zulässige Schwankungsbreite: $\pm 1,0 \mathrm{v} . \mathrm{H}$.

De facto ist die monetäre Basis zu über 100 v.H. durch die Währungsreserven der lettischen Zentralbank gedeckt. Eine gesetzliche Verpflichtung dazu besteht aber nicht.

Juni 1994 formale Anerkennung des Artikels VIII des IWF-Abkommens

\subsection{Wechselkurspolitik in Litauen $1992-2000^{5}$}

Mai 1992 Einführung des Litauischen Talonas als Interims-Parallelwährung zum Russischen Rubel

(Talonas ist das litauische Wort für Kupon. Die Interimslösung hat keine eigene Währungsbezeichnung.)

Das Umtauschverhältnis zwischen Litauischem Talonas und Russischem Rubel beträgt 1:1.

flexibler Wechselkurs

Oktober 1992 Der Litauische Talonas ist alleiniges gesetzliches Zahlungsmittel.

Juni 1993 Die neue Währung Litas wird in Umlauf gebracht.

Umtauschverhältnis: 1 Litas $=100$ Taloni

Umstellung der Bankguthaben auf Litas

August 1993 Der Litas ist alleiniges gesetzliches Zahlungsmittel.

April 1994 Einführung eines Currency Boards

Parität: 4 LTL = 1 USD

Mai 1994 formale Anerkennung des Artikels VIII des IWF-Abkommens

Januar 1997 Verabschiedung des geldpolitischen Programms der litauischen Zentralbank für 1997-99:

Entwicklung einer Strategie zum Ausstieg aus dem Currency Board in drei Schritten mit anschließender Bindung des Litas an europäische Währungen

$1998 \quad$ Vereinbarung zwischen der Regierung und der Zentralbank über den Aufschub des geplanten Ausstiegs aus dem Currency Board bis mindestens zum Jahr 2000

5 Zur Wechselkurspolitik in Litauen siehe u.a. Lainela/Sutela (1994) und Balino et al. (1997). 
Oktober 1999 Beschluß der Zentralbank, erst in der zweiten Hälfte des Jahres 2001 das Currency Board aufzugeben und den Litas zum dann gültigen Wechselkurs EUR/USD gegenüber dem Euro zu binden

\subsection{Wechselkurspolitik in Polen $1990-2000^{6}$}

Januar 1990 Vereinheitlichung der Wechselkurse nominale Abwertung um 46,2 v.H. gegenüber dem US-Dollar Wechselkursbindung gegenüber dem US-Dollar im Verhältnis 9.500 PLN = 1 USD

Mai 1991 diskretionäre nominale Abwertung um 14,4 v.H.

Bindung an einen Währungskorb, Zusammensetzung des Korbes: 45 v.H. USD, 35 v.H. DEM, 10 v.H. GBP, 5 v.H. FRF, 5 v.H. CHF

Oktober 1991 Einführung eines Crawling Peg Systems angekündigte monatliche nominale Abwertungsrate: $1,8 \mathrm{v} . \mathrm{H}$.

Februar 1992 diskretionäre nominale Abwertung der gleitenden Parität um 12,0 v.H.

August 1993 diskretionäre nominale Abwertung der gleitenden Parität um 8,1 v.H.

Senkung der monatlichen nominalen Abwertungsrate auf 1,6 v.H.

September 1994 Senkung der monatlichen nominalen Abwertungsrate auf 1,5 v.H.

November 1994 Senkung der monatlichen nominalen Abwertungsrate auf 1,4 v.H.

Januar 1995 Währungsredenomination: 10.000 ,alte“ Zloty = 1 „neuer“ Zloty

Februar 1995 Senkung der monatlichen nominalen Abwertungsrate auf 1,2 v.H.

März 1995 Ausweitung des Wechselkursbandes von $\pm 0,5$ v.H. auf $\pm 2,0$ v.H.

Mai 1995 Ausweitung des Wechselkursbandes auf \pm 7,0 v.H.

Zur Wechselkurspolitik in Polen siehe u.a. Lipton/Sachs (1990), Radzyner/Riesinger (1996) und Dibooglu/Kutan (2000). 
Juni 1995 formale Anerkennung des Artikels VIII des IWF-Abkommens

Dezember 1995 diskretionäre nominale Aufwertung der gleitenden Parität um 6 v.H.

Januar 1996 Senkung der monatlichen nominalen Abwertungsrate auf 1,0 v.H.

Februar 1998 Senkung der monatlichen nominalen Abwertungsrate auf 0,8 v.H. Ausweitung des Wechselkursbandes auf \pm 10 v.H.

Juli 1998 Senkung der monatlichen nominalen Abwertungsrate auf $0,65 \mathrm{v} . \mathrm{H}$.

September 1998 Senkung der monatlichen nominalen Abwertungsrate auf 0,5 v.H.

Oktober 1998 Ausweitung des Wechselkursbandes auf $\pm 12,5$ v.H.

Januar 1999 Änderung der Zusammensetzung des Währungskorbes, neuer Korb: 55 v.H. EUR, 45 v.H. USD

März 1999 Senkung der monatlichen nominalen Abwertungsrate auf 0,3 v.H. Ausweitung des Wechselkursbandes auf \pm 15 v.H.

April 2000 Übergang zu flexiblen Wechselkursen

\subsection{Wechselkurspolitik in Rumänien $1990-2000^{7}$}

November 1990 Abwertung des Leu von 21 auf 35 ROL/USD

Februar 1991 Einführung eines dualen Wechselkurssystems:

fester (offizieller) Kurs für wichtige Importgüter;

am Interbankenmarkt gebildeter flexibler Kurs für sonstige Transaktionen

April 1991 Abwertung des Festkurses auf 60 ROL/USD

November 1991 Abschaffung des festen Wechselkurses

7 Zur Wechselkurspolitik in Rumănien siehe u.a. Fröhlich (1992), OECD (1993), OECD (1998), Borensztein/Masson (1993), und DB Research (1999a). 
Vereinheitlichung der Kurse auf einem Niveau von 180 ROL/USD

offizieller Übergang zu einem Managed Floating

Tatsächlich bildeten sich zwei Kurse heraus. Zum offiziellen Kurs, der von der Zentralbank festgelegt wird, besteht eine Überschußnachfrage nach Devisen, so daß der Wechselkurs in den Wechselstuben deutlich über diesem offiziellen Kurs liegt.

schrittweise nominale Anhebung des offiziellen Wechselkurses bis im August eine Anpassung an den "freien“ Wechselkurs erreicht ist

Von September bis Dezember hält die rumänische Zentralbank den offiziellen Wechselkurs konstant.

Auch in den folgenden Jahren wird der offizielle Kurs jeweils für bestimmte Zeiträume konstant gehalten. Diese Phasen enden in der Regel mit deutlichen nominalen Abwertungen.

März 1996 Einführung weitreichender Kontrollen auf dem Interbankenmarkt Außer vier staatlichen Banken werden allen Marktteilnehmern die Zulassungen zum Devisenhandel entzogen.

Anfang 1997 Umkehr der Politik des Jahres 1996:

Die Devisenhändler erhalten ihre Lizenzen zurück.

Freigabe des Wechselkurses

kräftige nominale Abwertung des Leu von 4.100 ROL/USD

Anfang Januar auf 8.5000 ROL/USD Mitte Februar

Übergang zu Managed Floating

Die rumänische Zentralbank interveniert häufig auf dem Devisenmarkt und versucht teilweise, den nominalen Wechselkurs des Leu für längere Zeiträume stabil zu halten.

März 1998 formale Anerkennung des Artikels VIII des IWF-Abkommens

Im geldpolitischen Programm der rumänischen Zentralbank wird für 1999 eine nominale Abwertung von 40 v.H. angestrebt. 


\subsection{Wechselkurspolitik in der Slowakei $1993-2000^{8}$}

Januar 1993 Aufgrund der tschechisch-slowakischen Vereinbarung vom Oktober 1992 über die Beibehaltung einer gemeinsamen Währung nach der Teilung der Tschechoslowakei in zwei souveräne Staaten bleibt die tschechoslowakische Krone für kurze Zeit gesetzliches Zahlungsmittel in der Slowakei.

Februar 1993 Auflösung der Währungsunion mit Tschechien

Einführung der Slowakischen Krone

Wechselkursbindung auf unverändertem Niveau gegenüber dem gleichen Währungskorb wie die Tschechoslowakische Krone: 49,07 v.H. USD, 36,15 v.H. DEM, 8,07 v.H. ATS, 3,79 v.H. CHF, 2,92 v.H. FRF

Schwankungsbreite unverändert: $\pm 0,5$ v.H.

Juli 1993 diskretionäre nominale Abwertung um 10 v.H.

Juli 1994 Änderung der Zusammensetzung des Währungskorbes, neuer Korb: 60 v.H. DEM, 40 v.H. USD

Ausweitung des Wechselkursbandes auf $\pm 1,5$ v.H.

Oktober 1995 formale Anerkennung des Artikels VIII des IWF-Abkommens

Januar 1996 Ausweitung des Wechselkursbandes auf $\pm 3,0$ v.H.

Juli 1996 Ausweitung des Wechselkursbandes auf $\pm 5,0$ v.H.

Januar 1997 Ausweitung des Wechselkursbandes auf \pm 7,0 v.H.

Oktober 1998 Übergang zu flexiblen Wechselkursen

Januar 1999 Die slowakische Nationalbank beobachtet seit Beginn der Europäischen Währungsunion die Entwicklung der Slowakischen Krone gegenüber dem Euro und greift bei starken Wechselkursausschlägen gegebenenfalls in das Geschehen auf dem Devisenmarkt ein.

$8 \quad$ Für die Entwicklung in der Tschechoslowakei bis Ende 1992 vgl. Anhang VI.2.9. Zur Wechselkurspolitik in der Slowakei siehe u.a. Radzyner/Riesinger (1996), Krzak et al. (1997), und DB Global Markets Research (2000). 


\subsection{Wechselkurspolitik in Slowenien $1991-2000^{9}$}

Oktober 1991 Einführung des Slowenischen Tolar

Umtauschverhältnis zwischen Slowenischem Tolar und Jugoslawischem Dinar $1: 1$

anfängliche Differenzierung der Wechselkurse nach Verwendung (CUREX = Wechselkurs für Leistungsbilanztransaktionen;

CAPEX $=$ Wechselkurs für Kapitalverkehrstransaktionen)

Managed Floating mit der Deutschen Mark als Referenzwährung nominale Abwertung von 32 SIT/DEM auf 42 SIT/DEM

$1994 / 95$

Die slowenische Zentralbank hält den nominalen Wechselkurs des Tolar gegenüber der Deutschen Mark von Mitte 1994 bis Mitte 1995 konstant.

Februar 1995 Einführung von Kapitalverkehrsbeschränkungen, um den Zustrom ausländischen Kapitals zu begrenzen

In den Jahren 1996 und 1997 erfolgt eine Ausweitung der Kapitalverkehrskontrollen.

September 1995 formale Anerkennung des Artikels VIII des IWF-Abkommens

1996

Nach einer Phase nominaler Abwertung des Tolar in der zweiten Jahreshälfte 1995 wird im Jahr 1996 der nominale Wechselkurs gegenüber der Deutschen Mark erneut nahezu konstant gehalten.

Januar 1999 Der Euro löst die Deutsche Mark als informelle Referenzwährung $\mathrm{ab}$.

Februar 1999 Lockerung einiger Kapitalverkehrsbeschränkungen, die in den Jahren 1995 bis 1997 eingeführt wurden

\subsection{Wechselkurspolitik in Tschechien $1990-2000^{10}$}

Januar 1990 Einführung eines einheitlichen kommerziellen Wechselkurses

Beibehaltung eines speziellen Wechselkurses für Touristen

9 Zur Wechselkurspolitik in Slowenien siehe u.a. Mencinger (1993), Pleskovic/Sachs (1994), Radzyner/Riesinger (1996) und Backé (1999).

10 Zur Wechselkurspolitik in Tschechien siehe u.a. Tosovský (1994), Goodhart (1995), OECD (1996), Radzyner/Riesinger (1996), Hrncir (1997) und Horvath/Jonas (1998). 
fester Wechselkurs gegenüber dem US-Dollar nominale Abwertung des kommerziellen Wechselkurses um 2,2 v.H. am 02.01.1990 und um 16,3 v.H. am 08.01.1990

Oktober 1990 nominale Abwertung des kommerziellen Wechselkurses um 55,2 v.H.

Dezember 1990 Abwertung des kommerziellen Wechselkurses um 15,9 v.H.

Abschaffung des speziellen Wechselkurses für Touristen und Vereinheitlichung der Kurse

Bindung der Tschechoslowakischen Krone an einen Währungskorb aus fünf Währungen; Zusammensetzung des Währungskorbes: 45,52 v.H. DEM, 31,34 v.H. USD, 12,35 v.H. ATS, 6,55 v.H. CHF, 4,24 v.H. GBP

Schwankungsbreite: \pm 0.5 v.H.

Januar 1992 Änderung der Zusammensetzung des Währungskorbes, neuer Korb: 49,07 v.H. USD, 36,15 v.H. DEM, 8,07 v.H. ATS, 3,79 v.H. CHF, 2,92 v.H. FRF

Oktober 1992 tschechisch-slowakische Vereinbarung über die Beibehaltung einer gemeinsamen Währung nach der Teilung der Tschechoslowakei in zwei souveräne Staaten

Februar 1993 Auflösung der Währungsunion zwischen Tschechien und der Slowakei

Einführung der Tschechischen Krone

Beibehaltung der Wechselkursbindung auf unverändertem Niveau gegenüber dem bisherigen Währungskorb

Mai 1993 Änderung der Zusammensetzung des Währungskorbes, neuer Korb: 65 v.H. DEM, 35 v.H. USD

Schwankungsbreite unverändert $\pm 0,5$ v.H.

Oktober 1995 formale Anerkennung des Artikels VIII des IWF-Abkommens

Februar 1996 Ausweitung des Wechselkursbandes auf \pm 7,5 v.H.

Mai $1997 \quad$ Freigabe des Wechselkurses

Übergang zu einem Managed Floating 
Der Wechselkurses der Tschechischen Krone gegenüber der Deutschen Mark ist ein wichtiger geldpolitischer Indikator der tschechischen Zentralbank.

Januar 1999 Der Euro löst die Deutsche Mark als Referenzwährung ab.

\subsection{Wechselkurspolitik in Ungarn $1990-2000^{11}$}

März 1989 Bindung an einen Währungskorb mit Währungen der wichtigsten Handelspartner

jährliche Überprüfung der Zusammensetzung des Korbes

Januar 1990 diskretionäre nominale Abwertung um 1,0 v.H.

Februar 1990 diskretionäre nominale Abwertung um jeweils 2,0 v.H. am 06.02.1990 und 20.02.1990

Januar 1991 diskretionäre nominale Abwertung um 15,0 v.H.

November 1991 diskretionäre nominale Abwertung um 5,8 v.H.

Dezember 1991 Bindung an einen Währungskorb aus zwei Währungen, Zusammensetzung des Korbes: 50 v.H. ECU, 50 v.H. USD

März 1992 diskretionäre nominale Abwertung um 1,9 v.H.

Juni 1992 diskretionäre nominale Abwertung um 1,6 v.H.

November 1992 diskretionäre nominale Abwertung um 1,9 v.H.

Februar 1993 diskretionäre nominale Abwertung um 1,9 v.H.

März 1993 diskretionäre nominale Abwertung um 2,9 v.H.

Juni 1993 diskretionäre nominale Abwertung um 1,9 v.H.

Juli 1993 diskretionäre nominale Abwertung um 3,0 v.H.

11 Zur Wechselkurspolitik in Ungarn siehe u.a. Radzyner/Riesinger (1996), Koch (1997), Orlowski (1998) und Szapáry/Jakab (1998). 
August 1993 Änderung der Zusammensetzung des Währungskorbes, neuer Korb: 50 v.H. DEM, 50 v.H. USD

September 1993 diskretionäre nominale Abwertung um 4,5 v.H.

Januar 1994 diskretionäre nominale Abwertung um 1,0 v.H.

Februar 1994 diskretionäre nominale Abwertung um 2,6 v.H.

Mai 1994 diskretionäre nominale Abwertung um 1,0 v.H. Änderung der Zusammensetzung des Währungskorbes, neuer Korb: 70 v.H. ECU, 30 v.H. USD

Juni 1994 diskretionäre nominale Abwertung um 1,2 v.H.

August 1994 diskretionäre nominale Abwertung um 8,0 v.H.

Oktober 1994 diskretionäre nominale Abwertung um 1,1 v.H.

November 1994 diskretionäre nominale Abwertung um 1,0 v.H.

Dezember 1994 Ausweitung des Wechselkursbandes von $\pm 1,25$ v.H. auf $\pm 2,25$ v.H.

Januar 1995 diskretionäre nominale Abwertung um 1,4 v.H.

Februar 1995 diskretionäre nominale Abwertung um 2,0 v.H.

März 1995 diskretionäre nominale Abwertung um 9,0 v.H. Einführung eines Crawling Peg Systems mit im voraus angekündigten monatlichen nominalen Abwertungsraten monatliche nominale Abwertungsrate zunächst 1,9 v.H. Beibehaltung des Währungskorbes (70 v.H. ECU, 30 v.H. USD) und der Schwankungsbreite von $\pm 2,25$ v.H.

Juli 1995 Senkung der monatlichen nominalen Abwertungsrate auf 1,3 v.H.

Januar 1996 formale Anerkennung des Artikels VIII des IWF-Abkommens Senkung der monatlichen nominalen Abwertungsrate auf 1,2 v.H.

Januar 1997 Änderung der Zusammensetzung des Währungskorbes, neuer Korb: 70 v.H. DEM, 30 v.H. USD 
April 1997 Senkung der monatlichen nominalen Abwertungsrate auf 1,1 v.H.

August 1997 Senkung der monatlichen nominalen Abwertungsrate auf 1,0 v.H.

Januar 1998 Senkung der monatlichen nominalen Abwertungsrate auf 0,9 v.H.

Juni 1998 Senkung der monatlichen nominalen Abwertungsrate auf 0,8 v.H.

Oktober 1998 Senkung der monatlichen nominalen Abwertungsrate auf 0,7 v.H.

Januar 1999 Senkung der monatlichen nominalen Abwertungsrate auf 0,6 v.H. Änderung der Zusammensetzung des Währungskorbes, neuer Korb: 70 v.H. EUR, 30 v.H. USD

Juli 1999 Senkung der monatlichen nominalen Abwertungsrate auf 0,5 v.H.

Oktober 1999 Senkung der monatlichen nominalen Abwertungsrate auf 0,4 v.H.

Januar 2000 Abschaffung des Währungskorbes,

Bindung ausschließlich gegenüber dem Euro

April 2000 Senkung der monatlichen nominalen Abwertungsrate auf 0,3 v.H. 


\section{Literaturverzeichnis}

Agénor, Pierre-Richard (1994): Credibility and Exchange Rate Management in Developing Countries, Journal of Development Economics, Vol. 45, No. 1, S. $1-16$.

Aghevli, Bijan B.; Khan, Mohsin S.; Montiel, Peter J. (1991): Exchange Rate Policy in Developing Countries: Some Analytical Issues, Occasional Paper No. 78, International Monetary Fund, Washington, D.C.

Aghevli, Bijan B.; Montiel, Peter J. (1991): Exchange Rate Policies in Developing Countries, in: Exchange Rate Policies in Developing and Post-Socialist Countries, ed. by Emil-Maria Claassen, ICS Press, San Francisco, S. $205-$ 237.

Andersen, Torben M.; Risagen, Ole (1991): The Role of Credibility for the Effects of a Change in the Exchange-Rate Policy, Oxford Economc Papers, Vol. 42, No. 1, S. $85-98$.

Angermüller, Niels O. (2000): Währungskrisenmodelle aus neuerer Sicht, Diskussionspapier Nr. 8, Zentrum für Globalisierung und Europäisierung der Wirtschaft, Göttingen.

Åslund, Anders; Boone, Peter; Johnson, Simon (1996): How to Stabilize: Lessons from Post-Communist Countries, Brookings Papers on Economic Activity, No. 1, The Brookings Institution, Washington, D.C., S. 217 - 313.

Backé, Peter (1996): Progress towards Convertibility in Central and Eastern Europe, Focus on Transition, 1/1996, S. $39-66$.

Backé, Peter (1997): Special Report on Bulgaria and Romania, Focus on Transition, 1/1997, S. 18 - 26.

Backé, Peter (1999): Developments in Selected Countries, Focus on Transition, 1/1999, S. 8 - 26.

Backé, Peter; Wójcik, Cezary (2000): Developments in Selected Countries, Focus on Transition, 1/2000, S. $10-28$.

Balino, Tomás J.T.; Enoch, Charles; Ize, Alain; Santiprabhob, Veerathai; Stella, Peter (1997): Currency Board Arrangements - Issues and Experiences, Occasional Paper No. 151, International Monetary Fund, Washington, D.C.

Banaian, King; Burdekin, Richard C.K.; Willett, Thomas (1998): Reconsidering the Principal Components of Central Bank Independence: The More the Merrier?, Public Choice, Vol. 97, Nos. 1-2, S. 1 - 12. 
Bank of Lithuania (1997): Monetary Policy Programme of the Bank of Lithuania for 1997-1999, Resolution No. 14 of the Board of the Bank of Lithuania, January 16, 1997.

Bank of Lithuania (1999): Statement of the Bank of Lithuania, October 13, 1999, http://www.lbank.lt/Eng/about/statment.htm.

Bank of Lithuania (2000): Annual Report 1999, Vilnius.

Barro, Robert J.; Gordon, David B. (1983a): A Positive Theory of Monetary Policy in a Natural Rate Model, Journal of Political Economy, Vol. 91, No. 4, S. $589-610$.

Barro, Robert J.; Gordon, David B. (1983b): Rules, Discretion and Reputation in a Model of Monetary Policy, Journal of Monetary Economics, Vol. 12, No. 1, S. $101-121$.

Begg, David (1998): Disinflation in Central and Eastern Europe: The Experience to Date, in: Moderate Inflation: The Experience of Transition Economies, ed. by Carlo Cottarelli and György Szapáry, International Monetary Fund and National Bank of Hungary, Washington, D.C., S. $102-126$.

Bennett, Adam G.G. (1993): The Operation of the Estonian Currency Board, IMF Staff Papers, Vol. 40, No. 2, S. 451 - 470.

Berg, Andrew; Borensztein, Eduardo; Sahay, Ratna; Zettelmeyer, Jeromin (1999):

The Evolution of Output in Transition Economies: Explaining the Differences, IMF Working Paper No. 99/73, International Monetary Fund, Washington, D.C.

Berg, Andrew; Blanchard, Olivier J.(1994): Stabilization and Transition: Poland 1990-91, in: The Transition in Eastern Europe, Vol. 1, ed. by Olivier J. Blanchard, Kenneth A. Froot and Jeffrey D. Sachs, The University of Chicago Press, Chicago, S. $51-85$.

Bernholz, Peter (1994): Probleme der Währungs- und Budgetpolitik, in: Marktwirtschaft als Aufgabe - Wirtschaft und Gesellschaft im Übergang vom Plan zum Markt, hrsg. von Carsten Herrmann-Pillath, Otto Schlecht und Horst Friedrich Wünsche, Grundtexte zur Sozialen Marktwirtschaft, Band 3, Gustav Fischer Verlag, Stuttgart u.a., S. 535- 545.

Blackburn, Keith; Christensen, Michael (1989): Monetary Polic and Policy Credibility: Theories and Evidence, Journal of Economic Literature, Vol. 27, No. 1, S. $1-45$.

Blanchard, Olivier (1996): Theoretical Aspects of Transition, The American Economic Review, Papers and Proceedings, Vol. 86, No. 2, S. 117 - 122.

Blanchard, Olivier; Kremer, Michael (1997): Disorganization, Quarterly Journal of Economics, Vol. 112, No. 4, S. $1091-1126$. 
Bofinger, Peter (1991): Options for the Payments and Exchange Rate System in Eastern Europe, CEPR Discussion Paper No. 545, Centre for Economic Policy Research, London.

Bofinger, Peter; Reischle, Julian; Schächter, Andrea (1996): Geldpolitik: Ziele, Institutionen, Strategien und Instrumente, Verlag Vahlen, München.

Borensztein, Eduardo; Masson, Paul R. (1993): Exchange Arrangements of Previously Centrally Planned Economies, in: Financial Sector Reforms and Exchange Arrangements in Eastern Europe, Occasional Paper No. 102, Part II, International Monetary Fund, Washington, D.C., S. 35 - 57.

Borensztein, Eduardo; Demekas, Dimitri G.; Ostry, Jonathan D. (1993): An Empirical Analysis of the Output Declines in Three Eastern European Countries, IMF Staff Papers, Vol. 40, No. 1, S. $1-31$.

Brada, Josef C. (1998): Introduction: Exchange Rates, Capital Flows, and Commercial Policies in Transition Economies, Journal of Comparative Economics, Vol. 26, No. 4, S. $613-620$.

Brada, Josef C.; King, Arthur E. (1992): Is There a J-Curve for the Economic Transition from Socialism to Capitalism, Economics of Planning, Vol. 25, No. 1 , S. $37-53$.

Bruno, Michael (1991): High Inflation and the Nominal Anchors of an Open Economy, Essays in International Finance, No. 183, Princeton University, Princeton, New Jersey.

Bruno, Michael (1993): Stabilization and the Macroeconomics of Transition How Different is Eastern Europe?, Economics of Transition, Vol. 1, No. 1, S. 5 - 19, wiederabgedruckt in: Transition to the Market Economy: Critical Perspectives on the World Economy, ed. by Paul G. Hare and Junior R. Davis, Vol. 1, Routledge, London u.a., 1997, S. 303 - 320.

Bruno, Michael; Easterly, William (1998): Inflation Crises and Long-Run Growth, Journal of Monetary Economics, Vol. 41, No. 1, S. 3-26.

Buch, Claudia M. (1995a): Monetary Policy and the Transformation of the Banking System in Eastern Europe, Kieler Arbeitspapier Nr. 676, Institut für Weltwirtschaft an der Universität Kiel.

Buch, Claudia M. (1995b): The Emerging Financial Systems of the Eastern European Economies: A Progress Report, Kieler Arbeitspapier Nr. 716, Institut für Weltwirtschaft an der Universität Kiel.

Buch, Claudia M.; Koop, Michael J.; Schweickert, Rainer; Wolf, Hartmut (1995): Währungsreformen im Vergleich: Monetäre Strategien in Rußland, Weißrußland, Estland und der Ukraine, Kieler Studien Nr. 270, J.C.B. Mohr, Tübingen. 
Budina, Nina; van Wijnbergen, Sweder (1997): Fiscal Policies in Eastern Europe, Oxford Review of Economics, Vol. 13, No. 2, S. 47 - 64.

Burdekin, Richard C. K.; Salamun, Suyono; Willett, Thomas D. (1995): The High Costs of Monetary Instability, in: Establishing Monetary Stability in Emerging Market Economies, ed. by Thomas D. Willett, Richard J. Sweeney, Richard C. K. Burdekin and Clas Wihlborg, Westview Press, Boulder u.a., S. $13-32$.

Burton, David; Fischer, Stanley (1998): Ending Moderate Inflations, in: Moderate Inflation: The Experience of Transition Economies, ed. by Carlo Cottarelli and György Szapáry, International Monetary Fund and National Bank of Hungary, Washington, D.C., S. $15-96$.

Calvo, Guillermo A. (1978): On the Time Consistency of Optimal Policy in a Monetary Economy, Econometrica, Vol. 46, No. 6, S. 1411 - 1428.

Calvo, Guillermo A.;Coricelli, Fabrizio (1993): Output Collapse in Eastern Europe: The Role of Credit, IMF Staff Papers, Vol. 40, No. 1, S. 32 - 52.

Calvo, Guillermo A.; Kumar, Manmohan S. (1993): Financial Markets and Intermediation, in: Financial Sector Reforms and Exchange Arrangements in Eastern Europe, Occasional Paper No. 102, Part I, International Monetary Fund, Washington, D.C., S. 2-33.

Canzoneri, Matthew B.; Nolan, Charles; Yates, Anthony (1997): Mechanisms for Achieving Monetary Stability: Inflation Targeting versus the ERM, Journal of Money, Credit, and Banking, Vol. 29, No. 1, S. 46-60.

Christoffersen, Peter; Doyle, Peter (1998): From Inflation to Growth: Eight Years of Transition, IMF Working Paper No. 98/100, International Monetary Fund, Washington, D.C.

Cihák, Martin; Holub, Tomáš (1998): Inflation Targeting in the Czech Republic: Old Wine in New Bottles, Eastern European Economics, Vol. 36, No. 3, S. $49-67$.

Claassen, Emil-Maria (1991): Exchange Rate Policies in Developing and PostSocialist Countries: An Overview, in: Exchange Rate Policies in Developing and Post-Socialist Countries, ed. by Emil-Maria Claassen, ICS Press, San Francisco, S. 3 - 20.

Clark, Peter; Bartolini, Leonardo; Bayoumi, Tamim; Symansky, Steven (1994): Exchange Rates and Economic Fundamentals - A Framework for Analysis, Occasional Paper No. 115, International Monetary Fund, Washington, D.C.

Coorey, Sharmini; Mecagni, Mauro; Offerdal, Erik (1997): Designing Disinflation Programs in Transitions Economies: The Implications of Relative Price Adjustment, Paper on Policy Analysis and Assessment No. 97/1, International Monetary Fund, Washington D.C. 
Coorey, Sharmini; Mecagni, Mauro; Offerdal, Erik (1998): Disinflation in Transition Economies: The Role of Relative Price Adjustment, in: Moderate Inflation: The Experience of Transition Economies, ed. by Carlo Cottarelli and György Szapáry, International Monetary Fund and National Bank of Hungary, Washington, D.C., S. $230-279$.

Corden, W. Max (1991): Exchange Rate Policy in Developing Countries, in: Trade Theory and Economic Reform: North, South, and East, Essays in Honor of Béla Balassa, ed. by Jaime de Melo and André Sapir, Cambridge, Mass., S. $224-245$.

Corden, W. Max (1993): Exchange Rate Policies for Developing Countries, The Economic Journal, Vol. 103, No. 416, S. 198 - 207.

Corker, Robert; Beaumont, Craig; van Elkan, Rachel; Iakova, Dora (2000): Exchange Rate Regimes in Selected Advanced Transition Economies - Coping with Transition, Capital Inflows, and EU Accession, IMF Policy Discussion Paper No. 00/3, International Monetary Fund, Washington, D.C.

Cukierman, Alex (1988): The End of High Israeli Inflation: An Experiment in Heterodox Stabilization, in: Inflation Stabilization - The Experience of Israel, Argentina, Brazil, Bolivia, and Mexico, ed. by Michael Bruno, Guido Di Tella, Rüdiger Dornbusch and Stanley Fischer, The MIT Press, Cambridge, Mass., S. 48 - 94.

DB Global Markets Research (1999): Emerging Markets Weekly, 13 August 1999.

DB Global Markets Research (2000): Emerging Markets Weekly, 21 January 2000.

DB Research (1999a): Aktueller Länderbericht Balkan, März 1999.

DB Research (1999b): Aktueller Länderbericht Osteuropa, Dezember 1999.

DB Research (2000a): Emerging Markets Infobase, http://www.dbresearch.com.

DB Research (2000b): Country Brief Czech Republic, April 2000.

DB Research (2000c): Economic \& Financial Outlook, No. 4, April 17, 2000.

DB Research (2000d): Country Brief Baltics, May 2000.

de Melo, Martha; Denizer, Cevdet; Gelb, Alan (1996): From Plan to Market: Patterns of Transition, Policy Research Working Paper No. 1564, World Bank, Washington, D.C.

de Melo, Martha; Denizer, Cevdet; Gelb, Alan (1997a): From Plan to Market: Patterns of Transition, in: Macroeconomic Stabilization in Transition Economies, ed. by Mario I. Blejer and Marko Škreb, Cambridge University Press, Cambridge (UK), S. 17 - 72.

de Melo, Martha; Denizer, Cevdet; Gelb, Alan; Tenev, Stoyan (1997b): Circumstance and Choice: The Role of Initial Conditions and Policies in 
Transition Economies, Policy Research Working Paper No. 1866, World Bank, Washington, D.C.

Denizer, Cevdet (1997): Stabilization, Adjustment, and Growth Prospects in Transition Economies, Policy Research Working Paper No. 1855, World Bank, Washington, D.C.

Deutsche Bundesbank (1998): Die technische Ausgestaltung des neuen europäischen Wechselkursmechanismus, Monatsbericht Oktober, S. 19-25.

Devarajan, Shantayanan; Rodrik, Dani (1992): Do the Benefits of Fixed Exchange Rates Outweigh their Costs? The CFA Zone in Africa, in: Open Economies - Structural Adjustment and Agriculture, ed. by Ian Goldin und L. Alan Winters, Cambridge University Press, Cambridge (UK), S. 66 - 85.

Dibooglu, Selahattin; Kutan, Ali M. (2000), Sources of Real Exchange Rate Fluctuations in Transition Economies: The Case of Poland and Hungary, Working Paper aus der Social Science Research Network Electronic Library, April 2000, http://papers.ssrn.com/paper.ta?abstract_id=216956 (SSRN Electronic Paper Collection).

Diehl, Markus; Schweickert, Rainer (1997): Wechselkurspolitik im Aufholprozeß - Erfahrungen lateinamerikanischer, europäischer und asiatischer Länder, Kieler Studien Nr. 286, J.C.B. Mohr, Tübingen.

Dobozi, Istvan; Pohl, Gerhard (1995): Real Output Decline in Transition Economies - Forget GDP, Try Power Consumption Data!, Transition, Vol. 6, No. 1-2, S. $17-18$.

Dornbusch, Rüdiger (1980): Open Economy Macroeconomics, Basic Books, New York.

Drabek, Zdenek; Brada, Josef C. (1998): Exchange Rate Regimes and the Stability of Trade Policy in Transition Economies, Journal of Comparative Economics, Vol. 26, No. 4, S. $642-668$.

EBRD (1995): Transition Report, European Bank for Reconstruction and Development, London.

EBRD (1998): Transition Report, European Bank for Reconstruction and Development, London.

EBRD (1999): Transition Report, European Bank for Reconstruction and Development, London.

EBRD (2000): Transition Report Update, European Bank for Reconstruction and Development, London.

EBRD (verschiedene Jahrgänge): Transition Reports und Transition Report Updates, European Bank for Reconstruction and Development, London. 
Edwards, Sebastian (1989): Real Exchange Rates and Adjustment: Exchange Rate Policy in Developing Countries, The MIT Press, Cambridge, Mass.

Edwards, Sebastian (1993): Exchange Rates as Nominal Anchors, Weltwirtschaftliches Archiv, Bd. 129, Heft 1, S. 1 - 32.

Edwards, Sebastian (1996a): Stabilization and Liberalization Policies for Economies in Transition: Latin American Lessons for Eastern Europe, in: The Emergence of Market Economies in Eastern Europe, ed. by Christopher Clague and Gordon C. Rauser, Blackwell Publishers, Cambridge, Mass., S. $129-159$.

Edwards, Sebastian (1996b): The Determinants of the Choice between Fixed and Flexible Exchange-Rate Regimes, NBER Working Paper No. 5756, National Bureau of Economic Research, Cambridge, Mass.

Edwards, Sebastian (1998): Two Crises: Inflation Inertia and Credibility, The Economic Journal, Vol. 108, No. 448, S. 680 - 702.

Eichengreen, Barry (1999): Kicking The Habit: Moving From Pegged Rates To Greater Exchange Rate Flexibility, The Economic Journal, Vol. 109, No. 454, S. C1 - C14.

Eucken, Walter (1952): Grundsätze der Wirtschaftspolitik, J.C.B. Mohr, Tübingen. Europäische Kommission (1997): AGENDA 2000 - Eine stärkere und erweiterte Union, Bulletin der Europäischen Union, Beilage 5/97.

Europäische Kommission (1998): Abkommen vom 1. September 1998 zwischen der Europäischen Zentralbank und den nationalen Zentralbanken der nicht dem Euro-Währungsgebiet angehörenden Mitgliedstaaten über die Funktionsweise eines Wechselkursmechanismus in der dritten Stufe der Wirtschafts- und Währungsunion, Amtsblatt der Europäischen Gemeinschaften, C 345, 13.11.1998, S. 6 - 12.

Europäische Kommission (2000): http://www.europa.eu.int.

Europäische Zentralbank (1999): Die stabilitätsorientierte geldpolitische Strategie des Eurosystems, Monatsbericht Januar, S. 44- 56.

Europäische Zentralbank (2000a): Das Eurosystem und die EU-Erweiterung, Monatsbericht Februar, S. 41 - 54.

Europäische Zentralbank (2000b): ECB Press Conference, Introductory Statement by Willem F. Duisenberg, President of the European Central Bank, and Christian Noyer, Vice-President of the European Central Bank, Frankfurt am Main, 13 April 2000, http://www.ecb.int.

Europäisches Währungsinstitut (1997): Die Einheitliche Geldpolitik in Stufe 3 Festlegung des Handlungsrahmens, Europäisches Währungsinstitut, Frankfurt am Main, Januar 1997. 
Europäisches Währungsinstitut (1998): Konvergenzbericht, Nach Artikel 109j des Vertrags zur Gründung der Europäischen Gemeinschaft vorgeschriebener Bericht, Europäisches Währungsinstitut, Frankfurt am Main, März 1998.

Fischer, Stanley (1980): Dynamic Inconsistency, Cooperation and the Benevolent Dissembling Government, Journal of Economic Dynamics and Control, Vol. 2, No. 1, S. $93-107$.

Fischer, Stanley (1986): Exchange Rate versus Money Targets in Disinflation, in: Indexing, Inflation and Economic Policy, by Stanley Fischer, Cambridge, Mass., S. 247 - 262.

Fischer, Stanley; Sahay, Ratna; Végh, Carlos A. (1996): Stabilization and Growth in Transition Economies: The Early Experience, Journal of Economic Perspectives, Vol. 10, No. 2, S. $45-66$.

Fischer, Stanley; Sahay, Ratna; Végh, Carlos A. (1997): From Transition to Market: Evidence and Growth Prospects, in: Lessons from Economic Transition - Central and Eastern Europe in the 1990s, ed. by Salvatore Zecchini, Kluwer Academic Publishers, Dordrecht u.a., S. 79 - 101.

Fischer, Stanley; Sahay, Ratna (2000): The Transition Economies After Ten Years, IMF Working Paper No. 00/30, International Monetary Fund, Washington, D.C.

Frankel, Jeffrey A. (1995): Monetary Regime Choice for a Semi-Open Country, in: Capital Controls, Exchange Rates, and Monetary Policy in the World Economy, ed. by Sebastian Edwards, Cambridge University Press, Cambridge (UK), S. 35 - 69.

Freytag, Andreas (1998): Einige Anmerkungen zur Wahl der Reservewährung eines Currency Boards, Zeitschrift für Wirtschaftspolitik, 47. Jg., Heft 1, S. 3 $-19$.

Friedman, Milton (1953): The Case for Flexible Exchange Rates, in: Essays in Positive Economics, ed. by Milton Friedman, The University of Chicago Press, Chicago, S. $157-203$.

Fröhlich, Hans-Peter (1992): Währungspolitische Reformen in Osteuropa, Beiträge zur Wirtschafts- und Sozialpolitik Nr. 197, Institut der deutschen Wirtschaft, Deutscher Instituts-Verlag, Köln.

Fröhlich, Hans-Peter (1994): Wechselkurspolitik in den osteuropäischen Reformstaaten: Erste praktische Erfahrungen, in: Integration oder Desintegration der Weltwirtschaft?, hrsg. von Wolfgang Filc und Claus Köhler, Veröffentlichungen des Instituts für Empirische Wirtschaftsforschung, Band 31, Berlin, S. 169-189.

Funke, Norbert (1993): The Role of Credibility of Government Policy: Lessons for Economies in Transition, Intereconomics, Vol. 28, No. 2, S. 73 - 78. 
Gerloff, Axel (1999): Stabilization During the Early Years of Transition - Some Stylized Facts, Diskussionsbeiträge aus dem Volkswirtschaftlichen Seminar der Universität Göttingen, Beitrag Nr. 98, März 1999.

Gerloff, Axel (2000): Stylized Facts About Stabilization in Central and Eastern Europe, International Advances of Economic Research, Vol. 6, No. 2, S. 127 $-149$.

Gerloff, Axel; Speidel-Walz, Elke (2000): Emerging Markets: Indicators for Banking Sector Distress, in: Frankfurt Voice, DB Research, Frankfurt am Main, February 28, 2000, S. 12 - 15.

Giavazzi, Francesco; Pagano, Marco (1998): The Advantage of Tying One's Hands - EMS Discipline and Central Bank Credibility, European Economic Review, Vol. 32, S. 1055 - 1082.

Goodhart, Charles A.E. (1995): The Political Economy of Monetary Union, in: Understanding Interdependence - The Macroeconomics of the Open Economy, ed. by Peter B. Kenen, Princeton University Press, Princeton, New Jersey.

Grafe, Clemens; Wyplosz, Charles (1998): The Real Exchange Rate in Transition Economies, Centre for Economic Performance, Discussion Paper No. 395, London School of Economics and Political Science.

Greene, Joshua E.; Isard, Peter (1991): Currency Convertibility and the Transformation of Centrally Planned Economies, Occasional Paper No. 81, International Monetary Fund, Washington, D.C.

Gröner, Helmut; Smeets, Heinz-Dieter (1991): Transformation der Außenwirtschaft: Zur Öffnung und Weltmarktintegration geschlossener Volkswirtschaften, in: Transformationsprozesse in sozialistischen Wirtschaftssystemen - Ursachen, Konzepte, Instrumente, hrsg. von KarlHans Hartwig und H. Jörg Thieme, Studies in Contemporary Economics, Springer Verlag, Berlin u.a., S. $357-405$.

Gröner, Helmut; Smeets, Heinz-Dieter (1994): Außenwirtschaft im Transformationsprozeß, in: Marktwirtschaft als Aufgabe - Wirtschaft und Gesellschaft im Übergang vom Plan zum Markt, hrsg. von Carsten Herrmann-Pillath, Otto Schlecht und Horst Friedrich Wünsche, Grundtexte zur Sozialen Marktwirtschaft, Band 3, Gustav Fischer Verlag, Stuttgart u.a., S. $589-608$.

Gulde, Anne-Marie (1999): The Role of the Currency Board in Bulgaria's Stabilization, IMF Policy Discussion Paper No.99/3, International Monetary Fund, Washington, D.C.

Gulde, Anne-Marie; Kähkönen, Juha; Keller, Peter (2000): Pros and Cons of Currency Board Arrangements in the Lead-up to EU Accession and 
Participation in the Euro Zone, IMF Policy Discussion Paper No. 00/1, International Monetary Fund, Washington, D.C.

Haberler, Gottfried (1954): Konvertibilität der Währungen, in: Die Konvertibilität der europäischen Währungen, hrsg. von Albert Hunold, Eugen Rentsch Verlag, Erlenbach-Zürich und Stuttgart, S. 15 - 59.

Hagemann, Michael; Klemencic, Alenka (1974): Die Sozialistische Marktwirtschaft Jugoslawiens, Schriften zum Vergleich von Wirtschaftsordnungen, Heft 22, Gustav Fischer Verlag, Stuttgart u.a.

Halpern, László; Wyplosz, Charles (1997): Equilibrium Exchange Rates in Transition Economies, IMF Staff Papers, Vol. 44, No. 4, S. 430 - 461.

Hamacher, Stefanie (1992): Die geld- und währungspolitischen Probleme osteuropäischer Reformländer, Deutscher Sparkassenverlag, Stuttgart.

Hartwig, Karl-Hans (1995): Geldpolitik im Transformationsprozeß - Verlauf und Restriktionen, in: Geld und Kredit im Transformationsprozeß, hrsg. von H. Jörg Thieme, Schriften des Vereins für Socialpolitik, Band 236, Duncker \& Humblot, Berlin, S. $11-35$.

Havrylyshyn, Oleh; Izorski, Ivailo; van Rooden, Ron (1998): Recovery and Growth in Transition Economies 1990-97: A Stylized Regression Analysis, IMF Working Paper No. 98/141, International Monetary Fund, Washington, D.C.

Havrylyshyn, Oleh; Izorski, Ivailo; van Rooden, Ron (1999): Growth in Transition Economies 1990-97: An Econometric Analysis with Application to Ukraine, in: Ukraine at the Crossroads - Economic Reforms in International Perspective, ed. by Axel Siedenberg and Lutz Hoffmann, Physica-Verlag, Heidelberg, S. $22-57$.

Havrylyshyn, Oleh;van Rooden, Ron (2000): Institutions Matter in Transition, but so do Policies, IMF Working Paper Ṇo. 00/70, International Monetary Fund, Washington, D.C..

Havrylyshyn, Oleh; Williamson, John (1991): From Soviet disUnion to Eastern Economic Community?, Policy Analyses in International Economics, No. 35, Institute for International Economics, Washington D.C.

Hernández-Catá, Ernesto (1997): Liberalization and Behavior of Output During the Transition from Plan to Market, IMF Staff Papers, Vol. 44, No. 4, S. 405 $-429$.

Hernández-Catá, Ernesto (1999): Price Liberalization, Money Growth, and Inflation During the Transition to a Market Economy, IMF Working Paper No. 99/76, International Monetary Fund, Washington, D.C.

Hochreiter, Eduard (1995): Central Banking in Economies in Transition, in: Establishing Monetary Stability in Emerging Market Economies, ed. by 
Thomas D. Willett, Richard J. Sweeney, Richard C. K. Burdekin and Clas Wihlborg, Westview Press, Boulder u.a., S. $127-144$.

Hochreiter, Eduard; Kowalski, Tadeusz (1999): Central Banking Institutions in Selected European Emerging Market Economies, mimeo, July 23, 1999.

Hochreiter, Eduard; Riesinger, Sandra (1995): Central Banking in Central and Eastern Europe - Selected Institutional Issues, Ecu: revue trimestrielle, No. 32, July 1995 , S. $17-22$.

Horn, Henrik; Persson, Torsten (1988): Exchange Rate Policy, Wage Formation, and Credibility, European Economic Review, Vol. 32, S. 1621 - 1636.

Horvath, Julius; Jonas, Jiri (1998): Exchange Rate Regimes in the Transition Economies - Case Study of the Czech Republic: 1990 - 1997, ZEI Working Paper B98-11, Zentrum für Europäische Integrationsforschung an der Universität Bonn, September 1998.

Hrncir, Miroslav (1994): The Exchange Rate and Transition: The Case of the Former Czechoslovakia, in: Macroeconomic Problems of Transformation: Stabilization Policies and Economic Restructuring, ed. by Hansjörg Herr, Silke Tober and Andreas Westphal, Edward Elgar, Aldershort u.a., S. 228 255.

Hrncir, Miroslav (1997): Monetary Policy in the Czech Republic: Strategies, Instruments and Transmission Mechanisms, in: Monetary Policy in Transition: Strategies, Instruments and Transmission Mechanisms, ed. by. Oesterreichische Nationalbank, Wien, S. $167-186$.

Ickes, Barry W. (1996): Comment on „How to Stabilize: Lessons from PostCommunist Countries" by Anders Åslund, Peter Boone, and Simon Johnson, in: Brookings Papers on Economic Activity, No. 1, The Brookings Institution, Washington, D.C., S. 298 - 305.

Illing, Gerhard (1997): Theorie der Geldpolitik - Eine spieltheoretische Einführung, Springer Verlag, Berlin u.a.

Illing, Gerhard; Fecht, Falko (1998): Konservativer Zentralbanker versus Optimaler Zentralbankkontrakt - Eine spieltheoretische Analyse, wisu - das wirtschaftsstudium, 27. Jg., Heft 1, S. 84 - 93.

Ilzkovitz, Fabienne (1996): Challenges to the Monetary and Exchange Rate Policies of Central and East European Acceding Countries: An EU Perspective, in: Monetary Policy in Central and Eastern Europe: Challenges of EU Integration, ed. by Olga Radzyner and Peter Havlik, Oesterreichische Nationalbank und Wiener Institut für internationale Wirtschaftsvergleiche, Wien, S. $242-257$.

IMF (1995): IMF Survey, November 20, 1995, International Monetary Fund, Washington D.C. 
IMF (1997a): World Economic Outlook, October 1997, International Monetary Fund, Washington D.C.

IMF (1997b): Government Finance Statistics, Yearbook 1997, International Monetary Fund, Washington D.C.

IMF (1998): World Economic Outlook, Chapter V, May 1998, International Monetary Fund, Washington D.C.

IMF (1999): The Economic Consequences of the Kosovo Crisis: An Updated Assessment, prepared by staff of the International Monetary Fund in consultation with the World Bank staff, May 25, 1999, http://www.imf.org/external/pubs/ft/kosovo/052599.htm.

IMF (2000): Czech Republic, IMF Staff Country Report No. 00/96, International Monetary Fund, Washington D.C., August 2000.

IMF (verschiedene Jahrgänge): World Economic Outlook, International Monetary Fund, Washington D.C.

Issing, Otmar (1989): Vom Primat der Währungspolitik, ORDO - Jahrbuch für die Ordnung von Wirtschaft und Gesellschaft, Band 40, S. $351-361$.

Issing, Otmar (1996), Einführung in die Geldpolitik, 6., überarb. Auflage, Verlag Franz Vahlen, München.

Janácková, Stanislava (1995): Transforming the Czech Economy - The Role of Convertibility and the Exchange-Rate Anchor, Eastern European Economics, Vol. 33, No. 5, S. $33-61$.

Janácková, Stanislava (1998): Convergence for European Union Accession Challenges for Czech Monetary Policy, Eastern European Economics, Vol. 36, No. 3, S. $80-95$.

Jarchow, Hans-Joachim (1993): Diskretionäre Geldpolitik, Zeitinkonsistenz und Politikglaubwürdigkeit, wisu - das wirtschaftsstudium, 22. Jg., Heft 2, S. $145-151$.

Jarchow, Hans-Joachim (1995): Theorie und Politik des Geldes, II. Geldpolitik, 7., neubearb. und erw. Auflage, Vandenhoeck \& Ruprecht, Göttingen.

Jarchow, Hans-Joachim (1998a): Theorie und Politik des Geldes 1, 10., überarb. und wesentlich erw. Auflage, Vandenhoeck \& Ruprecht, Göttingen.

Jarchow, Hans-Joachim (1998b): Zur Diskussion über die Europäische Währungsunion und ihre Realisierung, in: Die ökonomischen Außenbeziehungen der EWU: währungs- und handelspolitische Aspekte, hrsg. von Rolf H. Hasse und Wolf Schäfer, Vandenhoeck \& Ruprecht, Göttingen, S. 5 - 25 . 
Jarchow, Hans-Joachim; Rühmann, Peter (1997): Monetäre Außenwirtschaft, II. Internationale Währungspolitik, 4., überarb. und erw. Auflage, Vandenhoeck \& Ruprecht, Göttingen.

Jarchow, Hans-Joachim; Rühmann, Peter (2000): Monetäre Außenwirtschaft, I. Monetäre Außenwirtschaftstheorie, 5., neubearb. und wesentlich erw. Auflage, Vandenhoeck \& Ruprecht, Göttingen.

Joebges, Heike (2000): Ursachen für die Häufigkeit von „Zwillingskrisen“ in Schwellenländern, DIW Vierteljahreshefte zur Wirtschaftsforschung, 69.Jg., Heft 1, S. $38-52$.

Johnson, Harry G. (1969): The Case For Flexible Exchange Rates, The Federal Reserve Bank of St. Louis Review, Vol. 51, No. 6, S. 12 - 24.

Kaminsky, Garciela; Reinhart, Carmen M. (1999): The Twin Crises: The Causes of Banking and Balance of Payments Problems, The American Economic Review, Vol. 89, No. 3, S. 473 - 500.

Kenen, Peter B. (1991): Transitional Arrangements for Trade and Payments Among the CMEA Countries, IMF Staff Papers, Vol. 38, No. 2, S. 235 267.

Keuzenkamp, Hugo A. (1991): A Precursor to Muth: Tinbergen's 1932 Model of Rational Expectations, The Economic Journal, Vol. 101, S. 1245 - 1253.

Kloten, Norbert (1989): Zur Transformation von Wirtschaftsystemen, ORDO Jahrbuch für die Ordnung von Wirtschaft und Gesellschaft, Band 40, S. 99 127.

Koch, Elmar B. (1997): Exchange Rates and Monetary Policy in Central Europe A Survey of Some Issues, OeNB Working Paper No. 24, Oesterreichische Nationalbank, Wien.

Köhler, Horst; Wes, Marina (1999): Bedeutung des Euro für den währungspolitischen Integrationsprozeß in Osteuropa, in: Die Europäische Zentralbank: Europäische Geldpolitik im Spannungsfeld zwischen Wirtschaft und Politik, hrsg. von Diethard B. Simmert und Ernst Welteke, Deutscher Sparkassenverlag, Stuttgart, S. 285 - 316.

Koen, Vincent; de Masi, Paula R. (1997): Prices in the Transition: Ten Stylized Facts, Staff Studies for the World Economic Outlook, International Monetary Fund, Washington, D.C., December 1997, S. 128 - 143.

Kopits, George (1999): Implications of EMU for Exchange Rate Policy in Central and Eastern Europe, IMF Working Paper No. 99/9, International Monetary Fund, Washington, D.C.

Korhonen, Iikka (1999a): Currency Boards in the Baltic Countries: What have we learned?, BOFIT Discussion Paper No. 6, Bank of Finland Institute for Economies in Transition, Helsinki. 
Korhonen, Iikka (1999b): Some Implications of EU Membership on Baltic Monetary and Exchange Rate Policies, BOFIT Online No. 8, Bank of Finland Institute for Economies in Transition, Helsinki.

Kornai, János (1994): Transformational Recession: The Main Causes, Journal of Comparative Economics, Vol. 19, No. 1, S. 39-63.

Krajnyák, Kornélia; Zettelmeyer, Jeromin (1998): Competitiveness in Transition Economies: What Scope for Real Appreciation?, IMF Staff Papers, Vol. 45, No. 2, S. $309-362$.

Krueger, Gary; Ciolko, Marek (1998): A Note on Initial Conditions and Liberalization during Transition, Journal of Comparative Economics, Vol. 26, No. 4, S. $718-734$.

Krzak, Maciej (1998): Developments in Selected Countries, Focus on Transition, 2/1998, S. 8 - 19.

Krzak, Maciej; Backé, Peter; Mauler, Kurt; Radzyner, Olga; Riesinger, Sandra (1997): Developments in Selected Countries, Focus on Transition, 1/1997, S. $8-17$.

Krzak, Maciej; Ertl, Helmut (1999): Is Direct Inflation an Alternative for Central Europe? The Case of the Czech Republic and Poland, Focus on Transition, $1 / 1999$, S. $28-59$.

Kydland, Finn E.; Prescott, Edward C. (1977): Rules Rather than Discretion: The Inconsistency of Optimal Plans, Journal of Political Economy, Vol. 85, No. 3, S. $473-491$.

Lahiri, Amartya (2000): Disinflation Programs Under Policy Uncertainty, Journal of International Economics, Vol. 50, No. 2, S. 351 - 373.

Lainela, Seija; Sutela, Pekka (1994): The Baltic Economies in Transition, Publications of the Bank of Finland, Series A, No. 91, Bank of Finland, Helsinki.

Lavigne, Marie (1998): Conditions for Accession to the EU, Comparative Economic Studies, Vol. 40, No. 3, S. 38 - 57.

Lipton, David; Sachs, Jeffrey D. (1990): Creating a Market Economy in Eastern Europe: The Case of Poland, Brookings Papers on Economic Activity, No. 1, The Brookings Institution, Washington, D.C., S. 75 - 133.

Loef, Hans-Edi; Ziemes, Georg (1989): Zeitinkonsistenz, WiSt Wirtschaftswissenschaftliches Studium, 18. Jg., Heft 10, S. 446 - 451.

Loungani, Prakash; Sheets, Nathan (1997): Central Bank Independence, Inflation, and Growth in Transition Economies, Journal of Money, Credit, and Banking, Vol. 29, No. 3, S. $381-399$. 
Lutz, Friedrich A. (1954): Die Konvertibilitätsdiskussion, in: Die Konvertibilität der europäischen Währungen, hrsg. von Albert Hunold, Eugen Rentsch Verlag, Erlenbach-Zürich und Stuttgart, S. $297-316$.

Lybek, Tonny (1999): Central Bank Autonomy, and Inflation and Output Performance in the Baltic States, Russia, and Other Countries of the Former Soviet Union, 1995 - 1997, IMF Working Paper No. 99/4, International Monetary Fund, Washington, D.C.

Machowski, Heinrich (1989): Rückwirkungen der sowjetischen Reformpolitik auf die Zusammenarbeit im „Rat für Gegenseitige Wirtschaftshilfe“ (RGW), in: Wirtschaftsreformen in Osteuropa, hrsg. von Sven Bradke, zugleich Heft III/IV 1989 der Zeitschrift Aussenwirtschaft, Verlag Rüegger, Grüsch, S. 93 $-110$.

Macours, Karen; Swinnen, Johan F.M. (2000): Causes of Output Decline in Economic Transition: The Case of Central and Eastern European Agriculture, in: Journal of Comparative Economics, Vol. 28, No. 1, S. 172 206.

Masson, Paul R. (1999): Monetary and Exchange Rate Policy of Transiton Economies of Central and Eastern Europe after the Launch of EMU, IMF Policy Discussion Paper No. 99/5, International Monetary Fund, Washington, D.C.

Masson, Paul R.; Savastano, Miguel A.; Sharma, Sunil (1997): The Scope for Inflation Targeting in Developing Countries, IMF Working Paper No. 97/130, International Monetary Fund, Washington, D.C.

McKinnon, Ronald I. (1963): Optimum Currency Areas, The American Economic Review, Vol. 53, No. 4, S. $717-725$.

Mencinger, Joze (1993): How to Create a Currency? - The Experience of Slovenia, Weltwirtschaftliches Archiv, Bd. 129, Heft 4, S. 418 - 431.

Mishkin, Frederic S. (1999): International Experiences With Different Monetary Policy Regimes, Journal of Monetary Economics, Vol. 43, No. 3, S. 579 605.

Moghadam, Reza (1998): What Determines Inflation in Hungary? A CrossCountry Perspective, in: Hungary: Economic Policies for Sustainable Growth, by Carlo Cottarelli, Thomas Krueger, Reza Moghadam, Perry Perone, Edgardo Ruggiero, and Rachel van Elkan, Occasional Paper No. 159, International Monetary Fund, Washington, D.C.

Mundell, Robert A. (1997): The Great Contractions in Transition Economies, in: Macroeconomic Stabilization in Transition Economies, ed. by Mario I. Blejer and Marko Škreb, Cambridge University Press, Cambridge (UK), S. $73-99$. 
Muth, John F (1961): Rational Expectations and the Theory of Price Movements, Econometrica, Vol. 29, No. 3, S. 315 - 335.

National Bank of Poland (1998): Medium-Term Strategy of Monetary Policy (1999-2003), Warschau, September 1998.

National Bank of Romania (1998): The National Bank of Romania Act, Law No. $101 / 1998$, http://www.bnro.ro/def_en.htm.

o.V. (1996): General Discussion of „How to Stabilize: Lessons from PostCommunist Countries" by Anders Åslund, Peter Boone, and Simon Johnson, in: Brookings Papers on Economic Activity, No. 1, The Brookings Institution, Washington, D.C., S. $305-308$.

o.V. (2000): Estland will den Euro einführen, Frankfurter Allgemeine Zeitung, 25.01.2000.

OECD (1993): Romania - An Economic Assessment, Paris.

OECD (1996): Economic Survey of the Czech Republic, Paris.

OECD (1997a): Economic Survey of Bulgaria, Paris.

OECD (1997b): Economic Survey of Slovenia, Paris.

OECD (1998): Economic Survey of Romania, Paris.

OECD (1999a): Economic Survey of Bulgaria, Paris.

OECD (1999b): Economic Survey of the Slovak Republic, Paris.

OECD (2000): Economic Survey of the Czech Republic, Paris.

Ohr, Renate (1996): Exchange Rate Policy in Eastern Europe, in: Openness and Development, hrsg. von Franz P. Lang und Renate Ohr, Yearbook of Economics and Social Relations 1996, Physica Verlag, Heidelberg, S. 217 242.

Okun, Arthur M. (1970): The Political Economy of Prosperity, The Brookings Institution, Washington, D.C.

Orlowski, Lucjan T. (1998): Exchange-Rate Policies in Central Europe and Monetary Union, Comparative Economic Studies, Vol. 40, No. 3, S. 58 - 78.

Petersen, Hans-Georg; Sowada, Christoph (1995): The Polish Success in Monetary Stabilization - New Insights into Monetary Policy in the Transformation Process, in: Konzepte und Erfahrungen der Geldpolitik, hrsg. von HansHermann Francke und Eberhart Ketzel, Beihefte zu Kredit und Kapital, Heft 13, Duncker \& Humblot, Berlin, S. $383-411$.

Pieper, Bernhard (1995): Währung in der Transformation: Wirtschaftslenkung, Stabilisierung und außenwirtschaftliche Öffnung beim Übergang von der Plan- zur Marktwirtschaft, Nomos Verlagsgesellschaft, Baden-Baden. 
Pitlik, Hans (2000): Explaining Economic Performance During Transition: What Do We Know?, Intereconomics, Vol. 35, No. 1, S. 38 - 45.

Pleskovic, Boris; Sachs, Jeffrey D. (1994), Political Independence and Economic Reform in Slovenia, in: The Transition in Eastern Europe, Vol. 1, ed. by Olivier J. Blanchard, Kenneth A. Froot, Jeffrey D. Sachs, The University of Chicago Press, Chicago, S. $191-219$.

Plötz, Peter; Ritter, Raymond (1998): Die Integration Litauens in die weltwirtschaftliche Arbeitsteilung unter besonderer Berücksichtigung der Beziehungen zur Europäischen Union, Osteuropa-Wirtschaft, 43. Jg., Heft 1, S. $1-25$.

Pujol, Thierry; Griffiths, Mark (1998): Moderate Inflation in Poland: A Real Story, in: Moderate Inflation: The Experience of Transition Economies, ed. by Carlo Cottarelli and György Szapáry, International Monetary Fund and National Bank of Hungary, Washington, D.C., S. 197 - 229.

Radzyner, Olga; Riesinger, Sandra (1996): Exchange Rate Policy in Transition Developments and Challenges in Central and Eastern Europe, Focus on Transition, 1/1996, S. 20 - 38.

Radzyner, Olga; Riesinger, Sandra (1997): Central Bank Independence in Transition: Legislation and Reality in Central and Eastern Europe, Focus on Transition, 1/1997, S. 57 - 90.

Rebelo, Sergio; Végh, Carlos A. (1995): Real Effects of Exchange-Rate-Based Stabilization: An Analysis of Competing Theories, in: NBER Macroeconomics Annual 1995, ed. by Ben S. Bernanke and Julio J. Rotemberg, National Bureau of Economic Research, Cambridge, Mass., S. $125-174$.

Repse, Einars (1999): Monetary Policy and Exchange Rate Strategies, Speech held at the ECB Seminar on the Accession Process, November 11, 1999, Helsinki, http://www.bank.lv/izdevumi/English/index_runas.html.

Rodrik, Dani (1989): Credibility of Trade Reform - a Policy Maker's Guide, The World Economy, Vol. 12, No. 1, S. 1 - 16.

Rodrik, Dani (1993): Making Sense of the Soviet Trade Shock in Eastern Europe: A Framework and Some Estimates, in: Eastern Europe in Transition: From Recession to Growth?, ed. by Mario I. Blejer, Guillermo A.Calvo, Fabrizio Coricelli and Alan H.Gelb, Proceedings of a Conference on the Macroeconomic Aspects of Adjustment, World Bank, Washington, D.C., S. $64-85$.

Rodrik, Dani (1995): Trade Liberalization in Disinflation, in: Understanding Interdependence: The Macroeconomics of the Open Economy, ed. by Peter B. Kenen, Princeton University Press, Princeton, New Jersey, S. 291 - 312. 
Rogoff, Kenneth (1985): The Optimal Degree of Commitment to an Intermediate Monetary Target, Quarterly Journal of Economics, Vol. 100, No. 4, S. 1169 $-1189$.

Roland, Gérard; Verdier, Thierry (1999): Transition and the Output Fall, The Economics of Transition, Vol. 7, No. 1, S. 1 - 28.

Rosati, Dariusz (1997): Exchange Rate Policies in Post-Communist Economies, in: Lessons from Economic Transition - Central and Eastern Europe in the 1990s, ed. by Salvatore Zecchini, Kluwer Academic Publishers, Dordrecht u.a., S. $481-502$.

Rose, Klaus; Sauernheimer, Karlhans (1999): Theorie der Außenwirtschaft, 13., überarb. Auflage, Verlag Franz Vahlen, München.

Sachs, Jeffrey D. (1996a): Economic Transition and the Exchange-Rate Regime, The American Economic Review, Papers and Proceedings, Vol. 86, No. 2, S. $147-152$.

Sachs, Jeffrey D. (1996b): The Transition at Mid Decade, The American Economic Review, Papers and Proceedings, Vol. 86, No. 2, S. 128 - 133.

Salter, W.E.G. (1959): Internal and External Balance: The Role of Price and Expenditure Effects, The Economic Record, Vol. 35, No. 71, S. 226 - 238.

Schäfer, Wolf (1994): Wechselkurspolitische Optionen für Osteuropa, in: Integration oder Desintegration der Weltwirtschaft?, hrsg. von Wolfgang Filc und Claus Köhler, Veröffentlichungen des Instituts für Empirische Wirtschaftsforschung, Band 31, Berlin, S. 191 - 205.

Schäfer, Wolf (1998): Zur monetären Anbindung der Transformationsländer an die EWU, in: Die ökonomischen Außenbeziehungen der EWU: währungs- und handelspolitische Aspekte, hrsg. von Rolf H. Hasse und Wolf Schäfer, Vandenhoeck \& Ruprecht, Göttingen, S. 129 - 139.

Schäfer, Wolf (2000): MOEL - Wechselkursarrangements, in: Geldpolitik und Europäische Währungsunion, Festschrift für Hans-Joachim Jarchow zum 65. Geburtstag, hrsg. von Günther Engel und Peter Rühmann, Vandenhoeck \& Ruprecht, Göttingen, S. $217-228$.

Schmieding, Holger (1992): Lending Stability to Europe's Emerging Market Economies - On the Potential Importance of the EC and the ECU for Central and Eastern Europe, Kieler Studien Nr. 251, J.C.B. Mohr, Tübingen.

Schmieding. Holger; Buch. Claudia M. (1992): Better Banks for Eastern Europe, Kieler Diskussionsbeitrag Nr. 197, Institut für Weltwirtschaft an der Universität Kiel.

Schuler, Kurt (1999): The Problem with Pegged Exchange Rates, Kyklos, Vol. 52, Fasc. 1, S. $83-102$. 
Schweickert, Rainer (1993): Implikationen alternativer geld- und wechselkurspolitischer Regeln im Transformationsprozeß, Kredit und Kapital, 26. Jg., Heft 2, S. $205-229$.

Schweickert, Rainer; Nunnenkamp, Peter; Hiemenz, Ulrich (1992): Stabilisierung durch feste Wechselkurse: Fehlschlag in Entwicklungsländern Erfolgsrezept für Osteuropa?, Kieler Diskussionsbeiträge Nr. 181, Institut für Weltwirtschaft an der Universtität Kiel.

Smeets, Heinz-Dieter (1995): Preisniveaustabilisierung durch Wechselkursbindung. Eine erfolgversprechende Strategie für die Länder Mittel- und Osteuropas?, in: Geld und Kredit im Transformationsprozeß, hrsg. von $\mathrm{H}$. Jörg Thieme, Schriften des Vereins für Socialpolitik, Band 236, Duncker \& Humblot, Berlin, S. 81 - 107.

Södersten, Bo; Reed, Geoffrey (1994): International Economics, $3^{\text {rd }}$ edition, Macmillan Press Ltd, Houndmills u.a.

Stippler, Irmgard (1998): Die Rolle der Wechselkurspolitik während des Übergangs von der Plan- zur Marktwirtschaft - Eine theoretische und empirische Analyse am Beispiel der Visegrád-Länder, Veröffentlichungen des Osteuropa-Institutes München, Reihe: Wirtschaft und Gesellschaft, Heft 23, Duncker \& Humblot, Berlin.

Stolze, Frank (1997): The Central and East European Currency Phenomenon Reconsidered, Eastern European Economics, Vol. 35, No. 1, S. 5 - 30.

Swan, Trevor W. (1960): Economic Control in a Dependent Economy, The Economic Record, Vol. 36, No. 73, S. $51-66$.

Swan, Trevor W. (1963): Longer-Run Problems of the Balance of Payments, in: The Australian Economy, A Volume of Readings, ed. by H. W. Arndt and W. M. Corden, S. $384-395$.

Szapáry, György; Jakab, Zoltán M. (1998): Exchange Rate Policy in Transition Economies: The Case of Hungary, Journal of Comparative Economics, Vol. 26, No. 4, S. $691-717$.

Temprano-Arroyo, Heliodoro; Feldman, Robert A. (1998): Selected Transition and Mediteranean Countries: An Institutional Primer on EMU and EU Relations, IMF Working Paper No. 98/82, International Monetary Fund, Washington, D.C.

Thieme, H. Jörg (1995): Vorwort, in: Geld und Kredit im Transformationsprozeß, hrsg. von H. Jörg Thieme, Schriften des Vereins für Socialpolitik, Band 236, Duncker \& Humblot, Berlin.

Tinbergen, Jan (1932): Ein Problem der Dynamik, Zeitschrift für Nationalökonomie, Bd. 3, Heft 2, S. 169 - 184. 
Tober, Silke (1995): Die Beendigung extremer monetärer Instabilität, in: Wirtschaftspolitik in einer Geldwirtschaft, hrsg. von Karl Betz und Hajo Riese, Studien zur monetären Ökonomie, Bd. 14, Metropolis-Verlag, Marburg, S. $29-52$.

Toren, Susanne (1999): Der Einsatz des Wechselkurses als nominaler Anker in den CEFTA-Staaten zwischen 1989/90 und 1997, Univerität Göttingen, Dissertation.

Tornell, Aarón; Velasco, Andrés (1998): Fiscal Discipline and the Choice of a Nominal Anchor in Stabilization, Journal of International Economics, Vol. 46, No. 1 , S. $1-30$.

Tornell, Aarón; Velasco, Andrés (2000): Fixed Versus Flexible Exchange Rates: Which Provides More Fiscal Discipline?, Journal of Monetary Economics, Vol. 45, No. 2, S. $399-436$.

Tosovský, Josef (1994): Exchange Rate and the Transition: The Case of the Czech Republic, in: Geld- und Währungspolitik in kleinen, offenen Volkswirtschaften: Österreich, Schweiz, Osteuropa, hrsg. von Dieter Duwendag, Duncker \& Humblot, Berlin, S. 71 - 85.

van Brabant, Jozef M. (1985): Exchange Rates in Eastern Europe - Types, Derivation, and Application, World Bank Staff Working Paper No. 778, World Bank, Washington, D.C.

Vaubel, Roland (1994): Die Währungsordnung im Transformationsprozeß, in: Marktwirtschaft als Aufgabe - Wirtschaft und Gesellschaft im Übergang vom Plan zum Markt, hrsg. von Carsten Herrmann-Pillath, Otto Schlecht und Horst Friedrich Wünsche, Grundtexte zur Sozialen Marktwirtschaft, Band 3, Gustav Fischer Verlag, Stuttgart u.a., S. 561 - 573.

Viksnins, George J.; Rimshevitchs, Ilmars (1995): The Latvian Monetary Reform, in: Establishing Monetary Stability in Emerging Market Economies, ed. by Thomas D. Willett, Richard J. Sweeney, Richard C. K. Burdekin, and Clas Wihlborg, Westview Press, Boulder u.a., S. 231 - 235.

Visser, Hans (1995): A Guide to International Monetary Economics - Exchange Rate Systems and Exchange Rate Theories, Edward Elgar, Aldershot.

Wagner, Helmut (1998a): Inflation Targeting, WiSt Wirtschaftswissenschaftliches Studium, 27. Jg., Heft 6, S. 295 - 301.

Wagner, Helmut (1998b): Central Banking in Transition Countries, IMF Working Paper No. 98/126, International Monetary Fund, Washington, D.C.

Weber, Ralf L. (1995): Außenwirtschaft und Systemtransformation: Zur Bedeutung der Zahlungsbilanzrestriktion im Übergang von der Zentralverwaltungswirtschaft zur Marktwirtschaft, Schriften zum Vergleich von Wirtschaftsordnungen, Band 46, Gustav Fischer Verlag, Stuttgart u.a.. 
Wellisz, Stanislaw (1997): Inflation and Stabilization in Poland 1990-95, in: Macroeconomic Stabilization in Transition Economies, ed. by Mario I. Blejer and Marko Škreb, Cambridge University Press, Cambridge (UK), S. $157-171$.

Westin, Ann-Margret (1998): The Baltic Countries and Accession to the European Union, in: The Baltic Countries - From Economic Stabilization to EU Accession, by Julian Berengaut, Augusto Lopez-Claros, Francoise Le Gall, Dennis Jones, Richard Stern, Ann-Margret Westin, Effie Psalida, and Pietro Garibaldi, Occasional Paper No. 173, International Monetary Fund, Washington, D.C.

Willett, Thomas D.; Al-Marhubi, Fahim (1994): Currency Policies for Inflation Control in the Formerly Centrally Planned Economies, The World Economy, Vol. 17, No. 6, S. $795-816$.

Williamson, John (1991): The Economic Opening of Eastern Europe, Policy Analyses in International Economics No. 31, Institute for International Economics, Washington D.C.

Williamson, John (1994): Estimates of FEERs, in: Estimating Equilibrium Exchange Rates, ed. by John Williamson, Institute for International Economics, Washington, D.C. S. $177-243$.

Wohlmann, Monika (1998): Der nominale Wechselkurs als Stabilitätsanker: Die Erfahrungen Argentiniens 1991-1995, Göttinger Studien zur Entwicklungsökonomik, Vervuert Verlag, Frankfurt am Main.

Wozniak, Przemyslaw (1998): Relative Prices and Inflation in Poland, 1989-97: The Special Role of Administered Price Increases, Policy Research Working Paper No. 1879, World Bank, Washington, D.C.

Zeitler, Franz-Christoph (2000): The Euro and the Currency Systems in Central and Eastern Europe, in: Deutsche Bundesbank, Auszüge aus Presseartikeln Nr. 17, 3. April 2000, S. 8 - 12. 
Axel Gerloff - 978-3-631-75700-0

Downloaded from PubFactory at 01/11/2019 02:46:37AM

via free access 


\section{CeGE-Schriften}

Das CeGE - Center for Globalization and Europeanization of the Economy - wurde 1999 von der Wirtschaftswissenschaftlichen Fakultät der Georg-August-Universität Göttingen gegründet. Das Zentrum dient als Forum zur internationalen und interdisziplinären Zusammenarbeit bei der Analyse ökonomischer Fragestellungen von europäischer oder globaler Bedeutung. In den CeGE-Schriften werden Forschungsergebnisse aus Dissertationen, Habilitationen und anderen Forschungsprojekten des Zentrums veröffentlicht.

Band 1 Axel Gerloff: Wechselkurspolitik in Mittel- und Osteuropa. Eine theoretische Analyse unter besonderer Berücksichtigung der Erfahrungen der zehn Kandidaten für eine EU-Osterweiterung. 2001. 


\title{
Welthandelsorganisation WTO (GATT)
}

\author{
Aufgaben / Aktivitäten / EU-Beziehungen \\ Ein Hand- und Lehrbuch
}

Frankfurt/M., Berlin, Bern, Bruxelles, New York, Oxford, Wien, 2001. IV, 300 S., zahlr. Tab. u. Graf.

ISBN 3-631-37865-3 • br. DM 49. -*

Die WTO ist die einzige internationale Wirtschaftsinstitution, deren Entscheidungen mit Sanktionen völkerrechtlich bindende Wirkung haben und selbst von den großen Wirtschaftsmächten der Welt akzeptiert werden. Deshalb zählt sie zu den mächtigsten Akteuren auf der internationalen Bühne. Der krasse Wandel durch die Neuordnung des GATT-Systems in der Weltwirtschaft ist ebenso unüberschaubar wie die Tatsache, dass die Welt von einem freien Warenaustausch noch weit entfernt ist. Industriestaaten verteuern nicht nur agrarische Importgüter, auch für Industriegüterimporte werden zusätzliche Handelshemmnisse ausgedacht. Der Multilateralismus enweist sich als positiv bezüglich des Interessenschutzes wirtschaftlich schwächerer Länder, trotz der derzeitigen strukturellen Krise. Der WTO wird deshalb in der zukünftigen Architektur der Weltwirtschaft eine tragende Funktion zugewiesen. Alle Probleme der „wilden Globalisierung" unmittelbar der WTO anzulasten, ändert nichts an der Tatsache, dass sie heute wichtigster Bestandteil der Weltwirtschaftsordnung geworden ist. Die am Export orientierten Unternehmen müssen das internationale Marketingumfeld, insbesondere das internationale Handelssystem verstehen können. Der Freihandel bringt denjenigen Wirtschaften, die sich auf dem gesunden Wege eines Strukturwandels befinden, wirtschaftliche Vorteile. Sein Beitrag zum dauerhaften Weltfrieden ist jedoch noch wichtiger.

Aus dem Inhalt: WTO - Weltwirtschaft · Europäische Union · Freihandel · Protektionismus · Handel und Umwelt · Handel und Wettbewerb - Internationale Wirtschaftsstandards · Internationale Korruption und Geldwäsche · Entwicklungsländer · Handelshemmnisse

Frankfurt/M - Berlin · Bern · Bruxelles - New York · Oxford · Wien

Auslieferung: Verlag Peter Lang AG

Jupiterstr. 15, CH-3000 Bern 15

Telefax (004131) 9402131

*inklusive Mehrwertsteuer

Preisänderungen vorbehalten

Homepage http://www.peterlang.de 